ELIANA MARIA DIAS SANTIAGO

Produção Pública para os Componentes da Assistência Farmacêutica - 2003 a 2013.

Brasília/2015 
UNIVERSIDADE DE BRASÍLIA

FACULDADE DE CIÊNCIAS DA SAÚDE

PROGRAMA DE PÓS-GRADUAÇÃo EM SAÚdE COLETIVA

ELIANA MARIA DIAS SANTIAGO

Produção Pública para os Componentes da Assistência Farmacêutica - 2003 a 2013.

Dissertação apresentada como requisito parcial para obtenção do Título de Mestre Profissionalizante em Saúde Coletiva pelo Programa de Pós-Graduação em Saúde Coletiva da Universidade de Brasília.

Orientador: Prof. Dr. Miguel Ângelo Montagner

Brasília 


\section{Produção Pública para os Componentes da Assistência Farmacêutica - 2003 a 2013.}

Dissertação apresentada como requisito parcial para a obtenção do Título de Mestre em Saúde Coletiva pelo Programa de pós-Graduação em Saúde Coletiva da Universidade de Brasília.

Aprovado em 30 de abril de 2015

\section{BANCA EXAMINADORA}

Prof. Dr. Miguel Ângelo Montagner - Presidente

Universidade de Brasília

Prof. Dr. Natan Monsores de Sá

Universidade de Brasília

Prof ${ }^{a}$. Dr- Maria Inez Montagner

Universidade de Brasília

Prof ${ }^{a}$. Drª . Maria Célia Delduque Nogueira Pires de Sá

Fundação Oswaldo Cruz 
Dedico este trabalho ao meu querido filho Daniel Ruy Santiago Ramos, por estar sempre ao meu lado, e por tantas vezes ter sido privado da minha presença, mas soube ter paciência para compreender as ausências e atribulações de sua mãe no decorrer dos anos de estudos e por estar presente em todos os momentos, sempre com uma palavra de carinho, um sorriso nos lábios e um abraço apertado. 


\title{
Agradeço especialmente
}

\begin{abstract}
À Deus que me concedeu força, coragem, perseverança e sabedoria para trilhar por esse caminho e atingir meu objetivo tão almejado.
\end{abstract}

\section{Agradeço carinhosamente}

Aos colegas da pós-graduação, especialmente Aline Amorim, Gisela Mascarenhas, Marema Patrício, Aedê Cadaxa, Linconl Benito, Alexandro Caruso, Renzo Gonçalves Chaves, Severino Azevedo de Oliveira Júnior e Maria da Cruz Oliveira Ferreira, que acredito que viraram amigos, pelas angústias, sofrimentos, alegrias e surpresas compartilhadas ao longo do curso. E aos professores com quem dividi um tempo da minha vida e que através das discussões do projeto muito enriqueceram este trabalho.

Ao meu orientador Prof. Dr. Miguel Ângelo Montagner, os maiores e mais sinceros agradecimentos.

As professoras Maria Fátima de Sousa e Ana Valéria Machado Mendonça, hoje minhas amigas. Muito obrigada por me ensinar, pelo incentivo e por me fazer acreditar que a sabedoria acadêmica pode ser cheia de idealismo e vontade de mudar a saúde coletiva no Brasil. Obrigada por ter me notado. Obrigada por ter me dado um pouco da sua atenção.

Ao professor, Dr. Natan Monsores de Sá pela oportunidade concedida, pela paciência, dedicação e pelo carinho com que sempre me recebeu, por compartilhar comigo seu tempo, sua experiência e seus conhecimentos. Obrigada pela confiança, amizade e dedicação.

A professora Dra Maria Inez Montagner, por aceitar participar da banca e por suas valiosas contribuições. Foi um prazer tê-la na banca examinadora.

A professora Drạ Maria Célia Delduque Nogueira Pires de Sá, por suas valiosas sugestões. 
A todos os professores do Departamento de Saúde Coletiva da Faculdade, o meu carinho e gratidão, que além de transmitir seus conhecimentos proporcionaram troca de experiências, aprendizados e bons momentos juntos e, souberam me apoiar em minhas dificuldades.

Ao meu amigo do curso de Gestão em Saúde Coletiva, Alexandre Gonzaga da Silva, que sempre se fez presente em minha vida acadêmica, com palavras de encorajamento, dividindo conhecimentos, momentos alegres, festivos e também de momentos difíceis de fim de semestre, trabalhos em cima da hora e grupos que davam mais trabalho do que ajudavam. Neste trajeto rimos, choramingamos e nos ajudamos mutuamente.

Ao meu grande amigo Marcolino Gonzaga da Silva (in memoriam), do curso de Gestão em Saúde Coletiva, que tive a honra de dividi um tempo de minha vida e que através das discussões sobre saúde coletiva enriqueceram minha trajetória profissional e acadêmica. Agradeço-lhe pelas alegrias compartilhadas e principalmente por ter me compreendido e estar sempre junto nos momentos mais difíceis. Deixou ensinamentos e saudades com sua ausência. Agradeço ao Senhor Jesus por ter me dado à oportunidade de tê-lo como amigo. "Amigo é coisa pra se guardar no lado esquerdo do peito" e eu levarei o meu amigo Marcolino eternamente dentro do meu coração. Qualquer dia, amigo eu volto a te encontrar.

Ao Departamento da Assistência Farmacêutica e Insumos Estratégicos da Secretaria de Ciência, Tecnologia e Insumos Estratégicos do Ministério da Saúde (DAF/SCTIE/MS) por me proporcionar o meu desenvolvimento profissional na área da assistência farmacêutica nos últimos sete anos e que autorizou o uso e disponibilizou informações sobre os medicamentos dispensados pelo Ministério da Saúde por seus Programas de Assistência Farmacêutica. Gostaria de agradecer de forma especial aos funcionários Margarida Soares Pereira e Cláudio Henrique Costa Diniz que ajudaram a resolver dúvidas que surgiram durante a realização desta pesquisa.

Aos servidores Secretaria do Programa de Pós-Graduação em Saúde Coletiva Fabiana Carvalho Martins e Ivanaldo Raimundo de Souza Moura, pela dedicação, carinho e paciência que tratam os alunos. 
Ao meu amigo Ricardo Chiappa por compartilhar comigo seus conhecimentos, pelo apoio, pelo incentivo e pelo carinho cotidiano e verdadeiro.

A minha mãe, Mary Dias Santiago, pela garra, pelo amor e ensinamentos recebidos durante toda minha vida. É a razão da minha paz, de minha educação e de tudo que sou hoje. Sempre batalhou pelo meu bem-estar!

Ao meu querido pai, Daniel da Rocha Santiago, pelo amor, ensinamentos, lembranças e saudades deixadas com sua ausência...

Aos meus irmãos Antonio, Vania Prisca e Roberto, às minhas cunhadas Silvia Rejane, Ana Christina, Ecilda, Cosete e Rosete e os meus cunhados Oswaldo, Hassan, B. de Paiva e Dilson, e aos meus sobrinhos: André, Maurício, Fabio, Rodrigo Santiago, Rafael, Renato, Luis Gabriel, Elana, Eduardo Ruy, Denise, João Gilberto, Nheyta, Rodrigo Ramos e Fabiano pelas alegrias compartilhadas sempre que nos encontramos e por me mostrarem a importância de enfrentar novos desafios e o recomeçar.

Ao Ruy Ramos, meu amor e companheiro, pelo seu apoio e principalmente por ter me compreendido e estar sempre junto nos momentos mais difíceis.

A todas as pessoas que de forma direta ou indireta contribuíram para a realização deste sonho.

E... finalmente, também agradeço àqueles que colocaram pedras no caminho. As pedras atrasaram um pouco a minha jornada, mas prossegui caminhando com firmeza para alcançar o meu objetivo. 
"Existe uso racional quando os pacientes recebem os medicamentos apropriados à sua condição clínica, em doses adequadas às suas necessidades individuais, por um período de tempo adequado e ao menor custo possível para eles e sua comunidade."

Conferência Mundial Sobre Uso Racional de Medicamentos, Nairobi, 1985. 


\section{RESUMO}

Esta dissertação elenca a produção de medicamentos e os gastos para os Componentes da Assistência Farmacêutica do Departamento de Assistência Farmacêutica e Insumos Farmacêuticos da Secretaria de Ciência, Tecnologia e Insumos Estratégicos do Ministério da Saúde, no período de 2003 a 2013. Destaca a produção de medicamentos dos laboratórios farmacêuticos oficiais. As informações foram obtidas junto ao Ministério da Saúde. Os Laboratórios Farmacêuticos Oficiais mesmo com a grande desigualdade tecnológica ainda existente nos processos e produtos conseguiram ampliar a capacidade produtiva para atender parte da demanda do elenco de medicamentos dos Componentes da Assistência Farmacêutica do Ministério da Saúde. No período pesquisado, alguns laboratórios oficiais conseguiram destaque na produção de medicamentos, como a FIOCRUZ, LAFEPE, FUNED, IQUEGO, LQFA, LFM e LQFAEX. No período de 2003 a 2013 o Ministério da Saúde adquiriu 9,9 milhões de unidades farmacêuticas para atender os Componentes da Assistência Farmacêutica dispensados no âmbito do Sistema Único de Saúde. Os laboratórios farmacêuticos oficiais fabricaram 6,6 milhões de unidades farmacêuticas. Os laboratórios nacionais (privados nacionais) foram responsáveis pela produção de 1,4 milhão de unidades e os laboratórios internacionais (estrangeiros) produziram 1,8 milhão de unidades farmacêuticas Os laboratórios farmacêuticos oficiais produziram mais para o Programa Nacional de Doenças Sexualmente Transmissíveis e AIDS, tratamento das doenças crônicodegenerativas, Programa Nacional de Controle da Hanseníase, Programa Nacional de Alimentação e Nutrição, Programa Nacional do Controle da Tuberculose e para as Endemias Focais. Em relação aos Medicamentos do Componente Especializado da Assistência Farmacêutica os laboratórios nacionais foram os que mais produziram. Os laboratórios internacionais foram os que mais produziram para o Programa Multidroga-Resistência.

Palavras-chaves: Laboratórios Farmacêuticos Oficiais, Componente da Assistência Farmacêutica, Produção Pública de Medicamentos, Política Nacional de Medicamentos, Assistência Farmacêutica, Sistema Único de Saúde, direitos sociais. 


\section{ABSTRACT}

This dissertation analyzes the production of drugs for the Pharmaceutical Assistance components of the Ministry of Health, from 2003 to 2013. We highlight in particular the production of medicines official pharmaceutical laboratories. The information was obtained from the Ministry of Health. Even with the great inequality still existing technological processes and products of official laboratories, managed to expand production capacity to meet part of the demand of the drug Pharmaceutical Assistance components of the Ministry of Health. Between researched, some officers were able laboratories highlighted in the production of drugs such as FIOCRUZ, LAFEPE, FUNED, Iquego, LQFA, LFM and LQFAEX. In the period 2003-2013 the Ministry of Health acquired 9 million pharmaceutical units to meet the Pharmaceutical Assistance components provided under the SUS. Official laboratories manufactured 6 million pharmaceutical units. National Laboratories (Private) were responsible for the production of 1 million units and international laboratories have produced one million pharmaceutical units Officials pharmaceutical companies produced more for the National Program of Sexually Transmitted Diseases and AIDS, treatment of chronic diseases, Program National Leprosy Control, National Program for Food and Nutrition National Program for Tuberculosis Control and to Endemic Diseases Focal. Regarding Medication Specialized Pharmaceutical Assistance Component national laboratories were the most produced. International laboratories were the most produced for multidrug-resistance program.

Keywords: Official Pharmaceutical Laboratories, Pharmaceutical Assistance Component, Public Production of Drugs, National Drug Policy, Pharmaceutical Care, Health System, social rights. 


\section{LISTA DE FIGURAS}

Figura 1 - Representação gráfica de Projetos Executivos de Parcerias para o Desenvolvimento Produtivo.

Figura 2 - Estrutura Organizacional do Departamento de Assistência Farmacêutica e Insumos Estratégicos.

Figura 3 - Representação gráfica da participação percentual pelos 85 laboratórios na produção do Elenco de medicamentos produzidos para o Programa Nacional de Doenças Sexualmente Transmissíveis e AIDS, no período de 2003 a 2013.

Figura 4 - Participação percentual da quantidade produzida pelos 92 laboratórios oficiais, nacionais e internacionais em número de Unidades Farmacêuticas (UF) para o Ministério da Saúde para o Programa Nacional de Doenças Sexualmente Transmissíveis e AIDS, no período de 2003 a 2013.

Figura 5 - Participação percentual do gasto com os laboratórios oficiais, 95 nacionais e internacionais pelo Ministério da Saúde com o Programa Nacional de Doenças Sexualmente Transmissíveis e AIDS, no período de 2003 a 2013.

Figura 6 - Representação gráfica da quantidade de medicamentos 96 produzidos pelos laboratórios oficiais para o Programa Nacional de Doenças Sexualmente Transmissíveis e AIDS, no período de 2003 a 2013.

Figura 7 - Representação gráfica da quantidade de medicamentos 98 produzidos pelos laboratórios oficiais para o Programa Nacional de Controle da Hanseníase, no período de 2003 a 2013.

Figura 8 - Representação gráfica da participação percentual pelos 98 laboratórios na produção do elenco de medicamentos produzidos para o Programa Nacional de Controle da hanseníase, período de 2003 a 2013.

Figura 9 - Participação percentual da quantidade produzida pelos 103 laboratórios oficiais, nacionais e internacionais em número de Unidades Farmacêuticas (UF) para o Ministério da Saúde para o Programa Nacional de Controle da Hanseníase, no período de 2003 a 2013. 
Figura 10 - Participação percentual do gasto com os laboratórios 103 oficiais, nacionais e internacionais pelo Ministério da Saúde com o Programa Nacional de Controle da Hanseníase, no período de 2003 a 2013.

Figura 11 - Representação gráfica da participação percentual pelos 107 laboratórios na produção do elenco de medicamentos produzidos para o Programa Nacional de Nutrição e Alimentação, no período de 2003 a 2013.

Figura 12 - Participação percentual da quantidade produzida pela 109 FIOCRUZ e laboratórios nacionais em número de Unidades Farmacêuticas (UF) para o Ministério da Saúde para o Programa Nacional de Nutrição e Alimentação, no período de 2003 a 2013.

Figura 13 - Participação percentual do gasto com a FIOCRUZ e os 110 laboratórios nacionais pelo Ministério da Saúde com o Programa Nacional de Nutrição e Alimentação, no período de 2003 a 2013. .

Figura 14 - Representação gráfica da participação percentual pelos 112 laboratórios na produção do elenco de medicamentos produzidos para o programa Nacional de Controle da Tuberculose, período de 2003 a 2013.

Figura 15 - Representação gráfica da quantidade de medicamentos 113 produzidos pelos laboratórios oficiais para o Programa Nacional de Combate a Tuberculose, no período de 2003 a 2013.

Figura 16 - Participação percentual da quantidade produzida pelos 118 laboratórios oficiais e internacionais em número de Unidades Farmacêuticas (UF) para o Ministério da Saúde para o Programa Nacional de Controle da Tuberculose, no período de 2003 a 2013.

Figura 17 - Participação percentual do gasto com os laboratórios oficiais 118 e internacionais pelo Ministério da Saúde com o Programa Nacional de Controle da Tuberculose, no período de 2003 a 2013.

Figura 18 - Representação gráfica da participação percentual pelos 126 laboratórios na produção do elenco de medicamentos produzidos para endemias focais, no período de 2003 a 2013.

Figura 19 - Participação percentual da quantidade produzida pelos laboratórios oficiais, nacionais e internacionais em número de Unidades 
Farmacêuticas (UF) para o tratamento das endemias focais, no período de 2003 a 2013.

Figura 20 - Participação percentual da quantidade no gasto com os laboratórios oficiais, nacionais e internacionais pelo Ministério da Saúde com o tratamento das endemias focais, no período de 2003 a 2013.

Figura 21 - Representação gráfica da participação percentual dos 141 laboratórios na produção do elenco de medicamentos produzidos para o Programa Multidroga-Resistência, no período de 2003 a 2013.

Figura 22 - Representação gráfica da quantidade de medicamentos 142 produzidos pelos laboratórios oficiais para o Programa Multidrogas Resistência, no período de 2003 a 2013.

Figura 23 - Participação percentual da quantidade produzida pelos 147 laboratórios oficiais, nacionais e internacionais em número de unidades farmacêuticas (UF) para o Ministério da Saúde para o Programa Multidrogas Resistência, no período de 2003 a 2013.

Figura 24 - Participação percentual do gasto do Ministério da Saúde 147 com a produção dos laboratórios oficiais, nacionais e internacionais para o Programa Multidrogas Resistência, no período de 2003 a 2013.

Figura 25 - Representação gráfica da participação percentual dos 152 laboratórios na produção de medicamentos para o Componente Especializado da Assistência Farmacêutica, no período de 2003 a 2013.

Figura 26 - Participação percentual da quantidade produzida pelos 159 laboratórios oficiais, nacionais e internacionais em número de unidades farmacêuticas (UF) para o Ministério da Saúde para o Componente Especializado da Assistência Farmacêutica, no período de 2003 a 2013. Figura 27 - Participação percentual do gasto do Ministério da Saúde 159 com a produção dos laboratórios oficiais, nacionais e internacionais para o Componente Especializado da Assistência Farmacêutica, no período de 2003 a 2013.

Figura 28 - Representação gráfica da produção pública por laboratório, 160 no período de 2003 a 2013. 


\section{LISTA DE QUADROS}

Quadro 1 - Relação dos Programas sob a responsabilidade do 78 DAF/SCTIE/MS no período de 2003 a 2013.

Quadro 2 - Elenco de medicamentos produzidos pelos laboratórios para 83 o Programa Nacional de Doenças Sexualmente Transmissíveis e AIDS, no período de 2003 a 2013.

Quadro 3 - Consolidação da produção dos laboratórios oficiais em 85 número de Unidades Farmacêuticas (UF) e valor pago pelo Ministério da Saúde para o Programa Nacional de Doenças Sexualmente Transmissíveis e AIDS, no período de 2003 a 2013.

Quadro 4 - Consolidação da produção dos laboratórios nacionais em 88 número de Unidades Farmacêuticas (UF) e valor pago pelo Ministério da Saúde para o Programa Nacional de Doenças Sexualmente Transmissíveis e AIDS, no período de 2003 a 2013.

Quadro 5 - Consolidação da produção dos laboratórios oficiais em 89 número de Unidades Farmacêuticas (UF) e valor pago pelo Ministério da Saúde para o Programa Nacional de Doenças Sexualmente Transmissíveis e AIDS, no período de 2003 a 2013.

Quadro 6 - Consolidação da produção dos laboratórios oficiais, 92 nacionais e internacionais em número de Unidades Farmacêuticas (UF) e valor pago pelo Ministério da Saúde para o Programa Nacional de Doenças Sexualmente Transmissíveis e AIDS, no período de 2003 a 2013.

Quadro 7 - Quantidade de Unidades Farmacêuticas e participação 95 percentual da quantidade produzida pelos laboratórios oficiais para o Ministério da Saúde para o Programa Nacional de Doenças Sexualmente Transmissíveis e AIDS, no período de 2003 a 2013.

Quadro 8 - Elenco de medicamentos produzidos pelos laboratórios para 98 o Programa Nacional de Controle da Hanseníase, período de 2003 a 2013.

Quadro 9 - Consolidação da produção dos laboratórios oficiais em número de Unidades Farmacêuticas (UF) e Valor Pago pelo Ministério 
da Saúde para o Programa Nacional de Controle da hanseníase, período 2003 a 2013.

Quadro 10 - Consolidação da produção dos laboratórios nacionais em 101 número de Unidades Farmacêuticas (UF) e Valor Pago pelo Ministério da Saúde para o Programa Nacional de Controle da hanseníase, período 2003 a 2013.

Quadro 11 - Consolidação da produção dos laboratórios internacionais 102 em número de Unidades Farmacêuticas (UF) e Valor Pago pelo Ministério da Saúde para o Programa Nacional de Controle da hanseníase, período 2003 a 2013.

Quadro 12 - Consolidação da produção dos laboratórios oficiais, 102 nacionais e internacionais em número de Unidades Farmacêuticas (UF) e Valor Pago pelo Ministério da Saúde para o Programa Nacional de Controle da hanseníase, período 2003 a 2013.

Quadro 13 - Quantidade de Unidades farmacêuticas e participação 105 percentual da quantidade produzida pelos laboratorios oficiais para 0 Ministério da Saúde para o Programa Nacional de Controle da hanseníase, no período de 2003 a 2013.

Quadro 14 - Elenco de medicamentos produzidos pelos laboratórios 106 para o Programa Nacional de Alimentação e Nutrição, no período de 2003 a 2013.

Quadro 15 - Elenco de medicamentos do Programa Nacional de 107 Nutrição e Alimentação e o laboratório produtor, no período de 2003 a 2013.

Quadro 16 - Consolidação da produção da FIOCRUZ em número de 108 Unidades Farmacêuticas (UF) e o valor pago pelo Ministério da Saúde para o Programa Nacional de Nutrição e Alimentação, no período de 2003 a 2013.

Quadro 17 - Consolidação da produção dos laboratórios nacionais em 108 número de Unidades Farmacêuticas (UF) e o valor pago pelo Ministério da Saúde para o Programa Nacional de Nutrição e Alimentação, no período de 2003 a 2013.

Quadro 18 - Consolidação da produção do laboratório oficial e dos 109 nacionais em Unidades Farmacêuticas (UF) e valor pago pelo Ministério 
da Saúde para o Programa Nacional de Nutrição e Alimentação, no período de 2003 a 2013.

Quadro 19 - Elenco de medicamentos produzidos pelos laboratórios pra

- Programa nacional de Controle da Tuberculose, período de 2003 a 2013.

Quadro 20 - Consolidação da produção dos laboratórios oficias em número de unidades Farmacêuticas (UF) e valor pago pelo Ministério da Saúde para o Programa Nacional de Controle da Tuberculose, no período de 2003 a 2013.

Quadro 21 - Consolidação da produção dos laboratórios internacionais em número de unidades Farmacêuticas (UF) e valor pago pelo Ministério da Saúde para o Programa Nacional de Controle da Tuberculose, no período de 2003 a 2013.

Quadro 22 - Consolidação da produção dos laboratórios oficiais e internacionais em número de Unidades Farmacêuticas (UF) e Valor Pago pelo Ministério da Saúde para o Programa de Controle da Tuberculose, no período de 2003 a 2013.

Quadro 23 - Consolidação da produção por laboratório oficial, o valor 119 pago pelo Ministério da Saúde, com a participação percentual, com o Programa Nacional de Controle da Tuberculose no período de 2003 a 2013.

Quadro 24 - Quantidade de Unidades Farmacêuticas e participação 120 percentual da quantidade produzida pelos laboratórios oficiais para o Ministério da Saúde para o Programa Nacional de Controle da Tuberculose, no período de 2003 a 2013.

Quadro 25 - Elenco de medicamentos produzidos pelos laboratórios 122 para tratamento das endemias focais, no período de 2003 a 2013.

Quadro 26 - Consolidação da produção dos laboratórios oficiais em 127 número de Unidades Farmacêuticas (UF) e valor pago pelo Ministério da Saúde para tratamento das endemias focais, no período de 2003 a 2013. Quadro 27 - Consolidação da produção dos laboratórios nacionais em 129 número de Unidades Farmacêuticas (UF) e valor pago pelo Ministério da Saúde para tratamento das endemias focais, no período de 2003 a 2013. 
Quadro 28 - Consolidação da produção dos laboratórios internacionais 132 em número de Unidades Farmacêuticas (UF) e valor pago pelo Ministério da Saúde para tratamento das endemias focais, no período de 2003 a 2013.

Quadro 29 - Consolidação da produção dos laboratórios oficiais, 134 nacionais e internacionais em número de Unidades Farmacêuticas (UF) e valor pago pelo Ministério da Saúde para tratamento das endemias focais, no período de 2003 a 2013.

Quadro 30 - Quantidade de medicamentos produzidos por laboratório 138 oficial para o tratamento das endemias focais, no período de 2003 a 2013.

Quadro 31 - Quantidade de Unidades farmacêuticas e participação 139 percentual da quantidade produzida pelos laboratórios oficiais para o Ministério da Saúde para o tratamento das endemias focais, no período de 2003 a 2013.

Quadro 32 - Elenco de medicamentos produzidos pelos laboratórios 140 para o Programa Multidroga-Resistência, no período de 2003 a 2013.

Quadro 33 - Consolidação da produção dos laboratórios oficiais em 143 número de Unidades Farmacêuticas (UF) e valor pago pelo Ministério da Saúde para Programa Multidrogas Resistência, no período de 2003 a 2013.

Quadro 34 - Consolidação da produção dos laboratórios nacionais em 144 número de Unidades Farmacêuticas (UF) e valor pago pelo Ministério da Saúde para Programa Multidrogas Resistência, no período de 2003 a 2013.

Quadro 35 - Consolidação da produção dos laboratórios internacionais 145 em número de Unidades Farmacêuticas (UF) e valor pago pelo Ministério da Saúde para o Programa Multidrogas Resistência, no período de 2003 a 2013.

Quadro 36 - Consolidação da produção dos laboratórios oficiais, 146 nacionais e internacionais em número de Unidades Farmacêuticas (UF) e valor pago pelo Ministério da Saúde para o Programa Multidrogas Resistência, no período de 2003 a 2013. 
Quadro 37 - Elenco de medicamentos produzidos pelos laboratórios 148 oficiais, nacionais e internacionais para o Componente Especializado da Assistência Farmacêutica, no período de 2003 a 2013.

Quadro 38 - Consolidação da produção dos laboratórios oficiais em 152 número de Unidades Farmacêuticas (UF) e valor pago pelo Ministério da Saúde para o Componente Especializado da Assistência Farmacêutica, no período de 2003 a 2013.

Quadro 39 - Consolidação da produção dos laboratórios nacionais em 154 número de Unidades Farmacêuticas (UF) e valor pago pelo Ministério da Saúde para o Componente Especializado da Assistência Farmacêutica, no período de 2003 a 2013.

Quadro 40 - Consolidação da produção dos laboratórios internacionais em número de Unidades Farmacêuticas (UF) e valor pago pelo Ministério da Saúde para o Componente Especializado da Assistência Farmacêutica, no período de 2003 a 2013.

Quadro 41 - Consolidação da produção dos laboratórios oficiais, 158 nacionais e internacionais em número de Unidades Farmacêuticas (UF) e o valor pago pelo Ministério da Saúde para o Componente Especializado da Assistência Farmacêutica, no período de 2003 a 2013.

Quadro 42 - Consolidação da quantidade produzida para os 162 Componentes da Assistência Farmacêutica do Ministério da Saúde, no período de 2003 a 2013.

Quadro 43 - Consolidação do valor pago pelo Ministério da Saúde para 162 os Componentes da Assistência Farmacêutica, no período de 2003 a 2013.

Quadro 44 - Consolidação da evolução da produção por 164 Programa/Tratamento da Assistência Farmacêutica do Ministério da Saúde, no período de 2003 a 2013. 


\section{LISTA DE TABELAS}

Tabela 1 - Relação dos laboratórios farmacêuticos oficiais por localização, ano 49 de fundação e linha de produção.

Tabela 2 - Consolidação da produção da Fundação Ezequiel Dias (FUNED) em número de Unidades Farmacêuticas (UF) e valor pago pelo Ministério da Saúde da talidomida, no período de 2003 a 2013. 


\section{LISTA DE APÊNDICE}

Apêndice 1 - Produção Pública, em número de Unidades Farmacêuticas 177 (UF) para o Programa Nacional de Doenças Sexualmente Transmissíveis e AIDS, no período de 2003 a 2013.

Apêndice 2 - Produção dos laboratórios nacionais, em número de 180 Unidades Farmacêuticas (UF) para o Programa Nacional de Doenças Sexualmente Transmissíveis e AIDS, no período de 2003 a 2013.

Apêndice 3 - Produção dos laboratórios internacionais, em número de 182 Unidades Farmacêuticas (UF) para o Programa Nacional de Doenças Sexualmente Transmissíveis e AIDS, no período de 2003 a 2013.

Apêndice 4 - Produção Pública, em número de Unidades Farmacêuticas 185 (UF) para o Programa Nacional de Controle da Hanseníase, período 2003 a 2013.

Apêndice $\mathbf{5}$ - Produção dos laboratórios nacionais, em número de 187 Unidades Farmacêuticas (UF) para o Programa Nacional de Controle da Hanseníase, período 2003 a 2013.

Apêndice 6 - Produção dos laboratórios internacionais, em número de 188 Unidades Farmacêuticas (UF) para o Programa Nacional de Controle da Hanseníase, período 2003 a 2013.

Apêndice 7 - Produção Pública, em número de Unidades Farmacêuticas 189 (UF) para o Programa Nacional de Alimentação e Nutrição, período de 2003 a 2013.

Apêndice 8 - Produção dos laboratórios nacionais, em número de 190 Unidades Farmacêuticas (UF) para o Programa Nacional de Alimentação e Nutrição, período de 2003 a 2013.

Apêndice 9 - Produção Pública, em número de Unidades Farmacêuticas 191 (UF), para o Programa Nacional de Controle da Tuberculose, no período de 2003 a 2013.

Apêndice 10 - Produção Internacional, em número de Unidades farmacêutica (UF) para o Programa Nacional de Controle da Tuberculose, no período de 2003 a 2013.

Apêndice 11 - Produção Pública, em número de Unidades 
Farmacêuticas (UF) para o tratamento das Endemias Focais, no período de 2003 a 2013.

Apêndice 12 - Produção dos laboratórios nacionais, em número de 198 Unidades Farmacêuticas (UF) para o tratamento das Endemias Focais, no período de 2003 a 2013.

Apêndice 13 - Produção dos laboratórios internacionais, em número de 201 Unidades Farmacêuticas (UF) para o tratamento das Endemias Focais, no período de 2003 a 2013.

Apêndice 14 - Produção Pública, em número de Unidades 203 Farmacêuticas (UF), para o Programa Multidrogas Resistência, no período de 2003 a 2013.

Apêndice 15 - Produção dos laboratórios nacionais, em número de 204 Unidades Farmacêuticas (UF), para o Programa Multidrogas Resistência, no período de 2003 a 2013.

Apêndice 16 - Produção dos laboratórios oficiais, em número de 206 Unidades Farmacêuticas (UF), para o Componente Especializado da Assistência Farmacêutica, no período de 2003 a 2013.

Apêndice 17 - Produção dos laboratórios nacionais, em número de 208 Unidades Farmacêuticas (UF), para o Componente Especializado da Assistência Farmacêutica, no período de 2003 a 2013.

Apêndice 18 - Produção dos laboratórios internacionais, em número de Unidades Farmacêuticas (UF), para o Componente Especializado da Assistência Farmacêutica, no período de 2003 a 2013.

Apêndice 19 - Elenco de medicamentos do Kit do Sistema Prisional e os que são produzidos pela FIOCRUZ.

Apêndice 20 - Elenco de medicamentos e correlatos do Kit do Programa 215 de Calamidade Pública e os que são produzidos pela FIOCRUZ. 


\section{LISTA DE ABREVIATURAS E SIGLAS}

\begin{tabular}{|c|c|}
\hline ALFOB & Laboratórios Farmacêuticos Oficiais do Brasil \\
\hline ANVISA & Agência Nacional de Vigilância Sanitária \\
\hline BPFC & Boas Práticas de Fabricação e Controle \\
\hline CATMAT & Código de Catálogo de Materiais \\
\hline CBAF & Componente Básico da Assistência Farmacêutica \\
\hline CEAF & Componente Especializadp da Assistência Farmacêutica \\
\hline CEME & Central de Medicamentos \\
\hline CESAF & Componete Estratégico da Assistência Farmacêutica \\
\hline CF & Constituição Federal \\
\hline CGAFB & Coordenação-Geral de Assistência Farmacêutica Básica \\
\hline CGAFME & $\begin{array}{l}\text { Coordenação-Geral de Assistência Farmacûtica e Medicamentos } \\
\text { Estratégicos }\end{array}$ \\
\hline CGCEAF & $\begin{array}{l}\text { Coordenação-Geral do Componente Especializado da Assistência } \\
\text { Farmacêutica }\end{array}$ \\
\hline CIT & Comissão Intergestores Tripartite \\
\hline CMED & Câmara de Regulação do Mercado de Medicamentos \\
\hline CONASEMS & Conselho Nacional das Secretarias Municipais de Saúde \\
\hline CONASS & Conselho Nacional dos Secretários Esaduais de Saúde \\
\hline DAF & Departamento de Assistência Farmacêutica e Insumos Estratégicos \\
\hline DECIIS & Departamento do Complexo Industrial e Inovação em Saúde \\
\hline DECIT & Departamento de Ciência e Tecnologia \\
\hline DLOG & Departamento de Logística em Saúde \\
\hline DST/Aids & $\begin{array}{l}\text { Doenças Sexualmente Transmissíveis/Síndrome da Imunodeficiência } \\
\text { Adquirida }\end{array}$ \\
\hline GM/MS & Gabinete do Ministro - Ministério da Saúde \\
\hline LFO & armacêuticos \\
\hline
\end{tabular}


PCDT Protocolos Clínicos e Diretrizes Terapêuticas

PDP Parcerias de Desenvolvimento Produtivo

PNAF Política Nacional de Assistência Farmacêutica

ESF Estratégia Saúde da Família

RBPPM Rede Brasileira de Produção Pública de Medicamentos

SCTIE/MS Secretaria de Ciência, Tecnologia e Insumos Estratégicos do Ministério da Saúde

SE Secretaria Executiva

SILOS Sistema de Logística em Saúde

SUS Sistema Único de Saúde 


\section{SUMÁRIO}

1 Introdução 26

2 Revisão Bibliográfica $\quad 30$

2.1 A Saúde e o SUS na Constituição Federal de 1988

2.2. Assistência Farmacêutica e Direito Social 32

2.3 Assistência Farmacêtica no Brasil 36

2.3.1 Histórico 36

2.3.2 Políticas Públicas de Disponibilidade de Medicamentos 38

2.3.2.1 Política Nacional de Medicamentos 39

2.3.2.2 Política Nacional de Assistência Farmacêutica 40

2.4 Componentes da Assistência Farmacêutica $\quad 41$

2.4.1 Componente Básico da Assistência Farmacêutica $\quad 41$

2.4.2 Componente Estratégico da Assistência Farmacêutica 43

2.4.3 Componente Especializado da Assistência Farmacêutica $\quad 44$

2.5 Laboratórios Farmacêuticos Oficiais $\quad 47$

2.5.1 Rede Brasileira de Produção Pública de Medicamentos 60

2.6 Secretaria de Ciência, Tecnologia e Insumos Estratégicos 61

2.6.1 Departamento de Assistência Farmacêutica e Insumos Estratégicos 63

$\begin{array}{ll}3 \text { Objetivos } & 67\end{array}$

$\begin{array}{ll}3.1 \text { Objetivo geral } & 67\end{array}$

$\begin{array}{ll}3.2 \text { Objetivos específicos } & 67\end{array}$

4 Métodos $\quad 68$

5 Resultados

5.1 Programa Nacional de Doenças Sexualmente Transmissíveis e AIDS 82

5.2 Doenças crônico-degenerativas (lúpus eritematoso, doença enxerto- 96 versus-hospedeiro e mieloma múltiplo) 
5.3 Programa Nacional de Controle da Hanseníase 97

5.4 Programa Nacional de Alimentação e Nutrição 106

5.5 Programa Nacional do Controle da Tuberculose 110

$\begin{array}{ll}5.6 \text { Endemias Focais } & 121\end{array}$

$\begin{array}{ll}\text { 5.7 Programa Multidroga-Resistência } & 140\end{array}$

5.8 Medicamentos do Componente Farmacêutico Especializado 148

5.9 Consolidação da produção para os Componentes da Assistência 160 Farmacêutica do Ministério da Saúde .

6 Discussão 165

7 Conclusão 167

$\begin{array}{ll}\text { Referências } & 169\end{array}$

$\begin{array}{ll}\text { Apêndices } & 176\end{array}$

$\begin{array}{ll}\text { Anexos - Autorização Institucional } & 217\end{array}$ 


\section{INTRODUÇÃO}

Com o reconhecimento da saúde como direito de todos pela Constituição de 1988 (CF, 1988), inicia-se o processo de regulamentação das questões de saúde e o direito à assistência farmacêutica pelo Sistema Único de Saúde (SUS) foi reconhecido como parte dessa nova política, conforme estabelecido pelo artigo 6으, I, "d" da Lei no 8.080/90, ou seja, o fornecimento gratuíto de medicamentos ${ }^{1}$. (BRASIL, 1990)

No processo saúde-doença o medicamento é a terapêutica mais utilizada (OLIVEIRA; BERMUDEZ; OSORIO-DE-CASTRO, 2007) e é apontado como fator relevante para a saúde das pessoas e utilizado pela medicina para interromper ou modificar o curso natural das doenças, de preveni-las ou de reduzir seus sintomas (ABAJO, 2001).

Por esta razão é dever dos Estados assegurar acesso aos medicamentos existentes por meio de políticas, programas e projetos de saúde que garantam a universalização da saúde; disponibilizando os medicamentos existentes em quantidades suficientes dentro do seu território, atendendo não só os centros urbanos, mas também a população das áreas longínquas. Os medicamentos devem ter o menor custo possível para que possa ser suportado pelo sistema de saúde e por todos os segmentos da população de maneira igualitária sem discriminação de sexo, raça, etnia e status socioeconômico. Os pacientes e os profissionais de saúde devem ter informações confiáveis sobre medicamentos para que possam utilizá-los de forma segura e para adotar decisões bem fundamentadas. (HUNT E KHOSLA, 2008)

O medicamento é concebido como um bem vital à saúde e um importante instrumento terapêutico para os médicos, sendo responsável por parte expressiva da melhoria da qualidade e expectativa de vida da população. O acesso a medicamentos é um indicador da qualidade e resolutividade de um sistema de saúde e um determinante importante do cumprimento do tratamento prescrito. A

\footnotetext{
${ }^{1}$ De acordo com a Lei oㅜ 5.991, de 17 de dezembro de 1973, que dispõe sobre o Controle Sanitário do Comércio de Drogas, Medicamentos, Insumos Farmacêuticos e Correlatos, e dá outras providências, medicamento é produto farmacêutico, tecnicamente obtido ou elaborado, com finalidade profilática, curativa, paliativa ou para fins de diagnóstico.
} 
literatura indica que a falta de acesso é uma causa frequente de retorno de pacientes aos serviços de saúde (ARRAIS, BRITO, BARRETO, COELHO, 2005).

A falta de medicamentos para tratamento de enfermidades pode levar ao agravamento do quadro e aumentar os gastos com a atenção secundária e terciária Considerando-se que a maioria da população atendida no serviço público de saúde é de baixa renda, a obtenção gratuita é, frequentemente, a única alternativa de acesso ao medicamento. Nesse contexto, o sistema público de saúde, e em particular o Programa Saúde da Família (PSF), desenvolve ações que visam a acompanhar de forma sistemática os indivíduos com essas morbidades e promover o cuidado integral, incluindo o acesso a medicamentos essenciais (PANIZ et al, 2008),

No Brasil, o SUS desenvolve ações para assegurar o fornecimento gratuito de medicamentos e a Política Nacional de Assistência Farmacêutica (PNAF) (BRASIL, 1998) do SUS está inserida na integralidade do cuidado e ações de saúde e não somente em uma logística de medicamentos - adquirir, armazenar e distribuir. A assistência farmacêutica ${ }^{2}$ é atividade de saúde e tem que constar na organização da gestão farmacêutica. O seu desenvolvimento qualifica e fortalece o SUS e os serviços farmacêuticos disponibilizados à população.

A promoção do acesso a medicamentos no âmbito do SUS é de responsabilidade dos gestores dos três níveis de governo (CF, 1988). A assistência farmacêutica no SUS é implementada por pactuações na Comissão Intergestores Tripartite (CIT) voltadas para a construção de um novo ordenamento na forma de acesso a medicamentos pela população (BRASIL, 1990).

Pela Portaria GM/MS no 204, de 29 de janeiro de 2007, as ações e os serviços de saúde estão alocados na forma de blocos de financiamento específicos, de acordo com seus objetivos e características. O bloco de financiamento para a assistência farmacêutica é constituído por três componentes: o Componente Básico, o Componente Estratégico e o Componente Especializado.

\footnotetext{
${ }^{2}$ Assistência farmacêutica é conjunto de ações voltadas à promoção, à proteção, e à recuperação da saúde, tanto individual quanto coletiva, tendo o medicamento como insumo essencial, que visa promover o acesso e o seu uso racional; esse conjunto que envolve a pesquisa, o desenvolvimento e a produção de medicamentos e insumos, bem como a sua seleção, programação, aquisição, distribuição, dispensação, garantia da qualidade dos produtos e serviços, acompanhamento e avaliação de sua utilização, na perspectiva da obtenção de resultados concretos e da melhoria da qualidade de vida da população (Resolução no 338, de 6 de maio de 2004 do Conselho Nacional de Saúde, que instituiu a Política Nacional de Assistência Farmacêutica - PNAF).
} 
O Componente Básico da Assistência Farmacêutica estabelece um elenco de medicamentos para o tratamento dos principais problemas de saúde da população em relação a sua demanda epidemiológica. Garantindo assim a primeira linha de cuidado em nível da atenção básica e de responsabilidade dos municípios e do Distrito Federal (BRASIL, 2013a).

O Componente Estratégico da Assistência Farmacêutica disponibiliza medicamentos para o atendimento de Programas de Saúde coordenados nacionalmente pelo Ministério da Saúde. Programa DST/Aids, tuberculose, hanseníase, malária e outra endemias focais, bem como os imuno-biológicos e insumos das coagulopatias e hemoderivados.

O Componente Especializado da Assistência Farmacêutica é uma estratégia de acesso a medicamentos no âmbito do SUS caracterizado pela busca da garantia da integralidade do tratamento medicamentoso, em nível ambulatorial, cujas linhas de cuidado estão definidas em Protocolos Clínicos e Diretrizes Terapêuticas, publicados pelo Ministério da Saúde. (BRASIL, 2013b)

A Política Nacional de Medicamentos, Portaria no 3.916 , de 30 de outubro de 1998, orienta o setor público para a contratação dos Laboratórios Farmacêuticos Oficias (LFO) para produção de medicamentos para serem distribuídos no âmbito do SUS, com o intuito de aproveitar a capacidade instalada destes laboratórios. Estes laboratórios configuram um verdadeiro patrimônio nacional e deverá ser utilizada preferencialmente, para atender a produção de medicamentos destinados ao tratamento de patologias cujos resultados tenham impacto sobre a saúde pública ou que são adquiridos em sua quase totalidade pelo setor público.

Os LFO fazem parte do complexo industrial farmacêutico do Brasil e é parte integrante do SUS, constituem recursos estratégicos para promoção do acesso da população a medicamentos de que ela necessita. (GOMES, CHAVES, NINOMYA, 2008)

Os laboratórios farmacêuticos oficiais são fundamentais para a estabilização dos preços de medicamentos no mercado nacional bem como para a produção de medicamentos para doenças negligenciadas, tendo em vista a falta de interesse dos laboratórios privados para estes fármacos. A produção desses medicamentos representa baixa lucratividade para os laboratórios produtores, por isso a falta de interesse dos laboratórios privados. 
A opção do Ministério da Saúde pela celebração de Convênio para produção e distribuição dos medicamentos para disponibilização no âmbito do SUS pelos Laboratórios Oficiais, tem por fundamento o atendimento da recomendação da PNM, Portaria GM n. 3.916 , de 30 de outubro de 1998, que orienta o Setor Público a contratação dos Laboratórios Oficias para aproveitamento da capacidade instalada dos laboratórios oficiais - que configura um verdadeiro patrimônio nacional - deverá ser utilizada, preferencialmente, para atender a produção de medicamentos destinados ao tratamento de patologias cujos resultados tenham impacto sobre a saúde pública ou que são adquiridos em sua quase totalidade pelo setor público.

A celebração de convênio entre o Ministério da Saúde e os Laboratórios Oficiais proporciona a estes a modernização dos seus sistemas de produção e o alcance de níveis de eficiência e competitividade, particularmente no que concerne aos preços dos produtos. (BRASIL, 1998)

Diante da escassez de informações sobre o atendimento pelo Ministério da Saúde da recomendação da PNM, sobre o aproveitamento da produção de medicamentos dos LFO para serem distribuídos no âmbito do SUS e a da evolução dos gastos com a assistência farmacêutica, é que esta pesquisa tem por objetivo avaliar a participação da produção de medicamentos dos laboratórios farmacêuticos oficiais, dos laboratórios privados nacionais e dos laboratórios internacionais para os Componentes da Assistência Farmacêutica da Secretaria de Ciência, Tecnologia e Insumos Estratégicos do Ministério da Saúde (SCTIE/MS) e os gastos para a aquisição destes medicamentos, no período de 2003 a 2012. 


\section{REVISÃO BIBLIOGRÁFICA}

A primeira etapa consistiu da revisão de literatura para elaboração de um marco conceitual teórico no qual este trabalho se apoiou. Para tanto, foram avaliados os seguintes macro conceitos: direitos fundamentais, direitos sociais e em particular a assistência farmacêutica no SUS, a Política Nacional de Medicamentos, a Política de Assistência Farmacêutica, a Rede de Laboratórios Oficiais e por fim a produção dos Laboratórios Oficiais para os Componentes da Assistência Farmacêutica.

A revisão de literatura foi realizada em textos e livros publicados, artigos, teses e dissertações sobre a temática relacionada nas bases de dados: Scielo, Biblioteca Virtual em Saúde e Lilacs, pesquisando artigos publicados entre 2000 e 2013, utilizando o cruzamento das seguintes palavras-chaves: Componente da Assistência Farmacêutica, Laboratórios Oficiais, direitos sociais, produção pública de medicamentos.

Não foram encontradas publicações sobre a produção pública para os Componentes da Assistência Farmacêutica. As publicações encontradas na revisão da literatura em relação à produção pública são estudos sobre o diagnóstico da situação do parque de laboratórios públicos; analise da modernização e ampliação da capacidade produtiva dos laboratórios farmacêuticos oficiais (HANSENCLEVER, 2008) (GOMES et al, 2008); sobre a relevância para saúde pública do Brasil dos laboratórios farmacêuticos oficiais (Magalhães et al, 2003); a produção pública para a Relação Nacional de Medicamentos Essenciais (Rename) (RODRIGUES, 2012) e estudos de casos sobre a produção de determinados laboratórios farmacêuticos oficias sem descriminar o quantitativo produzido e para qual gestão do SUS.

Encontramos também estudos que abordam uma visão geral da produção pública de medicamentos no Brasil examinando as principais características da indústria farmacêutica (OLIVEIRA et al, 2006) e do mercado de medicamentos em suas dimensões internacional e nacional e os aspectos da visão governamental sobre a produção de medicamentos do setor público OLIVEIRA et al, 2006).

Em relação ao financiamento foram encontrados estudos sobre as características do Sistema de Informações sobre Orçamentos Públicos de Saúde (Siops), que reúne informações sobre o financiamento e o gasto com saúde pública 
dos municípios, dos estados e da União, com as ações em saúde, não contém dados sobre a produção pública de medicamentos. Alguns estudos analisaram a problemática do financiamento da saúde pública brasileira (MARQUES, et al, 2012).

Foram encontrados estudos que discutiram a evolução do financiamento da assistência farmacêutica no Sistema Único de Saúde - SUS, identificandos os valores alocados para aquisição de medicamentos, para o Programa Farmácia Popular e para estruturação de serviços farmacêuticos públicos. Os valores referentes ao financiamento da União, por meio do Ministério da Saúde, foram obtidos do sistema Siga Brasil e, dos Estados, do Distrito Federal e dos municípios, do Sistema de Informações sobre Orçamentos Públicos em Saúde - SIOPS, entre 2005 e 2009 (VIEIRA et al, 2013).

Um estudo que identificou a estimativa de recursos alocados para aquisição de medicamentos pelo Sistema Único de Saúde em 2008, por componente de financiamento definido nacionalmente, especialmente para uso ambulatorial Sistema Único de Saúde, (VIEIRA et al, 2013).

\subsection{A SAÚDE E O SUS NA CONSTITUIÇÃO FEDERAL DE 1988}

As propostas defendidas pelo movimento sanitário brasileiro foram incorporadas pela Constituição Federal de 1988, assegurando a saúde como direito de todos e dever do Estado, como direito fundamental e como de relevância pública.( AITH, 2007)

Art. $6^{\circ}$ - São direitos sociais a educação, a saúde, o trabalho, a moradia, o lazer, a segurança, a previdência social, a proteção à maternidade e à infância, a assistência aos desamparados, na forma desta Constituição. (Redação dada pela Emenda Constitucional no 26, de 2000) (O grifo é nosso)

Art. 196 - A saúde é direito de todos e dever do Estado, garantido mediante políticas sociais e econômicas que visem à redução do risco de doença e de outros agravos e ao acesso universal e igualitário às ações e serviços para sua promoção, proteção e recuperação. (O grifo é nosso)

Art. 197 - São de relevância pública as ações e serviços de saúde, cabendo ao Poder Público dispor, nos termos da lei, sobre sua regulamentação, fiscalização e controle, devendo sua execução ser feita diretamente ou através de terceiros e, também, por pessoa física ou jurídica de direito privado. (O grifo é nosso) 
A Constituição Federal de 1988 ao estabelecer o direito universal à saúde como dever do Estado trouxe aos brasileiros que antes eram excluídos dos serviços e ações de saúde, o pleno direito à saúde.

Para efetivar o direito à saúde a Carta Magna instituiu um Sistema Único de Saúde, descentralizado e com garantias à participação da sociedade em seu controle. Este sistema garante o atendimento universal, igualitário e integral a todo o cidadão brasileiro que dele precisar, através das unidades de saúde, ambulatórios, clínicas e hospitais, sem que nada seja cobrado da população usuária.

\footnotetext{
Art. 198. As ações e serviços públicos de saúde integram uma rede regionalizada e hierarquizada e constituem um sistema único, organizado de acordo com as seguintes diretrizes:

I - descentralização, com direção única em cada esfera de governo;

II - atendimento integral, com prioridade para as atividades preventivas, sem prejuízo dos serviços assistenciais;

III - participação da comunidade.
}

O dever do Estado em garantir a saúde consiste na formulação e execução de políticas econômicas e sociais que visem à redução de riscos de doenças e de outros agravos e no estabelecimento de condições que assegurem o acesso universal e igualitário às ações e aos serviços para a sua promoção, proteção e recuperação.

\subsection{ASSISTÊNCIA FARMACÊUTICA E DIREITO SOCIAL}

A saúde, antes da criação do SUS, não era considerada um direito social. O modelo de saúde adotado até então dividia os brasileiros em três grupos: os que podiam pagar por serviços de saúde privados; os que tinham direito à saúde pública por serem segurados pela previdência social (trabalhadores com carteira de trabalho assinada); e os que não possuíam direito algum e eram atendidos pelas Santas Casas de Misericórdia (PORTAL BRASIL, 2009).

Então, o SUS foi instituído para oferecer atendimento igualitário, para cuidar e promover a saúde e assistência à saúde dos brasileiros. 
Pode-se afirmar que o SUS é a concretização dos anseios do movimento sanitário e que teve na $8^{a}$ Conferência de Saúde (1986) um de seus "locus" privilegiados para o estabelecimento das grandes diretrizes para a reorganização do sistema de saúde no Brasil, tendo em vista que esta recomendou a reestruturação do Sistema Nacional de Saúde através da criação de um "Sistema Único de Saúde", com um comando único em cada esfera de governo.

A 8 ${ }^{\text {a }}$ Conferência Nacional de Saúde estabeleceu ainda os marcos político e conceitual para a orientação da transformação no campo da saúde no Brasil. A saúde foi reconhecida como um direito fundamental e o Estado deveria garantir o acesso aos serviços e a promoção da saúde para a população (CARVALHO, 2008).

Os direitos sociais tiveram origem no século XIX, com a Revolução Industrial e organizados primeiramente pelas constituições Mexicana em 1917 e de Weimar em 1919. Em 1948 foram positivados internacionalmente com a Declaração Universal dos Direitos Humanos, pela Assembleia Geral das Nações Unidas, e mais tarde detalhados no Pacto Internacional dos Direitos Econômicos, Sociais e Culturais, em 1966, documento adotado pela XXI Sessão da Assembleia-Geral das Nações Unidas, em 19 de dezembro de 1966. O Pacto apresenta um rol extenso de direitos, indo além da Declaração Universal. O referido diploma internacional foi promulgado no Brasil pelo Decreto №. 591, de 6 de julho de 1992.

Para o artigo 25 da Declaração Universal dos Direitos Humanos a saúde é elemento de cidadania (UNESCO, 1948). Podemos então afirmar que, o Direito à Saúde é um Direito Humano essencial, absolutamente necessário, indispensável, o direito mais importante, o núcleo da vida.

\footnotetext{
Toda pessoa tem direito a um padrão de vida capaz de assegurar, a si e a sua família, saúde e bem estar, inclusive alimentação, vestuário, habitação, cuidados médicos e os serviços sociais indispensáveis, e direito à segurança em caso de desemprego, doença, invalidez, viuvez, velhice ou outros casos de perda dos meios de subsistência fora de seu controle. A maternidade e a infância têm direito a cuidados e assistência especiais.
}

Os direitos fundamentais sociais foram conquistados ao longo dos séculos, sendo a maioria deles no século XX por meio da força dos trabalhadores e dos movimentos sociais. Estão necessariamente sujeitos à observância do Estado. (RAMOS, 2008) 
Para COMPARATO (2003), historicamente os direitos sociais apareceram, "como criações do movimento socialista, que sempre colocou no pináculo da hierarquia de valores a igualdade de todos os grupo ou classes sociais, no acesso a condições de vida digna".

O direito à saúde, como direito fundamental social representa uma das formas de expressão da dignidade humana e como núcleo essencial dos direitos fundamentais (BARROSO, 2009).

Os direitos sociais são direitos fundamentais do homem. São verdadeiras liberdades positivas, de observância obrigatória em um Estado Social de Direito, tendo por finalidade a melhoria de condições de vida aos hipossuficientes, com o objetivo da concretização da igualdade social, e no Brasil são consagrados fundamentos do Estado Democrático. (SILVA, 1999).

SILVA (1999) acrescenta ainda que os direitos sociais são:

(...) prestações positivas proporcionadas pelo Estado direta ou indiretamente, enunciados em normas constitucionais, que possibilitam melhores condições de vida aos mais fracos, direitos que tendem a realizar a igualização de situações sociais desiguais. São, portanto, direitos que se ligam ao direito de igualdade.

Conforme BONAVIDES (1999), em princípio, o cerne dos direitos fundamentais encontra-se em uma liberdade ilimitada diante da intervenção do Estado, que só pode ser alterada por meio de lei. Acrescenta que:

\footnotetext{
A vinculação essencial dos direitos fundamentais à liberdade e a dignidade humana, enquanto valores históricos e filosóficos, nos conduzirá sem óbices ao significado de universalidade inerente a esses direitos como ideal da pessoa humana. A universalidade se manifestou pela primeira vez, qual a descoberta do racionalismo francês da Revolução, por ensejo da célebre Declaração dos direitos do Homem de 1799.
}

A saúde por ser concebida como um dos principais elementos da vida é classificada na esfera jurídica, por vários doutrinadores, um direito de segunda geração. São os chamados direitos econômicos, sociais e culturais, ligados à atuação estatal positiva, pois se faz necessário a intervenção do Estado para que tais direitos se concretizem e se consubstancia como forma obrigatória no âmbito dos direitos fundamentais sociais.

No Brasil, desde a Constituição de 1824 (BRASIL, 1824) já havia vestígios de direitos sociais, seguindo o modelo das declarações de direito da Revolução 
Francesa de 1789. Mas foi a Constituição de 1934 (BRASIL, 1934) a primeira a proclamar uma ordem econômica e social, em seu Título IV. Todavia, somente em 1988, a Constituição reconheceu o direito à saúde como direito fundamental social e ampliou os valores da dignidade humana e os direitos fundamentais. Concebeu ser a vida o bem soberano do ser humano e elevou estes direitos ao plano de direitos fundamentais da pessoa humana. (BRASIL, 1988)

As Constituições de 1890, 1934, 1937, 1946, 1967 não consagraram questões relativas à saúde e, quando o fizeram, foi de maneira ilusória ou equivocando-a com ações de assistência social. Havia um entendimento de que as prestações de saúde constituíam apenas um gesto de caridade, solidariedade ou uma dádiva estatal e não um dever. (BRASIL, 1890; BRASIL, 1934; BRASIL,1937; BRASIL,1946 e BRASIL,1967)

Na Constituição brasileira de 1988, os direitos fundamentais estão dispostos em capítulo próprio, denominado "dos diretos sociais", onde estão relacionados diversos direitos fundamentais, dentre os quais o direito a educação, saúde, trabalho, moradia, lazer, segurança e previdência social (art. 6o, caput, CF-88).

\footnotetext{
São direitos sociais a educação, a saúde, a alimentação, o trabalho, a moradia, o lazer, a segurança, a previdência social, a proteção à maternidade e à infância, a assistência aos desamparados, na forma desta Constituição. (Redação dada pela Emenda Constitucional no ${ }^{\circ}$ 4, de 2010)
}

Com o reconhecimento da saúde como direito de todos pela Constituição de 1988 (CF, 1988), inicia-se o processo de regulamentação das questões de saúde, e o direito à assistência farmacêutica pelo SUS foi reconhecido como parte dessa nova política, conforme estabelecido pelo artigo $6^{\circ}$, I, "d" da Lei $n^{\circ} 8.080 / 90$, ou seja, o fornecimento gratuito de medicamentos. (BRASIL, 1990)

Assim como direito à assistência farmacêutica é reconhecido pela Constituição Federal de 1988 como um direito fundamental social está assegurado aos necessitados o fornecimento, pelo Estado, dos medicamentos indispensáveis ao restabelecimento da saúde e faz sobressair seu aspecto de imposição de deveres ao Estado, com o intuito de proporcionar uma vida saudável.

Como todo direito fundamental, o direito social de assistência farmacêutica possui o conteúdo essencial da dignidade da pessoa humana (fundamentalidade material - que diz respeito à possibilidade de considerá-lo como um direito 
fundamental). Para efetivação do direito social de assistência farmacêutica no âmbito do SUS há necessidade de implementação de políticas públicas para fornecimento gratuito de medicamentos para controlar, reduzir ou eliminar os sofrimentos causados pelas enfermidades, mas nunca perdendo de vista o uso racional de medicamentos ${ }^{3}$.

Com a implementação de políticas públicas de assistência farmacêutica os gestores do SUS efetivam concretamente o princípio da dignidade da pessoa humana, previsto no artigo 1ํ, inciso III da Constituição da República de 1988 e garantem integralmente aos cidadãos brasileiros a integralidade da assistência.

\subsection{ASSISTÊNCIA FARMACÊUTICA NO BRASIL}

\subsubsection{Histórico}

Mesmo antes do reconhecimento constitucional da assistência farmacêutica como direito social o governo federal já promovia ações com o intuito de proporcionar o acesso à população de baixa renda a medicamentos, através da regular produção e distribuição estatal, através da Central de Medicamentos (CEME).

A Central de Medicamentos foi criada em 1971 com o objetivo de "promover e organizar o fornecimento, de medicamentos de uso humano a quantos não puderem, por suas condições econômicas, adquiri-los no mercado". Além disso, deveria "funcionar como reguladora da produção e distribuição de medicamentos dos laboratórios farmacêuticos subordinados ou vinculados aos Ministérios da Marinha, do Exército, da Aeronáutica, da Saúde, do Trabalho e Previdência Social". (BRASIL, 1971)

\footnotetext{
${ }^{3}$ De acordo com a Organização Mundial de Saúde (Nairóbi, Quênia, 1985), entende-se que há uso racional de medicamentos quando pacientes recebem medicamentos apropriados para suas condições clínicas, em doses adequadas às suas necessidades individuais, por um período adequado e ao menor custo para si e para a comunidade (Ministério da Saúde).
} 
Neste período todas as ações de assistência farmacêutica no Brasil eram centralizadas pela CEME. Era responsável pela aquisição e de distribuição de medicamentos de forma vertical. A dispensação dos medicamentos não levava em conta o perfil epidemiológico da população de cada região, resultando em excesso de alguns medicamentos e falta de outros, ou seja, em desperdício de recursos e a não garantia da assistência farmacêutica à população brasileira pela ausência de uma gestão efetiva da assistência farmacêutica no Brasil.

Em 1998, o Ministério da Saúde assumiu a Atenção Básica como Política de Saúde e eixo orientador para reorganizar o modelo de atenção à saúde (PAIM e ALMEIDA FILHO, 1998). Nesse sentido, publicou o Manual para a Organização da Atenção Básica, - Portaria GM/MS no 3.925, de novembro de 1998 - cuja discussão envolveu a participação de diversos setores do Ministério, do Conselho Nacional dos Secretários Estaduais de Saúde (CONASS) e do Conselho Nacional das Secretarias Municipais de Saúde (CONASEMS). O manual especificava o conceito ampliado da Atenção Básica ${ }^{4}$, ressaltando ser essa ampliação necessária para avançar na direção de um sistema de saúde centrado na qualidade de vida das pessoas e de seu meio ambiente. (BRASIL, 1998)

No final do ano 1999, o Ministério da Saúde reestruturou suas atividades com a finalidade de intensificar as ações voltadas para melhorar a qualidade de vida da população. Para potencializar e integrar ainda mais as ações da Assistência à Saúde, a Secretaria de Políticas de Saúde, que antes apenas formulava e avaliava políticas que fortalecia a capacidade de gestão nos três níveis de governo passou também a coordenar e articular, sob a lógica da descentralização do SUS, as ações de promoções da saúde e prevenção de doenças e agravos no âmbito da Atenção Básica. Passou também a coordenar a gestão da política de recursos humanos do SUS, a política de ciência e tecnologia em saúde e a Rede Interagencial de Informações em Saúde (RIPSA).

Para garantir assistência farmacêutica à população, o Ministério da Saúde desenvolve ações que consistem em promover à pesquisa, o desenvolvimento, a compra e a produção de medicamentos e insumos, bem como sua seleção,

\footnotetext{
${ }^{4}$ Segundo o manual, Atenção Básica é um conjunto de ações, de caráter individual ou coletivo, situadas no primeiro nível de atenção dos sistemas de saúde, voltadas para a promoção da saúde, a prevenção de agravos, o tratamento e a reabilitação. Essas ações não se limitam àqueles procedimentos incluídos no Grupo de Assistência Básica da tabela do SIA/SUS, quando da implantação do Piso de Atenção Básica.
} 
programação, aquisição, distribuição e avaliação de sua utilização, na perspectiva da obtenção de resultados concretos e da melhoria da qualidade de vida da população.

Assim, se depreende que a questão da assistência farmacêutica sempre foi uma preocupação do Governo Federal, mas hoje ela se encontra sistematizada no formato de política pública - Política Nacional de Medicamentos (BRASIL, 1998), a Política Nacional de Assistência Farmacêutica (BRASIL, 2004) e o Pacto pela Saúde ${ }^{5}$ - que busca garantir o acesso da população a medicamentos de qualidade e o seu uso racional, e onde esse acesso se reveste na qualidade de direito constitucional.

\subsubsection{Políticas públicas de disponibilidade de medicamentos}

Para a concretização dos direitos fundamentais previstos na Constituição de 1988, o Estado brasileiro implementa políticas públicas, que são os instrumentos de que dispõe para planejar uma série de ações dirigidas à coletividade (ordem pública) com a finalidade de concretizar um direito constitucional da população.

Podemos, então, definir políticas públicas como um planejamento governamental, de ações articuladas (coordenadas), cujo propósito é dar movimento a máquina governamental, para realizar algum objetivo de ordem pública, ou, na ótica dos juristas, concretizar um direito constitucionalmente assegurado. É a principal ferramenta de ação estatal com vistas à concretização dos direitos sociais, econômicos e culturais, é um instrumento privilegiado para a realização desses direitos, tendo em vista serem eles os fins do Estado Constitucional. (VIANA et al, 2008)

Para garantir assistência farmacêutica à população, o Ministério da Saúde desenvolve políticas públicas que consistem em promover à pesquisa, o desenvolvimento, a compra e a produção de medicamentos e insumos, bem como sua seleção, programação, aquisição, distribuição e avaliação de sua utilização, na

\footnotetext{
${ }^{5}$ O Pacto pela Saúde é composto pelas seguintes Portarias: no 699, de 30 de março de 2006, no 3.085, de 1 de dezembro de 2006, № 3.332, de 28 de dezembro de 2006; ํㅡ 204, de 29 de janeiro de 2007.
} 
perspectiva da obtenção de resultados concretos e da melhoria da qualidade de vida da população e a ampliação do acesso a medicamentos.

\subsubsection{Política Nacional de Medicamentos}

A Política Nacional de Medicamentos foi instituída pela Portaria oㅡ 3.916/GM de 30 de outubro de 1998 sendo instrumento norteador do Ministério da Saúde. Propõe garantir a segurança, a eficácia e qualidade dos medicamentos ao menor custo possível, promover o uso racional e o acesso da população aqueles considerados essenciais (BRASIL, 1998).

Para o alcance dos seus objetivos, a Política Nacional de Medicamento estabelece diretrizes gerais e prioridades. As diretrizes gerais visam garantir o acesso da população a medicamentos seguros, eficazes e de qualidade, ao menor custo possível, devendo os gestores do SUS, das três esferas de Governo, atuarem em parceria e concentrarem seus esforços em ações direcionadas para o alcance desses objetivos. As prioridades servem de base para o alcance do propósito desta Política, bem como para a implementação das diferentes ações indispensáveis ao seu efetivo cumprimento.

Uma das diretrizes fundamentais contidas na Política Nacional de Medicamentos é a "Reorientação da Assistência Farmacêutica", em que um novo modelo está sendo desenhado de modo que não se restrinja à aquisição e à distribuição de medicamentos. As ações incluídas nesse campo da assistência têm por objetivo implementar, no âmbito das três esferas do SUS, todas as atividades relacionadas à promoção do acesso da população aos medicamentos essenciais.

Esta reorientação do modelo fundamenta-se, em especial, na descentralização da gestão e na otimização e eficácia do sistema de distribuição no setor público. (BRASIL, 2001)

Esta portaria tem, dentre seus objetivos, formular as diretrizes de reorientação do modelo de assistência farmacêutica, com a definição do papel das três instâncias do SUS. Com tal reestruturação, era esperado que houvesse uma facilitação do acesso da população aos medicamentos, uma vez que as competências dos 
gestores foram definidas de modo haver uma ação coordenada entre os três níveis (MESSEDER, 2005).

\subsubsection{Política Nacional de Assistência Farmacêutica (PNAF)}

A Resolução no 338 de 6 de maio de 2004, do Conselho Nacional de Saúde, aprovou a Política Nacional de Assistência Farmacêutica (PNAF), em continuidade à Política Nacional de Medicamentos. Esta política envolve um conjunto de ações voltadas à promoção, proteção e recuperação da saúde e assegurando os princípios da universalidade, integralidade e eqüidade e tem como principais diretrizes garantir o uso racional de medicamentos e o acesso a medicamentos essenciais. (BRASIL, 2004)

A PNAF foi instituída para viabilizar a articulação e reorientação da assistência farmacêutica a partir: da política de medicamentos, ciência e tecnologia, desenvolvimento industrial, formação de recursos humanos, entre outros, que convoquem, para esta tarefa, tanto o setor público como o privado de atenção à saúde.

Esta política está fundamentada na descentralização da gestão da Assistência Farmacêutica, na promoção do uso racional de medicamentos, na otimização e na eficácia do sistema de abastecimento no setor público. A consolidação desse modelo gerou desafios, como por exemplo: identificação da situação epidemiológica dos municípios, identificação dos pacientes em situação de esquemas terapêuticos crônicos, definição do perfil de consumo de medicamentos no município, identificação de pacientes com baixa adesão a terapias prescritas, a fim de atuar no sentido de melhorar a efetividade dos tratamentos entre outros. (JARAMILLO et al, 2005)

O foco central da Assistência Farmacêutica é o paciente. Sua atuação integrada com as outras ações de saúde contribui decisivamente para a melhoria da qualidade de vida e saúde dos indivíduos. Seu papel se concentra em atividades educativas que dão ao paciente possibilidade de melhor compreender a sua doença ou agravo, a importância do seguimento terapêutico e uso correto dos 
medicamentos. Em seu conjunto de atividades educa, ajuda e dá suporte ao paciente no autocuidado e na avaliação dos resultados de seu tratamento.

A Política Nacional de Medicamentos (Portaria no 3.916, de 30 de outubro de 1998) e a Política Nacional de Assistência Farmacêutica (Resolução no 338, de 06 de maio de 2004) têm como uma de suas principais diretrizes a adoção da Relação de Medicamentos Essenciais (RENAME).

\subsection{COMPONENTES DA ASSISTÊNCIA FARMACÊUTICA}

A Portaria GM/MS № 204, de 29 de janeiro de 2007, criou três componentes da assistência farmacêutica no âmbito do SUS: o Componente Básico da Assistência Farmacêutica, o Componente Estratégico da Assistência Farmacêutica e o Componente Especializado da Assistência Farmacêutica'

Os Componentes da Assistência Farmacêutica desenvolvidos pelo Ministério da Saúde no âmbito da Política Nacional de Assistência Farmacêutica têm como objetivo garantir o acesso da população a medicamentos previamente estabelecidos em listas oficiais que são periodicamente revisadas.

\subsubsection{Componente Básico da Assistência Farmacêutica (CBAF)}

O Componente Básico da Assistência Farmacêutica é financiado pelo Ministério da Saúde, Estados, Municípios e o Distrito Federal e estabelece um elenco de medicamentos para o tratamento dos principais problemas de saúde da população em relação a sua demanda epidemiológica. Garantindo assim a primeira linha de cuidado em nível da atenção básica e de responsabilidade dos municípios e do Distrito Federal. (BRASIL, 2013)

De acordo com a Portaria $n^{\circ} 1.555$, de 30 de julho de 2013, a contribuição federal é de $R \$ 5,10 /$ habitante/ano, e as contribuições estadual e municipal devem ser de, no mínimo, $R \$ 2,36 /$ habitante/ano cada, sendo que esses recursos devem se 
aplicados na aquisição dos medicamentos destinados aos agravos prevalentes e prioritários da Atenção Básica, presentes na Relação Nacional de Medicamentos Essenciais $^{6}$ (RENAME) vigente. Também podem ser adquiridas com esses recursos, os medicamentos fitoterápicos estabelecidos na RENAME vigente, matrizes homeopáticas e tinturas-mães conforme Farmacopeia Homeopática Brasileira, $3^{\text {a }}$ edição. O Distrito Federal aplicará, no mínimo, o somatório dos valores definidos para os estados e municípios.

Para estruturação das farmácias do SUS e para a qualificação dos serviços farmacêuticos destinados à Assistência Farmacêutica Básica os estados, os municípios e o Distrito Federal podem aplicar até 15\% (quinze por cento) da soma de suas contrapartidas. (BRASIL, 2013a)

A contribuição federal é repassada mensalmente pelo Fundo Nacional de Saúde, aos estados, aos municípios, e ao Distrito Federal de forma regular e automática, em parcelas de um doze avos. A contrapartida estadual é efetuada por meio do repasse de recursos financeiros aos municípios, ou em alguns casos, por meio do fornecimento de medicamentos básicos, definidos e pactuados pelas Comissões Intergestores Bipartite. (BRASIL, 2013a)

A contrapartida municipal é executada pelas prefeituras, com recursos do tesouro municipal, e destinados ao custeio dos medicamentos básicos previstos na RENAME vigente, ou ainda em ações de estruturação e qualificação da Assistência Farmacêutica Básica, respeitados os limites e demais normas estabelecidas na Portaria no 1.555/2013. (BRASIL, 2013a)

Além do repasse financeiro aos estados, aos municípios e ao Distrito Federal, - Ministério da Saúde também é responsável pela aquisição e distribuição das insulinas humanas NPH e Regular (frascos de $10 \mathrm{~mL}$ ) e dos contraceptivos orais e injetáveis, além do DIU e diafragma para distrubuição no âmbito da atenção básica do SUS. As insulinas e os contraceptivos são entregues nos Almoxarifados de Medicamentos dos Estados, a quem compete distribuí-los aos municípios. Os municípios das capitais e os grandes municípios brasileiros, com população maior

\footnotetext{
${ }^{6}$ A Relação Nacional de Medicamentos Essenciais (RENAME) é uma publicação do Ministério da Saúde com os medicamentos para combater as doenças mais comuns que atingem a população brasileira. Os estados utilizam a RENAME para elaborar suas listas de assistência farmacêutica básica. (Ministério da Saúde. $\quad$ Disponível http://portal.saude.gov.br/portal/saude/profissional/visualizar texto.cfm?idtxt=32820\&janela=1. Acessado em 14 de novembro de 2013)
} 
que 500 mil habitantes, recebem os contraceptivos diretamente dos fornecedores contratados pelo Ministério da Saúde. (BRASIL, 2013a)

\subsubsection{Componente Estratégico da Assistência Farmacêutica (CESAF)}

O Componente Estratégico da Assistência Farmacêutica disponibiliza medicamentos para 0 atendimento de Programas Estratégicos de Saúde coordenados nacionalmente pelo Ministério da Saúde que considera como estratégicos todos os medicamentos utilizados para tratamento das doenças de perfil endêmico, cujo controle e tratamento tenham protocolo e normas estabelecidas e que tenham impacto socioeconômico.

O Ministério da Saúde é responsável pela elaboração dos protocolos de tratamento; pelo planejamento e programação; pelo financiamento e aquisição centralizada e pela distribuição aos estados e/ou municípios.

As secretarias estaduais de saúde são responsáveis pelo armazenamento; distribuição às regionais ou municípios e pela programação. As secretarias municipais de saúde são responsáveis pelo armazenamento; distribuição às unidades de saúde; programação e dispensação.

Os Programas Estratégicos de Saúde são: DST/Aids, tuberculose, hanseníase, endemias focais, sangue e hemoderivados, alimentação e nutrição, tabagismo, influenza e Saúde da Criança.

Estes programas são voltados ao tratamento dos seguintes agravos: Coagulopatias; Cólera; Tabagismo; Dengue; Doença de Chagas; Esquistosomose; DST/AIDS; Febre Maculosa; Filariose; Geohelmintíases; Hanseníase; Influenza; Leishmaniose (LTA e LV); Lúpus - Mieloma Múltiplo -Enxerto versus Hospedeiro; Malária; Meningite; Micoses Sistêmicas; Raiva; Tracoma; Tuberculose; Tuberculose Multidroga resistente; Alimentação e nutrição (Vitamina A) e Prevenção da infecção pelo VSR.

Este Componente visa o tratamento de um conjunto de doenças causadas por agentes infecciosos e parasitários (vírus, bactérias, protozoários e helmintos) que são endêmicas em populações de baixa renda. São as chamadas "doenças 
negligenciadas" ou "doenças emergentes e re-emergentes" que não despertam interesse das grandes empresas farmacêuticas multinacionais em realizar pesquisas para produção de novos medicamentos e vacinas, que não vêem nessas doenças compradores potenciais de novos medicamentos, e por outro o estudo dessas doenças vem sendo pouco financiado pelas agências de fomento. (SOUZA, 2010)

As doenças negligenciadas não só prevalecem em condições de pobreza, mas também contribuem para a manutenção do quadro de desigualdade, já que representam forte entrave ao desenvolvimento dos países. (DECIT/SCTIE/MS, 2010)

O Componente visa garantir o acesso aos medicamentos por portadores de doenças que configuram problemas de saúde pública, consideradas de caráter estratégico pelo Ministério da Saúde.

\subsubsection{Componente Especializado da Assistência Farmacêutica (CEAF)}

O Componente Especializado da Assistência Farmacêutica (CEAF) ${ }^{7}$ é considerado uma importante estratégia na efetivação do acesso a medicamentos no SUS. Busca a garantia da integralidade do tratamento medicamentoso para todas as doenças contempladas no CEAF. Procurando disponibilizar os medicamentos e outras tecnologias em saúde necessários para efetivar a integralidade do tratamento recomendados nos Protocolos Clínicos e Diretrizes Terapêuticas (PCDT) ${ }^{8}$ por meio das diferentes linhas de cuidado. (BRASIL, 2013b)

$\mathrm{O}$ acesso aos medicamentos que fazem parte das linhas de cuidado para as doenças contempladas no âmbito deste Componente será garantido mediante a

\footnotetext{
7 Este Componente substituiu o Componente de Medicamentos de Dispensação Excepcional, popularmente conhecido como Medicamentos de Alto Custo.

${ }^{8}$ Os PCDT têm o objetivo de estabelecer claramente os critérios de diagnóstico de cada doença, o algoritmo de tratamento das doenças com as respectivas doses adequadas e os mecanismos para o monitoramento clínico em relação à efetividade do tratamento e a supervisão de possíveis efeitos adversos. Observando ética e tecnicamente a prescrição médica, os PCDT, também, objetivam criar mecanismos para a garantia da prescrição segura e eficaz. Portanto, no âmbito do CEAF, os medicamentos devem ser dispensados para os pacientes que se enquadrarem nos critérios estabelecidos no respectivo Protocolo Clínico e Diretriz Terapêutica. (Ministério da Saúde. Disponível em http://portal.saude.gov.br/portal/saude/profissional/visualizar texto.cfm?idtxt=35490\&janela=1. Acessado em 15 de novembro de 2013.
} 
pactuação entre a União, estados, municípios e o Distrito Federal, conforme as diferentes responsabilidades definidas na Portaria nำ 1.554 de 30 de julho de 2013 .

Os medicamentos que fazem parte das linhas de cuidado para as doenças contempladas neste Componente estão divididos em três grupos com características, responsabilidades e formas de organização distintas. Os grupos foram constituídos considerando os seguintes critérios gerais: complexidade do tratamento da doença; garantia da integralidade do tratamento da doença no âmbito da linha de cuidado; e manutenção do equilíbrio financeiro entre as esferas de gestão do SUS. (BRASIL, 2013b)

O Grupo 1 é aquele cujo financiamento está sob a responsabilidade exclusiva da União. É constituído por medicamentos que representam elevado impacto financeiro para o Componente, por aqueles indicados para doenças mais complexas, para os casos de refratariedade ou intolerância a primeira e/ou a segunda linha de tratamento e por aqueles que se incluem em ações de desenvolvimento produtivo no complexo industrial da saúde e se divide em dois grupos.

No Grupo 1A os medicamentos são adquiridos pelo Ministério da Saúde de forma centralizada e no Grupo 1B os medicamentos são adquiridos pelos estados e o Distrito Federal com transferência de recursos financeiros pelo Ministério da Saúde, na modalidade fundo a fundo. A responsabilidade pelo armazenamento, distribuição e dispensação dos medicamentos dos Grupos 1 (1A e 1B) é das Secretarias Estaduais de Saúde.

Os medicamentos do Grupo 1 devem ser dispensados somente para as doenças (CID-10) contempladas no Componente e deve obedecer aos critérios de diagnóstico, indicação de tratamento, inclusão e exclusão de pacientes, esquemas terapêuticos, monitoramento, acompanhamento e demais parâmetros contidos nos PCDT. (BRASIL, 2013b)

O elenco de medicamentos deste Grupo é composto por 86 fármacos em 145 apresentações farmacêuticas, sendo que destes, 41 medicamentos em 67 apresentações são adquiridos pelo Ministério da Saúde. (BRASIL, 2013b)

O Grupo 2 é constituído por medicamentos, cuja responsabilidade pelo financiamento é das Secretarias Estaduais de Saúde. É constituído por medicamentos para tratamento ambulatorial de doenças de menor complexidade em relação aos elencados no Grupo 1 e para os casos de refratariedade ou intolerância 
a primeira linha de tratamento. Este Grupo é composto por 54 medicamentos em 120 apresentações farmacêuticas. (BRASIL, 2013b)

O Grupo 3 é composto por medicamentos, cuja responsabilidade pelo financiamento é tripartite, sendo a aquisição e dispensação de responsabilidade dos municípios conforme regulamentação da Portaria GM/MS № 1.555, de 30 de julho de 2013, que aprova a Assistência Farmacêutica na Atenção Básica. (BRASIL, 2013b). Os medicamentos devem constar da RENAME vigente e recomendados pelos Protocolos Clínicos e Diretrizes Terapêuticas, publicados na versão final pelo Ministério da Saúde, como a primeira linha de cuidado para o tratamento das doenças contempladas neste Componente.

Os três Grupos do CEAF juntos disponibiliza 194 fármacos em 383 apresentações farmacêuticas indicadas para tratamento das diferentes fases evolutivas das doenças comtempladas.

A Portaria $\mathrm{n}^{0} 1.554$ de 30 de julho de 2013 mantém os conceitos originais da Portaria no 2.981/GM/MS, de 26 de novembro de 2009, mas inova nos seguintes aspectos:

a) inclusão dos procedimentos para os medicamentos incorporados pela Comissão Nacional de Incorporação de Tecnologias no SUS (CONITEC);

b) atualização dos atributos da Tabela de Procedimentos, Medicamentos, Órteses, Próteses e Materiais Especiais do SUS a partir da publicação de novos PCDT; transferência de medicamentos para o Componente Básico da Assistência Farmacêutica;

c) inclusão dos medicamentos para tratamento do glaucoma e;

d) atualização dos valores de ressarcimento dos medicamentos do Grupo $1 \mathrm{~B}$.

O governo federal, atendendo ao disposto na Constituição Federal e ao Princípio da Supremacia do Interesse Público, desenvolveu estas políticas públicas de disponibilização de medicamentos, mas de acordo com BADIM (2005) estas políticas não são capazes de atender, individualmente, todas as necessidades terapêuticas dos cidadãos brasileiros, porque "são elaboradas com base na tomada de decisões coletivas pelo sistema político, sob uma perspectiva coletiva e distributiva". 


\subsection{LABORATÓRIOS OFICIAIS}

Os laboratórios oficiais são instituições públicas vinculadas aos governos federal, estaduais e universidades que produzem medicamentos, soros e vacinas para atender às necessidades do SUS. Com natureza jurídica diversa: autarquias federais, fundações públicas federais, fundações públicas estaduais, autarquias estaduais, órgãos públicos estaduais, sociedades de economia mista e sociedade anônima. (HASENCLEVER, 2002; BRASIL)

A missão principal dos laborátorios farmacêuticos oficiais é produzir medicamentos da RENAME para atender a demanda do SUS. Cabe ressaltar que capacitam recursos humanos nas áreas administrativa, química, farmacêutica, produtiva e de engenharia do país. (HASENCLEVER, 2002; BRASIL)

Em três portarias (BRASIL, 2008c; 2008d; 2008e), o governo reconhece o valor dos LFO e demonstra a preocupação em proteger o patrimônio nacional, destacando a sua importância para assegurar o acesso a medicamentos pela população por meio da soberania tecnológica e garantia da segurança nacional. Com a edição destas normas, o governo reconhece os LFO como indutores do aumento da capacidade inovadora do Brasil.

Segundo GOMES et. al (2008), os laboratórios farmacêuticos oficiais são de porte variados, com características técnicas, administrativas e financeiras distintas, com semelhantes linhas de produtos.

As funções principais dos laboratórios farmacêuticos oficiais no SUS, destacam-se:

- $\quad$ produção de medicamentos;

- garantia de suporte a essa produção em casos de comoção ou de graves necessidades da saúde pública;

- implementação do desenvolvimento tecnológico farmacêutico, via criação, apropriação ou transferência de tecnologia;

- busca de novos fármacos, com prioridade para aqueles necessários ao enfrentamento das doença negligenciadas;

- $\quad$ suporte à regulação econômica; 
- indução de mercados e desenvolvimento tecnológico via políticas públicas, e;

- desenvolvimento de talentos humanos.

Os LFO têm valioso papel na assistência farmacêutica do SUS, tanto no abastecimento direto do Ministério da Saúde e das secretarias estaduais e municipais de saúde, por meio da produção de medicamentos a baixo custo, permitindo com isso um avanço no acesso da população aos medicamentos de que necessita.

$\mathrm{Na}$ Tabela consta a relação dos 29 laboratórios oficiais identificados, sendo que 21 (vinte e um) tem linha de produção de medicamentos, os outros estão na produção industrial de hemoderivados, vacina, soros, segmentos da hemoterapia e hematologia e produção de kits para diagnóstico laboratorial. Eles estão situados nas regiões Nordeste, Centro-Oeste, Sudeste e Sul.

Estes laboratórios oficiais participavam da Rede Brasileira de Produção Pública de Medicamentos (RBPPM) criada pela Portaria no 843/GM, de 02 junho de 2005 (BRASIL, 2005b), com objetivo de otimização da gestão, a estruturação e socialização das iniciativas de fomento e de desenvolvimento tecnológico dos LFO.

A Portaria oㅡ 2.438 de 7 de dezembro de 2005, revogou a Portaria no 843/GM, de 02 junho de 2005, com a finalidade de melhorar a estruturação da produção pública da Rede Brasileira de Produção Pública de Medicamentos. Esta portaria tem como um de seus principais objetivos a expansão de ações que visassem à reorganização do sistema oficial de produção de medicamentos (o que incluia matérias-primas e insumos), visando a garantia do suprimento regular e adequado de medicamentos demandados pelo SUS, com ênfase nos medicamentos estratégicos, produzidos exclusivamente pelo parque fabril oficial.

A Portaria oㅡ 374, de 28 de fevereiro de 2008, revogou a Portaria № 2.438 de 7 de dezembro de 2005 e instituiu no âmbito do SUS, o Programa Nacional de Fomento à Produção Pública e Inovação no Complexo Industrial da Saúde, com objetivo promover o fortalecimento e a modernização do conjunto de laboratórios públicos encarregados da produção de medicamentos e imunobiológicos de relevância estratégica para o SUS, por intermédio da ampliação da participação no Complexo Produtivo da Saúde, do aumento da capacidade inovadora e da mudança de patamar competitivo, contribuindo para a redução da defasagem tecnológica existente e o desenvolvimento econômico, científico e tecnológico do País. 
A RBPPM era composta por representantes do Ministério da Saúde, ANVISA, ALFOB, CONASS e CONASEMS e destinada a viabilizar a produção dos medicamentos e princípios ativos correspondentes, de interesse da saúde pública.

A adesão à rede era institucional e tinha como foco o desenvolvimento de ações que visavam a reorganizar o sistema oficial de produção de medicamentos, de matérias-primas e de insumos. Deste modo, buscava-se o suprimento regular e adequado das demandas do SUS, principalmente para atender aos programas de saúde pública em AIDS, tuberculose e endemias focais.

continua

Tabela 1 - Relação dos laboratórios farmacêuticos oficiais por localização, ano de fundação e linha de produção

\begin{tabular}{|c|c|c|c|c|c|}
\hline № & Laboratório & Sigla & Localização/UF & Fundação & Produção \\
\hline 1 & $\begin{array}{l}\text { Centro de Pesquisa e Produção de } \\
\text { Medicamentos do Amazonas/ } \\
\text { Fundação Universidade do } \\
\text { Amazonas }\end{array}$ & CEPRAM/FUAM & Amazonas-AM & 1995 & Medicamentos \\
\hline 2 & $\begin{array}{l}\text { Centro de Produção e Pesquisa de } \\
\text { Imunobiologia }\end{array}$ & CPPI & Piraquara - PR & 1987 & $\begin{array}{l}\text { Soros antivenenos, insumos e } \\
\text { antígenos para auxílio diagnóstico }\end{array}$ \\
\hline 3 & $\begin{array}{lll}\text { Empresa } & \text { Brasileira } & \text { de } \\
\text { Hemoderivados e Biotecnologia }\end{array}$ & HEMOBRÁS & Goiana - PE & 2004 & $\begin{array}{l}\text { Produção } \\
\text { hemoderivados }\end{array}$ \\
\hline 4 & $\begin{array}{l}\text { Faculdade de Farmácia, } \\
\text { Odontologia e Enfermagem - } \\
\text { Farmácia Escola, Universidade } \\
\text { Federal do Ceará }\end{array}$ & FFOE & Fortaleza - CE & 1959 & Medicamentos \\
\hline 5 & Fundação Ataulpho de Paiva & FAP & Rio de Janeiro - RJ & 1900 & Vacinas \\
\hline 6 & $\begin{array}{l}\text { Fundação Baiana de Pesquisa } \\
\text { Científica e Desenvolvimento } \\
\text { Tecnológico, Fornecimento e } \\
\text { Distribuição de Medicamentos. }\end{array}$ & BAHIAFARMA & Simões Filho - BA & 2009 & Medicamentos \\
\hline 7 & Fundação Ezequiel Dias & FUNED & Belo Horizonte - MG & 1907 & Medicamentos \\
\hline 8 & Fundação Hemope & - & Amazonas-AM & 1977 & $\begin{array}{l}\text { Segmentos da Hemoterapia e } \\
\text { Hematologia, através da produção } \\
\text { científica, formação qualificada de } \\
\text { recursos humanos e prestação de } \\
\text { serviços especializados. }\end{array}$ \\
\hline 9 & $\begin{array}{l}\text { Fundação para o Remédio Popular } \\
\text { "Chopin Tavares Lima" }\end{array}$ & FURP & Guarulhos - SP & 1972 & Medicamentos \\
\hline 10 & $\begin{array}{l}\text { Indústria Química do Estado de } \\
\text { Goiás S/A }\end{array}$ & IQUEGO & Goiânia - GO & 1964 & Medicamentos \\
\hline 11 & Instituto Butantan & - & São Paulo - SP & 1899 & $\begin{array}{l}\text { Vacinas e soros para uso profilático e } \\
\text { curativo }\end{array}$ \\
\hline 12 & Instituto Carlos Chagas & ICC/FIOCRUZ & Curitiba - PR & 2009 & $\begin{array}{l}\text { Produção de kits para diagnóstico } \\
\text { laboratorial } \\
\text { de hantavirose. }\end{array}$ \\
\hline 13 & Instituto de Tecnologia do Paraná & TECPAR & Curitiba - PR & 1940 & $\begin{array}{l}\text { Vacinas e antígenos para diagnóstico } \\
\text { de brucelose e tuberculose bovina } \\
\text { (ATA, prova do anel no leite, prova } \\
\text { lenta, tuberculinas PPD bovina e } \\
\text { aviária) }\end{array}$ \\
\hline 14 & $\begin{array}{l}\text { Instituto de Tecnologia em } \\
\text { Imunobiológicos/Fundação Oswaldo } \\
\text { Cruz }\end{array}$ & $\begin{array}{l}\text { BIO- } \\
\text { MANGUINHOS/FI } \\
\text { OCRUZ }\end{array}$ & Rio de Janeiro - RJ & 1976 & $\begin{array}{l}\text { Novas vacinas, medicamentos à } \\
\text { base de plantas, métodos de } \\
\text { diagnóstico e monitoramento da } \\
\text { saúde do trabalhador, }\end{array}$ \\
\hline 15 & $\begin{array}{l}\text { Instituto de Tecnologias em } \\
\text { Fármacos/Fundação Oswaldo Cruz }\end{array}$ & $\begin{array}{l}\text { FARMANGUINHO } \\
\text { S/FIOCRUZ }\end{array}$ & Rio de Janeiro - RJ & 1956 & Medicamentos \\
\hline
\end{tabular}


conclusão

Tabela 1 - Relação dos laboratórios farmacêuticos oficiais por localização, ano de fundação e linha de produção

\begin{tabular}{|c|c|c|c|c|c|}
\hline № & Laboratório & Sigla & Localização/UF & Fundação & Produção \\
\hline 16 & Instituto Vital Brazil S/A & IVB & Niterói - RJ & 1918 & Medicamentos \\
\hline 17 & $\begin{array}{l}\text { Laboratório de Ensino, Pesquisa e } \\
\text { Extensão em Medicamentos e } \\
\text { Cosméticos / Unidade de Produção } \\
\text { de Medicamentos. FUEM - } \\
\text { Fundação Universidade de Maringá }\end{array}$ & LEPEMC & Maringá - PR & 1993 & Medicamentos \\
\hline 18 & $\begin{array}{l}\text { Laboratório de } \begin{array}{l}\text { Produção de } \\
\text { Medicamentos }-\end{array} \text { Universidade } \\
\text { Estadual de Londrina }\end{array}$ & LPM & Londrina - PR & 1989 & Medicamentos \\
\hline 19 & $\begin{array}{lcc}\text { Laboratório } & \text { de } & \text { Tecnologia } \\
\text { Farmacêutica } & - & \text { Universidade } \\
\text { Federal da Paraíba } & \end{array}$ & LTF & João Pessoa - PB & 1968 & Medicamentos \\
\hline 20 & $\begin{array}{l}\text { Laboratório Farmacêutico de Santa } \\
\text { Catarina }\end{array}$ & LAFESC & Florianópolis - SC & 1969 & Medicamentos \\
\hline 21 & $\begin{array}{l}\text { Laboratório Farmacêutico do Estado } \\
\text { de Pernambuco Governador Miguel } \\
\text { Arraes S.A }\end{array}$ & LAFEPE & Recife - PE & 1967 & Medicamentos \\
\hline 22 & $\begin{array}{l}\text { Laboratório Farmacêutico do Rio } \\
\text { Grande do Sul }\end{array}$ & LAFERGS & Porto Alegre - RS & 1972 & Medicamentos \\
\hline 23 & $\begin{array}{l}\text { Laboratório Industrial Farmacêutico } \\
\text { de Alagoas SA }\end{array}$ & LIFAL & Maceió - AL & 1974 & Medicamentos \\
\hline 24 & $\begin{array}{l}\text { Laboratório Industrial Farmacêutico } \\
\text { do Estado da Paraíba }\end{array}$ & LIFESA & João Pessoa -PB & 1997 & Medicamentos \\
\hline 25 & $\begin{array}{l}\text { Laboratório Químico Farmacêutico } \\
\text { da Aeronáutica }\end{array}$ & LAQFA & Rio de Janeiro - RJ & 1971 & Medicamentos \\
\hline 26 & $\begin{array}{l}\text { Laboratório Químico Farmacêutico } \\
\text { da Marinha }\end{array}$ & LFM & Rio de Janeiro - RJ & 1906 & Medicamentos \\
\hline 27 & $\begin{array}{l}\text { Laboratório Químico Farmacêutico } \\
\text { do Exército }\end{array}$ & LQFEx & Rio de Janeiro - RJ & 1808 & Medicamentos \\
\hline 28 & $\begin{array}{l}\text { Núcleo de Pesquisa em Alimentos e } \\
\text { Medicamentos - Universidade } \\
\text { Federal do Rio Grande do Norte }\end{array}$ & NUPLAN & Natal - RN & 1991 & Medicamentos \\
\hline 29 & $\begin{array}{l}\text { Núcleo de Tecnologia Farmacêutica } \\
\text { - Universidade Federal do Piauí }\end{array}$ & NTF & Teresina - PI & n.d & Medicamentos \\
\hline
\end{tabular}

Fonte: Elaboração própria a partir de Magalhães et. al. (2011), Oliveira et. al. (2003), Hasenclever (2004), MS/SCTIE/DAF e ALFOB.

Apenas 19 (dezenove) LFO pertencem à Associação dos Laboratórios Farmacêuticos Oficiais do Brasil (ALFOB). ALFOB é uma associação civil sem fins lucrativos, de direito privado, que se pauta pelos princípios do direito público, com autonomia administrativa, financeira e patrimonial, de duração indeterminada. (ALFOB, 2014)

Segundo a ALFOB (2014), os LFO foram estruturados, em sua maioria, há mais de 20 anos, em cooperação com a política de medicamentos implementada pela Central de Medicamentos (CEME). Reconhece a existência de uma forte dependência dos LFO com as ações e do fomento proporcionados pelo Ministério da Saúde. Reconhece, ainda, ser inadiável e imperativa, a modernização do parque 
industrial e tecnológico, dos seus processos de: gestão, capacitação, motivação e fixação dos recursos humanos dos LFO.

A ALFOB (2014) reconhece que há necessidade de investimentos junto aos LFO para modernização de suas plantas industriais e realização de certificação de suas Boas Práticas de Fabricação e Controle. Assegura que os LFO têm dificuldades em manter os seus registros sanitários, as certificações de BPFC e de atualizar seu elenco de produtos.

A situação dos LFO já tinha sido retratada no Relatório Final da CPI dos Medicamentos (2000) e não difere da posição atual da ALFOB. Pelo Relatório da CPI os LOB enfrentavam a falta de investimento no campo da pesquisa e desenvolvimento, além da importação de fármacos, que mantinham os laboratórios públicos reféns dos laboratórios internacionais, o que encarecia os custos e inviabilizava a linha de produção. Além disso, os baixos ou quase inexistentes incentivos à produção e à distribuição eram determinantes para a obsolescência ou mesmo ausência de equipamentos na maioria dos laboratórios. Tinham como agravante uma força de trabalho insuficiente, mal qualificada e mal remunerada. Apesar dessa situação desfavorável, os laboratórios oficiais produziam a um custo muito inferior ao dos laboratórios privados.

Para Loyola (2008), os LFO são atores importantes para a estabilização dos preços dos medicamentos no mercado brasileiro e principalmente na produção de medicamentos para atender os programas do Ministério da Saúde das doenças negligenciadas, que devido à reduzida lucratividade normalmente recebem pouco incentivo às pesquisas pelos países desenvolvidos ou por parte da indústria farmacêutica. Estes laboratórios dão apoio em ocasiões emergenciais, como: guerras, acidentes naturais e desabastecimento no mercado mundial. Ao mesmo tempo, possuem importante papel na produção de medicamentos para programas estratégicos do Ministério da Saúde, como por exemplo, o Programa DST/Aids e o Programa Nacional de Imunizações (PNI). Alguns LFO apresentaram saldo negativo em duas décadas de funcionamento. Por isso, o estabelecimento das PDPs constituem projetos desejados pelos laboratórios públicos. (LOYOLA, 2008)

A ALFOB (2014) afirma que os LFO devem ser vistos como um organismo público de cunho técnico, científico, independente, imparcial, que podem proporcionar o necessário suporte à Rede Brasileira de Produção Pública de Medicamentos, com o finalidade de executar, implementar e acompanhar projetos, 
assessorar tecnicamente às áreas reguladas que envolvem a ANVISA (Desenvolvimentos, Estudos, Registros, Inspeções, Certificações), catalisar e induzir novas alianças. Serem certificadores qualificados de fornecedores e serviços, com intercâmbio dentro da Rede Brasileira de Produção Pública de Medicamentos. Serem os facilitadores qualificados para interagir e colaborarem na busca de sinergias e soluções dentro e fora da REDE, de forma direta e independente, bem como, formadores de Recursos Qualificados, focado nas necessidades específicas da REDE.

Antes das Parcerias para o Desenvolvimento Produtivo (PDPs) os LFO produziam apenas medicamentos que não eram de interesse dos grandes laboratórios de capital privado, pois tratam as doenças negligenciadas ${ }^{9}$, que hoje atingem principalmente as populações de países em desenvolvimento. (BRASIL, 2012)

Boechat (2011) ao proferir palestra no XIII Encontro Regional da Sociedade Brasileira de Química-Rio de Janeiro (SBQ-Rio) ao abordar o mercado público de medicamentos, a palestrante destacou na mesa "Desafios da Indústria Farmacêutica no Brasil”, alguns pontos fracos da produção pública nacional, dentre eles que a produção é vulnerável às constantes inovações do mercado farmacêutico privado e sofre com a competição dos genéricos, já que os LFO não podem produzir estes medicamentos.

Os Laboratórios Oficiais não podem produzir genéricos. Eles produzem medicamentos similares embora tenham que fazer a equivalência. Mas é um produtor diferente de cada vez. Isso varia também na matéria-prima. Então, cada vez que se compra, é de um produtor diferente que tem qualidades diferentes. Temos também que atender a todos os requisitos da ANVISA. (Boechat, 2011)

Um dos caminhos apontados por Boechat (2011) na palestra como eficiente para o setor farmacêutico brasileiro é o das Políticas Público-Privadas (PPPs), principalmente envolvendo os LFO. Segundo ela, essas parcerias poderão, eventualmente, trazer progressos significativos na produção pública de medicamentos e visam diminuir o déficit de US\$10 bilhões da balança comercial de saúde, transferindo tecnologias para a indústria brasileira. Para ela o principal

\footnotetext{
${ }^{9}$ Doenças negligenciadas são doenças que não só prevalecem em condições de pobreza, mas também contribuem para a manutenção do quadro de desigualdade, já que representam forte entrave ao de senvolvimento dos países. Como exemplos de doenças negligenciadas, podemos citar: dengue, doença de Chagas, esquistossomose, hanseníase, leishmaniose, malária, tuberculose, entre outras. Segundo dados da Organização Mundial de Saúde (OMS) (DECIT/SCTIE/MS)
} 
objetivo das PPPs é a "fabricação local de novas drogas e a ampliação do acesso aos medicamentos no SUS". Mas, fez críticas ao período, estabelecido na lei das PPPs, de reserva de mercado para a indústria farmacêutica internacional. Segundo ela, essa indústria geralmente produz os medicamentos fora do nosso país e tem garantido, em torno de 3 a 4 anos, de vendas diretas para o governo brasileiro. Só após esse período é que há a transferência total de tecnologia para os Laboratórios Oficiais.

Como instrumento de política pública, os laboratórios oficiais proporcionam suporte essencial às políticas nacionais de saúde de combate e controle de doenças, e de promoção do acesso aos medicamentos pela população, principalmente a de baixa renda (CASAS, 2009).

Para amenizar os problemas dos LFO em relação à Lei de Licitações foi editada a Lei de Inovação Tecnológica - Lei no 10.973, de 2 de dezembro de 2004, em especial os artigos 19, 20, 24, 25, que inclui o inciso XXV no art. 24 da Lei no 8.666, de 21 de junho de 1993 e o art. 27, inciso IV, desse mesmo diploma, que permite o tratamento preferencial na aquisição de bens e serviços pelo Poder Público, às empresas que invistam em pesquisa e desenvolvimento de tecnologia no País.

No ano de 2008, foram editadas pelo Ministério da Saúde portarias que colaboraram para o fortalecimento da produção pública de medicamento e produtos para a saúde, estratégicos para o Brasil por meio da compra de insumos produzidos nacionalmente. A Portaria $\mathrm{GM} \mathrm{n}{ }^{\circ} 374$, de 28 de fevereiro de 2008, que instituiu no âmbito do SUS, o Programa Nacional de Fomento à Produção Pública e Inovação no Complexo Industrial da Saúde (CIS), é considerada uma das ferramentas de fomento aos laboratórios públicos para a formação de parcerias com o setor privado e produção dos insumos considerados estratégicos e não produzidos no País, conforme os artigos $3^{\circ}$ e $4^{\circ}$ da referida portaria.

Art. $3 \underline{\underline{0}}$ Estabelecer que os objetivos específicos do Programa, segundo os segmentos que compõem a produção do conjunto de laboratórios públicos, são:

I - Segmento Farmacêutico:

a) - estimular a internalização da produção de farmoquímicos e medicamentos de maior impacto para o Sistema Único de Saúde;

b) modernizar os Laboratórios Farmacêuticos Oficiais em termos tecnológicos e organizacionais e capacitá-los para estabelecer parcerias com o setor produtivo privado; 
c) estimular a produção de medicamentos para doenças negligenciadas e de suas matérias-primas, superando o hiato entre o esforço de produção e inovação dos países desenvolvidos e as necessidades nacionais; e

(...)

II - Segmento Biotecnológico (imunobiológicos, biofármacos, hemoderivados e reagentes para diagnóstico):

a) capacitar os produtores públicos do País para a produção da matériaprima ativa com recursos às novas biotecnologias;

b) modernizar os produtores públicos em termos tecnológicos e organizacionais e capacitá-los para estabelecer parcerias com 0 setor produtivo privado;

(...)

f) consolidar a produção pública de reagentes biológicos para diagnóstico e estabelecer parcerias com o setor privado e instituições científicas para o desenvolvimento e a comercialização de novos produtos e insumos para diagnóstico;

(...)

h) favorecer a consolidação do produtor estatal nacional (Hemobras) como uma empresa pública eficiente, comprometida com resultados e tecnologicamente qualificada; e

Art. 4으 As diretrizes estabelecidas para o Programa Nacional de Fomento à Produção Pública e Inovação no Complexo Industrial da Saúde são:

I - fortalecer, ampliar e qualificar a participação dos produtores públicos no Complexo Industrial da Saúde, de modo a contribuir no processo de transformação da estrutura produtiva do País, tornando-a compatível com um novo padrão de consumo em saúde e com novos padrões tecnológicos; II - fomentar as atividades de PD\&I no âmbito dos produtores públicos, tornando-os competitivos e capacitados a enfrentar a concorrência global em bases permanentes num contexto de incessante mudança tecnológica;

III - promover melhorias na gestão dos produtores públicos, estimulando o planejamento estratégico e a adoção de estruturas organizacionais e modelos de gestão capazes de dotá-los de maior agilidade, flexibilidade e eficiência;

IV - promover a articulação entre os produtores públicos buscando atuação coordenada e cooperada em todas as áreas, mediante a estratégia de organização em rede;

(...)

VII - promover a articulação entre os produtores públicos e a indústria privada com vistas à realização de ações complementares e sinérgicas em benefício do mercado público de saúde;

(...)

IX - promover a articulação dos produtores públicos com a infra-estrutura científica e tecnológica no País para atender aos requerimentos da inovação, viabilizando o desenvolvimento de produtos e processos e a adequação da produção pública aos requerimentos de saúde e de competitividade. (os grifos são nossos)

A Portaria GM n 375, de 28 de fevereiro de 2008 que instituiu, no âmbito do SUS, o Programa Nacional para qualificação, produção e inovação em equipamentos e materiais de uso em saúde, no seu artigo $3^{\circ}$, incisos VI e IX abaixo transcritos também prevê estímulo às atividades privadas para o desenvolvimento tecnológico do setor público e a adoção de políticas de compras governamentais baseadas na transferência de tecnologia. 
Art. 3 o Os objetivos específicos estabelecidos para o Programa são:

(...)

VI - estimular o setor privado a utilizar os instrumentos de apoio existentes

para ampliar o desenvolvimento tecnológico no setor público e privado;

(...).

IX) Propor a adoção de políticas de compras governamentais baseadas na

qualidade dos insumos e na transferência de tecnologia. (O grifo é nosso)

Ainda em 2008, por meio da Portaria Interministerial MPOG/MS/MCT/MDIC $n^{\circ} 128$, de 29 de maio de 2008, que estabeleceu que a contratação pública de medicamentos e fármacos pelo SUS, deve ser de forma preferencial por meio de licitações de âmbito nacional e estabelece também que, os laboratórios públicos devem dar preferência a produtores locais em suas compras de fármacos.

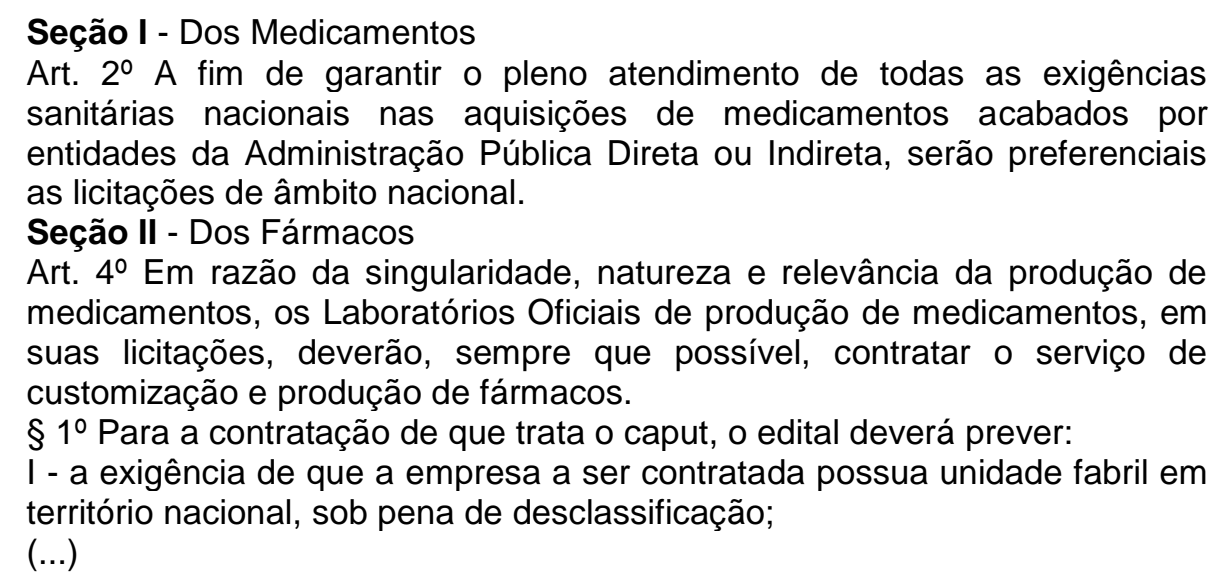

A Portaria $n^{\circ} 3.031$, de 16 de dezembro de 2008, estabelece que os laboratórios oficiais que produzem medicamentos devem ao adquirir matériasprimas, preferencialmente das entidades privadas que produzam ingredientes farmacêuticos ativos no Brasil. Quando houver mais de um fornecedor que atenda os requisitos os LFO de produção de medicamentos devem levar em conta, em seu processo licitatório, o grau de verticalização da produção no País, apresentado pelos fornecedores. Esta orientação para a compra de insumos em farmoquímicas nacionais gera economia para os LFO.

Art. $1^{0}$ - Estabelecer que os laboratórios oficiais de produção de medicamentos, em suas licitações, devam dar preferência à aquisição dos ingredientes farmacêuticos ativos necessários à sua linha de produção de empresa que produza essas matérias-primas no País. Art. 2ํ- Quando houver mais de um fornecedor que atenda às condições estabelecidas pelo artigo $1^{0}$ desta Portaria, os laboratórios oficiais de produção de medicamentos deverão levar em conta, no processo licitatório, o grau de verticalização da produção no País, apresentado pelos fornecedores. 
Art. 3ำ - A observância dessa norma ora instituída deverá constituir-se em critério discriminante positivo e deverá estar compulsoriamente presente nas análises de projetos de compras e investimentos realizados pelo Ministério da Saúde junto aos Laboratórios Oficiais de produção de medicamentos.

Outro incentivo de fomento à produção de medicamentos dos LFO concedido pelo governo federal se deu por meio da Lei oㅜ 12.349/10, de 15 de dezembro de 2010, visando a promoção do desenvolvimento nacional sustentável em áreas estratégicas instituiu margens de preferências nas licitações realizadas no âmbito da Administração Pública Federal para aquisição de fármacos e medicamentos produzidos pelos laboratórios oficiais. Esta norma foi regulamentada pelo Decreto $\mathrm{n}^{\circ}$ 7.713, de 03 de abril de 2012.

Dando continuidade às ações voltadas para o setor produtivo público o Ministério da Saúde editou a Portaria oㅡ 837, de 18 de abril de 2012, que define as diretrizes e os critérios para 0 estabelecimento das Parcerias para 0 Desenvolvimento Produtivo (PDP).

PDP são parcerias realizadas entre instituições públicas e entidades privadas com vistas ao acesso a tecnologias prioritárias, à redução da vulnerabilidade do Sistema Único de Saúde (SUS) a longo prazo e à racionalização e redução de preços de produtos estratégicos para saúde, com o comprometimento de internalizar e desenvolver novas tecnologias estratégicas e de valor agregado elevado. (BRASIL, 2012)

O desenho da PDP surgiu em 2009, como parte de uma política única que articula saúde e desenvolvimento voltados para o bem-estar da população e do desafio de consolidar a produção nacional de tecnologias estratégicas para o SUS e ampliam o acesso a tecnologias estratégicas e reduzem a vulnerabilidade do Sistema Único de Saúde (SUS), por meio do fortalecimento do Complexo Industrial e Inovação em Saúde. (DECIIS/SCTIE/MS)

Os principais objetivos da Parceria para o Desenvolvimento Produtivo, são:

- Racionalizar o poder de compra do Estado, mediante a centralização seletiva dos gastos na área da saúde, com vistas à diminuição nos custos de aquisição do SUS e à viabilização da produção no País de produtos inovadores de alta essencialidade para a saúde, tendo como foco a melhoria do acesso da população a insumos estratégicos; 
- Fomentar a desenvolvimento tecnológico conjunto e o intercâmbio de conhecimentos para a inovação;

- $\quad$ Priorizar a fabricação local de produtos de alto custo ou de grande impacto sanitário e social; e

- Reduzir de forma significativa e progressiva os preços na medida em que a tecnologia é transferida e desenvolvida.

Abaixo as razões da importância das PDP para a assistência farmacêutica do Ministério da Saúde:

1) Ampliar o acesso da população a produtos estratégicos e diminuir a vulnerabilidade do SUS;

2) Reduzir a dependência produtiva e tecnológica;

3) Racionalizar o poder de compra na saúde;

4) Proteger os interesses da Administração Pública e da sociedade, ao buscar a economicidade;

5) Fomentar o desenvolvimento tecnológico e o intercâmbio de conhecimentos;

6) Promover o desenvolvimento e a fabricação em território nacional de produtos estratégicos para o sus

7) Buscar a sustentabilidade tecnológica e econômica do SUS a curto, médio e longo prazos, promovendo condições estruturais para aumentar a capacidade produtiva e de inovação do país, para contribuir para redução do déficit comercial do CEIS e garantir o acesso à saúde; $\mathrm{e}$

8) Estimular o desenvolvimento da rede de produção pública no país e do seu papel estratégico para o SUS.

O Ministério da Saúde publicou Consulta Pública ํㅜ 59, que ficou aberta para contribuições no período de 14 de agosto de 2014 a 05 de setembro de 2014 (23 dias), para redefinir as novas diretrizes e os critérios para a definição da lista de produtos estratégicos para o Sistema Único de Saúde (SUS) e o estabelecimento das Parcerias para o Desenvolvimento Produtivo (PDP) e disciplina os respectivos processos de submissão, instrução, decisão, transferência e absorção de tecnologia, aquisição de produtos estratégicos para o SUS no âmbito das PDP, monitoramento e avaliação.

Os objetivos da nova normatização das PDPs são: 
1) Tornar esta uma política de Estado com um marco institucional seguro e estável;

2) Aumentar a segurança jurídica, econômica e tecnológica dos Processos de PDP como política de Estado (forte contribuição "proativa" dos órgãos de controle interno e externo)

3) Fortalecer e definir o processo de normatização, com clareza e transparência;

4) Consolidar todos os instrumentos normativos em um único marco da política; e

5) Fortalecer a saúde como parte da agenda da política nacional de desenvolvimento, com um processo deliberativo interministerial.

Dando continuidade ao fomento pelo governo federal aos LFO, foi editada a Lei $n^{\circ} 12.715$, de 17 de setembro de 2012, que por meio de seu artigo no 73 modificou o artigo no 24 da Lei de Licitações (Lei ํ 8.666) para incluir, entre os casos de dispensa de licitações públicas, a contratação em que houver transferência de tecnologia de produtos estratégicos para o SUS, no âmbito da Lei no 8.080 , de 19 de setembro de 1990, conforme elencados em ato da direção nacional do SUS, inclusive por ocasião da aquisição destes produtos durante as etapas de absorção tecnológica. Esta alteração possibilitou a continuidade/melhoria das adequações do processo das PDPs.

Art. 24. (...)

XXXII - na contratação em que houver transferência de tecnologia de produtos estratégicos para o Sistema Único de Saúde - SUS, no âmbito da Lei no 8.080 , de 19 de setembro de 1990, conforme elencados em ato da direção nacional do SUS, inclusive por ocasião da aquisição destes produtos durante as etapas de absorção tecnológica.

A alteração do artigo 24 da Lei o 8.666/93, com a inclusão do inciso XXXII, possibilitou a transferência de tecnologia para a Administração Pública. Esta inclusão consolida a importância das parcerias para o desenvolvimento do complexo industrial da saúde e a produção de medicamentos e insumos estratégicos para o SUS, tem-se a perspectiva de dar continuidade a essas parcerias para medicamentos estratégicos para o SUS (BRASIL, 2010). 
O número total de Projetos Executivos de Parcerias para o Desenvolvimento Produtivo formalizados foram 104 parcerias, que totaliza 97 produtos acabados, sendo 66 medicamentos, 7 vacinas, 19 produtos para saúde e 5 P\&D. Dentre os projetos formalizados encontramos 76 parceiros envolvidos, sendo 20 laboratórios públicos e 57 privados. (DCIIS/SCTIE/MS)

A FURP foi o LFO que mais firmou PDP com o Ministério da Saúde para produção de medicamentos e produtos para à saúde, um total de 19 medicamentos, seguido por Farmanguinhos com 18 medicamentos e em terceira posição encontramos Biomanguinhos, com 14 medicamentos, conforme se verifica na Figura 1, abaixo.

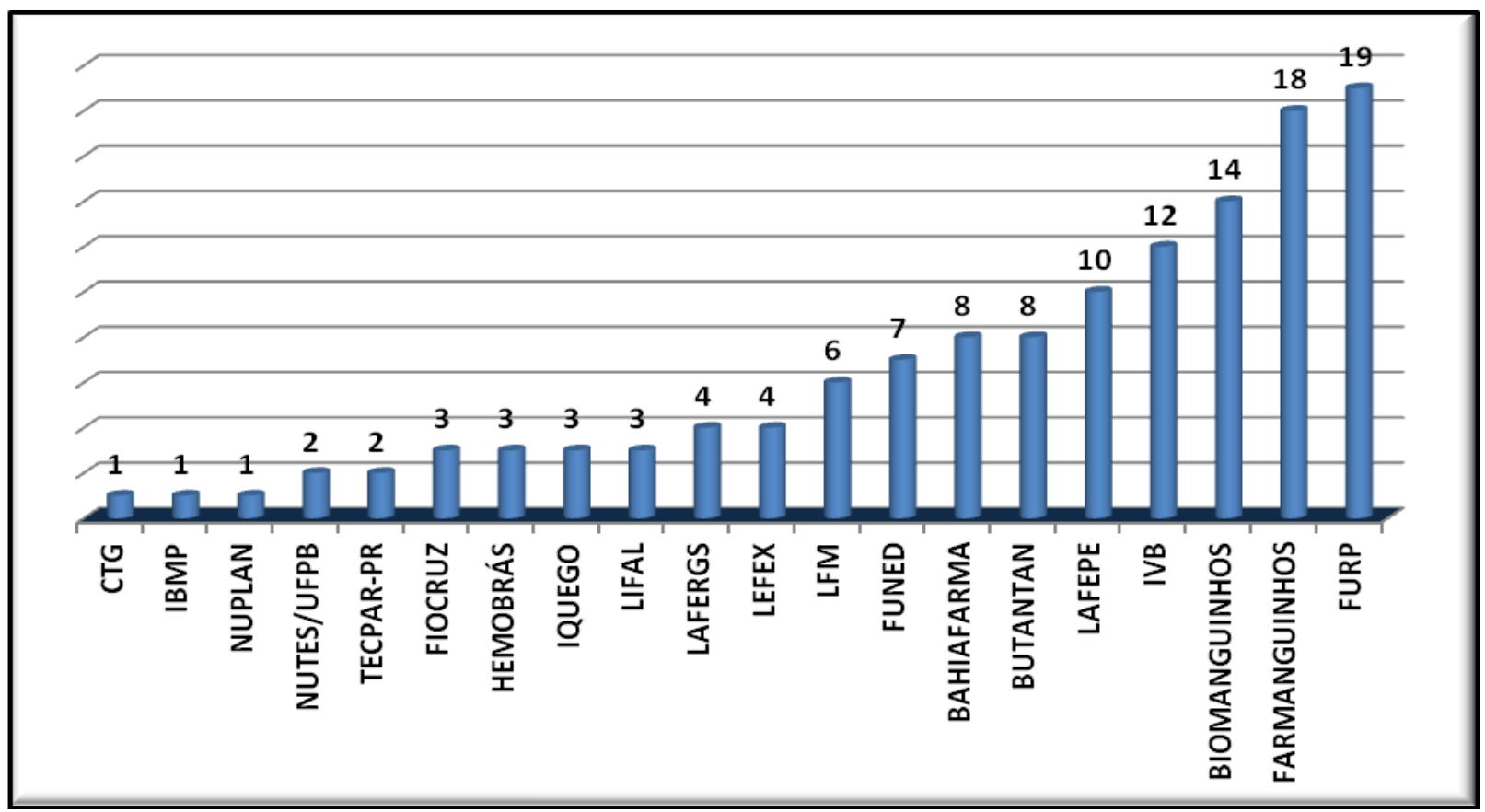

Figura 1 Representação gráfica de Projetos Executivos de Parcerias para o Desenvolvimento Produtivo.

Fonte: Autoria Própria

Apenas uma PDP para o medicamento micofenolato de mofetila, da classe terapêutica imunossupressor, celebrada entre o Laboratório Oficial Farmanguinhos que envolviam os Laboratórios privados Roche/Nortec foi extinta. Somente uma PDP teve o Contrato de Transferência de Tecnologia encerrado em $1^{\circ}$ de outubro de 2014. Esta PDF foi celebrada entre o Laboratório Oficial Butantan e o laboratório privado Sanofi Pasteur para o medicamento Vacina Influenza. (DCIIS/SCTIE/MS) 
Com a formalização dos Projetos Executivos de Parcerias para o Desenvolvimento Produtivo o Ministério da Saúde terá uma economia média estimada em torno de $\mathrm{R} \$ 4,1$ bilhões/ano e uma economia de divisas ao final dos projetos de US\$ 3,9 bilhões. O gasto do Ministério da Saúde, sem a formalização Projetos Executivos de Parcerias para o Desenvolvimento Produtivo, seria em torno de $\mathrm{R} \$ 8,9$ bilhões/ano em compras. (DCIIS/SCTIE/MS)

\subsubsection{Rede Brasileira de Produção Pública de Medicamentos (RBPP)}

O Ministério da Saúde buscando a otimização da gestão, a estruturação e socialização das iniciativas de fomento e de desenvolvimento tecnológico dos LFO, criou a Rede Brasileira de Produção Pública de Medicamentos (RBPPM) pela Portaria no 843/GM, de 02 junho de 2005 (BRASIL, 2005b). A RBPPM era composta por representantes do Ministério da Saúde, ANVISA, ALFOB, CONASS e CONASEMS e destinada a viabilizar a produção dos medicamentos e princípios ativos correspondentes, de interesse da saúde pública.

A adesão à rede era institucional e tinha como foco o desenvolvimento de ações que visavam a reorganizar o sistema oficial de produção de medicamentos, de matérias-primas e de insumos. Deste modo, buscava-se o suprimento regular e adequado das demandas do SUS, principalmente para atender aos programas de saúde pública em AIDS, tuberculose e endemias focais.

A Portaria № 2.438 de 7 de dezembro de 2005, revogou a Portaria no 843/GM, de 02 junho de 2005, com a finalidade de melhorar a estruturação da produção pública da Rede Brasileira de Produção Pública de Medicamentos. Esta portaria teve como um de seus principais objetivos a expansão de ações que visassem à reorganização do sistema oficial de produção de medicamentos (o que incluia matérias-primas e insumos), visando a garantia do suprimento regular e adequado de medicamentos demandados pelo SUS, com ênfase nos medicamentos estratégicos, produzidos exclusivamente pelo parque fabril oficial. 


\subsection{SECRETARIA DE CIÊNCIA, TECNOLOGIA E INSUMOS ESTRATÉGICOS}

O Decreto Presidencial № 4.726 , de $09 / 06 / 03^{10}$, criou a Secretaria de Ciência, Tecnologia e Insumos Estratégicos. Essa Secretaria incorporou as funções da extinta Secretaria de Políticas de Saúde, que realizava atividades no âmbito da atenção básica. Sob a subordinação desta Secretaria foi criado o Departamento de Assistência Farmacêutica (DAF). (BRASIL, 2003)

A Secretaria de Ciência, Tecnologia e Insumos Estratégicos - SCTIE tem como principais competências a formulação, implementação e avaliação da Política Nacional de Ciência e Tecnologia em Saúde. Cabe à SCTIE viabilizar a cooperação técnica a estados, municípios e DF, no âmbito da sua atuação; e articular a ação do MS - no âmbito das suas atribuições - com as organizações governamentais e nãogovernamentais, com vistas ao desenvolvimento científico e tecnológico em saúde. (SCTIE/MS)

Além disso, a Secretaria também formula, implementa e avalia as Políticas Nacionais de Assistência Farmacêutica e de Medicamentos, incluindo hemoderivados, vacinas, imunobiológicos e outros insumos relacionados; participa da formulação e implementação das ações de regulação do mercado da Saúde; e fomenta, realiza e avalia estudos e projetos no âmbito das suas responsabilidades. (SCTIE/MS)

Visa ao desenvolvimento da capacidade científica, tecnológica e produtiva nacional para o fortalecimento do SUS como sistema de saúde universal. A SCTIE/MS formula e implementa políticas nacionais de ciência, tecnologia e inovação em saúde, assistência farmacêutica e fomento à pesquisa, desenvolvimento e inovação na área de saúde. Também desenvolve métodos e mecanismos para a análise da viabilidade econômico-sanitária de empreendimentos públicos no Complexo Industrial da Saúde, promove a implementação de parcerias público-privadas no desenvolvimento tecnológico e na produção de produtos

\footnotetext{
${ }^{10}$ Publicado no DOU de 10 de junho de 2003, que "Aprova a Estrutura Regimental e o Quadro Demonstrativo dos Cargos em Comissão e das Funções Gratificadas do Ministério da Saúde, e dá outras providências”.
} 
estratégicos para o país e coordena o processo de incorporação e desincorporação de tecnologias em saúde no âmbito do SUS. (SCTIE/MS)

A SCTIE/MS é composta por 4 Departamentos:

1) Departamento de Ciência e Tecnologia (Decit), área de Ciência e Tecnologia responsável pelo incentivo à pesquisas em saúde no país, por meio de fomento viabilizados por verba federal. Atua em ações conjuntas com outros ministérios e órgãos estatais, a Secretaria orienta a política do Complexo Industrial da Saúde para o setor público, favorecendo o desenvolvimento da indústria farmacêutica, de equipamentos e de tecnologias de saúde. O objetivo do Governo Federal é, dessa maneira, tornar o Brasil independente em relação ao mercado externo. Tem como objetivo primordial a pesquisa.

2) Departamento de Assistência Farmacêutica (DAF), A Assistência Farmacêutica busca promover, proteger e recuperar a saúde individual e coletiva da população. Atua para promover a ampliação do acesso dos cidadãos aos medicamentos e o estímulo de seu uso racional. Fazem parte da área: o Programa de Componentes Básicos que garante custeio e distribuição de medicamentos e insumos essenciais à atenção primária; o Programa de Componentes Especializados, que fornece medicação de alto custo gratuitamente para doenças raras; e o Programa de Medicamentos Estratégicos, para doenças específicas como aids, hanseníase, doenças do sangue e malária. Resume na promoção da população ao acesso aos medicamentos.

3) Departamento de Gestão e Incorporação de Tecnologias (DGITS) este Departamento aloca a Secretaria Executiva da Comissão Nacional de Incorporação, que tem por objetivo assessorar o Ministério da Saúde - MS nas atribuições relativas à incorporação, exclusão ou alteração de tecnologias em saúde pelo SUS, bem como na constituição ou alteração de Protocolos Clínicos e Diretrizes Terapêuticas - PCDT. Responsável pela incorporação de novas tecnologias pelo Ministério da Saúde.

4) Departamento do Complexo Industrial e Inovação em Saúde (Deciis), este visa impulsionar a indústria farmacêutica e de equipamentos para a saúde, com o objetivo de fomentar a produção pública de tecnologias estratégicas para o Sistema Único de Saúde - SUS e consolidar a estratégia nacional 
de fomento, desenvolvimento e inovação no âmbito do Complexo Industrial da Saúde - CIS.

\subsubsection{Departamento de Assistência Farmacêutica e Insumos Estratégicos}

A criação do DAF foi o primeiro passo para a institucionalização da Assistência Farmacêutica no Ministério da Saúde, com estrutura própria e a atribuição de formular e implementar a Política Nacional de Medicamentos e de Assistência Farmacêutica, já que antes as ações eram desenvolvidas por Assessoria Técnica, ligada diretamente ao Secretário de Políticas de Saúde.

O Departamento de Assistência Farmacêutica responde pelas atividades técnico-administrativas e operacionais do ciclo do medicamento, ou seja, desenvolve as ações e serviços alusivos à seleção, programação, aquisição, armazenamento, distribuição e uso de produtos farmacêuticos, em especial, dos medicamentos, em benefício da coletividade enferma usuária do SUS; possui as seguintes competências regimentais (BRASIL, 2009):

O DAF tem como principal objetivo a execução de ações que garantam e ampliem o acesso da população a medicamentos que tenham qualidade, segurança e eficácia, promovendo o seu uso racional, sob orientação técnica e em estreita consonância com a Política Nacional de Saúde e de Assistência Farmacêutica. (DAF/SCTIE/MS)

É vinculado à Secretaria de Ciência, Tecnologia e Insumos Estratégicos (SCTIE), de acordo com o Decreto № 8.065, de 7 de agosto de 2013, que aprova a Estrutura Regimental do Ministério da Saúde, tem a competência de:

1) subsidiar a Secretaria de Ciência, Tecnologia e Insumos Estratégicos na formulação de políticas, diretrizes e metas para as áreas e temas estratégicos, necessários à implementação da Política Nacional de Saúde, no âmbito de suas atribuições;

2) formular e implementar, e coordenar a gestão das Políticas Nacionais de Assistência Farmacêutica e de Medicamentos, incluindo sangue, hemoderivados, vacinas e imunobiológicos, na qualidade de partes 
integrantes da Política Nacional de Saúde, observados os princípios e as diretrizes do SUS;

3) prestar cooperação técnica para o aperfeiçoamento da capacidade gerencial e operacional de Estados, dos Municípios e do Distrito Federal, no âmbito de sua atuação;

4) coordenar a organização e o desenvolvimento de programas, projetos e ações, em áreas e temas de abrangência nacional;

5) normatizar, promover e coordenar a organização da assistência farmacêutica, nos diferentes níveis da atenção à saúde, obedecendo aos princípios e diretrizes do SUS;

6) programar a aquisição e a distribuição de insumos estratégicos para a saúde, em particular para a assistência farmacêutica, em articulação com o Departamento de Logística em Saúde da Secretaria-Executiva;

7) propor acordos e convênios com os Estados, os Municípios, e o Distrito Federal para a execução descentralizada de programas e projetos especiais no âmbito do SUS, no limite de suas atribuições;

8) orientar, capacitar e promover ações de suporte aos agentes envolvidos no processo de assistência farmacêutica e insumos estratégicos, com vistas à sustentabilidade dos programas e projetos em sua área de atuação;

9) elaborar e acompanhar a execução de programas e projetos relacionados à produção, à aquisição, à distribuição, à dispensação e ao uso de medicamentos no âmbito do SUS; e

10) coordenar a implementação de ações relacionadas à assistência farmacêutica e ao acesso aos medicamentos no âmbito dos Programas de Assistência Farmacêutica do Ministério da Saúde.

O Departamento de Assistência Farmacêutica e Insumos Estratégicos possui a seguinte estrutura organizacional: 


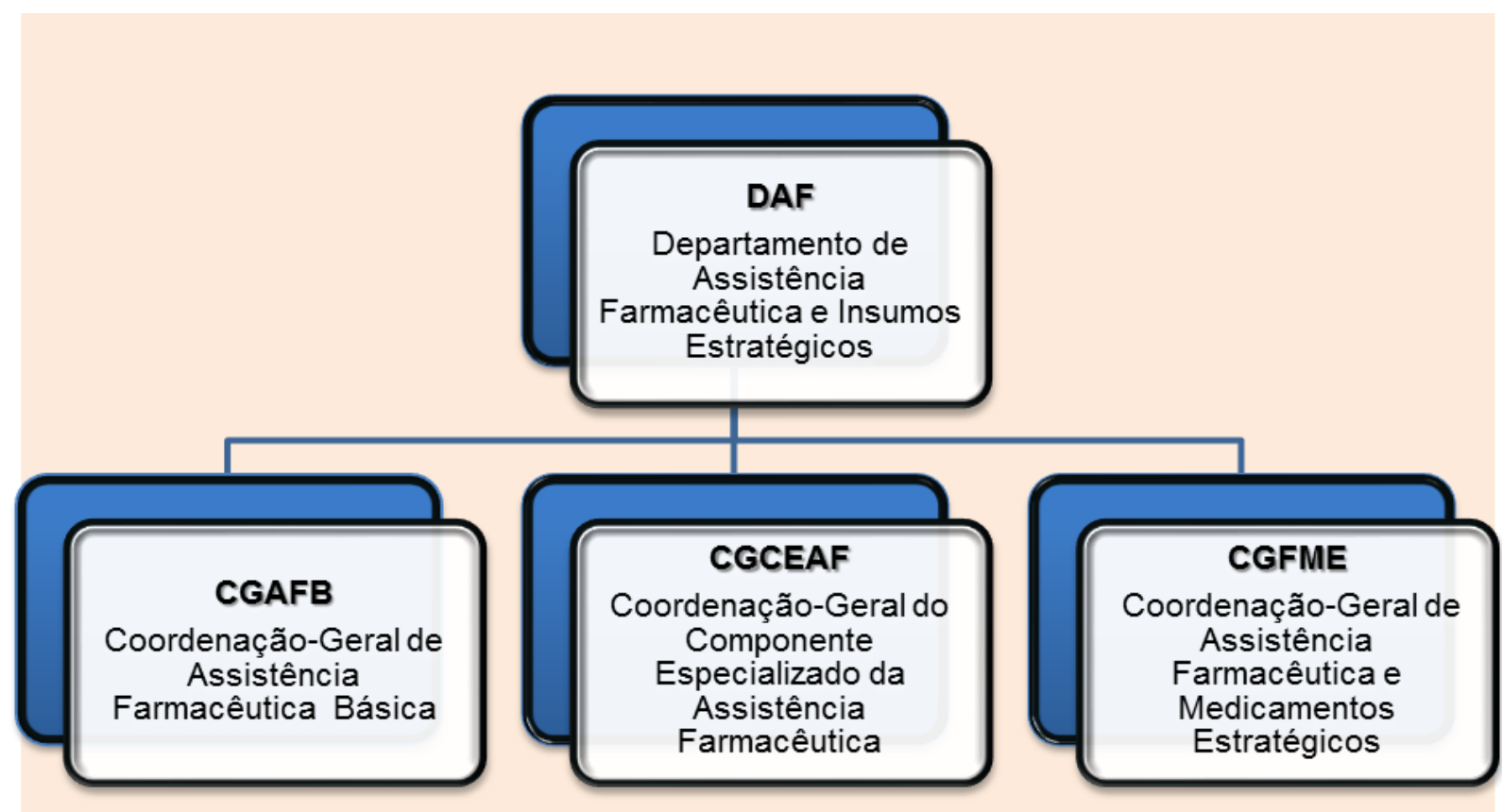

Figura 2 - Estrutura Organizacional do Departamento de Assistência Farmacêutica e Insumos Estratégicos.

Fonte: Elaboração própria.

A Coordenação-Geral de Assistência Farmacêutica Básica é responsável pela aquisição e distribuição dos medicamentos do Componente Básico da Assistência Farmacêutica: insulinas humanas NPH e Regular (frascos de $10 \mathrm{~mL}$ ) e dos contraceptivos orais e injetáveis, além do DIU e diafragma e dos medicamentos e correlatos para os programas penitenciário e calamidade pública.

Coordenação-Geral de Assistência Farmacêutica e Medicamentos Estratégicos disponibiliza medicamentos para o atendimento de Programas Estratégicos de Saúde coordenados nacionalmente pelo Ministério da Saúde: DST/Aids, tuberculose, hanseníase, endemias focais, sangue e hemoderivados, alimentação e nutrição, tabagismo, influenza e Saúde da Criança.

A Coordenação-Geral do Componente Especializado da Assistência Farmacêutica é responsável pela disponibilização dos medicamentos e outras tecnologias em saúde necessários para efetivar a integralidade do tratamento recomendados nos Protocolos Clínicos e Diretrizes Terapêuticas (PCDT) ${ }^{11}$ por meio das diferentes linhas de cuidado.

\footnotetext{
${ }^{11}$ Os PCDT têm o objetivo de estabelecer claramente os critérios de diagnóstico de cada doença, o algoritmo de tratamento das doenças com as respectivas doses adequadas e os mecanismos para o monitoramento clínico em relação à efetividade do tratamento e a supervisão de possíveis efeitos adversos. Observando ética e tecnicamente a prescrição médica, os PCDT, também, objetivam criar
} 
Assim, se depreende que a questão da assistência farmacêutica sempre foi uma preocupação do Governo Federal, mas hoje ela se encontra sistematizada no formato de política pública - Política Nacional de Medicamentos (BRASIL, 1998), a Política Nacional de Assistência Farmacêutica (BRASIL, 2004) e o Pacto pela Saúde12 - que busca garantir o acesso da população a medicamentos de qualidade e o seu uso racional, e onde esse acesso se reveste na qualidade de direito constitucional.

O DAF tem como principal objetivo a execução de ações que garantam e ampliem o acesso da população a medicamentos que tenham qualidade, segurança e eficácia, promovendo o seu uso racional, sob orientação técnica e em estreita consonância com a Política Nacional de Saúde e de Assistência Farmacêutica.

Estão ainda sob a competência do DAF os programas Farmácia Popular, que oferece medicamentos subsidiados pelo Governo Federal, desde 2004; e o Programa Nacional de Plantas Medicinais e Fitoterápicos, que prevê o incentivo ao acesso seguro e racional de plantas medicinais e o estímulo à exploração sustentável da biodiversidade.

mecanismos para a garantia da prescrição segura e eficaz. Portanto, no âmbito do CEAF, os medicamentos devem ser dispensados para os pacientes que se enquadrarem nos critérios estabelecidos no respectivo Protocolo Clínico e Diretriz Terapêutica. (Ministério da Saúde. Disponível em http://portal.saude.gov.br/portal/saude/profissional/visualizar texto.cfm?idtxt=35490\&janela=1. Acessado em 15 de novembro de 2013.

${ }^{12}$ O Pacto pela Saúde é composto pelas seguintes Portarias: no 699, de 30 de março de 2006, no 3.085, de 1 de dezembro de 2006, ㄲo 3.332, de 28 de dezembro de 2006; ํㅡ 204, de 29 de janeiro de 2007. 


\section{OBJETIVOS}

\subsection{OBJETIVO GERAL}

Avaliiar a produção pública de medicamentos e os recursos alocados aos laboratórios farmacêuticos oficiais para a produção de medicamentos dos Componentes da Assistência Farmacêutica da Secretaria de Ciência, Tecnologia e Insumos Estratégicos do Ministério da Saúde (SCTIE/MS) destinados a garantir a integralidade do direito social à medicamentos no período de 2003 a 2013.

\subsection{OBJETIVOS ESPECÍFICOS}

3.2.1 Descrever e analisar a estruturação dos Componentes da Assistência Farmacêutica da Secretaria de Ciência, Tecnologia e Insumos Estratégicos (SCTIE) do Ministério da Saúde;

3.2.2 Identificar e analisar a produção de medicamentos dos laboratórios farmacêuticos oficiais, nacionais e internacionais para atender aos Componentes da Assistência Farmacêutica da Secretaria de Ciência, Tecnologia e Insumos Estratégicos (SCTIE) do Ministério da Saúde;

3.2.3 Levantar e analisar a participação percentual quantitativa e de gastos dos fornecedores públicos, nacionais e internacionais de medicamentos dos Componentes da Assistência Farmacêutica. 


\section{MÉTODOS}

O estudo realizado é do tipo longitudinal, descritivo e retrospectivo sobre a produção de medicamentos pelos Laboratórios Farmacêuticos Oficiais, laboratórios nacionais (privados) e os laboratórios internacionais privados para atender a demanda dos Componentes da Assistência Farmacêutica e os gastos da SCTIE/MS com esta produção.

Os dados de natureza quantitativa - valores financeiros e a quantidade produzida, relativos aos gastos públicos federais e a produção de todos os Laboratórios Farmacêuticos, no período entre 2003 e 2013. Entende-se aqui como gastos os recursos despendidos pela SCTIE/MS, para aquisição dos medicamentos dos Componentes da Assistência Farmacêutica.

O estudo foi realizado no Departamento de Assistência Farmacêutico e Insumos Estratégicos da Secretaria de Ciências e Tecnologia e Insumos Estratégicos do Ministério da Saúde DAF/SCTIE/MS).

Os dados foram obtidos a partir dos registros históricos de monitoramento das compras de medicamentos lançados em planilhas eletrônicas em formato EXCEL versão 5.0/95, denominadas "BíBLIA"13 considerada a principal base de dados do DAF. Nesta base de dados são descritos o nome do programa, o número do processo, a data de vigência da modalidade firmada para a aquisição de medicamentos, o número do Contrato/Convênio, o nome do medicamento, a forma farmacêutica, a quantidade demandada, o nome do fornecedor, o preço unitário, o custo da aquisição do medicamento, a quantidade entregue, entre outros. Portanto, cabe destacar que estas informações referem-se às aquisições do Ministério da Saúde para seus programas estratégicos.

Não constam deste banco de dados do Ministério da Saúde as informações de compras de medicamentos, produzidos pelos Laboratórios Oficiais, realizadas diretamente pelos Estados e Municípios, o monitoramento destas aquisições específicas é efetuado por estes entes federados.

\footnotetext{
${ }^{13}$ As informações constantes da Bíblia datam de 1998. No anexo consta modelo de planilha. Nela constam dados das aquisições de medicamentos do Ministério da Saúde junto aos Laboratórios Públicos ou Privados.
} 
A partir das planilhas anuais do DAF foi realizada análise descritiva para cada Componente da Assistência Farmacêutica elaborando uma planilha em EXCEL, 2010 contemplando os seguintes parâmetros:

- Total de medicamentos;

- $\quad$ Laboratório produtor;

- $\quad$ Total pago ao laboratório;

- Unidade farmacológica produzida (cápsula, comprimido, frasco e ampola);

- Quantidade de Medicamentos Produzidos para o Programa e;

- Participação percentual de cada laboratório produtor.

Primeiro foram consolidados todos os dados coletados elaborando uma série histórica de produção para o Ministério da Saúde nos segmentos dos laboratórios oficiais, nacionais e internacionais, no período de 2003 a 2013, apresentando o medicamento, o laboratório produtor, o número de unidades farmacêuticas (UF) produzidas e o valor pago pelo Ministério da Saúde, por ano. Bem como o valor total de UF produzida e o valor total no período pesquisado. Os dados sobre a produção dos laboratórios nacionais e internacionais não foram separados por laboratório e sim como um todo, primeiro por que o levantamento da participação por laboratório destes segmentos individualizado não faz parte dos objetivos da pesquisa.

Ressaltamos que alguns dados sobre o nome do laboratório internacional que produziu para o Ministério da Saúde, não estava disponibilizado, apenas constava o nome da Organização Pan Americana de Saúde (OPAS) ou pelo Fundo das Nações Unidas para a Infância (em inglês United Nations Children's Fund - UNICEF), que por meio de cooperação adquiriu os medicamentos para distribuição no âmbito do SUS. Como os processos de compra encontravam-se no arquivo central do Ministério da Saúde inviabilizou a identificação do laboratório. A não identificação do laboratório produtor não prejudicou a análise, tendo em vista que os outros dados estavam disponíveis.

No segmento dos laboratórios oficiais a planilha foi divida por laboratório para definir da participação de cada um na produção pública, um dos objetivos desta pesquisa. 
Os dados quantitativos foram tratados em software EXCEL (Microsoft Office 2003) e geram tabelas e gráficos; os indicadores obtidos serviram para análise e afirmações no presente trabalho. 


\section{RESULTADOS}

Na pesquisa exploratória junto ao DAF/SCTIE/MS primeiramente foi levantado o procedimento de aquisição dos medicamentos para os Componentes da Assistência Farmacêutica pelo Ministério da Saúde para dispensação no âmbito do SUS.

Todo procedimento de compra de medicamentos para distribuição no âmbito do SUS pelo Ministério da Saúde é normatizado pela Portaria no 2.710 , de 17 de novembro de 2011 (BRASIL, 2011).

As aquisições dos medicamentos estão diretamente relacionadas às demandas dos Componentes da Assistência Farmacêutica. Primeiramente é realizado o levantamento do quantitativo da necessidade de compra do elenco de medicamentos relacionado a cada componente. Este levantamento é realizado pelas Coordenações responsáveis pela aquisição do medicamento pelo DAF, visando ao atendimento das demandas dos referidos componentes (com exceção do programa AIDS, que realiza o próprio planejamento).

No levantamento realizado pelo DAF/SCTIE/MS consta o número de casos estimados pelas Coordenações Estaduais da enfermidade a serem tratados no ano seguinte, 0 estoque existente nos Estados, informados diretamente pelas Coordenações Estaduais de Assistência farmacêutica; distribuição histórica dos últimos 12 meses, informado pelas Coordenações Estaduais de Assistência Farmacêutica, desconsiderando perda e remanejamento; entregas pendentes da programação em curso, a serem concluídas pelo Ministério da Saúde.

Com este levantamento realizado o DAF/SCTIE/MS faz análise das informações, fazendo os ajustes necessários em relação ao fator de embalagem dos quantitativos programados e atendimento da necessidade de complementação para cobertura do período de cobertura, a utilização do estoque disponível para remanejamento dos Estados e o estoque estratégico do Serviço de Almoxarifado de Medicamentos (SEAME) do Ministério da Saúde para atender demandas extras ou emergenciais; a SCTIE elabora até o dia 30 de junho do ano em curso o Plano de Demandas, por intermédio do Sistema de Logística em Saúde (SILOS), e disponibilizado ao DLOG/SE/MS. 
O Plano de Demandas é requisito para que sejam contemplados os recursos necessários para a aquisição dos Insumos Estratégicos para a Saúde (IES) no orçamento do próximo exercício financeiro. Este Plano de Demandas contém, as seguintes informações:

I - descrição do item a ser adquirido, conforme Código de Catálogo de Materiais (CATMAT);

II - quantidade, unidade de fornecimento e estoque estratégico;

III - modalidade, valor unitário e fornecedor da última aquisição;

IV - data da $1^{\text {a }}$ entrega;

$\mathrm{V}$ - características da armazenagem; e

VI - características da distribuição.

O DLOG/SE/MS é o órgão do Ministério da Saúde responsável de sistematizar os Planos de Demandas elaborados pelas Secretarias e coordenar o planejamento logístico, visando à economicidade e à celeridade nos processos de contratações de serviços relativos a IES. Os pedidos de contratações destinadas ao fornecimento de bens e à prestação de serviços relativos a IES não contemplados no Plano de Demandas serão encaminhados à Secretaria-Executiva do Ministério da Saúde (SE/MS), devidamente justificados, para análise e autorização do procedimento de aquisição.

O SILOS a partir do Plano de Demandas gera eletronicamente no SILOS, o Termo de Referência que é analisado e validado pelo DLOG/SE/MS e impressos pela área demandante a partir do próprio Sistema. Após a impressão, os Termos de Referência serão assinados pelo responsável de cada área demandante e aprovados pela autoridade competente. É de responsabilidade do DAF/SCTIE/MS ou à área demandante que elaborou o Termo de Referência solicitar a autuação do documento e inserir despacho-padrão no Sistema Integrado de Protocolo e Arquivo (SIPAR) para autuação do processo de compra.

A partir deste momento a tramitação dos processos de aquisição de medicamentos a partir de 2013, com a edição da Portaria no 2.758, 18 de novembro de 2013, é por meio eletrônico. Esta portaria instituiu o Processo de Compra Eletrônico (PEC) do Ministério da Saúde. O PEC tem as seguintes diretrizes: garantia da confiabilidade e integridade das informações relativas a documentos e processos realizados; a transparência; a facilidade e agilidade na obtenção de informações gerenciais e de caráter estratégico relativas a documentos e processos 
de aquisição de IES, bens e serviços administrativos e de tecnologia da informação; a celeridade no andamento processual e na movimentação de documentos no Ministério da Saúde; e a adoção de práticas de gestão alinhadas com os princípios da sustentabilidade e com a redução dos impactos ambientais decorrentes da atividade institucional.

As tarefas realizadas no PEC, mediante a inserção de um documento eletrônico ou pela utilização de funcionalidade do sistema tem dia e hora designados pelo sistema para sua realização, que são armazenados em ambiente seguro e por meio de tecnologia que garante a integridade, a autenticidade e a disponibilidade das informações.

Os documentos eletrônicos produzidos no PEC têm autoria, autenticidade e integridade asseguradas, nos termos da Lei, mediante utilização de: assinatura eletrônica; ou certificado digital, de uso pessoal e intransferível, sendo de responsabilidade do titular sua guarda e sigilo. Os documentos que tramitam no PEC exclusivamente em meio eletrônico, e atendem os requisitos de autenticidade, integridade e validade jurídica.

É realizado "back up" do banco de dados e de infraestrutura de armazenamento ("storage") do PEC para garantir a guarda dos documentos eletrônicos realizado pelo Departamento de Informática do SUS ( DATASUS/ SGEP/ MS).

A aquisição junto aos laboratórios privados nacionais e internacionais é realizada por meio da modalidade de licitação denominada pregão eletrônico ${ }^{14}$, tendo em vista o disposto na Lei no 10.520 , de 17 de julho de 2002, regulamentada pelo Decreto $n^{\circ} 5.450$, de 31 de maio de 2005 . É redigido edital que obedece a todos os requisitos exigidos pelo art. 40 da Lei no 8.666/93. O Ministério da Saúde celebra contrato com a empresa vencedora do certame. Para dá publicidade ao contrato celebrado é publicado no Diário Oficial da União o Extrato do Contrato.

O Pregão é utilizado pela Administração Pública para aquisição de bens de qualquer valor tendo em vista a determinação do Decreto ํㅜ 5.450/05. Essa é a razão de sua utilização na aquisição de medicamentos pelo Ministério da Saúde.

\footnotetext{
${ }^{14}$ Pregão eletrônico é uma modalidade de licitação para aquisição de bens e serviços comuns no âmbito da União, Estados, Municípios e Distrito Federal, cujos padrões de desempenho e qualidade possam ser objetivamente definidos pelo edital, por meio de especificações usuais no mercado.
} 
Após o cumprimento da fase interna do pregão (preparatória), onde o Ministério da Saúde observa todas as regras determinadas pela lei, começa a fase externa do pregão com a convocação dos interessados e o cumprimento das demais exigências da legislação do pregão e subsidiariamente as normas da Lei no 8.666/93.

O Ministério da Saúde utiliza o pregão eletrônico com os recursos da internet, assim tem a disputa à distância, em sessão pública onde são recebidas propostas e lances. Sendo o vencedor aquele que ofertar o menor preço (melhor proposta), deste que atendidos todas as condições fixadas no edital, que são examinadas pelo pregoeiro e verificada a documentação para sua habilitação. Com a constatação do atendimento de todas as exigências do edital, a empresa é declarada vencedora e é homologado o pregão e esta é convocada para assinatura do contrato no prazo fixado no edital.

Alguns medicamentos do Componente Especializado da Assistência Farmacêutica são adquiridos pelo Ministério da Saúde sem licitação, pois, não há possibilidade de competição tendo em vista a existência de um único medicamento com registro sanitário concedido pela Anvisa e sendo produzido por apenas um laboratório farmacêutico, configurando assim ausência de mercado concorrencial. Nesta hipótese o Ministério da Saúde lança mão da inexigibilidade de licitação prevista no artigo 25 , da Lei ํo 8.666/93. A realização de licitação nestes casos é inteiramente desnecessária dada a inviabilidade de competição, ser o medicamento singular e por apenas um único laboratório farmacêutico está em condições de atender ao interesse público.

Nestes casos o DAF/SCTIE/MS abre mesa de negociação com o laboratório produtor para ajustar o preço que será adquirido o medicamento. Os resultados dessas negociações tem se mostrado exitosas, pois, alguns preços são acordados com valor bem inferior ao preço autorizado pela Câmara de Regulação do Mercado de Medicamentos - CMED.

Este êxito na redução do preço se deve ao fato da aquisição ser centralizada pelo Ministério da Saúde. A centralização da compra de alguns medicamentos foi uma alternativa pactuada entre o Ministério da Saúde e os gestores das unidades federadas. Esta centralização além de considerar os custos envolvidos no tratamento medicamentoso, em nível ambulatorial, visa obter melhores preços em proveito de um aumento da necessidade de aquisição, bem como, contratos 
estáveis, regularidade das entregas e pagamentos, e redução de processos administrativos.

Os preços obtidos pelo Ministério da Saúde nestas negociações qualificam a gestão do Sistema Único de Saúde, tanto ao promover uma economia nos orçamentos públicos como, também, no atendimento dos pacientes que poderão contar com maior segurança no recebimento regular do medicamento. Por outro lado, a compra centralizada implica em maior responsabilidade do gestor federal do SUS no sentido de assegurar contratos em quantitativos e prazos que assegurem a oferta permanente de um medicamento que, na sua falta, significa agravamento das condições de saúde do paciente.

Em relação às aquisições de medicamentos pelo DAF/SCTIE/MS junto aos Laboratórios Oficiais, este utiliza a dispensa de licitação prevista na Lei 8.66693, artigo 24, inciso VII, que autoriza a dispensa de licitação para aquisição de bens produzidos por órgão ou entidade que integre a Administração Pública e que tenha sido criado para esse fim específico em data anterior à vigência da lei de licitações, desde que o preço ajustado seja compatível com o praticado no mercado. Esta é a fundamentação jurídica para a celebração de Convênio entre o Ministério da Saúde e os Laboratórios Oficiais e por meio de Portaria.

A fundamentação jurídica para celebração dos convênios com os laboratórios oficiais é a Constituição Federal/88, a Lei de Diretrizes Orçamentárias (LDO), a Lei de Responsabilidade Fiscal (LRF), a Lei no 8.666/93 e a Instrução Normativa da Secretaria do Tesouro Nacional no 1/97 (regulamento federal sobre celebração de convênios de natureza financeira).

Para a celebração dos convênios o DAF/SCTIE/MS entra em contato os LFO e verifica o interesse destas instituições produzirem os medicamentos de acordo com a demanda do Ministério da Saúde, conforme planejamento do quantitativo necessário elaborado. Além disso, estabelece a quantidade e os produtos que serão produzidos por cada laboratório. Quando possível, a produção é rateada entre os Laboratórios Oficiais. Tanto os Laboratórios Federais quanto os Estaduais e de Economia Mista.

É elaborado um plano de trabalho que contém a descrição completa do objeto a ser executado; descrição das metas a serem atingidas qualitativa e quantitativamente; etapas de execução do objeto; previsão de início e fim da 
execução; aplicação dos recursos a serem desembolsados pela concedente e cronograma de desembolso. A convenente nesta oportunidade apresenta toda a documentação exigida pela legislação que comprova a sua regularidade para a celebração do convênio com o Ministério da Saúde.

Após estes procedimentos, o DAF/SCTIE/MS encaminha ao Departamento de Logística $^{15}$ a documentação para a realização do Convênio, quando for com Laboratórios Oficiais Estaduais ou de Sociedade de Economista Mista; ou ao Fundo Nacional de Saúde $(\mathrm{FNS})^{16}$, para a edição da Portaria, quando as aquisições de medicamentos forem realizadas com Laboratórios Federais.

Os recursos financeiros são repassados aos LFO por meio da Conta Única do Tesouro Nacional, no caso de Portaria, ou por meio de Conta Específica, quando da Celebração de Convênio.

Foi constatado na pesquisa exploratória alguns entraves que atrapalham a tramitação desses dos convênios celebrados com os LFO como: a inadimplência dos laboratórios com a documentação exigida que demanda a reformulação do Plano de Trabalho já aprovado (alteração do cronograma de entrega do medicamento e cronograma de desembolso), o parecer da Advocacia Geral da União (AGU) que faz vários questionamentos e sem padronização pois esta avaliação depende do consultor, muitas vezes os esclarecimentos já constam do processo; problemas com dotação orçamentária pois o convênio com empenho feito em um ano mas como teve inadimplência houve necessidade de cancelamento e a busca de nova dotação orçamentária e a não votação do orçamento até o final da legislatura, não cumprimento por parte dos LFO do prazo de entrega dos medicamentos, em alguns casos o medicamento é entregue após vários dias após a necessidade do medicamento. Existe também demorada da publicação da Portaria pelo Ministério da Saúde, em alguns casos o Ministério demorou dois meses para efetivar a publicação após a data da necessidade do medicamento, com isso prejudica a entrega do medicamento.

Vale ressaltar que a minuta de Portaria é encaminhada a Advocacia Geral da União (AGU) para aprovação que elabora parecer jurídico concordando com os

\footnotetext{
${ }^{15}$ Pertence à Sub-Secretaria de Assuntos Administrativos (SAA), subordinada a Secretaria-Executiva do Ministério da Saúde.

${ }^{16}$ O FNS é o gestor financeiro dos recursos do SUS na esfera federal.
} 
termos da minuta, que em alguns casos vem com diligência, acarretando a demora na publicação.

Solucionado todos os entraves a primeira parcela do recurso financeiro do Ministério da Saúde para o LFO pode demorar até seis meses ou mais.

A demora na votação do orçamento atrasa a tramitação dos processos de aquisição de medicamentos, tanto os da inciativa privada como os dos LFO, pois todos ficam esperando a aprovação do orçamento pelo Poder Legislativo.

A pesquisa não constatou que a paralização dos processos de aquisição de medicamentos pelo Ministério da Saúde se dá pela não aprovação do orçamento e não pelos quantitativos insuficientes para atender ações demandas.

Todos os convênios celebrados pelo Ministério da Saúde com os LFO são cadastrados no Sistema Integrado de Administração Financeira do Governo Federal (SIAFI) instrumento informatizado que processa e controla a execução orçamentária, financeira, patrimonial e contábil dos órgãos da Administração Publica Direta Federal, das autarquias, fundações, das empresas públicas federais e das sociedades de economia mista.

A partir de 2014 o Ministério da Saúde não está mais celebrando convênio com os LFO e sim contratos onde são previstos cláusula com direitos, obrigações e penalidades. O resultado da eficiência deste novo instrumento contratual só será conhecido ao término do prazo contratual. O Ministério da Saúde vem substituindo os convênios com os LFO pela PDP para aquisição da produção de medicamentos dos LFO.

Para todos os procedimentos de aquisição de medicamentos para dispensação no âmbito do SUS utilizado pelo Ministério da Saúde, antes da realização do processo licitatório por determinação da Portaria MS no 2.170, de 17 de novembro de 2011 o DAF/SCTIE/MS é obrigado a elaborar um parecer de preço, com realização de ampla pesquisa de preço que são divulgados no Portal de Compras Governamentais, no Banco de Preços (BPS) do Ministério da Saúde e no Sistema Integrado de Administração de Serviços Gerais (SIASG) do Ministério do Planejamento, Orçamento e Gestão (MPOG), onde são lançadas compras efetuadas por outros entes da federação (preço de licitação).

Este parecer também aponta os preços informado no Relatório de Comercialização de 2014, nos termos da legislação vigente da Câmara de Regulação do Mercado de Medicamentos - CMED, Lei 8.159, de 08 de janeiro de 
1991 e do Decreto 4.553, de 27 de dezembro de 2002 e o seu preço divulgado na homepage da Anvisa (www.anvisa.gov.br).

Além dos preços praticados nas licitações e os autorizados pela CMED é informado os preços praticados no mercado internacional, disponíveis em Banco de Dados Internacionais relacionados no Anexo IV da Portaria no 2.170 , de 17 de novembro de 2011.

O parecer de preço tem como primeiro objetivo permitir ao ordenador de despesa do Ministério da Saúde a verificação de existência de recursos orçamentários suficientes para pagamento da despesa com a contratação e serve também de balizamento para a análise das propostas dos licitantes. Em segundo lugar é em relação aos convênios de produção e distribuição celebrados com os LFO este tem como objetivo a verificação de ser o preço pactuado pelo DAF/SCTIE/MS com os LFO mais vantajoso para o Ministério da Saúde.

O preço final para a aquisição de medicamento com os laboratórios privados nacionais e estrangeiros é definido pelo ordenador de despesa ou pelo agente encarregado da compra no âmbito do Ministério da Saúde, conforme dispõe a letra "a", do inciso III, do Art. $8^{\circ}$, do Decreto n ${ }^{\circ} 3.555 / 00$.

Em relação à distribuição dos medicamentos adquiridos pelo Ministério da Saúde para dispensação no âmbito do SUS alguns medicamentos são encaminhados ao Serviço de Almoxarifado de Medicamentos (SEAME) do Ministério da Saúde, localizado em Brasília, enquanto que outros são entregues pelos laboratórios aos Almoxarifados das Secretarias Estaduais de Saúde.

$\mathrm{Na}$ pesquisa exploratório do procedimento de compra foi realizado levantamento para identificar quais os programas que estão sob a responsabilidade do DAF/SCTIE/MS no período de 2003 a 2013. Estes programas estão identificados no Quadro 1.

\section{continua}

Quadro 1 - Relação dos programas sob a responsabilidade do DAF/SCTIE/MS no período de 2003 a 2013

\section{Programas}

Programa Nacional de Doenças Sexualmente Transmissíveis e AIDS

Programa Nacional de Alimentação e Nutrição

Programa de Calamidade Pública 


\section{Conclusão}

Quadro 1 - Relação dos programas sob a responsabilidade do DAF/SCTIE/MS no período de 2003 a 2013

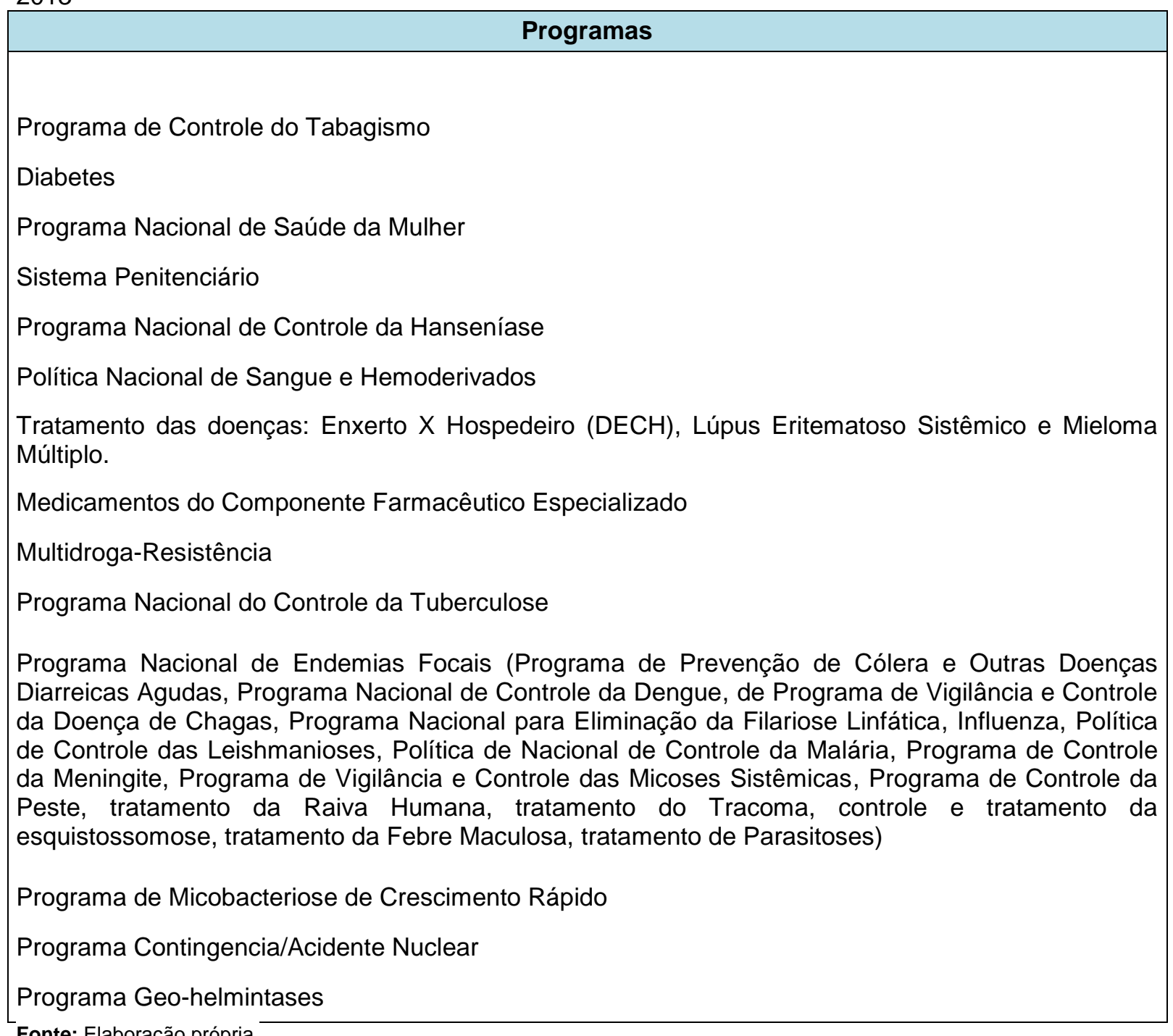

No ano de 2008, foi implementado o Programa de Micobacteriose de Crescimento Rápido, em 2011 o Programa Contingencia/Acidente Nuclear e em 2012 o Programa Geo-helmintases ${ }^{17}$.

No período de 2002 a 2013 foram extintos os seguintes Programas: Asma e Rinite, Emergencial (Raiva), Hipertensão Arterial e Diabetes Mellitus, Pneumologia Sanitária, Portadores de Hemoglobinopatias, Projeto Nascer-Maternidades, Saúde da Família e Saúde do Adolescente e do Jovem.

Os Programas Hipertensão Arterial e Diabetes Mellitus foram descontinuados tendo em vista a implementação do Programa Farmácia Popular do Brasil, um

\footnotetext{
${ }^{17}$ As Geo-helmintíases constituem um grupo de doenças parasitárias intestinais e são causadas principalmente pelos Ascaris Lumbricoides, Trichuris Trichiuria e Ancilostomídeos.
} 
sistema de copagamento, do governo federal que tem o intuito de melhorar a qualidade de vida dos brasileiros que gastam quase $20 \%$ da renda familiar com medicamentos. O governo paga uma parte do valor dos medicamentos e o cidadão paga o restante. O valor pago pelo Governo pode chegar a $90 \%$ do Valor de Referência, variando de acordo com o medicamento ou laboratório. Por esse motivo, o cidadão pode pagar menos para alguns medicamentos do que para outros. Atualmente, o Sistema de Copagamento está trabalhando com medicamentos para hipertensão, diabetes, colesterol, anticoncepcionais e fraldas geriatra.

Os medicamentos para hipertensão ${ }^{18}$ e diabetes ${ }^{19}$ com a campanha "Saúde Não Tem Preço" do Ministério da Saúde, implementada em 14 de fevereiro de 2011, a população brasileira passou a ter acesso gratuito aos medicamentos para o tratamento destas doenças, sem a necessidade de aquisição por gestor do SUS, basta apresentação de prescrição médica.

Com exceção das insulinas, os medicamentos, para abastecimento dos Programas Hipertensão Arterial e Diabetes Mellitus, eram produzidos pelos LFO, adquiridos pelo Ministério da Saúde por meio de compra centralizada para dispensação no âmbito do SUS. Atualmente os LFO não participam da produção de medicamentos para o Programa "Aqui tem Farmácia Popular", dispensados pelas farmácias e drogarias, acarretando queda na produção pública. Os medicamentos dispensados para tratamento dessas enfermidades são produzidos pelos laboratórios nacionais e internacionais privados.

Os Programas de Controle de Tabagismo, Diabetes, Saúde da Mulher, Sistema Penitenciário e Hemoderivados não foram objeto de análise desta pesquisa tendo em vista que não há produção pública.

Em relação à aquisição dos medicamentos do elenco do Sistema Penitenciário é celebrado convênio com a FIOCRUZ apenas para montagem e distribuição de um Kit de medicamentos para atender ao Sistema Prisional. Os medicamentos que constam do elenco não são todos produzidos pela FIOCRUZ. Por esta razão não foi objeto de análise desta pesquisa, pois não há como separar a produção pública. No DAF encontramos apenas o valor total do kit não

\footnotetext{
${ }^{18}$ Captopril $25 \mathrm{mg}$, Maleato de enalapril $10 \mathrm{mg}$, Cloridrato de propranolol $40 \mathrm{mg}$, Atenolol $25 \mathrm{mg}$, Hidroclorotiazida $25 \mathrm{mg}$ e Losartana potássica $50 \mathrm{mg}$.

${ }^{19}$ Glibenclamida $5 \mathrm{mg}$, Cloridrato de metformina $500 \mathrm{mg}$, Cloridrato de metformina $500 \mathrm{mg}$, ação prolongada, Cloridrato de metformina $850 \mathrm{mg}$, Insulina humana NPH $100 \mathrm{UI} / \mathrm{ml}$ e Insulina humana Regular $100 \mathrm{UI} / \mathrm{ml}$.
} 
disponibilizado o volume da produção para cada medicamento. Para colher estes dados havia necessidade de consultar os processos de compras que já se encontravam no arquivo central do Ministério da Saúde. Também no DAF não havia informações de quais laboratórios a FIOCRUZ adquire os medicamentos do elenco para a montagem dos kits.

Foi realizado pesquisa no site da FIOCRUZ para identificar quais os medicamentos constantes do seu portifólio. Foi verificado que dos 45 medicamentos que compõe o kit a FIOCRUZ produz apenas 9 medicamentos, ou seja, produz apenas $20 \%$ dos medicamentos do elenco: ácido fólico $5 \mathrm{mg}$, amoxicilina $500 \mathrm{mg}$, captopril $25 \mathrm{mg}$, cloridrato de propranolol $40 \mathrm{mg}$, dexametasona $0,1 \% \mathrm{creme}$, glibenclamida $5 \mathrm{mg}$, hidroclorotiazida $25 \mathrm{mg}$, metildopa $250 \mathrm{mg}$ e sulfato ferroso $40 \mathrm{mg}$. No apêncie 23 consta o elenco do elenco do Sistema Penitenciário

Igualmente não foi objeto de análise a produção de medicamentos e correlatos adquiridos pelo DAF para o Programa de Calamidade Pública, pois, à aquisição do elenco é celebrado convênio com a FIOCRUZ para montagem e distribuição de um Kit. Os medicamentos que constam do elenco não são todos produzidos pela FIOCRUZ. Por esta razão não foi objeto de análise desta pesquisa, pois não há como separar a produção pública. No DAF encontramos apenas o valor total do kit não disponibilizado o volume da produção para cada medicamento. Para colher estes dados havia necessidade de consultar os processos de compras que já se encontravam no arquivo central do Ministério da Saúde. Também no DAF não havia informações de quais laboratórios a FIOCRUZ adquire os medicamentos do elenco para a montagem dos kits.

Do elenco de 31 medicamentos do Programa de Calamidade Pública a FIOCRUZ produz apenas 6 medicamentos, ou seja, apenas $19,35 \%$ dos medicamentos: Amoxicilina cápsula $500 \mathrm{mg}$, Captopril comprimido $25 \mathrm{mg}$, Cloridrato de propranolol comprimido $40 \mathrm{mg}$, Dexametasona creme $0,1 \%$ bisnaga $\mathrm{c} / 10 \mathrm{~g}$, Glibenclamida comprimido $5 \mathrm{mg}$ e Hidroclorotiazida comprimido $25 \mathrm{mg}$.

Também não foi realizada análise dos correlatos (testes, seringas, preservativos, DIU) produzidos para o Ministério da Saúde para atender alguns programas, pois não há produção pública.

As vacinas adquiridas pelo Ministério da Saúde para distribuição no âmbito do SUS não estão incluídas em nenhum Componente da Assistência Farmacêutica e 
também não são de responsabilidade do Departamento de Assistência Farmacêutica e Insumos Estratégicos.

A pesquisa exploratória identificou produção pública nos Programas: Programa Nacional de Doenças Sexualmente Transmissíveis e AIDS, Alimentação e Nutrição, Hanseníase, Lupus (Enxerto Versus Hospedeiro e Mieloma Múltiplo) Multidroga-Resistência, Tuberculose, Endemias Focais20 e medicamentos do Componente Especializado. A apresentação dos resultados será apresentada por programa.

\subsection{PROGRAMA NACIONAL DE DOENÇAS SEXUALMENTE TRANSMISSÍVEIS E AIDS.}

Este Programa disponibiliza medicamentos estratégicos para populações infectadas com o vírus HIV, bem como profilaxia de indivíduos expostos ao vírus, de forma a controlar a transmissão.

$\mathrm{Na}$ pesquisa exploratória foi feito o levantamento de todos os medicamentos que compõe o elenco do Programa Nacional de Doenças Sexualmente Transmissíveis e AIDS. Atualmente, compõe o elenco 59 medicamentos. Identificou quais os medicamentos foram produzidos por cada um dos segmentos do setor farmacêuticos: público, nacional e internacional. O resultado está representado no Quadro 2.

Conforme observado no Quadro 2, do elenco de medicamentos do Programa Nacional de Doenças Sexualmente Transmissíveis e AIDS, no período de 2003 a 2013, os LFO produziram 18 tipos de medicamentos, os laboratórios nacionais produziram 22 medicamentos e os laboratórios internacionais produziram 31 medicamentos. Foi observado que 30 medicamentos são produzidos apenas pelos laboratórios nacionais e internacionais, não havendo qualquer participação dos LFO.

\footnotetext{
${ }^{20}$ Cólera, Dengue, Doença de Chagas, Esquistossomose, Febre Maculosa, Filariose, Influenza, Leishmaniose, Malária, Meningite, Micoses, Parasitoses, Peste, Raiva Humana, Tracoma
} 
continua

Quadro 2 - Elenco de medicamentos produzidos pelos laboratórios para o Programa Nacional de Doenças Sexualmente Transmissíveis e AIDS, no período de 2003 a 2013

\begin{tabular}{|c|c|c|c|}
\hline \multirow{2}{*}{ Medicamentos } & \multicolumn{3}{|c|}{ Laboratório } \\
\hline & Oficial & Nacional & Internacional \\
\hline Abacavi $20 \mathrm{mg} / \mathrm{ml}$ solução oral & & $x$ & $x$ \\
\hline Abacavir 300 mg comprimido & & $\mathrm{x}$ & $\mathrm{x}$ \\
\hline Amprenavir 150mg cápsula & & $x$ & $x$ \\
\hline Amprenavir $15 \mathrm{mg} / \mathrm{ml}$ solução oral & & $x$ & \\
\hline Atazanavir $150 \mathrm{mg}$ cápsula gelatinosa dura & & & $x$ \\
\hline Atazanavir 200 mg cápsula gelatinosa dura & & & $x$ \\
\hline Atazanavir 300 mg cápsula gelatinosa dura & & & $x$ \\
\hline Darunavir 150 mg comprimido & & $x$ & \\
\hline Darunavir 300 mg comprimido & & $x$ & \\
\hline Darunavir 75 mg comprimido & & $x$ & \\
\hline Didanosina $25 \mathrm{mg}$ comprimido & $x$ & & \\
\hline $\begin{array}{l}\text { Didanosina (4g) Pó Tamponado + } 200 \text { ml de antiácido } \\
\text { solução oral }\end{array}$ & $\mathrm{x}$ & & \\
\hline Didanosina 100 mg comprimido & $x$ & & \\
\hline Didanosina $25 \mathrm{mg}$ comprimido & $x$ & & \\
\hline Didanosina EC 250 mg cápsula & & & $x$ \\
\hline Didanosina EC 400 mg cápsula & & $x$ & $x$ \\
\hline Efavirenz 200 mg cápsula & & & $x$ \\
\hline Efavirenz 600 mg comprimido & $x$ & & $x$ \\
\hline Enfuvirtida $90 \mathrm{mg} / \mathrm{ml}$ & & & $x$ \\
\hline Estavudina 20 mg pó para solução oral & & $x$ & \\
\hline Estavudina 30 mg cápsula & $x$ & & $x$ \\
\hline Estavudina $40 \mathrm{mg}$ cápsula & $x$ & & \\
\hline Etravirina 100 mg comprimido & & $x$ & \\
\hline Fosamprenavir $50 \mathrm{mg} / \mathrm{ml}$ solução oral sseringa & & & $x$ \\
\hline Fosamprenavir 700 mg comprimido & & & $x$ \\
\hline Indinavir 400 mg cápsula & $\mathrm{x}$ & $\mathrm{x}$ & $\mathrm{x}$ \\
\hline
\end{tabular}




\section{Conclusão}

Quadro 2 - Elenco de medicamentos produzidos pelos laboratórios para o Programa Nacional de Doenças Sexualmente Transmissíveis e AIDS, no período de 2003 a 2013

\begin{tabular}{|c|c|c|c|}
\hline \multirow{2}{*}{ Medicamentos } & \multicolumn{3}{|c|}{ Laboratório } \\
\hline & Oficial & Nacional & Internacional \\
\hline Lamivudina $150 \mathrm{mg}$ comprimido & $x$ & & \\
\hline Lamivudina10 mg/ml solução oral & $\mathrm{x}$ & & $\mathrm{x}$ \\
\hline Lopinavir 100 mg + Ritonavir 25 mg comprimido & & & $x$ \\
\hline Lopinavir 133,3 + Ritonavir 33,3 mg cápsula & & & $x$ \\
\hline Lopinavir 200 mg + Ritonavi 50 mg comprimido & & & $x$ \\
\hline Lopinavir 80 mg + Ritonavir 20 mg solução oral & & & $x$ \\
\hline Maraviroque $150 \mathrm{mg}$ comprimido & & $x$ & \\
\hline Nelfinavir 250 mg cápsula & & $\mathrm{x}$ & \\
\hline Nelfinavir 50 mg pó para suspensão oral & & & $x$ \\
\hline Nevirapina $10 \mathrm{mg}$ suspensão oral & & $x$ & $x$ \\
\hline Nevirapina 200 mg comprimido & $x$ & $x$ & $x$ \\
\hline Raltegravir $400 \mathrm{mg}$ comprimido & & & $x$ \\
\hline Ritonavir 100 mg cápsula & $x$ & $\mathrm{x}$ & $x$ \\
\hline Ritonavir 80 mg solução oral & & $x$ & $x$ \\
\hline Saquinavir 200 mg cápsula & & $x$ & $x$ \\
\hline Talidomida $100 \mathrm{mg}$ comprimido & $x$ & & \\
\hline Tenofovir 300 mg comprimido & $\mathrm{x}$ & & $\mathrm{x}$ \\
\hline Tipranavir 100mg solução oral & & & $x$ \\
\hline Tipranavir 250 mg cápsula & & $x$ & \\
\hline Zidovudina $10 \mathrm{mg}$ xarope & $\mathrm{x}$ & $x$ & \\
\hline Zidovudina 100 mg cápsula & $x$ & $x$ & $x$ \\
\hline Zidovudina $300 \mathrm{mg}$ + Lamivudina $150 \mathrm{mg}$ comprimido & $x$ & $\mathrm{x}$ & \\
\hline Zidovudina 50 mg solução oral & $\mathrm{x}$ & & $x$ \\
\hline Total & 18 & 22 & 31 \\
\hline
\end{tabular}

Fonte: Elaboração própria.

A participação percentual dos LO, na produção dos medicamentos do elenco do Programa Nacional de Doenças Sexualmente Transmissíveis e AIDS no período 
de 2003 a 2013 foi de 25\%, enquanto os laboratórios internacionais produziram 44\% dos medicamentos e os laboratórios nacionais produziram $31 \%$ dos medicamentos do elenco.

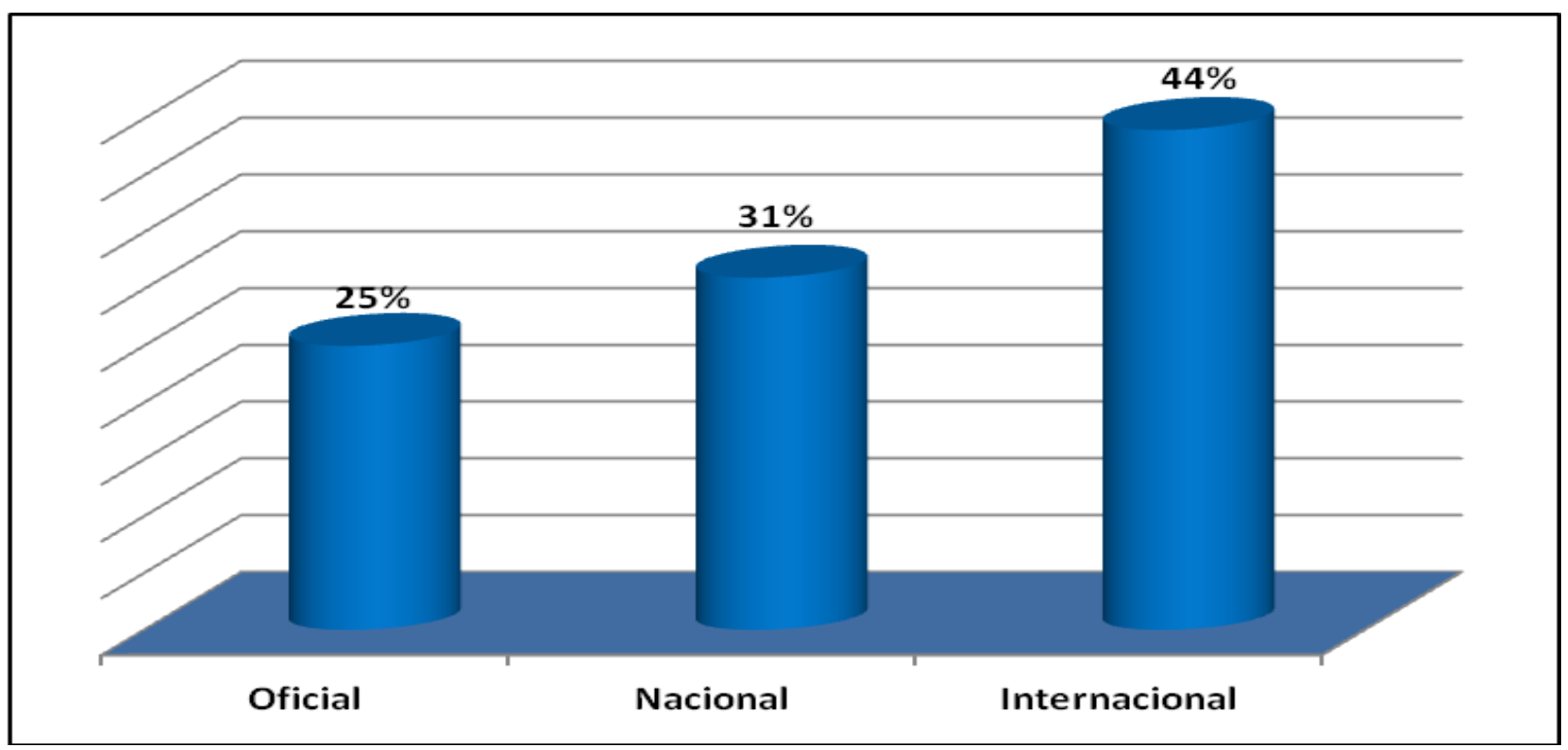

Figura 3 Representação gráfica da participação percentual pelos laboratórios na produção do Elenco de medicamentos produzidos para o Programa Nacional de Doenças Sexualmente Transmissíveis e AIDS, no período de 2003 a 2013.

Fonte: Elaboração própria.

Nos Quadros 3, 4 e 5 está consolidada toda a produção dos laboratórios oficiais, nacionais e internacionais discriminada anualmente no Apêndice 1, com o respectivo gasto do Ministério da Saúde, no período de 2003 a 2013, por medicamentos.

\section{continua}

Quadro 3 - Consolidação da produção dos laboratórios oficiais em número de Unidades Farmacêuticas (UF) e valor pago pelo Ministério da Saúde para o Programa Nacional de Doenças Sexualmente Transmissíveis e AIDS, no período de 2003 a 2013

\begin{tabular}{|l|c|c|}
\hline Medicamentos & $\begin{array}{c}\text { Quantidade de Unidades } \\
\text { Farmacêuticas } \\
\text { (comprimidos, cápsulas, } \\
\text { seringas e frascos) } \\
\text { produzidas }\end{array}$ & $\begin{array}{c}\text { Valor pago pelo Ministério da Saúde } \\
\text { (R\$) }\end{array}$ \\
\hline Didanosina $100 \mathrm{mg}$ & FIOCRUZ & $13.102 .857,37$ \\
Didanosina $25 \mathrm{mg}$ & 14.208 .260 & $821.340,00$ \\
Efavirenz $600 \mathrm{mg}$ & 3.802 .500 & $251.160 .750,00$ \\
Estavudina $40 \mathrm{mg}$ & 186.045 .000 & $10.355 .817,60$ \\
Estavudina, Cáps. $30 \mathrm{mg}$ & 19.635 .120 & $11.672 .485,86$ \\
Indinavir $400 \mathrm{mg}$ & 33.800 .740 & $9.417 .353,40$
\end{tabular}


continuação

Quadro 3 - Consolidação da produção dos laboratórios oficiais em número de Unidades Farmacêuticas (UF) e valor pago pelo Ministério da Saúde para o Programa Nacional de Doenças Sexualmente Transmissíveis e AIDS, no período de 2003 a 2013

\begin{tabular}{|c|c|c|}
\hline Medicamentos & $\begin{array}{l}\text { Quantidade de Unidades } \\
\text { Farmacêuticas } \\
\text { (comprimidos, cápsulas, } \\
\text { seringas e frascos) } \\
\text { produzidas }\end{array}$ & $\begin{array}{l}\text { Valor pago pelo Ministério da Saúde } \\
\qquad(\mathbf{R} \$)\end{array}$ \\
\hline \multicolumn{3}{|c|}{ FIOCRUZ } \\
\hline Lamivudina $150 \mathrm{mg}$ & 259.034 .580 & $148.745 .227,62$ \\
\hline Nevirapina 200mg & 79.321 .620 & $58.091 .064,60$ \\
\hline Zidovudina $100 \mathrm{mg}$ & 45.841 .400 & $13.340 .993,48$ \\
\hline Zidovudina 300 mg +Lamivudina 150 mg & 459.287 .220 & $538.533 .376,80$ \\
\hline Subtotal & 1.108.998.590 & $1.055 .241 .266,73$ \\
\hline \multicolumn{3}{|c|}{ FUNED } \\
\hline Didanosina $100 \mathrm{mg}$ & 2.082 .240 & $1.920 .241,73$ \\
\hline Nevirapina $200 \mathrm{mg}$ & 47.194 .920 & $34.163 .838,60$ \\
\hline Talidomida $100 \mathrm{mg}$ & 640.800 & $152.315,28$ \\
\hline Tenofovir $300 \mathrm{mg}$ & 65.100 .000 & $258.385 .500,00$ \\
\hline Zidovudina 300 mg +Lamivudina 150 mg & 68.383 .140 & $79.271 .454,00$ \\
\hline Subtotal & 183.401 .100 & 373.893.349,61 \\
\hline \multicolumn{3}{|c|}{ FURP } \\
\hline Didanosina $100 \mathrm{mg}$ & 4.969 .500 & $4.582 .872,90$ \\
\hline Estavudina $40 \mathrm{mg}$ & 15.390 .960 & $8.157 .208,80$ \\
\hline Estavudina, Cáps. 30 mg & 6.712 .140 & $2.717 .913,81$ \\
\hline Lamivudina $150 \mathrm{mg}$ & 115.155 .480 & $67.881 .506,22$ \\
\hline Zidovudina $100 \mathrm{mg}$ & 11.677 .230 & $3.861 .659,96$ \\
\hline Zidovudina 300 mg +Lamivudina 150 mg & 151.244 .940 & $182.763 .249,00$ \\
\hline Zidovudina 50 mg solução oral & 138.056 & $1.226 .158,17$ \\
\hline Subtotal & 305.288 .306 & $271.190 .568,86$ \\
\hline \multicolumn{3}{|c|}{ IQUEGO } \\
\hline Didanosina $25 \mathrm{mg}$ & 360.000 & $77.760,00$ \\
\hline Didanosina $100 \mathrm{mg}$ & 5.966 .120 & $5.501 .955,86$ \\
\hline Estavudina $40 \mathrm{mg}$ & 17.342 .940 & $9.191 .758,20$ \\
\hline Lamivudina $150 \mathrm{mg}$ & 83.063 .980 & $52.006 .141,22$ \\
\hline Lamivudina10 mg/ml solução oral & 650.087 & $14.677 .921,06$ \\
\hline Zidovudina $100 \mathrm{mg}$ & 42.382 .020 & $35.902 .472,87$ \\
\hline Zidovudina 300 mg +Lamivudina 150 mg & 118.943 .040 & $147.351 .202,80$ \\
\hline Didanosina 100 mg (doação) & 101.400 & 0,00 \\
\hline Subtotal & 268.809 .587 & 264.709.212,02 \\
\hline
\end{tabular}




\section{conclusão}

Quadro 3 - Consolidação da produção dos laboratórios oficiais em número de Unidades Farmacêuticas (UF) e valor pago pelo Ministério da Saúde para o Programa Nacional de Doenças Sexualmente Transmissíveis e AIDS, no período de 2003 a 2013

\begin{tabular}{|c|c|c|}
\hline Medicamentos & $\begin{array}{c}\text { Quantidade de Unidades } \\
\text { Farmacêuticas } \\
\text { (comprimidos, cápsulas, } \\
\text { seringas e frascos) } \\
\text { produzidas } \\
\end{array}$ & $\begin{array}{l}\text { Valor pago pelo Ministério da Saúde } \\
\qquad(\mathbf{R} \$)\end{array}$ \\
\hline \multicolumn{3}{|c|}{ IVB } \\
\hline Lamivudina $150 \mathrm{mg}$ & 110.974 .160 & 141.537.367,99 \\
\hline Subtotal & 110.974 .160 & 141.537.367,99 \\
\hline \multicolumn{3}{|c|}{ LAFEPE } \\
\hline $\begin{array}{l}\text { Didanosina (4g) Pó Tamp. Sol. Oral + } 200 \mathrm{ml} \mathrm{de} \\
\text { antiácido }\end{array}$ & 218.901 & $16.205 .161,37$ \\
\hline Didanosina $100 \mathrm{mg}$ & 7.902 .480 & $7.287 .667,06$ \\
\hline Efavirenz $600 \mathrm{mg}$ & 24.000 .000 & $32.400 .000,00$ \\
\hline Estavudina $40 \mathrm{mg}$ & 13.927 .020 & $7.381 .320,60$ \\
\hline Estavudina, Cáps. 30 mg & 26.330 .120 & $7.567 .529,61$ \\
\hline Indinavir $400 \mathrm{mg}$ & 20.261 .610 & $22.246 .520,40$ \\
\hline Lamivudina $150 \mathrm{mg}$ & 45.592 .480 & $31.874 .326,22$ \\
\hline Ritonavir $100 \mathrm{mg}$ & 6.663 .938 & $10.438 .392,48$ \\
\hline Tenofovir $300 \mathrm{mg}$ & 43.500 .000 & $171.553 .500,00$ \\
\hline Zidovudina $10 \mathrm{mg}$ xarope & 150.000 & $1.066 .500,00$ \\
\hline Zidovudina $100 \mathrm{mg}$ & 17.207 .500 & $5.797 .589,25$ \\
\hline Zidovudina 300 mg +Lamivudina 150 mg & 133.115 .640 & $162.941 .062,80$ \\
\hline Zidovudina 50 mg solução oral & 1.031 .056 & $8.335 .404,57$ \\
\hline Subtotal & 339.900 .745 & $485.094 .974,36$ \\
\hline \multicolumn{3}{|c|}{ LIFAL } \\
\hline Didanosina $100 \mathrm{mg}$ & 7.639 .040 & $7.044 .722,69$ \\
\hline Indinavir $400 \mathrm{mg}$ & 27.344 .610 & $30.022 .112,70$ \\
\hline Nevirapina 200mg & 9.744 .000 & $8.087 .520,00$ \\
\hline Nevirapina 200 mg (doação) & 48.660 & 0,00 \\
\hline Subtotal & 44.776.310 & 45.154.355 \\
\hline Total & 2.362.148.798 & 2.636.821.094,95 \\
\hline
\end{tabular}

Fonte: Produção Própria 
Quadro 4 - Consolidação da produção dos laboratórios nacionais em número de Unidades Farmacêuticas (UF) e valor pago pelo Ministério da Saúde para o Programa Nacional de Doenças Sexualmente Transmissíveis e AIDS, no período de 2003 a 2013

\begin{tabular}{|c|c|c|c|}
\hline \multirow[b]{2}{*}{ Medicamentos } & \multirow[b]{2}{*}{ Fornecedor } & \multicolumn{2}{|c|}{ Total } \\
\hline & & $\begin{array}{c}\text { Quantidade de Unidades } \\
\text { Farmacêuticas } \\
\text { (comprimidos, cápsulas e } \\
\text { frascos) produzidas }\end{array}$ & $\begin{array}{c}\text { Valor pago pelo Ministério } \\
\text { da Saúde (R\$) }\end{array}$ \\
\hline Nevirapina 10 mg suspensão oral & BOEHRINGER & 81.321 & $5.683 .093,58$ \\
\hline Tipranavir 250 mg & BOEHRINGER & 319.080 & $2.734 .515,60$ \\
\hline Didanosina EC $400 \mathrm{mg}$ & BRISTOL & 8.349 .000 & $33.358 .641,00$ \\
\hline Estavudina 20 mg pó para solução oral & CRISTÁLIA & 464.973 & $25.352 .678,00$ \\
\hline Ritonavir $100 \mathrm{mg}$ & CRISTÁLIA & 62.007 .736 & $59.390 .400,68$ \\
\hline Ritonavir 80 mg solução oral & CRISTÁLIA & 14.818 .500 & $19.137 .528,00$ \\
\hline Saquinavir $200 \mathrm{mg}$ & Cristália & 22.744 .200 & $36.353 .553,00$ \\
\hline Nevirapina 200 mg & $\begin{array}{l}\text { Eurofarma - } \\
\text { Doação }\end{array}$ & 66.840 & 0,00 \\
\hline Zidovudina 10 mg solução injetável & Cristália & 220.016 & $1.030 .062,60$ \\
\hline Ritonavir 80 mg solução oral & Cristália - Doação & 900 & 0,00 \\
\hline Maraviroque $150 \mathrm{mg}$ & GLAXO & 276.000 & $4.876 .920,00$ \\
\hline Abacavir, Comp. $300 \mathrm{mg}$ - Fr. c/ 60 & Glaxo Wellcome & 4.803 .660 & $26.756 .386,20$ \\
\hline $\begin{array}{l}\text { Abacavir, Sol. Oral } 20 \mathrm{mg} / \mathrm{ml} \text { Frasco de } \\
240 \mathrm{ml}\end{array}$ & Glaxo Wellcome & 11.028 & $1.125 .738,24$ \\
\hline Amprenavir, Cáps. 150mg - Fr. 240 & Glaxo Wellcome & 4.746 .960 & $9.731 .268,00$ \\
\hline Abacavir, Comp. $300 \mathrm{mg}$ - Fr. c/ 60 & GlaxoSmithKline & 5.476 .500 & $12.242 .089,00$ \\
\hline Abacavir, Sol. Oral $20 \mathrm{mg} / \mathrm{ml}$ & GlaxoSmithKline & 9.625 & $702.611,25$ \\
\hline Amprenavir, Cáps. 150mg - Fr. 240 & GlaxoSmithKline & 2.136 .000 & $4.378 .800,00$ \\
\hline Amprenavir, Sol. Oral $15 \mathrm{mg} / \mathrm{ml}$ & GlaxoSmithKline & 5.026 & $1.242 .563,15$ \\
\hline Darunavir, Comp. 150mg & JANSSEN & 240.000 & $816.365,23$ \\
\hline Darunavir, Comp. $75 \mathrm{mg}$ & JANSSEN & 123.840 & $190.005,12$ \\
\hline Etravirina100mg & JANSSEN & 4.151 .280 & $33.074 .214,00$ \\
\hline Darunavir, Comp. 300mg & Janssen-Cilag & 54.551 .520 & $382.791 .510,70$ \\
\hline Indinavir $400 \mathrm{mg}$ & LAOB & 23.889 .420 & $29.193 .000,00$ \\
\hline Zidovudina $100 \mathrm{mg}$ & MEDAPI & 5.000 .000 & $1.653 .500,00$ \\
\hline Zidovudina 300 mg +Lamivudina 150 mg & MEDAPI & 10.500 .000 & $14.280 .000,00$ \\
\hline Nelfinavir $250 \mathrm{mg}$ & ROCHE & 237.786 .300 & $312.359 .990,26$ \\
\hline Total & & 462.779 .725 & $1.018 .455 .433,61$ \\
\hline
\end{tabular}




\section{continua}

Quadro 5 - Consolidação da produção dos laboratórios oficiais em número de Unidades Farmacêuticas (UF) e valor pago pelo Ministério da Saúde para o Programa Nacional de Doenças Sexualmente Transmissíveis e AIDS, no período de 2003 a 2013

\begin{tabular}{|c|c|c|c|}
\hline \multirow[b]{2}{*}{ Medicamentos } & \multirow[b]{2}{*}{ Fornecedor } & \multicolumn{2}{|c|}{ Total } \\
\hline & & $\begin{array}{l}\text { Quantidade de Unidades } \\
\text { Farmacêuticas } \\
\text { (comprimidos, cápsulas } \\
\text { e frascos) produzidas }\end{array}$ & $\begin{array}{l}\text { Valor pago pelo Ministério } \\
\text { da Saúde }(\mathbf{R} \$)\end{array}$ \\
\hline Lopinavir $100 \mathrm{mg}+$ Ritonavir $25 \mathrm{mg}$ & АВBOTT & 2.634 .000 & $1.705 .065,57$ \\
\hline Lopinavir 133,3 + Ritonavir 33,3 mg & ABBOTT & 206.872 .807 & $538.517 .447,42$ \\
\hline Lopinavir 200 mg + Ritonavi 50 mg & ABBOTT & 375.970 .320 & $485.653 .623,47$ \\
\hline $\begin{array}{l}\text { Lopinavir } 80 \text { mg + Ritonavir } 20 \text { mg solução } \\
\text { oral }\end{array}$ & ABBOTT & 53.000 & $3.720 .145,00$ \\
\hline Ritonavir $100 \mathrm{mg}$ & ABBOTT & 80.077 .008 & $43.991 .279,13$ \\
\hline Ritonavir 80 mg solução oral & ABBOTT & 14.157 & $2.374 .052,01$ \\
\hline Lopinavir $100 \mathrm{mg}+$ Ritonavir $25 \mathrm{mg}$ & ABBVIE & 2.040 .000 & $1.257 .945,60$ \\
\hline Lopinavir $200 \mathrm{mg}+$ Ritonavir $50 \mathrm{mg}$ & ABBVIE & 97.200 .000 & $89.806 .482,00$ \\
\hline $\begin{array}{l}\text { Lopinavir } 80 \text { mg + Ritonavir } 20 \text { mg solução } \\
\text { oral }\end{array}$ & ABBVIE & 28.000 & $1.552 .853,68$ \\
\hline Ritonavir 80 mg solução oral & ABBVIE & 300 & $31.552,70$ \\
\hline Tipranavir 100mg solução oral & BOEHRINGER & 2.856 & $1.062 .432,00$ \\
\hline Atazanavir 150 mg Cáps. & BRISTOL & 39.762 .780 & $288.348 .300,00$ \\
\hline Atazanavir 200 mg Cáps & BRISTOL & 33.735 .120 & $249.690 .781,50$ \\
\hline Didanosina EC $250 \mathrm{mg}$ & BRISTOL & 5.475 .030 & $15.867 .736,88$ \\
\hline Tenofovir $300 \mathrm{mg}$ & GILEAD & 80.262 .000 & $523.669 .320,00$ \\
\hline $\begin{array}{l}\text { Fosamprenavir, Suspensão Oral } 50 \mathrm{mg} / \mathrm{mL} \\
\text { Ser. } 95 \mathrm{ml}\end{array}$ & GLAXO & 2.030 & $383.199,38$ \\
\hline Abacavir, Comp. Revest. 300 mg & Glaxo Group & 5.135 .000 & $20.682 .000,00$ \\
\hline Amprenavir, Sol. Oral $15 \mathrm{mg} / \mathrm{ml}$ & Glaxo Group & 3.849 & $658.179,00$ \\
\hline Fosamprenavir Comp. 700mg & Glaxo Group & 16.614 .000 & $65.854 .761,75$ \\
\hline Atazanavir $150 \mathrm{mg}$, Cáps.Gelatinosa Dura & Lawrence & 8.250 .000 & $35.970 .000,00$ \\
\hline Atazanavir 200 mg, Cáps. Gelatinosa Dura & Lawrence & 26.765 .100 & $102.792 .505,95$ \\
\hline Atazanavir 200mg Cáps.Gelatinosa Dura & LAWRENCE & 2.004 .000 & $10.470 .900,00$ \\
\hline Atazanavir 300mg, Cáps.Gelatinosa Dura & Lawrence & 55.594 .920 & $379.159 .663,20$ \\
\hline Didanosina EC $250 \mathrm{mg}$ & LAWRENCE & 4.311 .000 & $7.563 .042,00$ \\
\hline
\end{tabular}




\section{continuação}

Quadro 5 - Consolidação da produção dos laboratórios oficiais em número de Unidades Farmacêuticas (UF) e valor pago pelo Ministério da Saúde para o Programa Nacional de Doenças Sexualmente Transmissíveis e AIDS, no período de 2003 a 2013

\begin{tabular}{|c|c|c|c|}
\hline \multirow[b]{2}{*}{ Medicamentos } & \multirow[b]{2}{*}{ Fornecedor } & \multicolumn{2}{|c|}{ Total } \\
\hline & & $\begin{array}{l}\text { Quantidade de Unidades } \\
\text { Farmacêuticas } \\
\text { (comprimidos, cápsulas } \\
\text { e frascos) produzidas }\end{array}$ & $\begin{array}{c}\text { Valor pago pelo Ministério } \\
\text { da Saúde }(R \$)\end{array}$ \\
\hline Didanosina EC $400 \mathrm{mg}$ & LAWRENCE & 6.197 .250 & $15.635 .335,50$ \\
\hline Indinavir $400 \mathrm{mg}$ & LKM & 800.100 & $920.115,00$ \\
\hline Lamivudina $150 \mathrm{mg}$ & LKM & 107.080 .020 & $138.030 .780,30$ \\
\hline Zidovudina $100 \mathrm{mg}$ & LKM & 2.800 .000 & $630.000,00$ \\
\hline Raltegravir $400 \mathrm{mg}$ & MERCK SHARP & 22.840 .000 & $356.880 .342,00$ \\
\hline Efavirenz $200 \mathrm{mg}$ & MERCK SHARP & 382.680 & $576.450,02$ \\
\hline Efavirenz $600 \mathrm{mg}$ & MERCK SHARP & 89.519 .070 & $400.077 .073,89$ \\
\hline Efavirenz $30 \mathrm{mg}$ solução oral & MERCK SHARP & 183.419 & $8.367 .599,73$ \\
\hline Indinavir $400 \mathrm{mg}$ & Merck Sharp & 2.200 .320 & 2.548.306,80 \\
\hline Efavirenz 200mg & OPAS & 203.040 & $40.021,21$ \\
\hline Nevirapina $10 \mathrm{mg}$ suspensão oral & OPAS & 5.774 & $52.358,52$ \\
\hline Efavirenz $600 \mathrm{mg}$ & OPAS (Ranbaxy) & 13.515 .000 & $12.019 .456,00$ \\
\hline Enfuvirtida $90 \mathrm{mg} / \mathrm{ml}$ & ROCHE & 108.918 & $310.166 .331,61$ \\
\hline Nelfinavir 50 mg pó para suspensão & ROCHE & 10.540 & $1.331 .202,00$ \\
\hline Saquinavir $200 \mathrm{mg}$ & Roche & 18.360 .000 & $28.978 .560,00$ \\
\hline Atazanavir $200 \mathrm{mg}$, Cáps.Gelatinosa Dura & SWORDS LA LAB & 27.630 .000 & $141.237 .180,00$ \\
\hline Abacavir Comprimido $300 \mathrm{mg}$ & UNICEF & 7.620 .000 & $6.726 .769,00$ \\
\hline Abacavir Solução Oral $20 \mathrm{mg} / \mathrm{ml}$ & UNICEF & 11.700 & $522.811,87$ \\
\hline Efavirenz $200 \mathrm{mg}$ & UNICEF & 1.809 .030 & $636.247,50$ \\
\hline Efavirenz $600 \mathrm{mg}$ & UNICEF & 18.000 .000 & 7.386.981,00 \\
\hline Lamivudina $150 \mathrm{mg}$ & UNICEF & 11.445 .000 & $3.081 .613,95$ \\
\hline Nevirapina $10 \mathrm{mg}$ suspensão oral & UNICEF & 71.000 & $507.862,50$ \\
\hline Nevirapina 200mg & UNICEF & 4.530 .000 & $1.226 .497,50$ \\
\hline Zidovudina $100 \mathrm{mg}$ & UNICEF & 8.000 .000 & $1.400 .000,00$ \\
\hline
\end{tabular}




\section{conclusão}

Quadro 5 - Consolidação da produção dos laboratórios oficiais em número de Unidades Farmacêuticas (UF) e valor pago pelo Ministério da Saúde para o Programa Nacional de Doenças Sexualmente Transmissíveis e AIDS, no período de 2003 a 2013

\begin{tabular}{|c|c|c|c|}
\hline \multirow[b]{2}{*}{ Medicamentos } & \multirow[b]{2}{*}{ Fornecedor } & \multicolumn{2}{|c|}{ Total } \\
\hline & & $\begin{array}{l}\text { Quantidade de Unidades } \\
\text { Farmacêuticas } \\
\text { (comprimidos, cápsulas } \\
\text { e frascos) produzidas }\end{array}$ & $\begin{array}{c}\text { Valor pago pelo Ministério } \\
\text { da Saúde (R\$) }\end{array}$ \\
\hline Zidovudina 300 mg +Lamivudina 150 mg & UNICEF & 21.840 .000 & $11.848 .200,00$ \\
\hline Efavirenz $200 \mathrm{mg}$ & $\begin{array}{l}\text { UNICEF } \\
\text { (Aurobindo) }\end{array}$ & 1.386 .000 & $549.509,72$ \\
\hline Efavirenz $600 \mathrm{mg}$ & $\begin{array}{l}\text { UNICEF } \\
\text { (Aurobindo) }\end{array}$ & 45.474 .900 & $35.661 .278,47$ \\
\hline Abacavir, Comp. Revest. 300 mg & $\begin{array}{l}\text { UNICEF } \\
\text { (Aurobindo) }\end{array}$ & 1.680 .000 & $1.275 .324,96$ \\
\hline Abacavir, Sol. Oral 20 mg/ml & $\begin{array}{l}\text { UNICEF } \\
\text { (Aurobindo) }\end{array}$ & 6.500 & $210.059,40$ \\
\hline Nevirapina 10 mg suspensão oral & $\begin{array}{l}\text { Boerhinger - } \\
\text { Doação }\end{array}$ & 829 & 0,00 \\
\hline Tenofovir $300 \mathrm{mg}$ & GILEAD - Doação & 5.778 .000 & $106.959 .600,00$ \\
\hline Efavirenz $600 \mathrm{mg}$ & MERCK - Doação & 525.000 & 0,00 \\
\hline Nelfinavir 50 mg pó para suspensão oral & ROCHE - Doação & 50.820 & 0,00 \\
\hline Nelfinavir 50 mg pó para suspensão oral & ROCHE - Doação & 9.081 & 0,00 \\
\hline Nevirapina $10 \mathrm{mg}$ suspensão oral & UNICEF-Doação & 3.500 & 0,00 \\
\hline Tenofovir $300 \mathrm{mg}$ & $\begin{array}{l}\text { United Medical - } \\
\text { Doação }\end{array}$ & 3.510 & 0,00 \\
\hline Lopinavir 133,3 + Ritonavir 33,3 mg & ABBOTT - Doação & 1.251 .678 & 0,00 \\
\hline Lopinavir 200 mg + Ritonavir 50 mg & ABBOTT - Doação & 3.624 .000 & 0,00 \\
\hline Ritonavir 80 mg solução oral & ABBOTT - Doação & 2.902 & 0,00 \\
\hline Total & & 1.467 .766 .858 & 4.466.267.136,67 \\
\hline
\end{tabular}

O Ministério da Saúde, no período de 2003 a 2013, adquiriu 4.292.695.381 unidades farmacêuticas (comprimidos, cápsulas e frascos) para abastecer 0 Nacional de Doenças Sexualmente Transmissíveis e AIDS. Para aquisição dos medicamentos para distribuição no âmbito do SUS o Ministério da Saúde teve um gasto com os fornecedores num total de $\mathrm{R} \$$ 8.121.543.665,23. Estes dados estão apresentados no Quadro 6 por cada um dos segmentos do mercado farmacêutico. 
Quadro 6 - Consolidação da produção dos laboratórios oficiais, nacionais e internacionais em número de Unidades Farmacêuticas (UF) e valor pago pelo Ministério da Saúde para o Programa Nacional de Doenças Sexualmente Transmissíveis e AIDS, no período de 2003 a 2013

\begin{tabular}{|c|c|c|}
\hline Laboratório & $\begin{array}{l}\text { Produção (Unidades de } \\
\text { comprimidos, cápsulas e } \\
\text { frascos), seringas }\end{array}$ & $\begin{array}{l}\text { Total pago pelo Ministério da Saúde } \\
\text { para os laboratórios } \\
\text { (R\$) }\end{array}$ \\
\hline Oficiais & 2.362 .148 .798 & 2.636.821.094,95 \\
\hline Nacionais & 462.779 .725 & $1.018 .455 .433,61$ \\
\hline Internacionais & 1.467 .766 .858 & $4.466 .267 .136,67$ \\
\hline Total & 4.292.695.381 & $8.121 .543 .665,23$ \\
\hline
\end{tabular}

Fonte: Produção Própria

Analisando os dados do Quadro 6 os laboratórios farmacêuticos oficiais foram responsáveis por $55 \%$ das unidades farmacêuticas adquiridas pelo Ministério da Saúde para o Programa Nacional de Doenças Sexualmente Transmissíveis e AIDS, no período de 2003 a 2013. No entanto, este quantitativo correspondeu a $32 \%$ do total do valor pago para todos os fornecedores. Os laboratórios internacionais produziram $34 \%$ das unidades farmacêuticas e receberam $55 \%$ dos recursos da aquisição e os laboratórios nacionais produziram apenas $11 \%$ das unidades farmacêuticas e receberam $13 \%$ dos recursos.

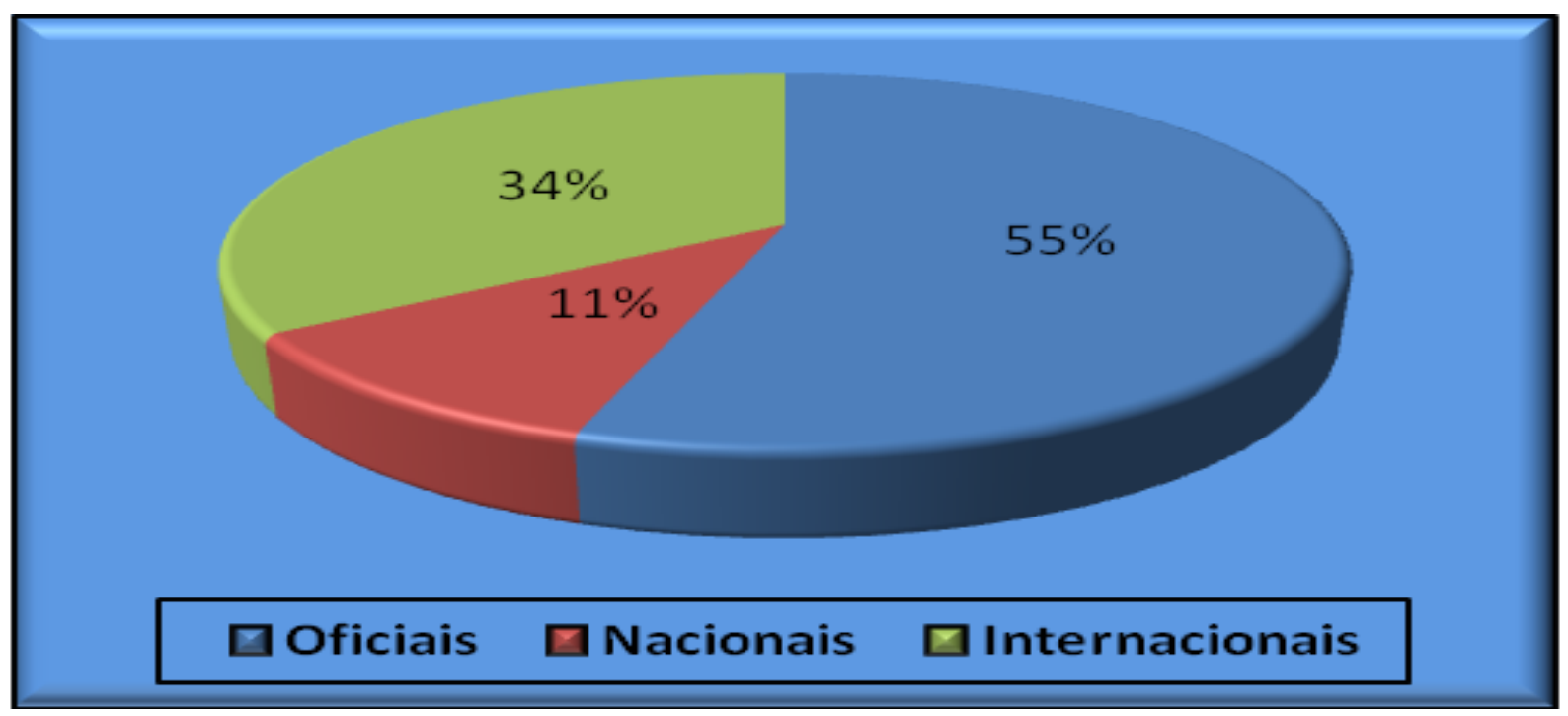

Figura 4 - Participação percentual da quantidade produzida pelos laboratórios oficiais, nacionais e internacionais em número de Unidades Farmacêuticas (UF) para o Ministério da Saúde para o Programa Nacional de Doenças Sexualmente Transmissíveis e AIDS, no período de 2003 a 2013.

Fonte: Produção Própria. 


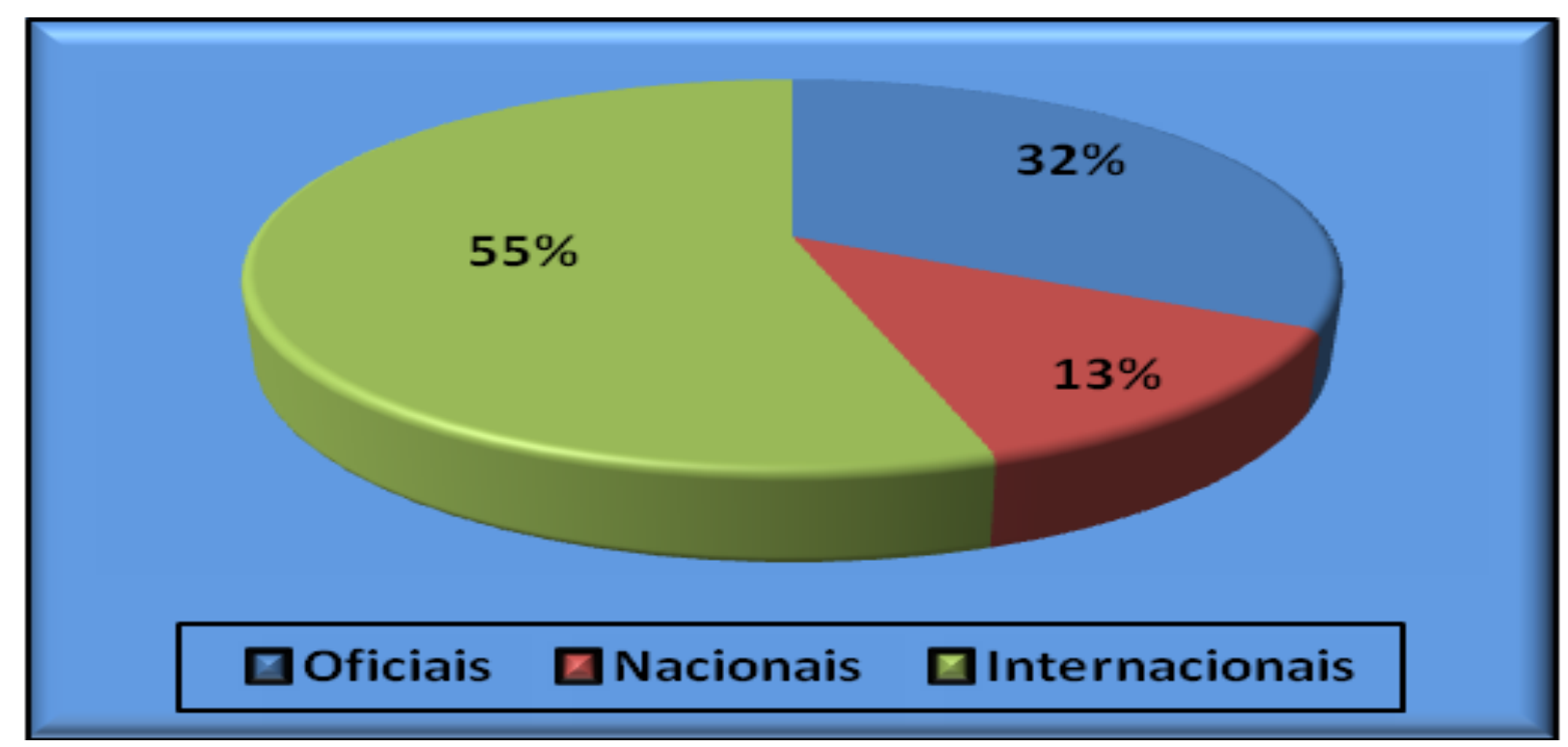

Figura 5 - Participação percentual do gasto com os laboratórios oficiais, nacionais e internacionais pelo Ministério da Saúde com o Programa Nacional de Doenças Sexualmente Transmissíveis e AIDS, no período de 2003 a 2013

Fonte: Produção Própria.

Dos 29 laboratórios farmacêuticos oficiais apenas 7 laboratórios participaramm da produção de medicamentos para o Programa Nacional de Doenças Sexualmente Transmissíveis e AIDS: LAFEPE, FIOCURZ, IQUEGO, FURP, FUNED, LIFAL E IVB, portanto apenas $24,14 \%$ dos LFO brasileiros.

Neste período o laboratório farmacêutico oficial que mais participou da produção pública para o Programa foi o laboratório LAFEPE, que totalizou 13 medicamentos do elenco, isto representa $28 \%$ do elenco. Em segundo lugar, ficou a FIOCRUZ, com $21 \%$, ou seja, produção de 10 medicamentos do elenco. O laboratório IQUEGO produziu 8 medicamentos, e sua participação percentual ficou em $17 \%$ do elenco de medicamentos. A FURP produziu 7 medicamentos (15\%), a FUNED produziu 5 medicamentos (11\%), o LIFAL produziu 3 medicamentos (6\%) e o IVB produziu apenas 1 medicamento em todo o período pesquisado, o que representa apenas $2 \%$ do elenco. 


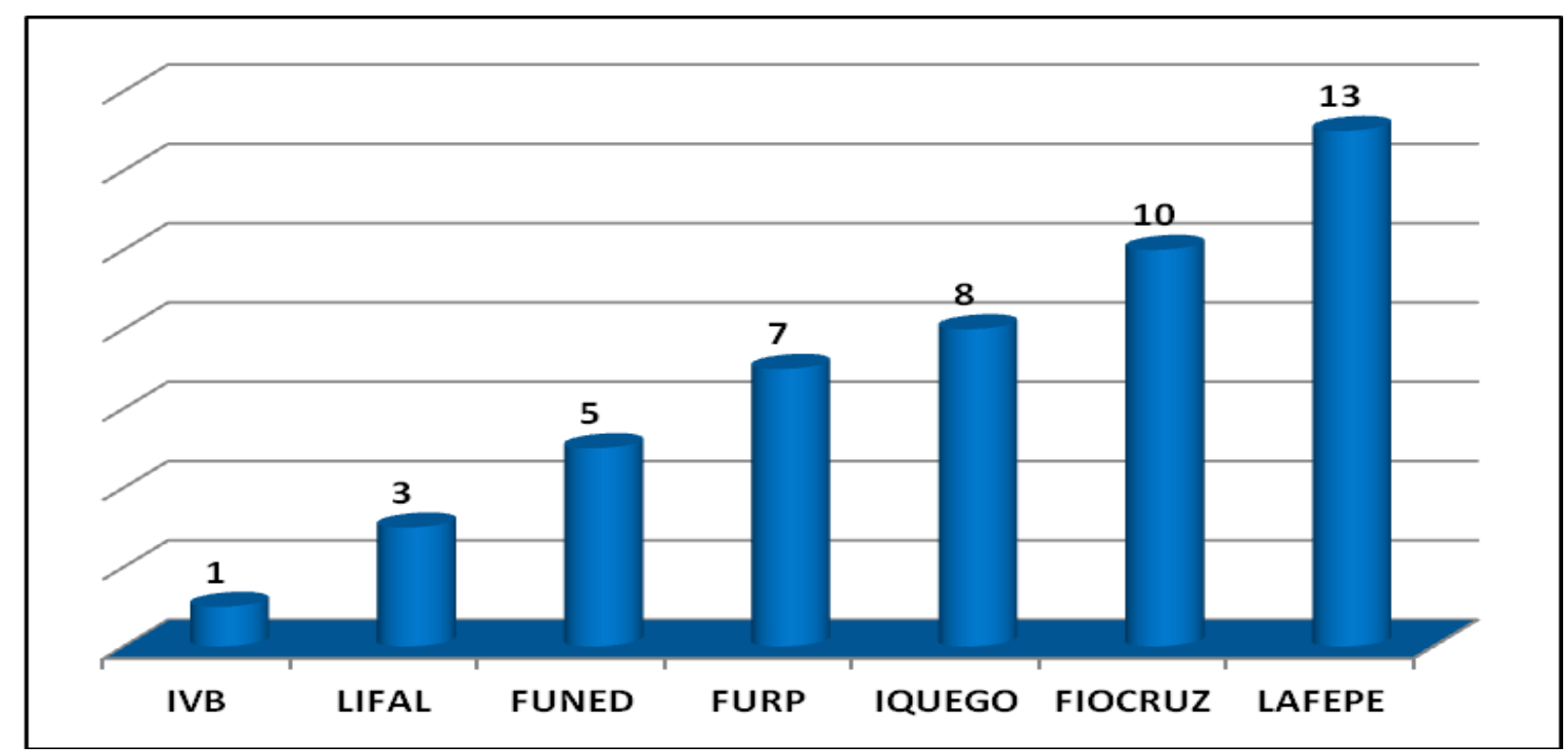

Figura 6 - Representação gráfica da quantidade de medicamentos produzidos pelos laboratórios oficiais para o Programa Nacional de Doenças Sexualmente Transmissíveis e AIDS, no período de 2003 a 2013

Fonte: Produção Própria

Em relação à quantidade produzida por unidade farmacêutica o laboratório oficial que mais produziu para o Programa Nacional de Doenças Sexualmente Transmissíveis e AIDS, no período de 2003 a 2013, foi a FIOCRUZ, com exceção ao ano de 2005 que ficou com o LAFEPE, conforme demonstra os dados consolidados no Quadro 7.

Os dados do Quadro 7 apontam que em segundo lugar na produção pública foi o laboratório LAFEPE, depois a FURP, o IQUEGO, a FUNED, o LIFAL e por último o IVB. 
Quadro 7 - Quantidade de Unidades Farmacêuticas e participação percentual da quantidade produzida pelos laboratórios oficiais para o Ministério da Saúde para o Programa Nacional de Doenças Sexualmente Transmissíveis e AIDS, no período de 2003 a 2013

\begin{tabular}{|c|c|c|c|c|c|c|c|c|c|c|c|c|c|c|c|}
\hline \multirow[b]{2}{*}{ Ano } & \multicolumn{2}{|c|}{ FIOCRUZ } & \multicolumn{2}{|c|}{ FUNED } & \multicolumn{2}{|c|}{ FURP } & \multicolumn{2}{|c|}{ IQUEGO } & \multicolumn{2}{|c|}{ IVB } & \multicolumn{2}{|c|}{ LAFEPE } & \multicolumn{2}{|c|}{ LIFAL } & \multirow[b]{2}{*}{ Total } \\
\hline & $\begin{array}{l}\text { Quantidade de } \\
\text { UF Produzida }\end{array}$ & $\begin{array}{l}\text { Participação } \\
\text { Percentual } \\
(\%)\end{array}$ & $\begin{array}{l}\text { Quantidade } \\
\text { de UF } \\
\text { Produzida }\end{array}$ & $\begin{array}{c}\text { Participaçã } \\
0 \\
\text { Percentual } \\
(\%)\end{array}$ & $\begin{array}{l}\text { Quantidade } \\
\text { de UF } \\
\text { Produzida }\end{array}$ & $\begin{array}{c}\text { Participaçã } \\
o \\
\text { Percentual } \\
(\%) \\
\end{array}$ & $\begin{array}{l}\text { Quantidade } \\
\text { de UF } \\
\text { Produzida }\end{array}$ & $\begin{array}{c}\text { Participacãão } \\
\text { Percentual (\%) }\end{array}$ & $\begin{array}{l}\text { Quantidade } \\
\text { de UF } \\
\text { Produzida }\end{array}$ & $\begin{array}{l}\text { Participação } \\
\text { Percentual (\%) }\end{array}$ & $\begin{array}{l}\text { Quantidade } \\
\text { de UF } \\
\text { Produzida }\end{array}$ & $\begin{array}{c}\text { Participaçã } \\
0 \\
\text { Percentual } \\
(\%)\end{array}$ & $\begin{array}{l}\text { Quantidade } \\
\text { de UF } \\
\text { Produzida }\end{array}$ & $\begin{array}{c}\text { Participacão } \\
\text { Percentual (\%) }\end{array}$ & \\
\hline 2003 & 69.278 .280 & 45,76 & 2.322 .240 & 1,53 & 25.243 .961 & 16,68 & 23.235.727 & 15,35 & & 0,00 & 29.516 .709 & 19,50 & 1.791 .000 & 1,18 & 151.387.917 \\
\hline 2004 & 32.086 .880 & 28,76 & 4.752 .420 & 4,26 & 23.596.905 & 21,15 & 22.281 .640 & 19,97 & 4.064 .160 & 3,64 & 23.630 .226 & 21,18 & 1.139 .040 & 1,02 & 111.551.271 \\
\hline 2005 & 51.807 .030 & 25,01 & 6.708 .000 & 3,24 & 34.372 .500 & 16,59 & 38.163 .520 & 18,42 & & 0,00 & 56.041 .380 & 27,05 & 20.070 .410 & 9,69 & 207.162.840 \\
\hline 2006 & 51.923 .100 & 30,29 & 9.700 .800 & 5,66 & 33.192 .000 & 19,36 & 31.780 .900 & 18,54 & & 0,00 & 37.860 .600 & 22,09 & 6.945 .000 & 4,05 & 171.402 .400 \\
\hline 2007 & 85.530 .000 & 54,78 & 11.880 .000 & 7,61 & 16.350 .000 & 10,47 & 16.438 .000 & 10,53 & & 0,00 & 19.857 .000 & 12,72 & 6.090 .000 & 3,90 & 156.145 .000 \\
\hline 2008 & 94.355 .000 & 51,52 & 10.101 .000 & 5,52 & 22.275 .000 & 12,16 & 15.058 .000 & 8,22 & & 0,00 & 39.201 .920 & 21,41 & 2.142 .000 & 1,17 & 183.132.920 \\
\hline 2009 & 99.971 .980 & 63,70 & 13.128 .000 & 8,36 & 25.309 .500 & 16,13 & 15.258 .000 & 9,72 & & 0,00 & 1.346 .300 & 0,86 & 1.933 .200 & 1,23 & 156.946 .980 \\
\hline 2010 & 130.217 .000 & 36,34 & 21.612 .540 & 6,03 & 48.057 .540 & 13,41 & 19.867 .500 & 5,55 & 106.910 .000 & 29,84 & 28.609 .000 & 7,98 & 3.018 .660 & 0,84 & 358.292.240 \\
\hline 2011 & 135.607 .920 & 52,69 & 41.600 .100 & 16,16 & 17.932 .500 & 6,97 & 40.146 .300 & 15,60 & & 0,00 & 20.432 .100 & 7,94 & 1.647 .000 & 0,64 & 257.365 .920 \\
\hline 2012 & 172.920 .000 & 56,62 & 33.294 .000 & 10,90 & 27.996 .000 & 9,17 & 22.082.000 & 7,23 & & 0,00 & 49.111 .000 & 16,08 & & 0,00 & 305.403 .000 \\
\hline 2013 & 185.301 .400 & 61,08 & 28.302 .000 & 9,33 & 30.962 .400 & 10,21 & 24.498 .000 & 8,08 & & 0,00 & 34.294 .510 & 11,30 & & 0,00 & 303.358.310 \\
\hline Total & 1.108 .998 .590 & & 183.401.100, & & 305.288.3060 & & 268.809.587 & & 110.974 .1600 & & 339.900 .7450 & & 44.776 .310 & & 2.362.148.798 \\
\hline
\end{tabular}

Fone: Produção Própria. 


\subsection{DOENÇAS CRÔNICO-DEGENERATIVAS (LÚPUS ERITEMATOSO, DOENÇA ENXERTO-VERSUS-HOSPEDEIRO E MIELOMA MÚLTIPLO).}

No elenco de medicamentos para o tratamento das doenças crônicodegenerativas (lúpus eritematoso, doença enxerto-versus-hospedeiro e mieloma múltiplo) consta apenas o medicamento talidomida.

Acontece que o medicamento talidomida somente é produzido por LFO, tendo em vista que o registro, a produção, a fabricação, a comercialização, a exposição à venda, a prescrição e a dispensação, no Brasil, são regulamentados de acordo com a Lei oㅜ 10.651, de 16 de abril de 2003 e a Resolução - RDC o 11, de 22 de março de 2011, RDC 24, de 12 de abril de 2012 e, pela Portaria SVS/MS no 354, de 15 de agosto de 1997, pelos seus efeitos teratogênicos comprovados.

Determina, a Portaria SVS/MS no $354 / 97$, no art. 16, que a fabricação da talidomida para atender aos programas oficiais já descritos, será efetuada sob licença especial, somente, por laboratórios faramacêuticos oficiais, sendo permitido, em caráter complementar e em havendo necessidade, o mesmo regime para a iniciativa privada.

No Brasil, o único LFO com registro sanitário concedido pela Agência Nacional de Vigilância Sanitária (Anvisa) para comercialização da talidomida no mercado brasileiro é a Fundação Ezequiel Dias (FUNED), que produz para todos os programas do Ministério da Saúde. Por estas razões toda a produção de talidomida está centralizada na FUNED.

A Portaria SVS/MS № 354/97, determina no seu artigo 5ำ que a talidomida só pode ser indicada e utilizada no âmbito dos seguintes programas oficiais: Hanseníase (reação hansênica do tipo II ou tipo eritema nodoso); Doenças Sexualmente Transmissíveis - DST/HIV/AIDS; Doenças crônico-degenerativas (lúpus eritematoso, doença enxerto-versus-hospedeiro e mieloma múltiplo).

A produção pública para tratamento das doenças crônico-degenerativas, no período pesquisado foi de 21.533 .760 de comprimidos e o gasto do Ministério da Saúde para esta produção foi de RS 7.258.579,49. 
Tabela 2 - Consolidação da produção da Fundação Ezequiel Dias (FUNED) em número de Unidades Farmacêuticas (UF) e valor pago pelo Ministério da Saúde da talidomida, no período de 2003 a 2013

\begin{tabular}{ccc}
\hline Ano & $\begin{array}{c}\text { Número de Unidades farmacêuticas } \\
\text { Produzidas }\end{array}$ & $\begin{array}{c}\text { Total pago pelo Ministério da Saúde } \\
\mathbf{( R \$ )}\end{array}$ \\
\hline $\mathbf{2 0 0 3}$ & 840.480 & $150.866,16$ \\
$\mathbf{2 0 0 4}$ & 1.635 .840 & $314.244,86$ \\
$\mathbf{2 0 0 5}$ & 1.844 .160 & $555.276,58$ \\
$\mathbf{2 0 0 6}$ & 2.001 .600 & $602.681,76$ \\
$\mathbf{2 0 0 8}$ & 1.896 .480 & $571.030,13$ \\
$\mathbf{2 0 0 9}$ & 2.467 .200 & $616.800,00$ \\
$\mathbf{2 0 1 0}$ & 2.651 .520 & $1.087 .123,20$ \\
$\mathbf{2 0 1 1}$ & 2.641 .920 & $1.083 .187,20$ \\
$\mathbf{2 0 1 2}$ & 1.740 .480 & $713.596,80$ \\
$\mathbf{2 0 1 3}$ & 1.044 .960 & $428.433,60$ \\
Total & 2.769 .120 & $1.135 .339,20$ \\
\hline
\end{tabular}

Fonte: Produção Própria.

\subsection{PROGRAMA NACIONAL DE CONTROLE DA HANSENÍASE}

A missão do Programa Nacional de Controle da Hanseníase é promover a vigilância e a atenção integral em saúde para o controle da hanseníase no Brasil, em consonância com os princípios e diretrizes do SUS, objetivando a melhoria da qualidade de vida e o exercício da cidadania em permanente integração com a sociedade.

A pesquisa exploratória levantou 12 medicamentos que constam do elenco de para tratamento da hanseníase adquiridos pelo Ministério da Saúde por meio do Componente Estratégico da Assistência Farmacêutica. No Quadro 8 relaciona o rol de medicamentos.

Apenas 8 laboratórios oficias participaram da produção pública: FUNED, FURP, IQUEGO, LAFEPE, LQFA, LQFEX, FIOCRUZ e LFM. Houve participação de apenas $27,59 \%$ dos laboratórios oficiais na produção de medicamentos para 0 Programa Nacional de Controle da Hanseníase.

Com a produção de 8 medicamentos para o controle da hanseníase pelos LFO este participaram com apenas $66,77 \%$ do elenco de medicamentos. A participação dos laboratórios nacionais representa $41,67 \%$, com a produção de 5 
medicamentos e os laboratórios internacionais produzem apenas 3 medicamento, ou seja, $25 \%$ do elenco.

Quadro 8 - Elenco de medicamentos produzidos pelos laboratórios para o Programa Nacional de Controle da Hanseníase, período de 2003 a 2013

\begin{tabular}{|c|c|c|c|}
\hline \multirow{2}{*}{ Medicamentos } & \multicolumn{3}{|c|}{ Laboratórios } \\
\hline & Oficiais & Nacionais & Internacionais \\
\hline Ciclosporina, Cápsula Gel mole 50 mg com microemulsão & & $\mathbf{x}$ & \\
\hline Clofazimina 100 mg cápsula & & $\mathbf{x}$ & $\mathbf{x}$ \\
\hline Clofazimina 50 mg cápsula & & $\mathbf{x}$ & $\mathbf{x}$ \\
\hline Dapsona 100 mg comprimido & $\mathbf{X}$ & & \\
\hline Minociclina (Cloridrato) $100 \mathrm{mg}$ comprimido & $\mathbf{x}$ & $\mathbf{x}$ & \\
\hline Ofloxacino $400 \mathrm{mg}$ comprimido & $\mathbf{x}$ & & \\
\hline Pentoxfilina 400 mg comprimido & & $\mathbf{x}$ & $\mathbf{x}$ \\
\hline Prednisona $20 \mathrm{mg}$ comprimido & $\mathbf{x}$ & & \\
\hline Prednisona 5 mg comprimido & $\mathbf{x}$ & & \\
\hline Rifampicina $2 \%$ suspensão frasco & $\mathbf{X}$ & & \\
\hline Rifampicina 300 mg cápsula & $\mathbf{x}$ & & \\
\hline Talidomida 100 mg comprimido & $\mathbf{x}$ & & \\
\hline Total & 8 & 5 & 3 \\
\hline
\end{tabular}

Fonte: Produção Própria.

O Laboratório Farmacêutico da Marinha produziu 4 medicamentos, que representa 33,33\% dos medicamentos do elenco. A FIOCRUZ e o LQFEX participaram com a produção de 3 medicamentos o que corresponde a $25 \%$ dos medicamentos para cada um, respectivamente. Os outros 6 laboratórios oficiais produziram cada um apena 1 medicamento do elenco o que corresponde $8,33 \%$ do elenco. 


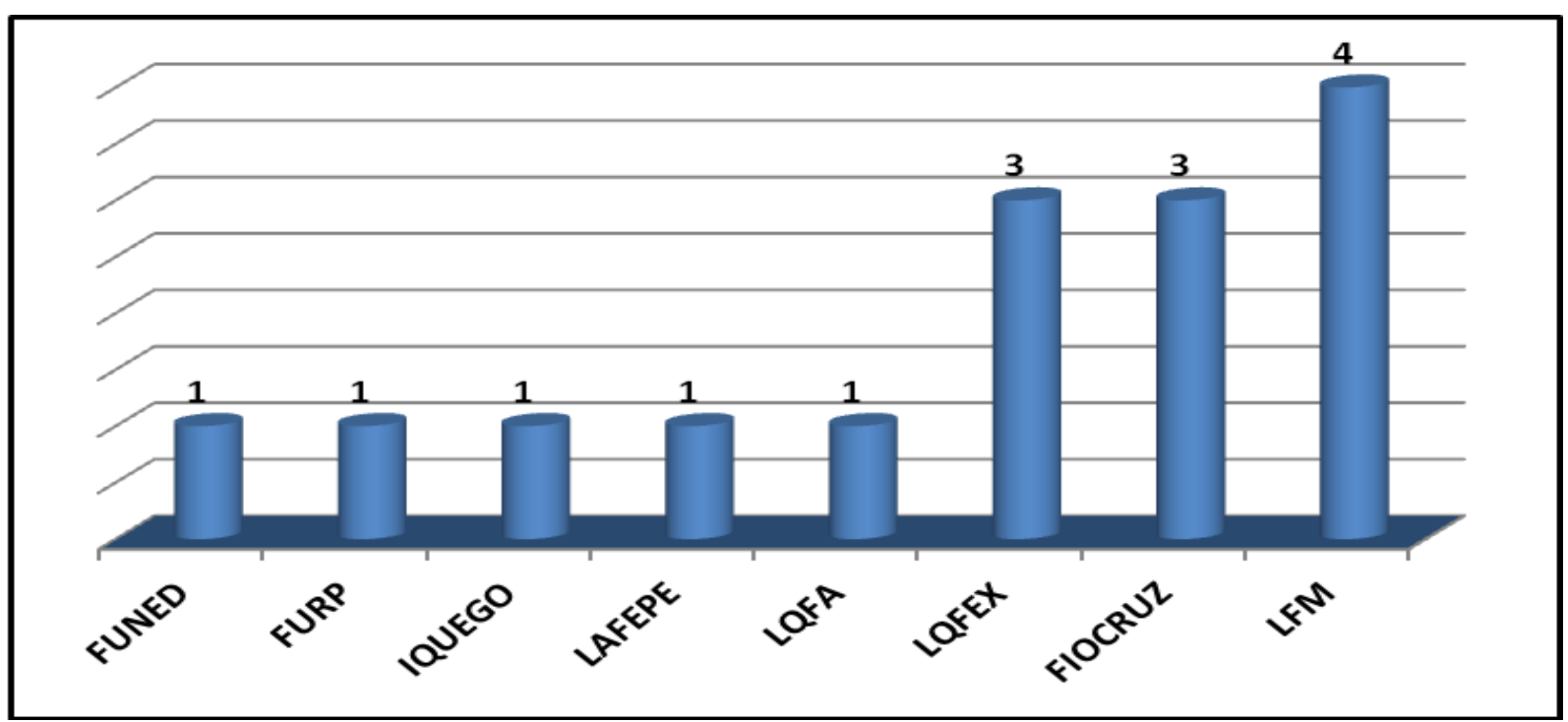

Figura 7 - Representação gráfica da quantidade de medicamentos produzidos pelos laboratórios oficiais para o Programa Nacional de Controle da Hanseníase, no período de 2003 a 2013. Fonte: Produção Própria.

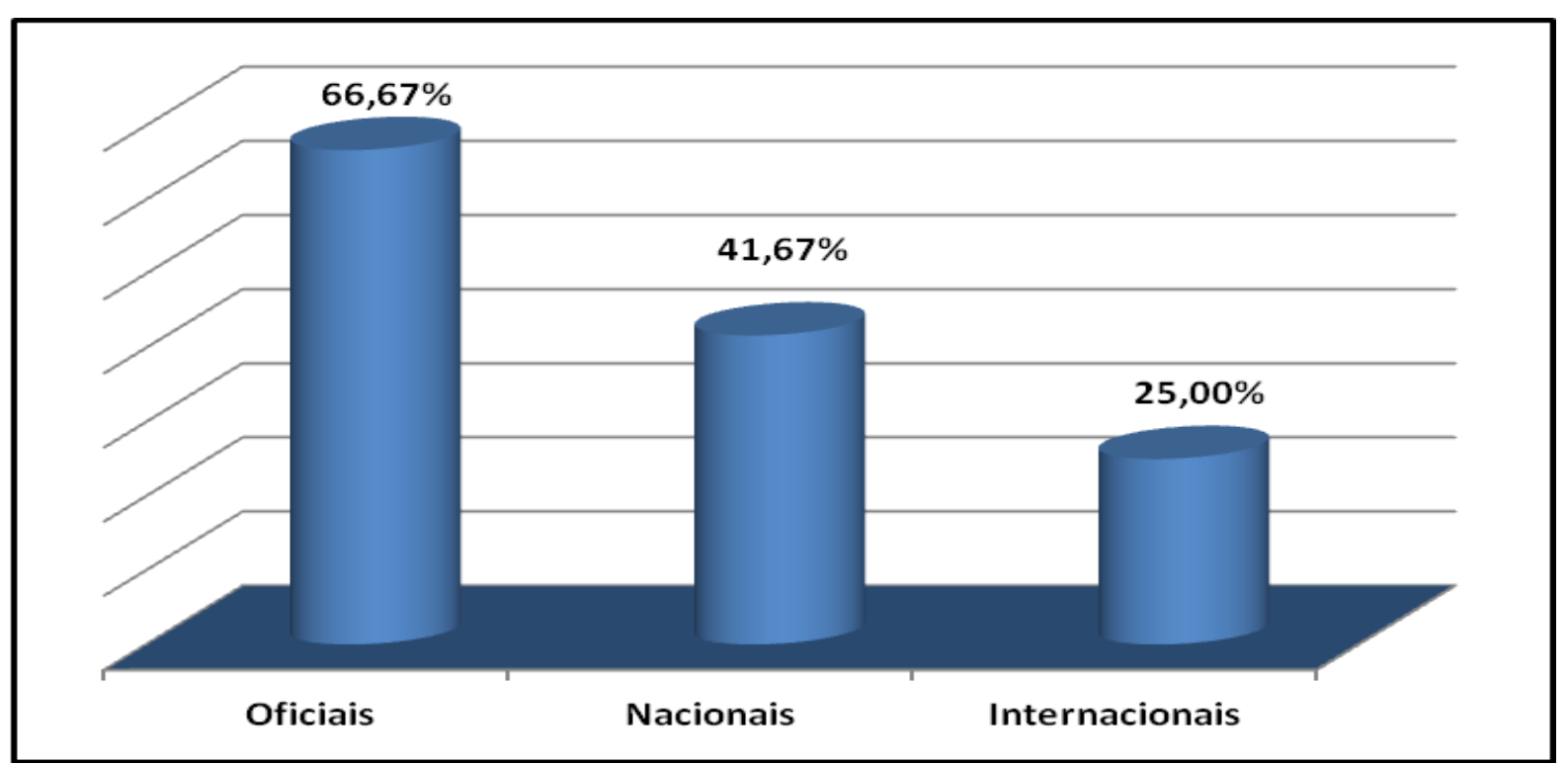

Figura 8 - Representação gráfica da participação percentual pelos laboratórios na produção do elenco de medicamentos produzidos para o Programa Nacional de Controle da Hanseníase, período de 2003 a 2013.

Fonte: Produção Própria.

Nos Quadros 9, 10 e 11 com os dados da série histórica foi elaborado um consolidado por quantidade de unidades farmacêuticas produzidas e o total do valor pago pelo Ministério da Saúde em reais, para cada tipo de laboratório, no período de 2003 a 2013. 


\section{continua}

Quadro 9 - Consolidação da produção dos laboratórios oficiais em número de Unidades Farmacêuticas (UF) e Valor Pago pelo Ministério da Saúde para o Programa Nacional de Controle da hanseníase, período 2003 a 2013

\begin{tabular}{|c|c|c|c|}
\hline Medicamentos & \multirow[t]{2}{*}{ Unid. } & \multirow{2}{*}{$\begin{array}{c}\text { Quantidade de } \\
\text { Unidades } \\
\text { farmacêuticas } \\
\text { (comprimidos, } \\
\text { cápsulas e frascos) } \\
\text { produzidas }\end{array}$} & \multirow[t]{2}{*}{$\begin{array}{l}\text { Valor pago pelo } \\
\text { Ministério da Saúde }\end{array}$} \\
\hline FIOCRUZ & & & \\
\hline Dapsona $100 \mathrm{mg}$ & Comp. & 907.000 & $10.884,00$ \\
\hline Prednisona $20 \mathrm{mg}$ & Comp. & 53.992 .500 & $3.514 .070,95$ \\
\hline Prednisona $5 \mathrm{mg}$ & Comp. & 13.096 .500 & $285.503,70$ \\
\hline Subtotal & & 67.996 .000 & $3.810 .458,65$ \\
\hline \multicolumn{4}{|c|}{ FUNED } \\
\hline Talidomida 100 mg & Comp. & 37.981 .440 & $12.131 .037,31$ \\
\hline Subtotal & & 37.981 .440 & 12.131.037,31 \\
\hline \multicolumn{4}{|c|}{ FURP } \\
\hline Rifampicina $2 \%$ suspensão & Frasco & 8.100 & $6.704,42$ \\
\hline Subtotal & & 8.100 & $6.704,42$ \\
\hline \multicolumn{4}{|c|}{ IQUEGO } \\
\hline Minociclina (Cloridrato) $100 \mathrm{mg}$ & Comp. & 1.313 .500 & $1.217 .726,40$ \\
\hline Subtotal & & 1.313 .500 & $1.217 .726,40$ \\
\hline \multicolumn{4}{|c|}{ LAFEPE } \\
\hline Rifampicina $300 \mathrm{mg}$ & Cáps. & 506.500 & $71.669,75$ \\
\hline Subtotal & & 506.500 & $71.669,75$ \\
\hline \multicolumn{4}{|c|}{ LFM } \\
\hline Ofloxacino $400 \mathrm{mg}$ & Comp. & 2.058 .000 & $774.550,00$ \\
\hline Prednisona $20 \mathrm{mg}$ & Comp. & 31.623 .500 & $2.067 .851,75$ \\
\hline Prednisona 20 mg & Comp. & 7.218 .000 & $472.779,00$ \\
\hline Prednisona $5 \mathrm{mg}$ & Comp. & 19.205 .000 & $418.669,00$ \\
\hline Subtotal & & 60.104 .500 & $3.733 .849,75$ \\
\hline \multicolumn{4}{|c|}{ LQFAR } \\
\hline Prednisona $5 \mathrm{mg}$ & Comp. & 1.396 .500 & $30.443,70$ \\
\hline Subtotal & & 1.396 .500 & $30.443,70$ \\
\hline
\end{tabular}


conclusão

Quadro 9 - Consolidação da produção dos laboratórios oficiais em número de Unidades Farmacêuticas (UF) e Valor Pago pelo Ministério da Saúde para o Programa Nacional de Controle da hanseníase, período 2003 a 2013

\begin{tabular}{|c|c|c|c|}
\hline Medicamentos & Unid. & $\begin{array}{c}\text { Quantidade de } \\
\text { Unidades } \\
\text { farmacêuticas } \\
\text { (comprimidos, } \\
\text { cápsulas e frascos) } \\
\text { produzidas }\end{array}$ & $\begin{array}{l}\text { Valor pago pelo } \\
\text { Ministério da Saúde }\end{array}$ \\
\hline \multicolumn{4}{|c|}{ LQFEX } \\
\hline Prednisona $20 \mathrm{mg}$ & Comp. & 15.934 .500 & $1.040 .222,25$ \\
\hline Prednisona $5 \mathrm{mg}$ & Comp. & 3.748 .500 & $81.717,30$ \\
\hline \multirow[t]{2}{*}{ Ofloxacino $400 \mathrm{mg}$} & Comp. & 215.400 & $77.544,00$ \\
\hline & & 19.898 .400 & $1.199 .483,55$ \\
\hline Total & & 189.204 .940 & 22.201 .374 \\
\hline
\end{tabular}

Fonte: Produção Própria.

Quadro 10 - Consolidação da produção dos laboratórios nacionais em número de Unidades Farmacêuticas (UF) e Valor Pago pelo Ministério da Saúde para o Programa Nacional de Controle da hanseníase, período 2003 a 2013

\begin{tabular}{|l|l|c|c|}
\hline \multicolumn{1}{|c|}{ Medicamentos } & Unidade & $\begin{array}{c}\text { Quantidade de } \\
\text { Unidades } \\
\text { farmacêuticas } \\
\text { (comprimidos, } \\
\text { cápsulas e frascos) } \\
\text { produzidas }\end{array}$ & $\begin{array}{c}\text { Valor pago pelo } \\
\text { Ministério da } \\
\text { Saúde (R\$) }\end{array}$ \\
\hline Ciclosporina, Cápsula Gel mole 50 mg com microemulsão (doação) & Cáps. & 80.000 & 0,00 \\
Clofazimina $100 \mathrm{mg}$ & Cáps. & 838.600 & $117.584,60$ \\
Clofazimina $50 \mathrm{mg}$ & Cáps. & 169.700 & $17.988,20$ \\
Minociclina (Cloridrato) $100 \mathrm{mg}$ & Comp. & 141.000 & $96.486,30$ \\
Pentoxfilina $400 \mathrm{mg}$ & Comp. & 410.660 & $96.946,95$ \\
Pentoxfilina $400 \mathrm{mg}$ & Comp. & 301.400 & $77.350,00$ \\
Pentoxfilina $400 \mathrm{mg}$ & Comp. & 138.550 & $34.637,50$ \\
\hline
\end{tabular}

Fonte: Produção Própria. 
Quadro 11 - Consolidação da produção dos laboratórios internacionais em número de Unidades Farmacêuticas (UF) e Valor Pago pelo Ministério da Saúde para o Programa Nacional de Controle da hanseníase, período 2003 a 2013

\begin{tabular}{|l|c|c|c|}
\hline \multicolumn{1}{|c|}{ Medicamentos } & Unid. & $\begin{array}{c}\text { Quantidade de } \\
\text { Unidades } \\
\text { farmacêuticas } \\
\text { (comprimidos, } \\
\text { cápsulas e frascos) } \\
\text { produzidas }\end{array}$ & $\begin{array}{c}\text { Valor pago pelo } \\
\text { Ministério da Saúde }\end{array}$ \\
\hline Clofazimina $100 \mathrm{mg}$ & Cáps. & 266.500 & $39.708,50$ \\
Clofazimina $50 \mathrm{mg}$ & Cáps. & 604.500 & $65.346,45$ \\
Pentoxfilina $400 \mathrm{mg}$ & Comp. & 217.020 & $62.935,80$ \\
Pentoxfilina $400 \mathrm{mg}$ & Comp. & 150.000 & 0,00 \\
\hline
\end{tabular}

Fonte: Produção Própria.

No período de 2003 a 2013 o Ministério da Saúde adquiriu 192.522.870 unidades farmacêuticas (comprimidos, cápsulas e frascos) para atender ao Programa Nacional de Controle da Hanseníase. Para adquirir estes medicamentos foi gasto a importância de $R \$ 22.810 .357,83$ com todos os fornecedores.

Quadro 12 - Consolidação da produção dos laboratórios oficiais, nacionais e internacionais em número de Unidades Farmacêuticas (UF) e Valor Pago pelo Ministério da Saúde para o Programa Nacional de Controle da hanseníase, período 2003 a 2013

\begin{tabular}{|c|c|c|}
\hline Medicamentos & $\begin{array}{c}\text { Quantidade de } \\
\text { Unidades } \\
\text { farmacêuticas } \\
\text { (comprimidos, } \\
\text { cápsulas e frascos) } \\
\text { produzidas }\end{array}$ & $\begin{array}{c}\text { Valor pago pelo Ministério } \\
\text { da Saúde }\end{array}$ \\
\hline Oficiais & 189.204 .940 & $22.201 .373,53$ \\
\hline Nacionais & 2.079 .910 & $440.993,55$ \\
\hline Internacionais & 1.238 .020 & $167.990,75$ \\
\hline Total & 192.522 .870 & $22.810 .357,83$ \\
\hline
\end{tabular}

Fonte: Produção Própria.

Os laboratórios oficiais foram responsáveis por 98,28\% da produção das unidades farmacêuticas (comprimidos, cápsulas, frascos e ampolas) adquiridas pelo Ministério da Saúde para abastecimento do Programa Nacional de Controle da Hanseníase. Este quantitativo correspondeu a 97,33\% do valor gasto pelo Ministério pago a todos os fornecedores. 
Os laboratórios nacionais produziram 1,08\% das unidades farmacêuticas e os internacionais ficaram com 0,64\%. A participação percentual destes laboratórios no gasto do Ministério da Saúde foi de 1,93\% e 0,74\%, respectivamente.

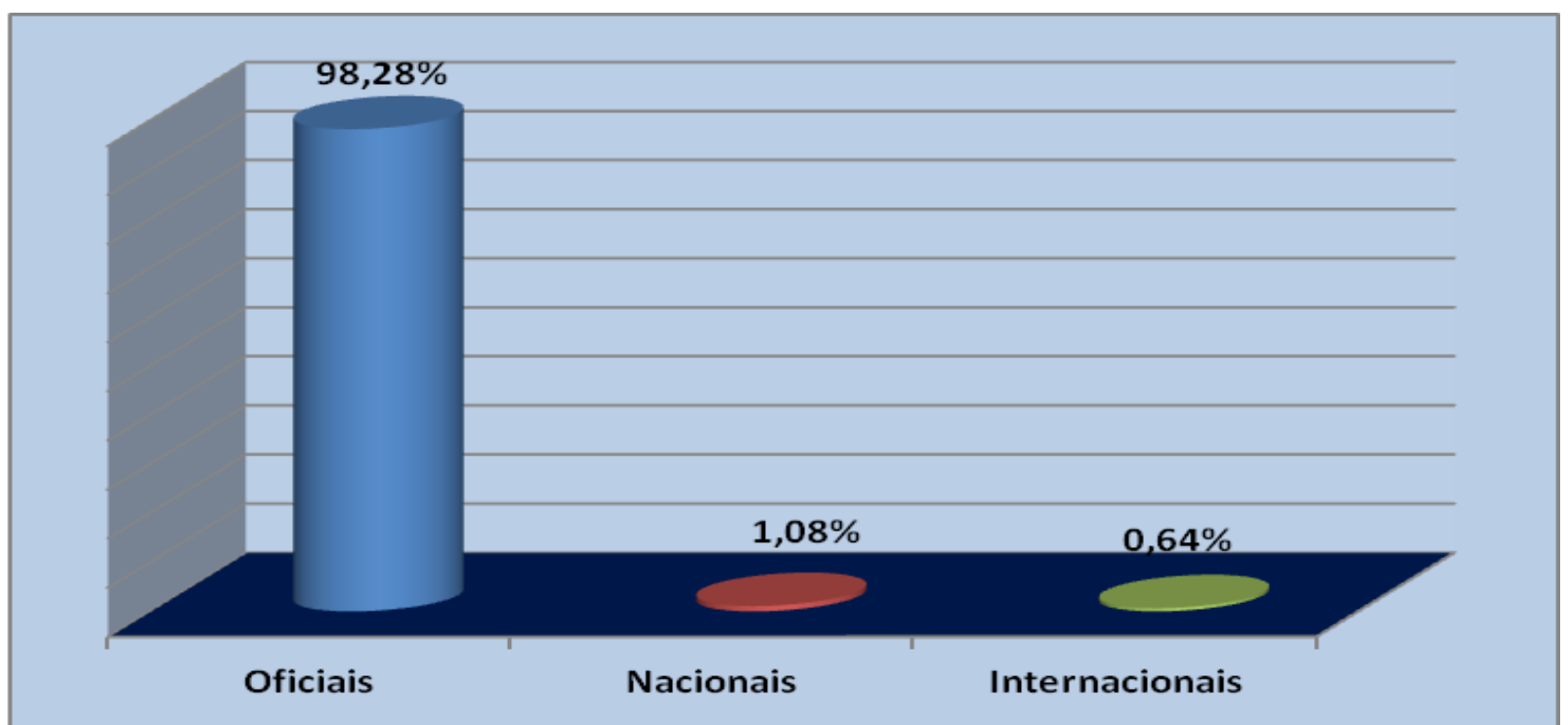

Figura 9 - Participação percentual da quantidade produzida pelos laboratórios oficiais, nacionais e internacionais em número de Unidades Farmacêuticas (UF) para o Ministério da Saúde para o Programa Nacional de Controle da Hanseníase, no período de 2003 a 2013.

Fonte: Produção Própria.

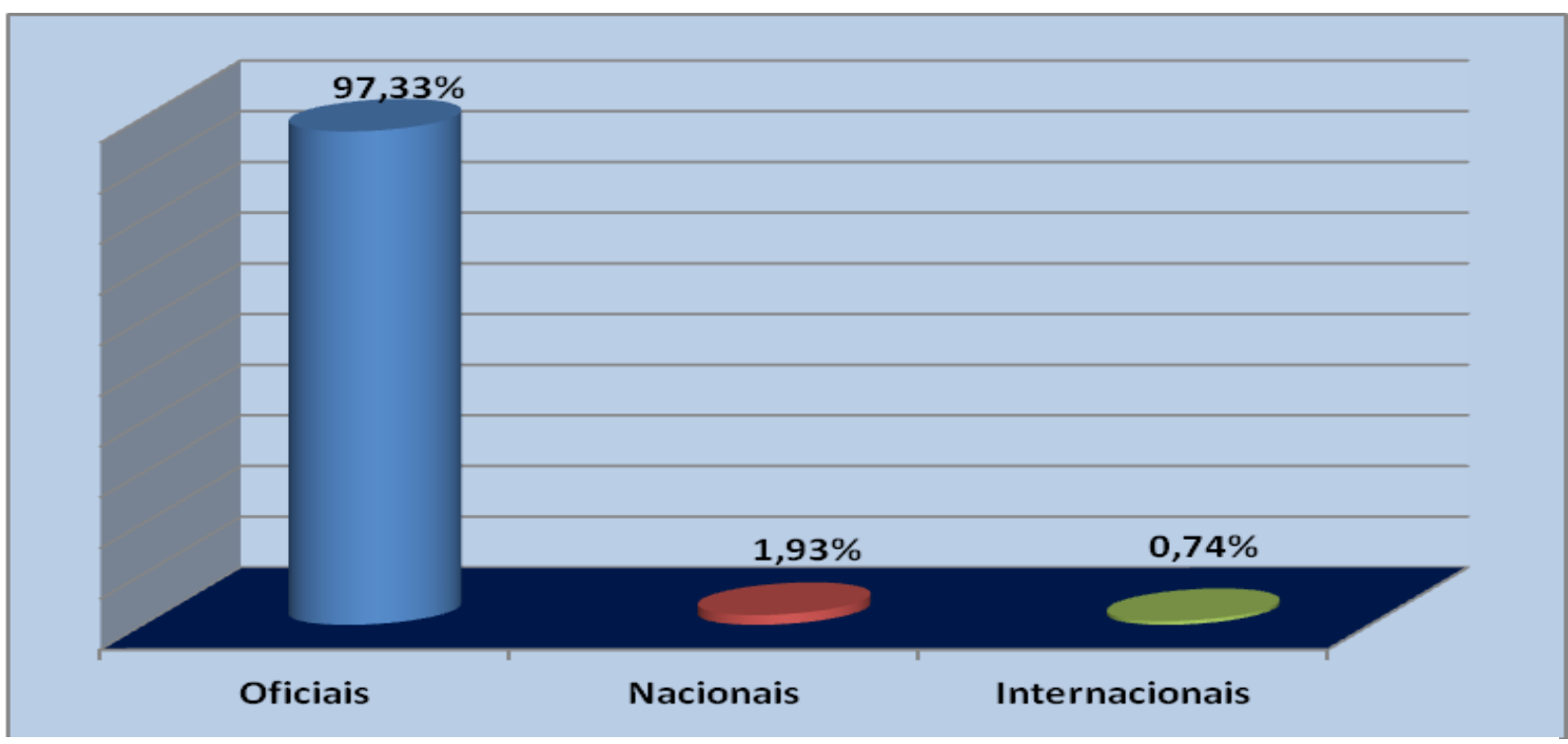

Figura 10 - Participação percentual do gasto com os laboratórios oficiais, nacionais e internacionais pelo Ministério da Saúde com o Programa Nacional de Controle da Hanseníase, no período de 2003 a 2013.

Fonte: Produção Própria.

Analisando os dados levantados, em relação à quantidade produzida de unidade farmacêutica, o laboratório oficial que mais produziu para o programa, foi a 
FIOCRUZ, apesar de produzir apenas 3 medicamentos do elenco. Sua produção corresponde a $35,94 \%$ da produção pública para o programa.

O LFM que produz 4 medicamentos do elenco ficou em segundo lugar em quantidade de unidade farmacêutica produzida, que corresponde a $31,77 \%$ da produção pública. A FUNED ficou em terceiro lugar na participação da produção pública, com a produção de apenas 1 medicamento do elenco, que representa 20,07\%. O LQFEX ficou em quarto lugar com uma participação de $10,52 \%$ da produção pública com 3medicamentos do elenco. Os laboratórios oficiais FURP, LAFEPE, IGUEGO e LQFA participaram com $1,70 \%$ da produção pública. 
Quadro 13 - Quantidade de Unidades farmacêuticas e participação percentual da quantidade produzida pelos laboratorios oficiais para o Ministério da Saúde para o Programa Nacional de Controle da hanseníase, no período de 2003 a 2013

\begin{tabular}{|c|c|c|c|c|c|c|c|c|c|c|c|c|c|c|c|c|c|}
\hline \multirow[b]{2}{*}{ Ano } & \multicolumn{2}{|c|}{ FIOCRUZ } & \multicolumn{2}{|c|}{ FUNED } & \multicolumn{2}{|c|}{ FURP } & \multicolumn{2}{|c|}{ IQUEGO } & \multicolumn{2}{|c|}{ LAFEPE } & \multicolumn{2}{|c|}{ LFM } & \multicolumn{2}{|c|}{ LQFA } & \multicolumn{2}{|l|}{ LQFEX } & \multirow[b]{2}{*}{$\begin{array}{l}\text { Total de UF } \\
\text { produzidas }\end{array}$} \\
\hline & $\begin{array}{l}\text { Quantidade de } \\
\text { UF Produzida }\end{array}$ & $\begin{array}{c}\text { Participaçã } \\
0 \\
\text { Percentual } \\
(\%)\end{array}$ & $\begin{array}{l}\text { Quantidade de } \\
\text { UF Produzida }\end{array}$ & \begin{tabular}{|c|} 
Participac \\
ao \\
Percentua \\
I(\%)
\end{tabular} & $\begin{array}{l}\text { Quantidade } \\
\text { de UF } \\
\text { Produzida }\end{array}$ & $\begin{array}{l}\text { Participacãa o } \\
\text { Percentual } \\
(\%)\end{array}$ & $\begin{array}{l}\text { Quantidade de } \\
\text { UF Produzida }\end{array}$ & \begin{tabular}{|c|} 
Participac \\
áo \\
Percentua \\
I $\%)$
\end{tabular} & $\begin{array}{l}\text { Quantidade } \\
\text { de UF } \\
\text { Produzida }\end{array}$ & $\begin{array}{c}\text { Participaçã } \\
\text { Percentual } \\
(\%)\end{array}$ & $\begin{array}{l}\text { Quantidade de } \\
\text { UF Produzida }\end{array}$ & $\begin{array}{c}\text { Participaç } \\
\text { aro } \\
\text { Percentual } \\
(\%)\end{array}$ & $\begin{array}{l}\text { Quantidade de } \\
\text { UF Produzida }\end{array}$ & \begin{tabular}{|c|} 
Participaç \\
ao \\
Percentual \\
$(\%)$
\end{tabular} & $\begin{array}{l}\text { Quantidade de UF } \\
\text { Produzida }\end{array}$ & $\begin{array}{c}\text { Participa } \\
\text { cão } \\
\text { Percentu } \\
\text { al (\%) }\end{array}$ & \\
\hline 2003 & 4.817 .500 & 7,08 & 2.766 .720 & 7,28 & 450 & 5,56 & 38.000 & 2,89 & 225.000 & 44,42 & 2.313 .500 & 3,85 & & & 2.340 .900 & 11,76 & 12.502 .070 \\
\hline 2004 & 6.716 .500 & 9,88 & 4.455 .840 & 11,73 & 7.650 & 94,44 & 27.000 & 2,06 & 197.500 & 38,99 & 3.181 .000 & 5,29 & & & 2.748 .000 & 13,81 & 17.333 .490 \\
\hline 2005 & 14.276 .000 & 21,00 & 4.444 .800 & 11,70 & & & 156.000 & 11,88 & 84.000 & 16,58 & 3.018 .000 & 5,02 & & & 2.650 .000 & 13,32 & 24.628 .800 \\
\hline 2006 & 7.218 .000 & 10,62 & 3.754 .560 & 9,89 & & & 172.500 & 13,13 & & & 7.422 .000 & 12,35 & & & 5.000 .000 & 25,13 & 23.567 .060 \\
\hline 2007 & 8.909 .500 & 13,10 & 3.133 .920 & 8,25 & & & & & & & 7.276 .000 & 12,11 & & & 7.159 .500 & 35,98 & 26.478 .920 \\
\hline 2008 & 5.192 .000 & 7,64 & 3.740 .640 & 9,85 & & & & & & & 1.585 .500 & 2,64 & 1.396 .500 & 100,00 & & & 11.914 .640 \\
\hline 2009 & & & 4.199 .040 & 11,06 & & & & & & & 2.934 .000 & 4,88 & & & & & 7.133 .040 \\
\hline 2010 & 8.576 .000 & 12,61 & 3.512 .640 & 9,25 & & & & & & & 3.419 .500 & 5,69 & & & & & 15.508 .140 \\
\hline 2011 & 12.290 .500 & 18,08 & 1.338 .720 & 3,52 & & & 500.000 & 38,07 & & & 1.350 .000 & 2,25 & & & & & 15.479 .220 \\
\hline 2012 & & 0,00 & 2.164 .800 & 5,70 & & & & & & & 11.992 .500 & 19,95 & & & & & 14.157 .300 \\
\hline 2013 & & 0,00 & 4.469 .760 & 11,77 & & & 420.000 & 31,98 & & & 15.612 .500 & 25,98 & & & & & 20.502 .260 \\
\hline $\begin{array}{l}\text { Total de } \\
\text { UF } \\
\text { produzida }\end{array}$ & 67.996 .000 & 100,00 & 37.981.440 & 100,00 & 8.100 & 100,00 & 1.313 .500 & 100,00 & 506.500 & 100,00 & 60.104 .500 & 100,00 & 1.396 .500 & 100,00 & 19.898 .400 & 100,00 & 189.204.940 \\
\hline
\end{tabular}

Fonte: Produção Própria. 


\subsection{PROGRAMA NACIONAL DE ALIMENTAÇÃO E NUTRIÇÃO.}

O elenco de medicamentos do Programa Nacional de Alimentação e Nutrição é composto por 6 medicamentos, conforme demonstrado no Quadro 14. Todos estes medicamentos são vitaminas. Vitaminas são compostos orgânicos, presentes nos alimentos, essenciais para o funcionamento normal do metabolismo, e em caso de falta, pode levar a doenças. Quase todas não são produzidas pelo organismo em questão, devendo obrigatoriamente ser obtidas na dieta (Stedman,/2007).

Cinco dos medicamentos do elenco foram produzidos por laboratório oficial, ou seja, a FIOCRUZ e um produzido pelo laboratório TEUTO, que é nacional.

Quadro 14 - Elenco de medicamentos produzidos pelos laboratórios para o Programa Nacional de Alimentação e Nutrição, no período de 2003 a 2013

\begin{tabular}{|c|c|c|c|c|}
\hline \multirow{2}{*}{ Medicamentos } & \multirow{2}{*}{ Unidade } & \multicolumn{3}{|c|}{ Laboratórios } \\
\hline & & Oficiais & Nacionais & Internacionais \\
\hline Ácido Fólico. $5 \mathrm{mg}$ & Comp. & $\mathbf{x}$ & & \\
\hline Sulfato Ferroso $40 \mathrm{mg}$ & Comp. & $\mathbf{x}$ & & \\
\hline Sulfato Ferroso xarope & $\mathrm{Fr}$ & $\mathbf{x}$ & & \\
\hline Vitamina A $100.000 \mathrm{UI}$ & Cáps. & $\mathbf{x}$ & & \\
\hline Vitamina A. $200.000 \mathrm{UI}$ & Cáps. & $\mathbf{x}$ & & \\
\hline Tiamina (Cloridrato) 300 mg (Vitamina B1) & Comp. & & $\mathbf{x}$ & \\
\hline Total & & 5 & 1 & 0 \\
\hline
\end{tabular}

Fonte: Produção Própria.

A FIOCRUZ produziu 5 medicamentos do elenco do Programa Nacional de Nutrição e Alimentação e teve uma participação percentual de $83,33 \%$ do elenco. $O$ laboratório TEUTO produziu apenas o medicamento cloridrato de tiamina, teve então uma participação de 16,33\% na produção.

A distribuidora de medicamentos DIMEBEL ${ }^{21}$ participou do pegão eletrônico apenas para entregar o medicamento cloridrato de tiamina, ou seja, não produziu. Não havia informações no DAF sobre o laboratório que produziu o medicamento entregue por esta distribuidora. Não há na legislação pátria proibição da participação

${ }^{21}$ Segundo o inciso XVI do Artigo 4ํ da Lei o 5.991, de 17 de dezembro de 1973, Distribuidor de Medicamentos é conceituado como a 'empresa que exerça direta ou indiretamente o comércio atacadista de drogas, medicamentos em suas embalagens originais, insumos farmacêuticos e de correlatos. 
de distribuidoras em todas as modalidades de licitações e também não há obrigatoriedade de informarem qual o laboratório produtor.

Quadro 15 - Elenco de medicamentos do Programa Nacional de Nutrição e Alimentação e o laboratório produtor, no período de 2003 a 2013

\begin{tabular}{|l|l|l|}
\hline \multicolumn{1}{|c|}{ Medicamentos } & Unidade & Fornecedor \\
\hline Ácido Fólico. $5 \mathrm{mg}$ & Comp. & FIOCRUZ \\
Sulfato Ferroso $40 \mathrm{mg}$ & Comp. & FIOCRUZ \\
Sulfato Ferroso xarope & Fr & FIOCRUZ \\
Vitamina A 100.000 UI & Cáps. & FIOCRUZ \\
Vitamina A. 200.000 UI & Cáps. & FIOCRUZ \\
Tiamina (Cloridrato) $300 \mathrm{mg}$ (Vitamina B1) & Comp. & TEUTO \\
Tiamina (Cloridrato) $300 \mathrm{mg}$ (Vitamina B1) & Comp. & DIMEBEL \\
\hline
\end{tabular}

Fonte: Produção Própria.

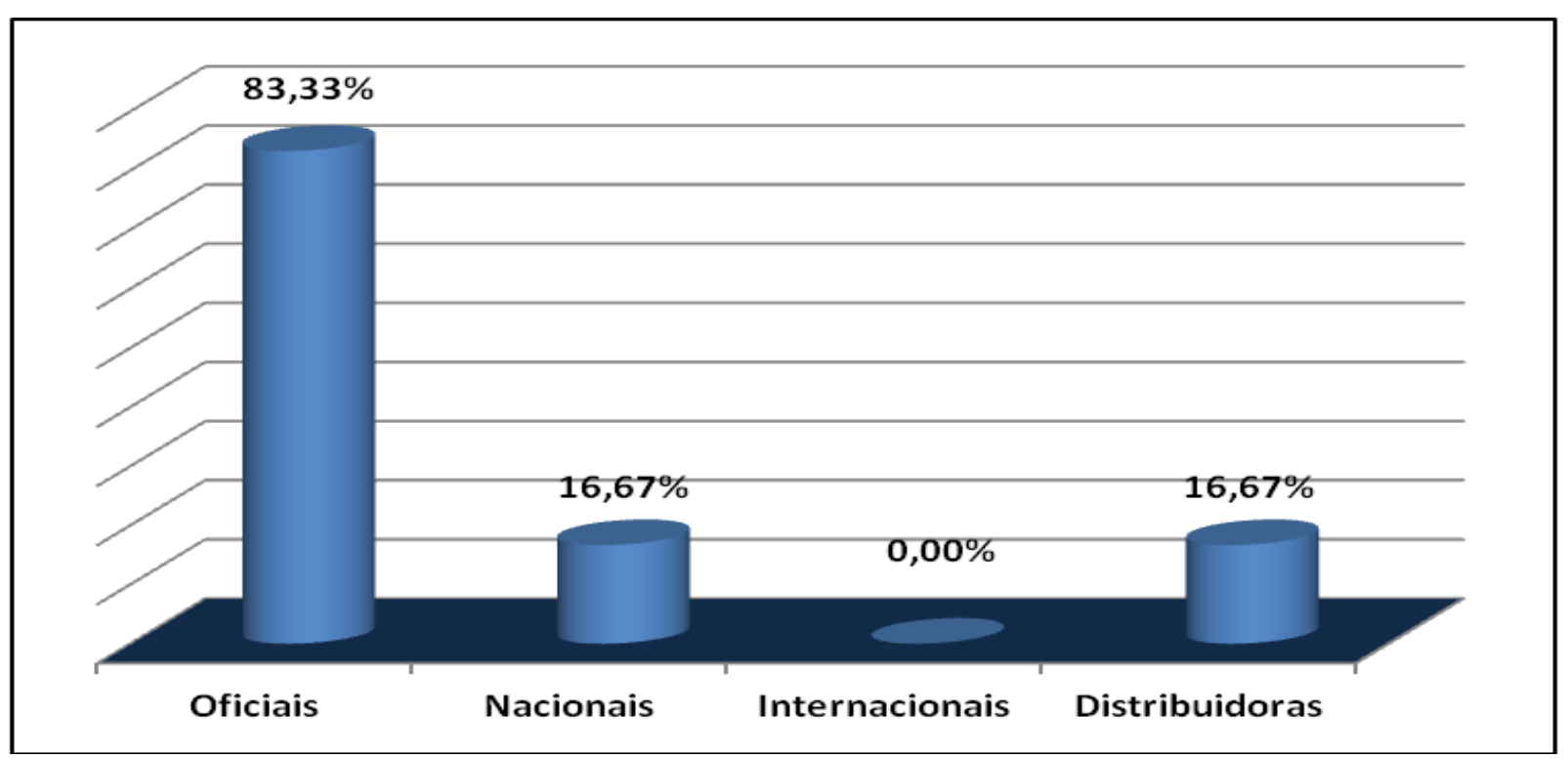

Figura 11 - Representação gráfica da participação percentual pelos laboratórios na produção do elenco de medicamentos produzidos para o Programa Nacional de Nutrição e Alimentação, no período de 2003 a 2013.

Fonte: Produção Própria.

O medicamento cloridrato tiamina $300 \mathrm{mg}$ (Vitamina B1), só foi disponibilizado no âmbito do SUS nos anos de 2006 e 2007. Antes e depois deste período não foi localizado qualquer registro de aquisição pelo Ministério da Saúde.

Nos Quadros 16 e 17 está consolidada toda a produção pública e a nacional para o Programa Nacional de Nutrição e Alimentação, bem como, o valor pago pelo Ministério da Saúde, em reais, no período pesquisado. 
Quadro 16 - Consolidação da produção da FIOCRUZ em número de Unidades Farmacêuticas (UF) e o valor pago pelo Ministério da Saúde para o Programa Nacional de Nutrição e Alimentação, no período de 2003 a 2013

\begin{tabular}{|l|c|c|c|c|} 
& & & \multicolumn{2}{|c|}{ Total } \\
\cline { 4 - 5 } \multicolumn{1}{|c|}{ Medicamentos } & Unidade & Fornecedor & $\begin{array}{c}\text { Quantidadde de } \\
\text { Unidades } \\
\text { Farmacêuticas } \\
\text { (Comprimidos, } \\
\text { Cápsulas e Frascos) } \\
\text { produzidas }\end{array}$ & $\begin{array}{c}\text { Valor pago pelo } \\
\text { Ministério da } \\
\text { Saúde (R\$) }\end{array}$ \\
\hline Ácido Fólico. $5 \mathrm{mg}$ & Comp. & FIOCRUZ & 821.147 .994 & $11.249 .727,52$ \\
Sulfato Ferroso $40 \mathrm{mg}$ & Comp. & FIOCRUZ & 1.164 .146 .300 & $31.431 .950,10$ \\
Sulfato Ferroso xarope & Fr & FIOCRUZ & 40.913 .929 & $74.247 .317,39$ \\
Vitamina A 100.000 UI & Cáps. & FIOCRUZ & 13.495 .200 & $2.155 .191,68$ \\
Vitamina A. $200.000 \mathrm{UI}$ & Cáps. & FIOCRUZ & 69.361 .950 & $15.310 .566,03$ \\
& & & $\mathbf{2 . 1 0 9 . 0 6 5 . 3 7 3}$ & $\mathbf{1 3 4 . 3 9 4 . 7 5 2 , 7 2}$ \\
\hline
\end{tabular}

Fonte: Produção Própria.

Quadro 17 - Consolidação da produção dos laboratórios nacionais em número de Unidades Farmacêuticas (UF) e o valor pago pelo Ministério da Saúde para o Programa Nacional de Nutrição e Alimentação, no período de 2003 a 2013

\begin{tabular}{|c|c|c|c|c|}
\hline \multirow[b]{2}{*}{ Medicamentos } & \multirow[b]{2}{*}{ Unidade } & \multirow[b]{2}{*}{ Fornecedor } & \multicolumn{2}{|c|}{ Total } \\
\hline & & & $\begin{array}{c}\text { Quantidadde de } \\
\text { Unidades } \\
\text { Farmacêuticas } \\
\text { (Comprimidos, } \\
\text { Cápsulas e } \\
\text { Frascos) } \\
\text { produzidas }\end{array}$ & $\begin{array}{l}\text { Valor pago pelo } \\
\text { Ministério da } \\
\text { Saúde (R\$) }\end{array}$ \\
\hline Tiamina (Cloridrato) 300 mg (Vitamina B1) & Comp. & TEUTO & 10.022 .680 & $1.599 .619,73$ \\
\hline Tiamina (Cloridrato) 300 mg (Vitamina B1) & Comp. & DIMEBEL & 350.000 & $44.450,00$ \\
\hline Total & & & 10.372 .680 & $1.644 .069,73$ \\
\hline
\end{tabular}

Fonte: Produção Própria.

No período de 2003 a 2013 o Ministério da Saúde adquiriu para o Programa Nacional de Nutrição e Alimentação a quantia de 2.119.438.053 de Unidades Farmacêuticas e para essa aquisição teve um gasto de $R \$ 136.038 .822,45$, no período de 2003 a 2013. 
Quadro 18 - Consolidação da produção do laboratório oficial e dos nacionais em Unidades Farmacêuticas (UF) e valor pago pelo Ministério da Saúde para o Programa Nacional de Nutrição e Alimentação, no período de 2003 a 2013

\begin{tabular}{|c|c|c|}
\hline Medicamentos & $\begin{array}{l}\text { Quantidadde de Unidades } \\
\text { Farmacêuticas (Comprimidos, } \\
\text { Cápsulas e Frascos) produzidas }\end{array}$ & $\begin{array}{l}\text { Valor pago pelo } \\
\text { Ministério da Saúde (R\$) }\end{array}$ \\
\hline Oficiais & 2.109 .065 .373 & $134.394 .752,72$ \\
\hline Nacionais & 10.372 .680 & $1.644 .069,73$ \\
\hline Total & 2.119.438.053 & $136.038 .822,45$ \\
\hline
\end{tabular}

Fonte: Produção Própria.

Para o Programa Nacional de Nutrição e Alimentação a FIOCRUZ foi responsável por 99,51\% da produção de medicamentos em unidades farmacêuticas, para o Programa e ficou com $98,78 \%$ dos recursos. A indústria nacional participou com $0,49 \%$ da produção e recebeu $1,22 \%$ da verba destinada ao programa

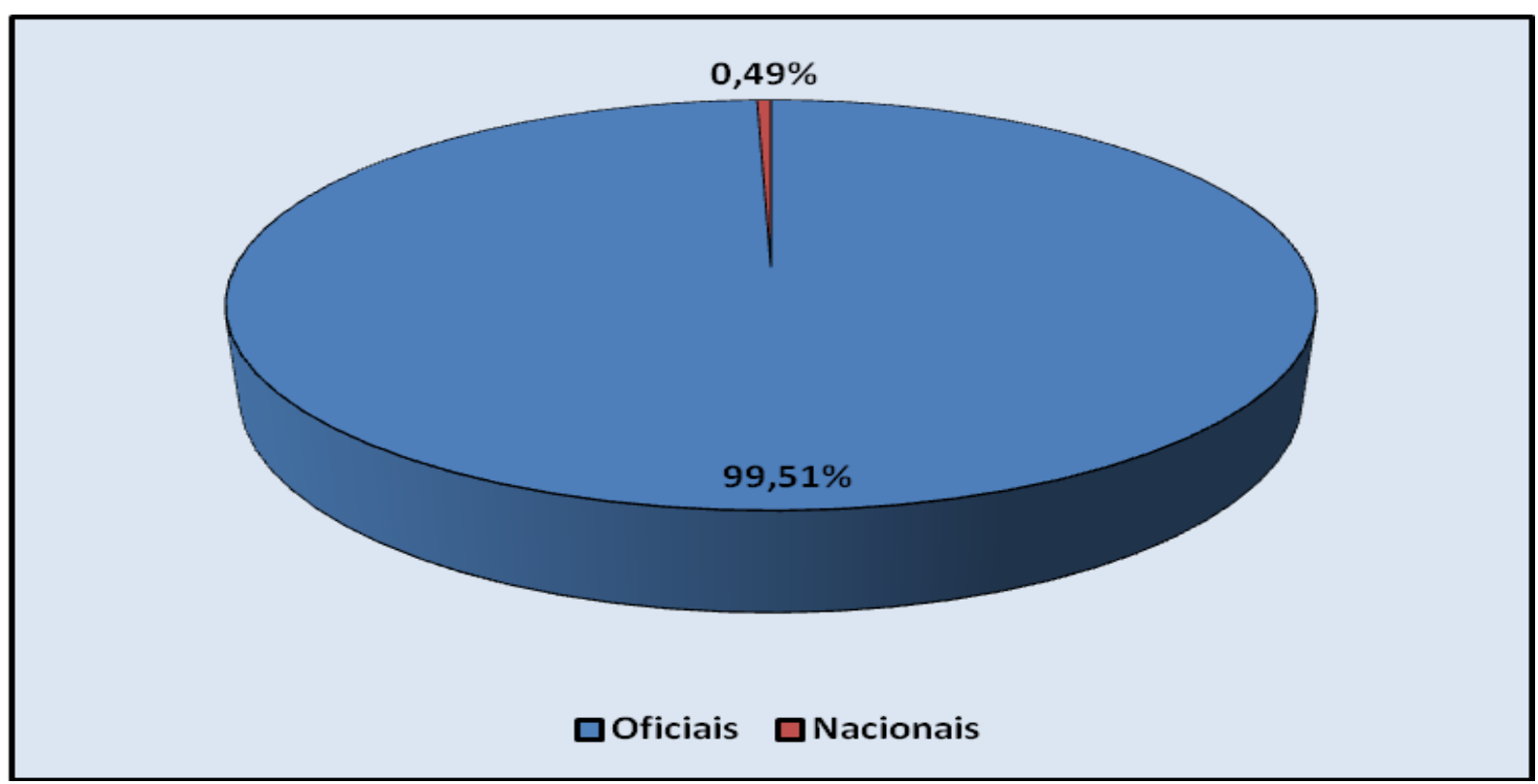

Figura 12 - Participação percentual da quantidade produzida pela FIOCRUZ e laboratórios nacionais em número de Unidades Farmacêuticas (UF) para o Ministério da Saúde para o Programa Nacional de Nutrição e Alimentação, no período de 2003 a 2013.

Fonte: Elaboração Própria. 


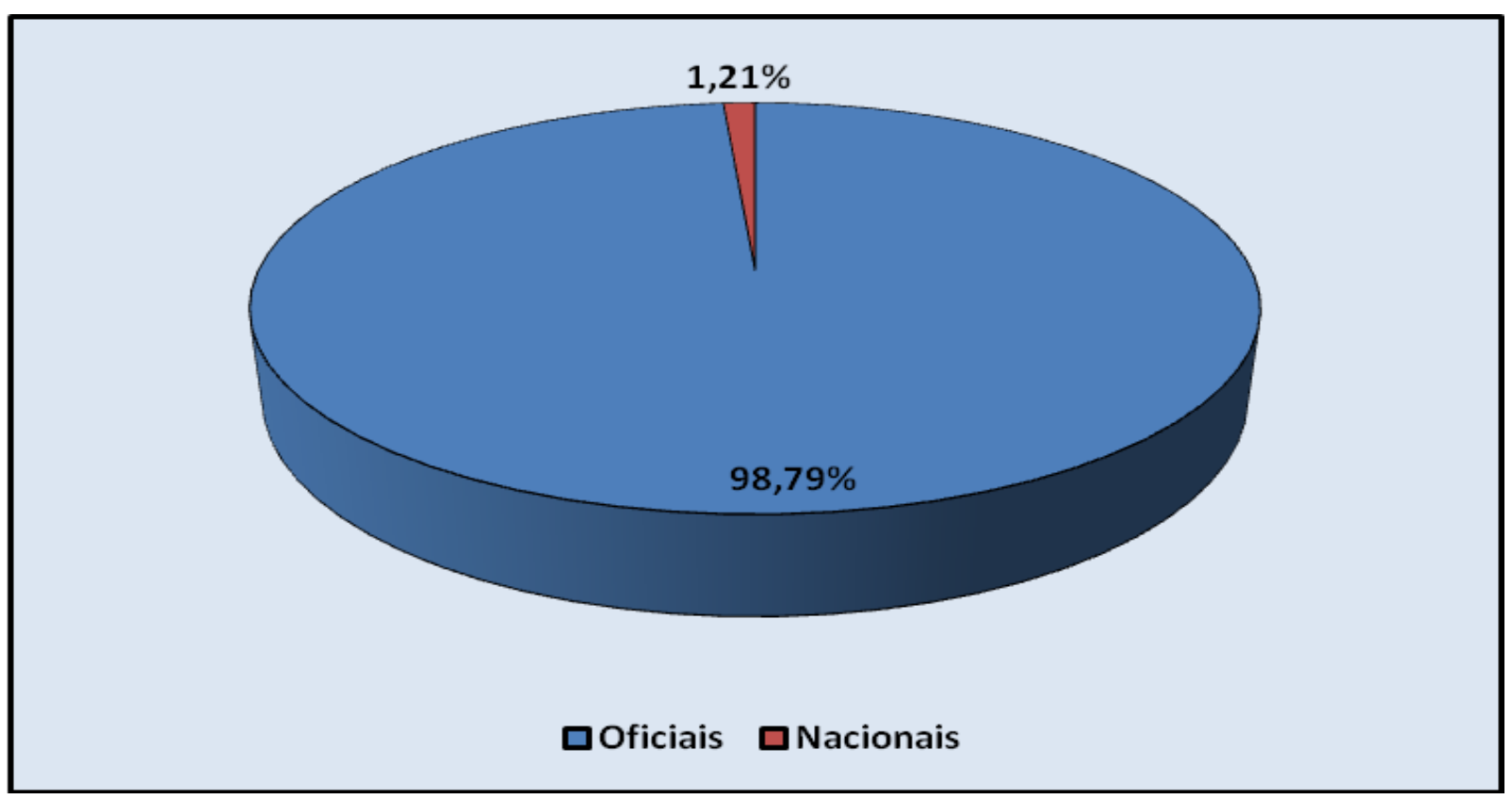

Figura 13 - Participação percentual do gasto com a FIOCRUZ e os laboratórios nacionais pelo Ministério da Saúde com o Programa Nacional de Nutrição e Alimentação, no período de 2003 a 2013.

Fonte: Elaboração Própria.

\subsection{PROGRAMA NACIONAL DO CONTROLE DA TUBERCULOSE}

Este programa tem como objetivo, não só o tratamento medicamentoso, mas o desenvolvimento de ações educativas em saúde, comunicação e mobilização social, nas esferas nacional, estaduais e municipais, enfocando a promoção, prevenção, assistência e reabilitação da saúde. Tem também como objetivo consolidar as ações do programa na Atenção Básica, incluindo a Estratégia do Saúde da Família (ESF) e Programa de Agentes Comunitários de Saúde (PACS).

A pesquisa exploratória identificou 13 medicamentos que compõe o elenco de medicamentos do Programa Nacional do Controle da Tuberculose, no período de 2003 a 2013, que foram adquiridos pelo Ministério da Saúde por meio do Componente Estratégico da Assistência Farmacêutica.

Os LFO foram responsáveis pela produção de 11 medicamentos do elenco do Programa Nacional de Controle da Tuberculose, no período de 2003 a 2013. Os laboratórios internacionais foram responsáveis por 3 medicamentos do elenco. Os laboratórios nacionais não produziram nenhum medicamento para o programa. 
A produção de 11 medicamentos para o combate a tuberculose pelos LFO representa uma participação percentual de $84,62 \%$ do elenco enquanto os laboratórios internacionais produziram $23,08 \%$.

Quadro 19 - Elenco de medicamentos produzidos pelos laboratórios pra o Programa nacional de Controle da Tuberculose, período de 2003 a 2013

\begin{tabular}{|c|c|c|c|}
\hline Medicamentos & Oficiais & Nacionais & Internacionais \\
\hline Estreptomicina $1 \mathrm{~g}$ solução injetável frasco ampola & $\mathrm{x}$ & & \\
\hline Etambutol $400 \mathrm{mg}$ comprimido & $\mathrm{x}$ & & \\
\hline Etionamida $250 \mathrm{mg}$ comprimido & $x$ & & \\
\hline Isoniazida $100 \mathrm{mg}$ comprimido & $x$ & & \\
\hline Isoniazida 100 mg + Rifampicina 150 mg cápsula & $\mathrm{x}$ & & \\
\hline Isoniazida 200 mg + Rifampicina 300 mg cápsula & $x$ & & \\
\hline Isoniazida 75 mg + Rifampicina 150 mg comprimido & $\mathrm{x}$ & & $\mathrm{x}$ \\
\hline Pirazinamida $3 \%$ solução oral frasco & $\mathrm{x}$ & & \\
\hline Pirazinamida 500 mg comprimido & $x$ & & \\
\hline $\begin{array}{l}\text { Rifampicina } 150 \mathrm{mg} \text { + Isoniazida } 75 \mathrm{mg}+\text { Pirazinamida } 400 \mathrm{mg} \text { + Etambutol } 275 \\
\text { mg comprimido }\end{array}$ & & & $x$ \\
\hline Rifampicina $2 \%$ frasco & $\mathrm{x}$ & & \\
\hline Rifampicina 300 mg cápsula & $x$ & & \\
\hline Tuberculina-PPD-Rt-23 frasco & & & $\mathrm{x}$ \\
\hline Total & 11 & & 3 \\
\hline
\end{tabular}

Fonte: Produção Própria.

No conjunto, os LFO produziram 11 medicamentos do elenco o que representa uma participação percentual de $84,62 \%$ e os internacionais de $23,08 \%$. 


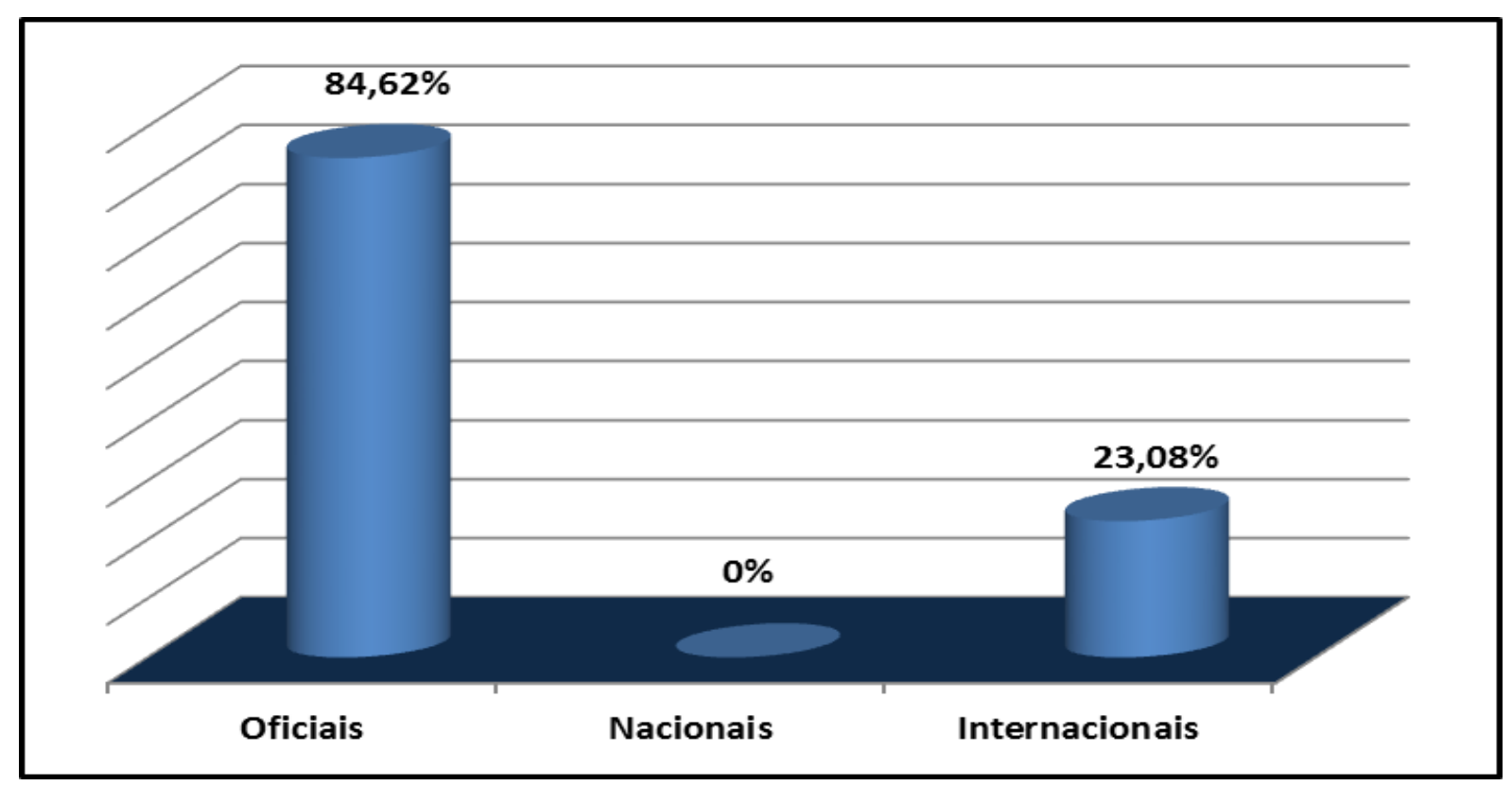

Figura 14 - Representação gráfica da participação percentual pelos laboratórios na produção do elenco de medicamentos produzidos para o programa Nacional de Controle da Tuberculose, período de 2003 a 2013.

Fonte: Produção Própria.

Dos 29 laboratórios farmacêuticos oficiais apenas 8 laboratórios (FIOCRUZ, FURP, IQUEGO, LAFEPE, LFM, LQFAE, LQFEX e NUPLAM) participaram da produção pública para o Programa, ou seja, 27,59\% dos LFO. A FURP foi o laboratório oficial que mais participou da produção pública com 8 medicamentos 0 que representa $72,73 \%$ dos medicamentos do elenco, seguido do LAFEPE com 6 medicamentos $(54,56 \%)$. Os laboratórios oficiais LQFEX, IQUEEGO e FIOCRUZ produziram 5 medicamentos $(45,45 \%)$ cada um. O laboratório LQFAER produziu 4 medicamentos $(36,36 \%)$ do elenco.Os laboratórios LFM e NUPLAN produziram 3 ( $27,27 \%$ ) dos medicamentos do elenco 


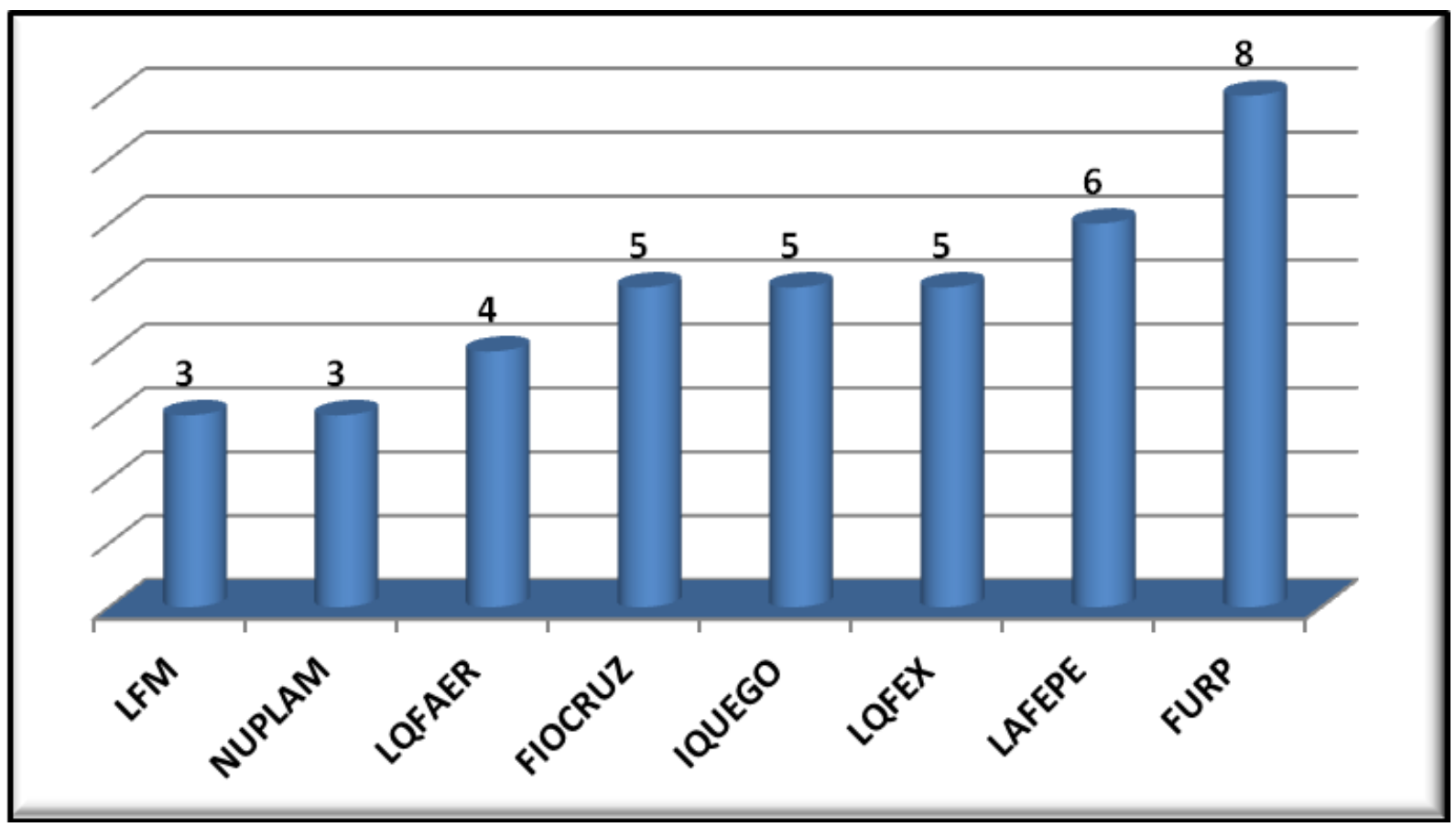

Figura 15 - Representação gráfica da quantidade de medicamentos produzidos pelos laboratórios oficiais para o Programa Nacional de Combate a Tuberculose, no período de 2003 a 2013.

Fonte: Produção Própria.

Nos Quadros 20 e 21 está consolidada a quantidade de unidades farmacêuticas produzidas e o total do valor pago pelo Ministério da Saúde em reais, para cada tipo de laboratório, no período de 2003 a 2013. 


\section{continua}

Quadro 20 - Consolidação da produção dos laboratórios oficiais em número de unidades Farmacêuticas (UF) e valor pago pelo Ministério da Saúde para o Programa Nacional de Controle da Tuberculose, no período de 2003 a 2013

\begin{tabular}{|c|c|c|c|}
\hline Medicamentos & Unidade & $\begin{array}{c}\text { Quantidade de } \\
\text { Unidades } \\
\text { Farmacêuticas } \\
\text { (comprimidos, } \\
\text { cápsulas e frascos) } \\
\text { produzidas }\end{array}$ & $\begin{array}{l}\text { Valor pago pelo } \\
\text { Ministério da Saúde } \\
\text { (R\$) }\end{array}$ \\
\hline \multicolumn{4}{|c|}{ FIOCRUZ } \\
\hline Etambutol $400 \mathrm{mg}$ & Comp. & 26.919 .000 & $2.709 .958,20$ \\
\hline Etionamida $250 \mathrm{mg}$ & Comp. & 5.678 .500 & $1.674 .021,80$ \\
\hline Isoniazida $100 \mathrm{mg}$ + Rifampicina $150 \mathrm{mg}$ & Cáps. & 6.771 .500 & $671.732,80$ \\
\hline Isoniazida $200 \mathrm{mg}$ + Rifampicina $300 \mathrm{mg}$ & Cáps. & 26.431 .500 & 4.371.770,10 \\
\hline Pirazinamida $500 \mathrm{mg}$ & Comp. & 3.000 .000 & $363.900,00$ \\
\hline Subtotal & & 68.800 .500 & $9.791 .382,90$ \\
\hline \multicolumn{4}{|c|}{ FURP } \\
\hline Estreptomicina $1 \mathrm{~g}$ solução injetável & $\mathrm{F} / \mathrm{A}$ & 9.739 .700 & $3.322 .085,84$ \\
\hline Etambutol $400 \mathrm{mg}$ & Comp. & 27.932 .000 & $2.816 .676,00$ \\
\hline Isoniazida $100 \mathrm{mg}$ & Comp. & 1.281 .500 & $20.023,40$ \\
\hline Isoniazida $100 \mathrm{mg}$ + Rifampicina $150 \mathrm{mg}$ & Cáps. & 5.000 .000 & $496.000,00$ \\
\hline Isoniazida $200 \mathrm{mg}$ + Rifampicina $300 \mathrm{mg}$ & Cáps. & 10.000 .000 & $1.654 .000,00$ \\
\hline Pirazinamida $500 \mathrm{mg}$ & Comp. & 21.355 .500 & $2.590 .422,15$ \\
\hline Rifampicina $2 \%$ & Fr. & 1.557 .100 & $1.286 .665,82$ \\
\hline Rifampicina $300 \mathrm{mg}$ & Cáps. & 480.000 & $67.920,00$ \\
\hline Subtotal & & 77.345 .800 & $12.253 .793,20$ \\
\hline \multicolumn{4}{|c|}{ IQUEGO } \\
\hline Etambutol $400 \mathrm{mg}$ & Comp. & 20.182 .500 & $2.248 .040,40$ \\
\hline Etionamida $250 \mathrm{mg}$ & Comp. & 1.768 .000 & $521.206,40$ \\
\hline Isoniazida $100 \mathrm{mg}$ + Rifampicina $150 \mathrm{mg}$ & Cáps. & 8.202 .000 & $273.208,90$ \\
\hline Isoniazida 200 mg + Rifampicina 300 mg & Cáps. & 21.780 .000 & $765.162,00$ \\
\hline Pirazinamida $500 \mathrm{mg}$ & Comp. & 19.093 .000 & $2.315 .980,90$ \\
\hline Subtotal & & 71.025 .500 & $6.123 .598,60$ \\
\hline
\end{tabular}


continuação

Quadro 20 - Consolidação da produção dos laboratórios oficiais em número de unidades Farmacêuticas (UF) e valor pago pelo Ministério da Saúde para o Programa Nacional de Controle da Tuberculose, no período de 2003 a 2013

\begin{tabular}{|c|c|c|c|}
\hline Medicamentos & Unidade & $\begin{array}{c}\text { Quantidade de } \\
\text { Unidades } \\
\text { Farmacêuticas } \\
\text { (comprimidos, } \\
\text { cápsulas e frascos) } \\
\text { produzidas }\end{array}$ & $\begin{array}{l}\text { Valor pago pelo } \\
\text { Ministério da Saúde } \\
\text { (R\$) }\end{array}$ \\
\hline \multicolumn{4}{|c|}{ LAFEPE } \\
\hline Isoniazida 100 mg & Comp. & 24.552 .000 & $398.975,30$ \\
\hline Isoniazida 100 mg + Rifampicina 150 mg & Cáps. & 7.436 .500 & $737.700,80$ \\
\hline Isoniazida 200 mg + Rifampicina 300 mg & Cáps. & 58.911 .500 & $9.743 .962,10$ \\
\hline Pirazinamida $3 \%$ solução oral & Fr. & 30.250 & $56.156,10$ \\
\hline Pirazinamida 500 mg & Comp. & 18.355 .500 & $2.226 .522,15$ \\
\hline Rifampicina $300 \mathrm{mg}$ & Cáps. & 2.958 .500 & $418.627,75$ \\
\hline Subtotal & & 112.244 .250 & $13.581 .944,20$ \\
\hline \multicolumn{4}{|c|}{ LFM } \\
\hline Isoniazida $100 \mathrm{mg}$ & Comp. & 57.859 .000 & $1.389 .244,40$ \\
\hline Pirazinamida $3 \%$ solução oral & Fr. & 420.800 & $807.887,08$ \\
\hline Pirazinamida $500 \mathrm{mg}$ & Comp. & 51.633 .700 & $6.607 .835,40$ \\
\hline Subtotal & & 109.913 .500 & $8.804 .966,88$ \\
\hline \multicolumn{4}{|c|}{ LQFAE } \\
\hline Isoniazida 100 mg & Comp. & 23.418 .000 & $583.555,20$ \\
\hline Pirazinamida $500 \mathrm{mg}$ & Comp. & 11.671 .500 & $1.415 .752,95$ \\
\hline Isoniazida $100 \mathrm{mg}$ & Comp. & 25.655 .500 & $490.804,00$ \\
\hline Pirazinamida $500 \mathrm{mg}$ & Comp. & 18.444 .500 & $2.237 .317,85$ \\
\hline Subtotal & & 79.189 .500 & 4.727.430,00 \\
\hline \multicolumn{4}{|c|}{ LQFEX } \\
\hline Etionamida $250 \mathrm{mg}$ & Comp. & 3.045 .500 & $879.970,40$ \\
\hline Isoniazida 100 mg + Rifampicina 150 mg & Cáps. & 19.240 .000 & $1.908 .608,00$ \\
\hline Isoniazida 200 mg + Rifampicina 300 mg & Cáps. & 68.351 .190 & $11.305 .286,83$ \\
\hline Pirazinamida 500 mg & Comp. & 24.601 .500 & $2.984 .161,95$ \\
\hline Rifampicina $300 \mathrm{mg}$ & Cáps. & 5.999 .000 & $848.858,50$ \\
\hline Subtotal & & 121.237.190 & $17.926 .885,68$ \\
\hline
\end{tabular}


conclusão

Quadro 20 - Consolidação da produção dos laboratórios oficiais em número de unidades Farmacêuticas (UF) e valor pago pelo Ministério da Saúde para o Programa Nacional de Controle da Tuberculose, no período de 2003 a 2013

\begin{tabular}{|c|c|c|c|}
\hline \multicolumn{1}{|c|}{ Medicamentos } & Unidade & $\begin{array}{c}\text { Quantidade de } \\
\text { Unidades } \\
\text { Farmacêuticas } \\
\text { (comprimidos, } \\
\text { cápsulas e frascos) } \\
\text { produzidas }\end{array}$ & $\begin{array}{c}\text { Valor pago pelo } \\
\text { Ministério da Saúde } \\
\text { (R\$) }\end{array}$ \\
\hline Isoniazida $100 \mathrm{mg}+$ Rifampicina $150 \mathrm{mg}$ & NUPLAM & 4.264 .000 & $422.988,80$ \\
Isoniazida $200 \mathrm{mg}+$ Rifampicina $300 \mathrm{mg}$ & Cáps. & 32.064 .000 & $5.137 .885,60$ \\
Pirazinamida $500 \mathrm{mg}$ & Cáps. & 1.128 .000 & $136.826,40$ \\
Subtotal & Comp. & $\mathbf{3 7 . 4 5 6 . 0 0 0}$ & $\mathbf{5 . 6 9 7 . 7 0 0 , 8 0}$ \\
\hline
\end{tabular}

Fonte: Produção Própria.

Quadro 21 - Consolidação da produção dos laboratórios internacionais em número de unidades Farmacêuticas (UF) e valor pago pelo Ministério da Saúde para o Programa Nacional de Controle da Tuberculose, no período de 2003 a 2013

\begin{tabular}{|c|c|c|c|c|}
\hline Medicamentos & Unid. & Fornecedor & $\begin{array}{l}\text { Quantidade de } \\
\text { Unidades } \\
\text { Farmacêuticas } \\
\text { (comprimidos, } \\
\text { cápsulas e } \\
\text { frascos) } \\
\text { produzidas }\end{array}$ & $\begin{array}{l}\text { Valor pago pelo } \\
\text { Ministério da } \\
\text { Saúde (R\$) }\end{array}$ \\
\hline Tuberculina-PPD-Rt-23 & Fr. & FLOMED & 72.738 & $1.963 .926,00$ \\
\hline Isoniazida $75 \mathrm{mg}$ + Rifampicina $150 \mathrm{mg}$ & Comp. & OPAS & 80.640 .000 & $4.079 .144,00$ \\
\hline $\begin{array}{l}\text { Rifampicina } 150 \mathrm{mg}+\text { Isoniazida } 75 \mathrm{mg}+ \\
\text { Pirazinamida } 400 \mathrm{mg}+\text { Etambutol } 275 \mathrm{mg}\end{array}$ & Comp. & OPAS & 189.820 .000 & $22.301 .076,53$ \\
\hline Total & & & 270.532 .738 & 28.344.147 \\
\hline
\end{tabular}

Fonte: Produção Própria.

No período pesquisado, o Ministério da Saúde adquiriu 947.744.978 unidades farmacêuticas para o combate à tuberculose e gastou $R \$ 107.251 .849,79$. Verificase que os laboratórios oficiais foram os que mais produziram unidades farmacêuticas para o programa, o que representa $71,46 \%$ da produção e os laboratórios internacionais produziram $28,54 \%$. 
Quadro 22 - Consolidação da produção dos laboratórios oficiais e internacionais em número de Unidades Farmacêuticas (UF) e Valor Pago pelo Ministério da Saúde para o Programa de Controle da Tuberculose, no período de 2003 a 2013

\begin{tabular}{|c|c|c|}
\hline Laboratórios & $\begin{array}{c}\text { Quantidade de Unidades } \\
\text { Farmacêuticas (comprimidos, } \\
\text { cápsulas e frascos) } \\
\text { produzidas }\end{array}$ & $\begin{array}{l}\text { Valor pago pelo Ministério da Saúde } \\
(\mathrm{R} \$)\end{array}$ \\
\hline Oficiais & 677.212 .240 & 78.907.702,26 \\
\hline Internacionais & 270.532 .738 & $28.344 .146,53$ \\
\hline Total & 947.744 .978 & $107.251 .848,79$ \\
\hline
\end{tabular}

Fonte: Produção Própria.

O laboratório militar do Exército (LQFEX) foi o laboratório oficial que mais produziu unidades farmacêuticas para o Ministério da Saúde para o controle da tuberculose; este produziu 121.237.190 UF, que corresponde a $17,90 \%$ do total. Depois foi o LAFEPE (16,57\%) e o LFM (16,23\%) que mais produziram. Em seguida encontramos os laboratórios LQFA e a FURP, com $11,69 \%$ e $11,42 \%$ da produção total do programa, respectivamente. O IQUEGO participou com 10,49\%, a FIOCRUZ com $10,16 \%$ e o NUPLAN com apenas $5,53 \%$.

Os laboratórios oficiais foram responsáveis pela produção de $71,46 \%$ das unidades farmacêuticas para o programa. Com este quantitativo o Ministério da Saúde gastou $73,57 \%$ da verba orçamentária destinada ao controle da tuberculose.

Os internacionais produziram $28,54 \%$ das unidades farmacêuticas e receberam $26,43 \%$ da verba orçamentária do programa. 


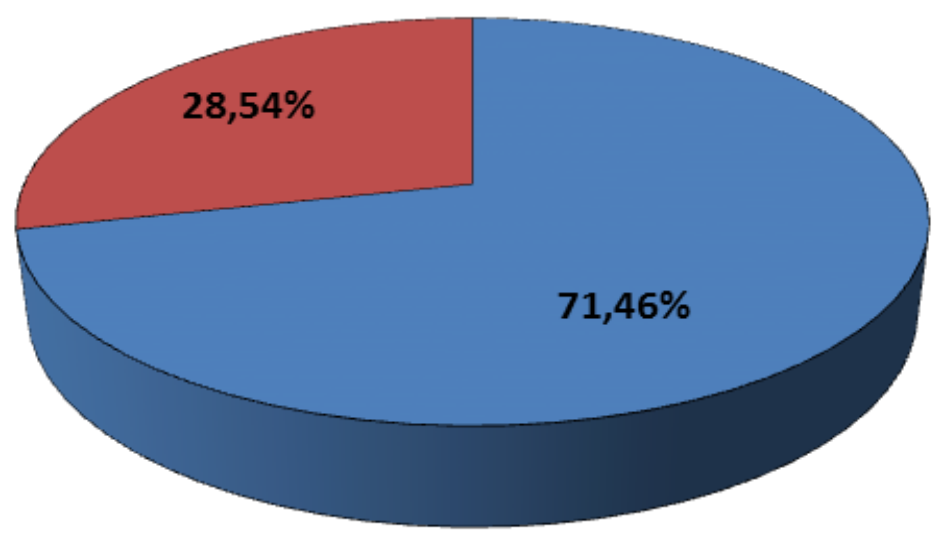

口Oficiais $\square$ Internacionais

Figura 16 - Participação percentual da quantidade produzida pelos laboratórios oficiais e internacionais em número de Unidades Farmacêuticas (UF) para o Ministério da Saúde para o Programa Nacional de Controle da Tuberculose, no período de 2003 a 2013.

Fonte: Produção Própria.

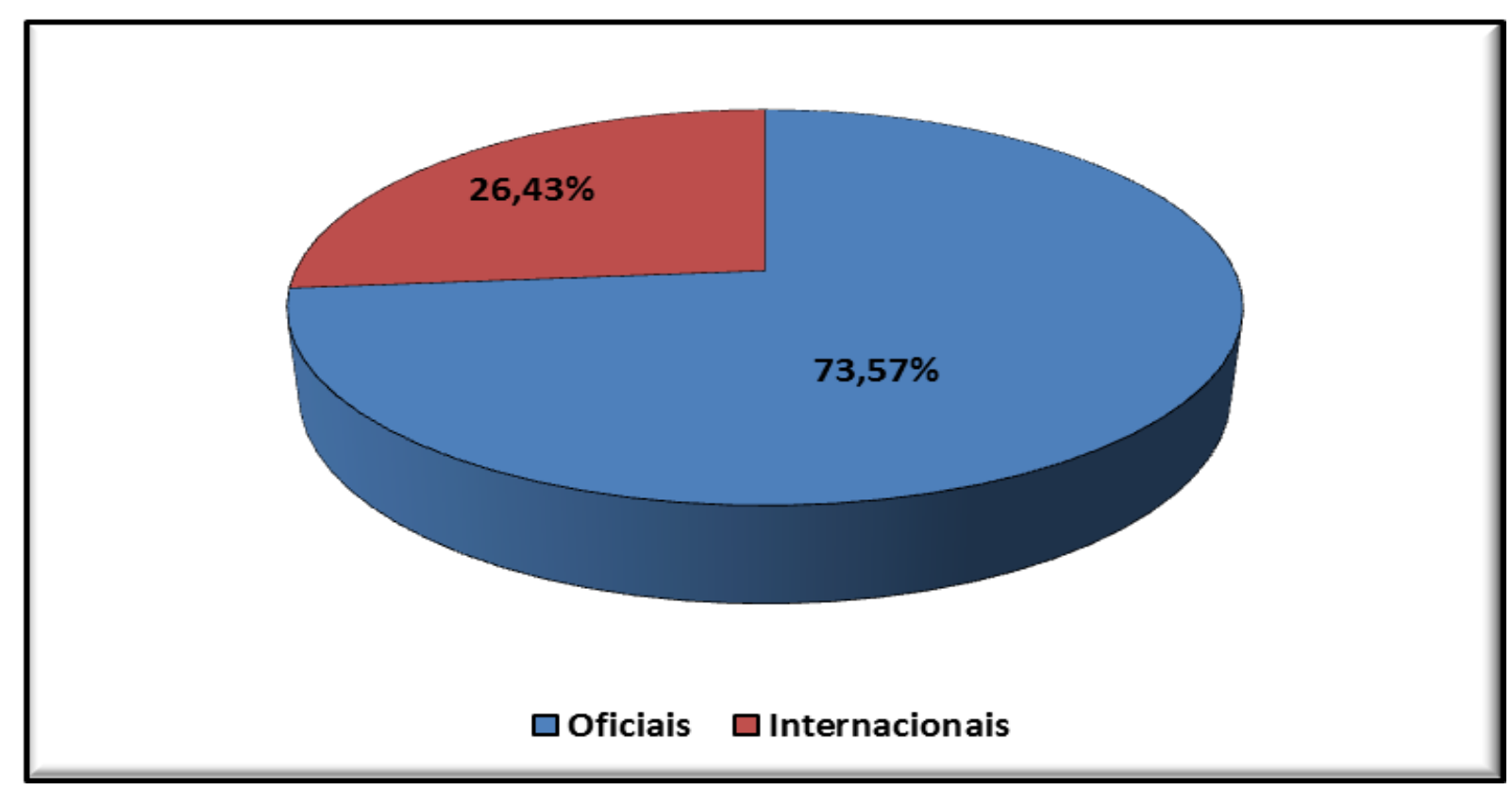

Figura 17 - Participação percentual do gasto com os laboratórios oficiais e internacionais pelo Ministério da Saúde com o Programa Nacional de Controle da Tuberculose, no período de 2003 a 2013

Fonte: Produção Própria. 
Quadro 23 Consolidação da produção por laboratório oficial, o valor pago pelo Ministério da Saúde, com a participação percentual, com o Programa Nacional de Controle da Tuberculose no período de 2003 a 2013

\begin{tabular}{|c|c|c|c|c|}
\hline Laboratório Oficial & $\begin{array}{l}\text { Quantidade de } \\
\text { Unidades } \\
\text { Farmacêuticas } \\
\text { (comprimidos, } \\
\text { cápsulas e } \\
\text { frascos) } \\
\text { produzidas }\end{array}$ & $\begin{array}{c}\text { Participação } \\
\text { percentual (\%) na } \\
\text { produção pública }\end{array}$ & $\begin{array}{c}\text { Valor pago pelo } \\
\text { Ministério da Saúde } \\
\text { (R\$) }\end{array}$ & $\begin{array}{l}\text { Participação percentua } \\
\text { (\%) no gasto do } \\
\text { Ministério da Saúde }\end{array}$ \\
\hline LQFEX & 121.237 .190 & 17,90 & $17.926 .885,68$ & 22,72 \\
\hline LAFEPE & 112.244 .250 & 16,57 & $13.581 .944,20$ & 17,21 \\
\hline LFM & 109.913 .500 & 16,23 & $8.804 .966,88$ & 11,16 \\
\hline LQFAER & 79.189 .500 & 11,69 & $4.727 .430,00$ & 5,99 \\
\hline FURP & 77.345 .800 & 11,42 & $12.253 .793,20$ & 15,53 \\
\hline IQUEGO & 71.025 .500 & 10,49 & $6.123 .598,60$ & 7,76 \\
\hline FIOCRUZ & 68.800 .500 & 10,16 & $9.791 .382,90$ & 12,41 \\
\hline NUPLAM & 37.456 .000 & 5,53 & $5.697 .700,80$ & 7,22 \\
\hline Total & 677.212 .240 & 100,00 & 78.907 .702 & 100,00 \\
\hline
\end{tabular}

Fonte: Produção Própria 
Quadro 24 - Quantidade de Unidades Farmacêuticas e participação percentual da quantidade produzida pelos laboratórios oficiais para o Ministério da Saúde para o Programa Nacional de Controle da Tuberculose, no período de 2003 a 2013

\begin{tabular}{|c|c|c|c|c|c|c|c|c|c|c|c|c|c|c|c|c|c|}
\hline \multirow{2}{*}{$\begin{array}{c}\text { Laboratório } \\
\text { Ano }\end{array}$} & \multicolumn{2}{|c|}{ FIOCRUZ } & \multicolumn{2}{|c|}{ FURP } & \multicolumn{2}{|c|}{ IQUEGO } & \multicolumn{2}{|c|}{ LAFEPE } & \multicolumn{2}{|c|}{ LFM } & \multicolumn{2}{|c|}{ LQFAER } & \multicolumn{2}{|c|}{ LQFEX } & \multicolumn{2}{|c|}{ NUPLAM } & \multirow{2}{*}{$\begin{array}{c}\text { Total } \\
2003 \text { a } 2013\end{array}$} \\
\hline & $\begin{array}{c}\text { UF } \\
\text { Produzida }\end{array}$ & $\%$ & $\begin{array}{c}\text { UF } \\
\text { Produzida }\end{array}$ & $\%$ & $\begin{array}{c}\text { UF } \\
\text { Produzida }\end{array}$ & $\%$ & $\begin{array}{c}\text { UF } \\
\text { Produzida }\end{array}$ & $\%$ & $\begin{array}{c}\text { UF } \\
\text { Produzida }\end{array}$ & $\%$ & \begin{tabular}{|c|} 
UF \\
Produzida
\end{tabular} & $\%$ & $\begin{array}{c}\text { UF } \\
\text { Produzida }\end{array}$ & $\%$ & $\begin{array}{c}\text { UF } \\
\text { Produzida }\end{array}$ & $\%$ & \\
\hline 2003 & 17.377 .000 & 25,26 & 7.853 .700 & 10,15 & 12.598 .000 & 17,74 & 18.713 .500 & 16,67 & 7.275 .100 & 6,62 & 7.817 .500 & 9,87 & 14.817 .690 & 12,22 & 1.267 .500 & 3,38 & 87.719 .990 \\
\hline 2004 & 23.013 .500 & 33,45 & 7.148 .200 & 9,24 & 13.558 .500 & 19,09 & 17.168 .750 & 15,30 & 4.537 .700 & 4,13 & 9.085 .000 & 11,47 & 16.497 .000 & 13,61 & $\cdots$ & $\cdots$ & 91.008 .650 \\
\hline 2005 & 4.733 .000 & 6,88 & 5.291 .800 & 6,84 & 25.300 .000 & 35,62 & 27.753 .000 & 24,73 & 5.848 .100 & 5,32 & 5.225 .500 & 6,60 & 29.113 .500 & 24,01 & $\cdots$ & $\cdots$ & 103.264 .900 \\
\hline 2006 & 2.498 .500 & 3,63 & 7.384 .000 & 9,55 & 6.924 .500 & 9,75 & 31.917 .500 & 28,44 & 8.640 .850 & 7,86 & 8.572 .000 & 10,82 & 28.871 .500 & 23,81 & $\ldots$ & $\cdots$ & 94.808 .850 \\
\hline 2007 & 6.140 .500 & 8,93 & 5.247 .550 & 6,78 & 5.040 .000 & 7,10 & 13.637 .500 & 12,15 & 3.129 .950 & 2,85 & 5.900 .000 & 7,45 & 13.897 .500 & 11,46 & 10.817 .500 & 28,88 & 63.810 .500 \\
\hline 2008 & 6.367 .000 & 9,25 & 449.300 & 0,58 & 4.540 .000 & 6,39 & $\ldots$ & 0,00 & 14.148 .700 & 12,87 & 14.089 .500 & 17,79 & $\ldots$ & 0,00 & 10.371 .000 & 27,69 & 49.965 .500 \\
\hline 2009 & 1.141 .000 & 1,66 & 3.343 .550 & 4,32 & 3.064 .500 & 4,31 & 3.054 .000 & 2,72 & 19.563 .900 & 17,80 & $\ldots$ & $\ldots$ & 1.000 .000 & 0,82 & $\ldots$ & $\ldots$ & 31.166 .950 \\
\hline 2010 & 6.830 .000 & 9,93 & 15.868 .500 & 20,52 & $\ldots$ & $\cdots$ & $\ldots$ & $\cdots$ & 8.181 .700 & 7,44 & 7.500 .000 & 9,47 & 15.000 .000 & 12,37 & 15.000 .000 & 40,05 & 68.380 .200 \\
\hline 2011 & $\ldots$ & $\ldots$ & $\ldots$ & 0,00 & $\ldots$ & $\ldots$ & $\ldots$ & $\ldots$ & 6.000 .000 & 5,46 & 6.000 .000 & 7,58 & 1.440 .000 & 1,19 & $\ldots$ & $\ldots$ & 13.440 .000 \\
\hline 2012 & 700.000 & 1,02 & 14.120 .000 & 18,26 & $\ldots$ & $\ldots$ & $\ldots$ & $\ldots$ & 7.500 .000 & 6,82 & $\ldots$ & $\ldots$ & $\ldots$ & $\ldots$ & $\ldots$ & $\ldots$ & 22.320 .000 \\
\hline 2013 & $\ldots$ & $\ldots$ & 10.639 .200 & 13,76 & $\ldots$ & $\ldots$ & $\ldots$ & $\ldots$ & 25.087 .500 & 22,82 & 15.000 .000 & 18,94 & 600.000 & 0,49 & $\ldots$ & $\ldots$ & 51.326 .700 \\
\hline $\begin{array}{c}\text { Total } \\
2003 \text { a } 2013\end{array}$ & 68.800 .500 & 100 & 77.345 .800 & 100 & 71.025 .500 & 100 & 112.244 .250 & 100 & 109.913 .500 & 100 & 79.189 .500 & 100 & 121.237 .190 & 100 & 37.456 .000 & 100 & 677.212 .240 \\
\hline
\end{tabular}

Fonte: Produção Própria. 


\subsection{ENDEMIAS FOCAIS}

As endemias focais compreendem algumas doenças que necessitam de ações estratégicas para que haja um controle e um tratamento adequado a cada uma delas. O Ministério da Saúde disponibiliza medicamentos aos seguintes programas e tratamentos:

- Programa de Prevenção de Cólera e Outras Doenças Diarreicas Agudas;

- Programa Nacional de Controle da Dengue;

- Programa de Vigilância e Controle da Doença de Chagas;

- Programa Nacional para Eliminação da Filariose Linfática;

- Influenza;

- Política de Controle das Leishmanioses;

- Política de Nacional de Controle da Malária;

- Programa de Controle da Meningite;

- Programa de Vigilância e Controle das Micoses Sistêmicas;

- Programa de Controle da Peste;

- Tratamento da Raiva Humana;

- Tratamento do Tracoma;

- Controle e tratamento da esquistossomose;

- Tratamento da Febre Maculosa e;

- Tratamento de Parasitoses.

A pesquisa exploratória relacionou 65 medicamentos que foram adquiridos no período de 2003 a 2013 para distribuição no âmbito do SUS para tratamento das endemias focais.

Os laboratórios oficiais produziram 30 medicamentos do elenco de 65 . Os laboratórios nacionais foram responsáveis pela produção de 34 medicamentos e os internacionais produziram 13 medicamentos. 


\section{continua}

Quadro 25 - Elenco de medicamentos produzidos pelos laboratórios para tratamento das endemias focais, no período de 2003 a 2013

\begin{tabular}{|c|c|c|c|c|}
\hline Medicamentos & Unidade & Oficiais & Nacionais & Internacionais \\
\hline \multicolumn{5}{|c|}{ Anti-Málaricos } \\
\hline Artemeter 80 mg injetável & $\mathrm{F} / \mathrm{A}$ & & & $\mathrm{x}$ \\
\hline Artemeter $20 \mathrm{mg}$ + Lumefantrina $120 \mathrm{mg}$ & Comp. & & & $x$ \\
\hline Artemeter $80 \mathrm{mg}$ & Comp. & & & $x$ \\
\hline Artesunato $100 \mathrm{mg}+$ Mefloquina $220 \mathrm{mg}$ & Comp. & $x$ & & \\
\hline Artesunato $25 \mathrm{mg}+$ Mefloquina $55 \mathrm{mg}$ & Comp. & $x$ & & \\
\hline Artesunato $50 \mathrm{mg}$ & Comp. & & $x$ & \\
\hline Artesunato de Sódio 60 mg injetável & Amp. & & $x$ & $x$ \\
\hline Clindamicina (Cloridrato) 300 mg & Cáps. & & $x$ & \\
\hline Clindamicina 150mg solução injetável & Amp. & & $x$ & \\
\hline Clindamicina $75 \mathrm{mg}$ ou $150 \mathrm{mg}$ & Cáps. & & $x$ & \\
\hline Clindamicina, Ampola 4ml & Amp. & & $x$ & \\
\hline Cloroquina $150 \mathrm{mg}$ & Comp. & $x$ & & \\
\hline Di-Cloridrato de Quinina 24mg injetável & Amp. & & & $x$ \\
\hline Doxiciclina $100 \mathrm{mg}$ & Comp. & $x$ & $x$ & \\
\hline Mefloquina $250 \mathrm{mg}$ & Comp. & $x$ & & \\
\hline Primaquina $15 \mathrm{mg}$ & Comp. & $x$ & & \\
\hline Primaquina $5 \mathrm{mg}$ & Comp. & $x$ & & \\
\hline Sulfato de Quinina $500 \mathrm{mg}$ & Comp. & $x$ & & \\
\hline Subtotal & & 8 & 7 & 5 \\
\hline \multicolumn{5}{|c|}{ Leishmaniose } \\
\hline Anfoterecina B Lipossonal Liofilizada,50 mg & Frasco & & $x$ & $x$ \\
\hline Antimoniato de Meglumina contendo 425 de Sbv & Amp. & & $x$ & \\
\hline Antimoniato de N-Metil Glucamina Ampola $5 \mathrm{ml}$ & Amp. & & $x$ & \\
\hline Isotionato de Pentamidina $300 \mathrm{mg}$ & $\mathrm{F} / \mathrm{A}$ & & $x$ & \\
\hline Miltefosina 10 mg (Pesquisa Clínica) & Cáps. & & $x$ & \\
\hline
\end{tabular}


continuação

Quadro 25 - Elenco de medicamentos produzidos pelos laboratórios para tratamento das endemias focais, no período de 2003 a 2013

\begin{tabular}{|c|c|c|c|c|}
\hline Medicamentos & Unidade & Oficiais & Nacionais & Internacionais \\
\hline \multicolumn{5}{|c|}{ Anti-Málaricos } \\
\hline Miltefosina 50 mg (Pesquisa Clínica) & Cáps. & & $x$ & \\
\hline Pentamidina 300 mg Injetável & Amp. & & & $x$ \\
\hline Subtotal & & 0 & 6 & 2 \\
\hline \multicolumn{5}{|c|}{ Meningite } \\
\hline Rifampicina 300 mg & Cáps. & $x$ & & \\
\hline Rifampicina 300 mg & Cáps. & $x$ & & \\
\hline Rifampicina, Frasco de $50 \mathrm{ml}$ & Frasco & $x$ & & \\
\hline Rifampicina $2 \%$ suspensão oral & Fr. & $x$ & & \\
\hline Vacinas contra Meningite & Doses & & & $x$ \\
\hline Subtotal & & 4 & 0 & 1 \\
\hline \multicolumn{5}{|c|}{ Peste } \\
\hline Sulfametoxazol $4 \%+$ Trimetoprina $0,8 \%$ suspensão oral & Fr. & $x$ & & \\
\hline Sulfametoxazol $400 \mathrm{mg}+$ Trimetoprina $80 \mathrm{mg}$ & Comp. & $x$ & & \\
\hline Tetraciclina 250mg & Cáps. & $x$ & & \\
\hline Subtotal & & 3 & 0 & 0 \\
\hline \multicolumn{5}{|c|}{ Tracoma } \\
\hline Azitromicina $500 \mathrm{mg}$ & Comp. & & $x$ & \\
\hline Azitromicina 600 mg pó para suspensão oral & Frasco & & $x$ & \\
\hline Tetraciclina, Pomada Ofta. $1 \%$ & Bisn. & $x$ & & \\
\hline Subtotal & & 1 & 2 & 0 \\
\hline \multicolumn{5}{|c|}{ Esquistossomose } \\
\hline Praziquantel $600 \mathrm{mg}$ & Comp. & $x$ & & \\
\hline Subtotal & & 1 & 0 & 0 \\
\hline \multicolumn{5}{|c|}{ Doença de Chagas } \\
\hline Benzonidazol 100mg & Comp. & $x$ & $x$ & \\
\hline Benzonidazol 12,5mg & Comp. & $x$ & & \\
\hline Subtotal & & 2 & 1 & 0 \\
\hline
\end{tabular}


continuação

Quadro 25 - Elenco de medicamentos produzidos pelos laboratórios para tratamento das endemias focais, no período de 2003 a 2013

\begin{tabular}{|c|c|c|c|c|}
\hline Medicamentos & Unidade & Oficiais & Nacionais & Internacionais \\
\hline \multicolumn{5}{|c|}{ Cólera } \\
\hline Hipoclorito de Sódio 2,5\% & Frasco & $\mathrm{x}$ & & \\
\hline Doxiciclina $100 \mathrm{mg}$ & Comp. & & $x$ & \\
\hline Eritromicina (Estolato) $500 \mathrm{mg}$ & Comp. & & $x$ & \\
\hline Ringer com Lactato de Sódio 500 ml Bolsa & Bolsa & & $x$ & \\
\hline Subtotal & & 1 & 3 & 0 \\
\hline \multicolumn{5}{|c|}{ Febre Maculosa } \\
\hline Cloranfenicol Xarope & Fr. & & & $x$ \\
\hline Subtotal & & 0 & 0 & 1 \\
\hline \multicolumn{5}{|c|}{ Filariose } \\
\hline Dietilcarbamazina, Comp. 50mg & Comp. & $x$ & & \\
\hline Subtotal & & 1 & 0 & 0 \\
\hline \multicolumn{5}{|c|}{ Dengue } \\
\hline Cloreto de Sódio 0,9\% & Fr. & & $\mathrm{x}$ & \\
\hline Metoclopramida $100 \mathrm{mg}$ & Comp. & $x$ & & \\
\hline Metoclopramida solução oral & Frasco & $\mathrm{x}$ & & \\
\hline Paracetamol $200 \mathrm{mg}$ gotas & Frasco & $x$ & $x$ & \\
\hline Paracetamol 500mg & Comp. & $x$ & & \\
\hline Sais para Reidratação Oral 27,9g & Env. & $x$ & $x$ & \\
\hline Subtotal & & 5 & 3 & 0 \\
\hline \multicolumn{5}{|c|}{ Influenza } \\
\hline Oseltamivir (Insumo Princípio Ativo Fosfato) & $\mathrm{kg}$ & & & $\mathrm{x}$ \\
\hline Oseltamivir $30 \mathrm{mg}$ & Cáps. & & $x$ & \\
\hline Oseltamivir $45 \mathrm{mg}$ & Cáps. & & $\mathrm{x}$ & \\
\hline Oseltamivir $75 \mathrm{mg}$ & Cáps. & $\mathrm{x}$ & $\mathrm{x}$ & $\mathrm{x}$ \\
\hline Oseltamivir 75 mg Desenv. Produção e Distribuição & Comp. & $x$ & & \\
\hline Oseltamivir S12 mg solução oral & Fr. & & & $\mathrm{x}$ \\
\hline Oseltamivir, Pó & $\mathrm{Kg}$ & & & $x$ \\
\hline
\end{tabular}




\section{conclusão}

Quadro 25 - Elenco de medicamentos produzidos pelos laboratórios para tratamento das endemias focais, no período de 2003 a 2013

\begin{tabular}{|c|c|c|c|c|}
\hline Medicamentos & Unidade & Oficiais & Nacionais & Internacionais \\
\hline \multicolumn{5}{|c|}{ Influenza } \\
\hline Vacina Humana Tipo A (H1N1) & Dose & & $\mathrm{x}$ & \\
\hline Zanamivir 5mg Pó Inalante Embalagem 20 doses + aplicador & Klt & & $x$ & \\
\hline Subtotal & & 2 & 5 & 4 \\
\hline \multicolumn{5}{|c|}{ Micoses Sistêmicas } \\
\hline Anfotericina B Lipossomal 50mg & Comp. & & $x$ & \\
\hline Complexo Lipídico de Anfotericina B & $\mathrm{F} / \mathrm{A}$ & & $\mathrm{x}$ & \\
\hline Fluconazol $100 \mathrm{mg}$ & Cáps. & & $\mathrm{x}$ & \\
\hline Fluconazol 2mg Injetável & Fr. & & $x$ & \\
\hline Itraconazol. 100mg & Cáps. & & $\mathrm{x}$ & \\
\hline Sulfa $4 \%+$ Trime $0,8 \%$ suspensão oral & Frasco & $\mathrm{x}$ & & \\
\hline Sulfa $400 \mathrm{mg}+$ Trime $80 \mathrm{mg}$ & Comp. & $x$ & & \\
\hline Sulfa+Trime. Solução injetável & Amp. & & $x$ & \\
\hline Tetraciclina $250 \mathrm{mg}$ & Cáps. & & $x$ & \\
\hline \multicolumn{2}{|l|}{ Subtotal } & 2 & 7 & 0 \\
\hline \multicolumn{2}{|l|}{ Total } & 30 & 34 & 13 \\
\hline
\end{tabular}

Fonte: Produção Própria.

Não foi encontrada produção pública para o tratamento da febre maculosa e leishmaniose. Para tratamento da febre maculosa apenas laboratório internacional produziu e para o tratamento da leishmaniose a produção ficou sob a responsabilidade dos laboratórios nacionais e internacionais.

Para tratamento da esquistossomose e filariose apenas os laboratórios oficiais foram responsáveis pela produção. Não há produção internacional para cólera, dengue, doença de chagas, esquistossomose, filariose, micoses sistêmicas, peste e tracoma.

Os laboratórios nacionais não produziram medicamentos para tratamento da esquistossomose, febre maculosa, filariose, menigite e peste. 
A participação percentual dos laboratórios oficiais na produção dos medicamentos do elenco foi de $46,15 \%$. Os laboratórios nacionais participaram com $52,31 \%$ e os internacionais $20,00 \%$ da produção, respectivamente.

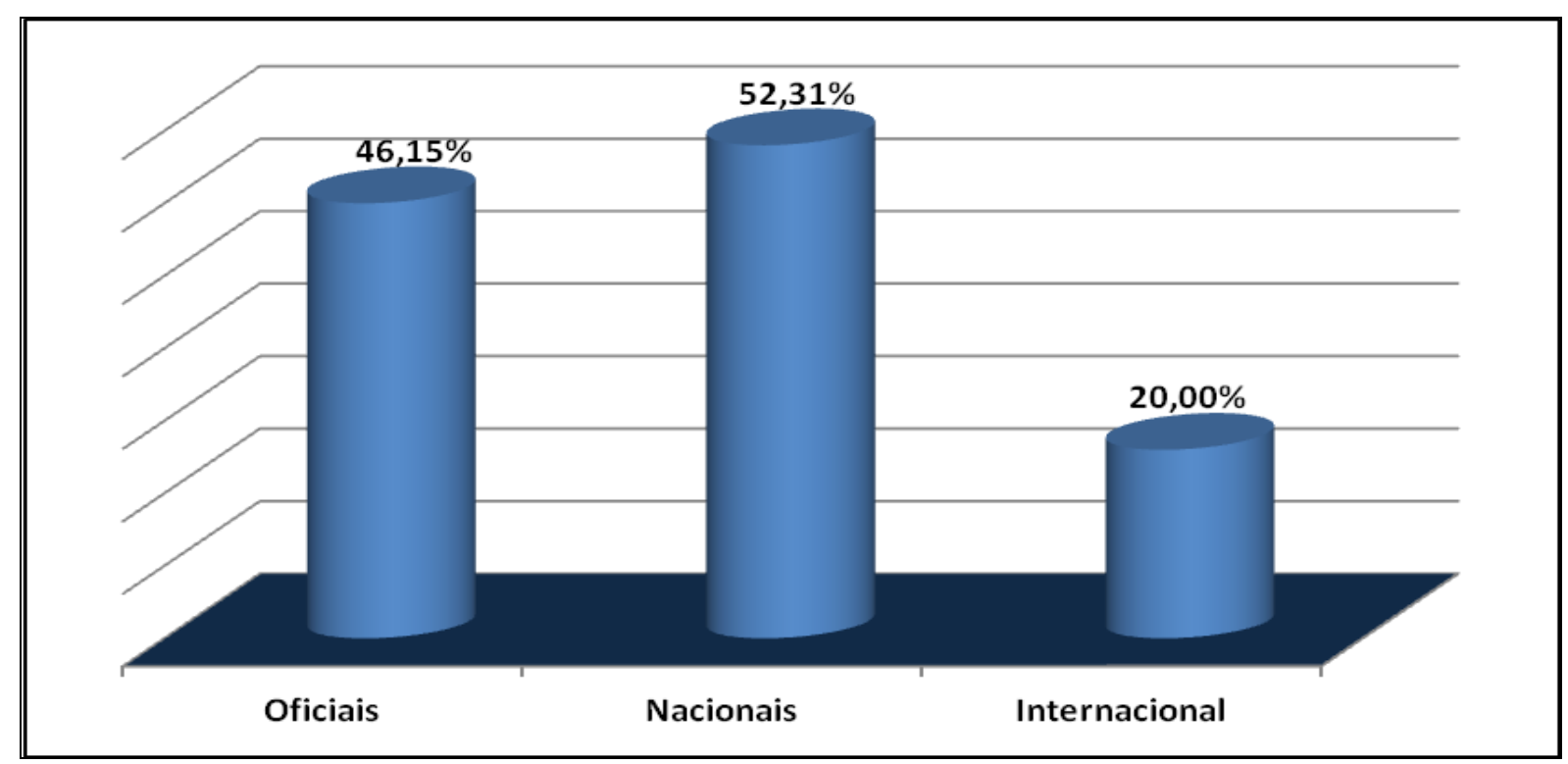

Figura 18 - Representação gráfica da participação percentual pelos laboratórios na produção do elenco de medicamentos produzidos para endemias focais, no período de 2003 a 2013.

Fonte: Produção própria

Para alguns medicamentos adquiridos pelo Ministério da Saúde não foi possível identificar qual laboratório internacional foi o produtor, tendo em vista que foram adquiridos pela OPAS e nos dados disponibilizados pelo DAF não constava o produtor. Para identificação do laboratório produtor havia necessidade de consultar o referido processo de compra. Isto não foi possível, pois este estava no arquivo central e isto inviabilizou a consulta.

Nos Quadros 26, 27 e 28 está consolidada toda a produção dos laboratórios oficiais, nacionais e internacionais discriminadas nas Tabelas 15 a 17, com o respectivo gasto do Ministério da Saúde, no período de 2003 a 2013. 


\section{continua}

Quadro 26 - Consolidação da produção dos laboratórios oficiais em número de Unidades Farmacêuticas (UF) e valor pago pelo Ministério da Saúde para tratamento das endemias focais, no período de 2003 a 2013

\begin{tabular}{|c|c|c|c|}
\hline Medicamentos & Laboratório Oficial & $\begin{array}{c}\text { Quantidade de } \\
\text { Unidades } \\
\text { Farmacêuticas } \\
\text { (comprimidos, } \\
\text { cápsukas, } \\
\text { seringas e } \\
\text { frascos) } \\
\text { produzidas }\end{array}$ & $\begin{array}{l}\text { Valor pago pelo } \\
\text { Ministério da Saúde } \\
\text { (R\$) }\end{array}$ \\
\hline \multicolumn{4}{|c|}{ Anti-Málaricos } \\
\hline Artesunato $100 \mathrm{mg}$ + Mefloquina $220 \mathrm{mg}$ & FIOCRUZ & 651.600 & $383.987,88$ \\
\hline Artesunato $25 \mathrm{mg}$ + Mefloquina $55 \mathrm{mg}$ & FIOCRUZ & 275.400 & $40.098,24$ \\
\hline Cloroquina $150 \mathrm{mg}$ & FIOCRUZ & 55.994 .500 & $1.713 .431,70$ \\
\hline Primaquina $15 \mathrm{mg}$ & FIOCRUZ & 68.412 .500 & $1.361 .408,75$ \\
\hline Primaquina $5 \mathrm{mg}$ & FIOCRUZ & 24.750 .000 & $336.600,00$ \\
\hline Doxiciclina $100 \mathrm{mg}$ & IQUEGO & 4.860 .700 & $221.647,92$ \\
\hline Doxiciclina $100 \mathrm{mg}$ & lquego - Doação & 188.000 & 0,00 \\
\hline Mefloquina $250 \mathrm{mg}$ & LFM & 1.696 .500 & $2.999 .330,40$ \\
\hline Sulfato de Quinina $500 \mathrm{mg}$ & LQFEX & 6.982 .000 & $2.081 .133,40$ \\
\hline \multicolumn{2}{|l|}{ Subtotal } & 163.811.200 & $9.137 .638,29$ \\
\hline \multicolumn{4}{|c|}{ Meningite } \\
\hline Rifampicina $300 \mathrm{mg}$ & LAFEPE & 729.500 & $103.224,25$ \\
\hline Rifampicina $300 \mathrm{mg}$ & LQFEX & 1.620 .500 & $229.300,75$ \\
\hline Rifampicina, Frasco de $50 \mathrm{ml}$ & FURP & 457.300 & $281.590,85$ \\
\hline Rifampicina $2 \%$ suspensão oral & FURP & 250.400 & $207.806,96$ \\
\hline Subtotal & & 3.057 .700 & $821.922,80$ \\
\hline \multicolumn{4}{|c|}{ Peste } \\
\hline Sulfametoxazol $400 \mathrm{mg}+$ Trimetoprina $80 \mathrm{mg}$ & FIOCRUZ & 10.500 & 532,35 \\
\hline $\begin{array}{l}\text { Sulfametoxazol } 4 \%+\text { Trimetoprina } 0,8 \% \text { suspensão } \\
\text { oral }\end{array}$ & FIOCRUZ & 1.000 & $1.154,80$ \\
\hline Tetraciclina 250mg & FIOCRUZ & 6.500 & 325,00 \\
\hline $\begin{array}{l}\text { Sulfametoxazol } 4 \%+\text { Trimetoprina } 0,8 \% \text { suspensão } \\
\text { oral }\end{array}$ & FURP & 4.100 & $4.526,22$ \\
\hline Subtotal & & 22.100 & $6.538,37$ \\
\hline \multicolumn{4}{|c|}{ Tracoma } \\
\hline Tetraciclina, Pomada Ofta. $1 \%$ & FIOCRUZ & 70.000 & $27.944,00$ \\
\hline Subtotal & & 70.000 & $27.944,00$ \\
\hline
\end{tabular}


continuação

Quadro 26 - Consolidação da produção dos laboratórios oficiais em número de Unidades Farmacêuticas (UF) e valor pago pelo Ministério da Saúde para tratamento das endemias focais, no período de 2003 a 2013

\begin{tabular}{|c|c|c|c|}
\hline 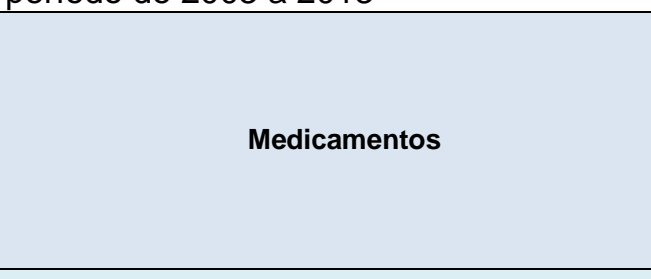 & Laboratório Oficial & $\begin{array}{c}\text { Quantidade de } \\
\text { Unidades } \\
\text { Farmacêuticas } \\
\text { (comprimidos, } \\
\text { cápsukas, } \\
\text { seringas e } \\
\text { frascos) } \\
\text { produzidas }\end{array}$ & $\begin{array}{c}\text { Valor pago pelo } \\
\text { Ministério da Saúde } \\
\text { (R\$) }\end{array}$ \\
\hline \multicolumn{4}{|c|}{ Esquistossomose } \\
\hline Praziquantel $600 \mathrm{mg}$ & FIOCRUZ & 13.946 .000 & $3.540 .889,40$ \\
\hline Subtotal & & 13.946 .000 & $3.540 .889,40$ \\
\hline \multicolumn{4}{|c|}{ Doença de Chagas } \\
\hline Benzonidazol 100mg & LAFEPE & 2.457 .200 & $603.250,08$ \\
\hline Benzonidazol $12,5 \mathrm{mg}$ & LAFEPE & 457.200 & $150.850,08$ \\
\hline Subtotal & & 2.914 .400 & $754.100,16$ \\
\hline \multicolumn{4}{|c|}{ Cólera } \\
\hline Hipoclorito de Sódio 2,5\% & LAFEPE & 486.649 .200 & $239.871 .149,13$ \\
\hline Subtotal & & 486.649 .200 & $239.871 .149,13$ \\
\hline \multicolumn{4}{|c|}{ Filariose } \\
\hline Dietilcarbamazina, Comp. 50mg & FIOCRUZ & 8.991 .000 & $129.470,40$ \\
\hline Subtotal & & 8.991 .000 & $129.470,40$ \\
\hline \multicolumn{4}{|c|}{ Dengue } \\
\hline Paracetamol 500mg & FIOCRUZ & 5.240 .060 & $200.026,41$ \\
\hline Paracetamol $200 \mathrm{mg}$ gotas & FIOCRUZ & 32.626 & $13.702,92$ \\
\hline Sais para Reidratação Oral $27,9 \mathrm{~g}$ & FIOCRUZ & 1.562 .705 & $750.410,94$ \\
\hline Paracetamol 500mg & IQUEGO & 1.000 .000 & $40.100,00$ \\
\hline Metoclopramida $100 \mathrm{mg}$ & LAFEPE & 10.000 & 276,00 \\
\hline Metoclopramida solução oral & LAFEPE & 20.000 & $7.190,00$ \\
\hline Paracetamol $200 \mathrm{mg}$ gotas & LAFEPE & 4.070 .000 & $174.542,00$ \\
\hline Subtotal & & 11.935.391 & 1.186.248,27 \\
\hline \multicolumn{4}{|c|}{ Influenza } \\
\hline Oseltamivir $75 \mathrm{mg}$ & FIOCRUZ & 21.500 .000 & $60.200 .000,00$ \\
\hline Oseltamivir 75 mg Desenv. Produção e Distribuição & FIOCRUZ & 2.065 .490 & $25.242 .287,80$ \\
\hline Subtotal & & 23.565 .490 & $85.442 .287,80$ \\
\hline
\end{tabular}


conclusão

Quadro 26 - Consolidação da produção dos laboratórios oficiais em número de Unidades Farmacêuticas (UF) e valor pago pelo Ministério da Saúde para tratamento das endemias focais, no período de 2003 a 2013

\begin{tabular}{|c|c|c|c|}
\hline \multicolumn{1}{|c|}{ Medicamentos } & Laboratório Oficial & $\begin{array}{c}\text { Quantidade de } \\
\text { Unidades } \\
\text { Farmacêuticas } \\
\text { (comprimidos, } \\
\text { cápsukas, } \\
\text { seringas e } \\
\text { frascos) } \\
\text { produzidas }\end{array}$ & $\begin{array}{c}\text { Valor pago pelo } \\
\text { Ministério da Saúde } \\
\text { (R } \$ \text { ) }\end{array}$ \\
\hline Sulfa $400 \mathrm{mg}+$ Trime $80 \mathrm{mg}$ & Micoses Sistêmicas & & 101,40 \\
Sulfa $4 \%+$ Trime $0,8 \%$ suspensão oral & FIOCRUZ & 2.000 & $1.154,80$ \\
Subtotal & FURP & 1.000 & $\mathbf{1 . 2 5 6 , 2 0}$ \\
\hline
\end{tabular}

Fonte: Produção própria.

\section{continua}

Quadro 27 - Consolidação da produção dos laboratórios nacionais em número de Unidades Farmacêuticas (UF) e valor pago pelo Ministério da Saúde para tratamento das endemias focais, no período de 2003 a 2013

\begin{tabular}{|c|c|c|c|}
\hline Medicamentos & Laboratório & $\begin{array}{c}\text { Quantidade de } \\
\text { Unidades } \\
\text { Farmacêuticas } \\
\text { (comprimidos, } \\
\text { cápsukas e } \\
\text { frascos) } \\
\text { produzidas }\end{array}$ & $\begin{array}{l}\text { Valorpago pelo } \\
\text { Ministério da Saúde } \\
\text { (R\$) }\end{array}$ \\
\hline \multicolumn{4}{|c|}{ Anti-Málaricos } \\
\hline Artesunato de Sódio 60 mg injetável & ATIVUS & 33.000 & $212.729,00$ \\
\hline Artesunato $50 \mathrm{mg}$ & ATIVUS & 50.000 & $31.000,00$ \\
\hline Clindamicina, Ampola 4ml & Cellofarm & 11.000 & $9.790,00$ \\
\hline Clindamicina (Cloridrato) $300 \mathrm{mg}$ & E.M.S & 17.600 & $7.040,00$ \\
\hline Clindamicina, Amp. $04 \mathrm{ml}$ & EUROFARMA & 3.400 & $4.760,00$ \\
\hline Clindamicina $75 \mathrm{mg}$ ou $150 \mathrm{mg}$ & HIPOLABOR & 35.000 & $41.000,00$ \\
\hline Clindamicina (Cloridrato) 150 mg injetável & HYPOFARMA & 150.000 & $110.250,00$ \\
\hline Doxiciclina 100mg & IMEX FARMA & 270.000 & $17.145,00$ \\
\hline Clindamicina 150mg solução injetável & Nova farma & 8.700 & $7.917,00$ \\
\hline Clindamicina (Cloridrato) $300 \mathrm{mg}$ & PRODIET & 80.000 & $26.000,00$ \\
\hline Clindamicina (Cloridrato) 300 mg & TEUTO & 20.000 & $4.580,00$ \\
\hline Clindamicina, Ampola 4ml & UNIÃO QUÍMICA & 10.000 & $14.500,00$ \\
\hline Subtotal & & 688.700 & $486.711,00$ \\
\hline
\end{tabular}




\section{continuação}

Quadro 27 - Consolidação da produção dos laboratórios nacionais em número de Unidades Farmacêuticas (UF) e valor pago pelo Ministério da Saúde para tratamento das endemias focais, no período de 2003 a 2013

\begin{tabular}{|c|c|c|c|}
\hline 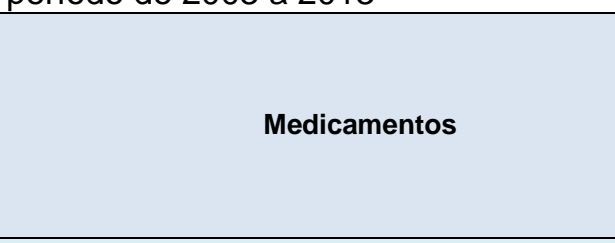 & Laboratório & $\begin{array}{l}\text { Quantidade de } \\
\text { Unidades } \\
\text { Farmacêuticas } \\
\text { (comprimidos, } \\
\text { cápsukas e } \\
\text { frascos) } \\
\text { produzidas }\end{array}$ & $\begin{array}{l}\text { Valorpago pelo } \\
\text { Ministério da Saúde } \\
\text { (R\$) }\end{array}$ \\
\hline \multicolumn{4}{|c|}{ Leishmaniose } \\
\hline Antimoniato de Meglumina contendo 425 de Sbv & AVENTIS & 6.732 .473 & $23.931 .655,50$ \\
\hline Anfoterecina B $50 \mathrm{mg}$ & CRISTÁLIA & 111.500 & $1.266 .900,00$ \\
\hline Isotionato de Pentamidina $300 \mathrm{mg}$ & Itaca Lab. & 20.000 & $780.000,00$ \\
\hline Miltefosina 10 mg (Pesquisa Clínica) & PALADIN & 13.496 & $104.728,96$ \\
\hline Miltefosina 50 mg (Pesquisa Clínica) & PALADIN & 53.760 & $653.184,00$ \\
\hline Antimoniato de N-Metil Glucamina Ampola 5ml & SANOFI & 6.679 .050 & $20.113 .881,00$ \\
\hline Meglumina antimoniato & SANOFI-AVENTIS & 5.840 .000 & $19.845 .200,00$ \\
\hline Subtotal & & 19.450 .279 & $66.695 .549,46$ \\
\hline \multicolumn{4}{|c|}{ Meningite } \\
\hline Vacinas contra Meningite & $\begin{array}{c}\text { Vacunas } \\
\text { Finlay/Cubanacan }\end{array}$ & 20.000 & $260.423,03$ \\
\hline Subtotal & & 20.000 & $260.423,03$ \\
\hline \multicolumn{4}{|c|}{ Tracoma } \\
\hline Azitromicina $600 \mathrm{mg}$ pó para suspensão oral & EUROFARMA & 57.500 & $194.925,00$ \\
\hline Azitromicina 600 mg pó para suspensão oral & Eurofarma - Doação & 528 & 0,00 \\
\hline Azitromicina 600 mg pó para suspensão oral & Greenpharma & 1.000 & $3.390,00$ \\
\hline Azitromicina $500 \mathrm{mg}$ & Itaca Lab. & 500 & 650,00 \\
\hline Azitromicina $500 \mathrm{mg}$ & Laboris & 40.000 & $14.000,00$ \\
\hline Azitromicina $500 \mathrm{mg}$ & Neo Química & 46.000 & $36.800,00$ \\
\hline Azitromicina $500 \mathrm{mg}$ & PRATI & 170.000 & $54.400,00$ \\
\hline Azitromicina 600 mg pó para suspensão oral & PRATI & 277.510 & $592.369,40$ \\
\hline Azitromicina $500 \mathrm{mg}$ & PRODIET & 372.200 & $118.992,00$ \\
\hline Subtotal & & 965.238 & $1.015 .526,40$ \\
\hline
\end{tabular}


continuação

Quadro 27 - Consolidação da produção dos laboratórios nacionais em número de Unidades Farmacêuticas (UF) e valor pago pelo Ministério da Saúde para tratamento das endemias focais, no período de 2003 a 2013

\begin{tabular}{|c|c|c|c|}
\hline Medicamentos & Laboratório & $\begin{array}{c}\text { Quantidade de } \\
\text { Unidades } \\
\text { Farmacêuticas } \\
\text { (comprimidos, } \\
\text { cápsukas e } \\
\text { frascos) } \\
\text { produzidas }\end{array}$ & $\begin{array}{l}\text { Valorpago pelo } \\
\text { Ministério da Saúde } \\
\text { (R\$) }\end{array}$ \\
\hline \multicolumn{4}{|c|}{ Doença de Chagas } \\
\hline Benzonidazol $100 \mathrm{mg}$ & ROCHE & 455.200 & $10.262,56$ \\
\hline Benzonidazol, Comp. 100mg & ROCHE - Doação & 360.000 & 0,00 \\
\hline Subtotal & & 815.200 & $10.262,56$ \\
\hline \multicolumn{4}{|c|}{ Cólera } \\
\hline Doxiciclina $100 \mathrm{mg}$ & IMEX FARMA & 15.000 & 952,50 \\
\hline Eritromicina (Estolato) $500 \mathrm{mg}$ & PMH PROD. & 10.000 & $2.400,00$ \\
\hline Ringer com Lactato de Sódio 500 ml Bolsa & PMH PROD. & 100.000 & $142.000,00$ \\
\hline Swab Cary Blair & ORION & 5.000 & $6.500,00$ \\
\hline Subtotal & & 130.000 & $151.852,50$ \\
\hline \multicolumn{4}{|c|}{ Dengue } \\
\hline Paracetamol $200 \mathrm{mg}$ gotas & 4MBR & 100.000 & $42.900,00$ \\
\hline Cloreto de Sódio $0,9 \%$ & EUROFARMA & 1.400 .000 & $1.922 .000,00$ \\
\hline Cloreto de Sódio $0,9 \%$ & HALEX & 200.000 & $490.000,00$ \\
\hline Sais para Reidratação Oral $27,9 \mathrm{~g}$ & PRATI & 1.000 .000 & $228.000,00$ \\
\hline Subtotal & & 2.700 .000 & $2.682 .900,00$ \\
\hline \multicolumn{4}{|c|}{ Influenza } \\
\hline $\begin{array}{l}\text { Zanamivir 5mg Pó Inalante Embalagem } 20 \text { doses + } \\
\text { aplicador }\end{array}$ & GLAXO & 200.000 & $8.312 .000,00$ \\
\hline Vacina Humana Tipo A (H1N1) & ID & 40.000 .000 & $465.532 .000,00$ \\
\hline Oseltamivir $30 \mathrm{mg}$ & ROCHE & 16.000 .000 & $27.804 .800,00$ \\
\hline Oseltamivir $45 \mathrm{mg}$ & ROCHE & 14.000 .000 & $36.495 .200,00$ \\
\hline Oseltamivir $75 \mathrm{mg}$ & ROCHE & 75.242 .630 & $325.844 .341,50$ \\
\hline Oseltamivir $75 \mathrm{mg}$ & ROCHE & 500.000 & 0,00 \\
\hline Subtotal & & 145.942 .630 & $863.988 .341,50$ \\
\hline
\end{tabular}




\section{conclusão}

Quadro 27 - Consolidação da produção dos laboratórios nacionais em número de Unidades Farmacêuticas (UF) e valor pago pelo Ministério da Saúde para tratamento das endemias focais, no período de 2003 a 2013

\begin{tabular}{|c|c|c|c|}
\hline Medicamentos & Laboratório & $\begin{array}{l}\text { Quantidade de } \\
\text { Unidades } \\
\text { Farmacêuticas } \\
\text { (comprimidos, } \\
\text { cápsukas e } \\
\text { frascos) } \\
\text { produzidas } \\
\end{array}$ & $\begin{array}{l}\text { Valorpago pelo } \\
\text { Ministério da Saúde } \\
\text { (R\$) }\end{array}$ \\
\hline \multicolumn{4}{|c|}{ Micoses Sistêmicas } \\
\hline Complexo Lipídico de Anfotericina B & BAGÓ & 36.540 & $21.859 .639,20$ \\
\hline Anfotericina B & Cristália & 3.000 & $33.000,00$ \\
\hline Fluconazol $100 \mathrm{mg}$ & CRISTÁLIA & 215.520 & $40.948,80$ \\
\hline Anfotericina B Lipossomal 50mg & Gilead & 600 & $285.525,00$ \\
\hline Anfotericina B Lipossomal 50mg & GILEAD - Doação & 3.000 & 0,00 \\
\hline Fluconazol 2mg Injetável & HALEX-ISTAR & 13.440 & $52.684,80$ \\
\hline Sulfa+Trime. Solução injetável & J.F GALLO & 18.000 & $7.200,00$ \\
\hline Itraconazol. 100mg & Neo Química & 657.000 & $134.685,00$ \\
\hline Itrazonazol 100mg & PRODIET & 486.000 & $140.940,00$ \\
\hline Tetraciclina $250 \mathrm{mg}$ & & 2.000 & 100,00 \\
\hline \multicolumn{2}{|l|}{ Subtotal } & 1.435 .100 & 22.554.722,80 \\
\hline \multicolumn{2}{|l|}{ Total } & 172.147 .147 & $957.846 .289,25$ \\
\hline
\end{tabular}

Fonte: Produção própria.

\section{continua}

Quadro 28 - Consolidação da produção dos laboratórios internacionais em número de Unidades Farmacêuticas (UF) e valor pago pelo Ministério da Saúde para tratamento das endemias focais, no período de 2003 a 2013

\begin{tabular}{|l|c|c|c|}
\hline \multicolumn{1}{|c|}{ Medicamentos } & Laboratóriol & $\begin{array}{c}\text { Quantidade de } \\
\text { Unidades } \\
\text { Farmacêuticas } \\
\text { (comprimidos, } \\
\text { cápsulas, seringas e } \\
\text { frascos) produzidas }\end{array}$ & $\begin{array}{c}\text { Valor pago pelo } \\
\text { Ministério da Saúde } \\
\text { (R\$) }\end{array}$ \\
\hline Artemeter $80 \mathrm{mg}$ & Anti-Málaricos & 10.000 & $22.285,00$ \\
Artemeter $80 \mathrm{mg}$ injetável & OPAS & 107.250 & $96.568,13$ \\
Artemeter $20 \mathrm{mg}+$ Lumefantrina $120 \mathrm{mg}$ & OPAS & 3.173 .640 & $1.217 .235,04$ \\
Artesunato de Sódio $60 \mathrm{mg}$ injetável & OPAS & 165.500 & $673.390,30$
\end{tabular}


conclusão

Quadro 28 - Consolidação da produção dos laboratórios internacionais em número de Unidades Farmacêuticas (UF) e valor pago pelo Ministério da Saúde para tratamento das endemias focais, no período de 2003 a 2013

\begin{tabular}{|c|c|c|c|}
\hline Medicamentos & Laboratóriol & $\begin{array}{l}\text { Quantidade de } \\
\text { Unidades } \\
\text { Farmacêuticas } \\
\text { (comprimidos, } \\
\text { cápsulas, seringas e } \\
\text { frascos) produzidas }\end{array}$ & $\begin{array}{l}\text { Valor pago pelo } \\
\text { Ministério da Saúde } \\
\text { (R\$) }\end{array}$ \\
\hline \multicolumn{4}{|c|}{ Anti-Málaricos } \\
\hline Di-Cloridrato de Quinina 24mg injetável & OPAS & 175.000 & $153.014,50$ \\
\hline Subtotal & & 3.631 .390 & 2.162.492,97 \\
\hline \multicolumn{4}{|c|}{ Leishmaniose } \\
\hline Anfoterecina B Lipossonal Liofilizada,50 mg & GILEAD & 224.587 & $18.067 .914,30$ \\
\hline Pentamidina 300 mg Injetável & OPAS & 14.500 & $193.886,18$ \\
\hline Anfotericina B Lipossomal 50mg & GILEAD - Doação & 50 & 0,00 \\
\hline Subtotal & & 239.137 & $18.261 .800,48$ \\
\hline \multicolumn{4}{|c|}{ Meningite } \\
\hline Vacinas contra Meningite & $\begin{array}{c}\text { Vacunas } \\
\text { Finlay/Cubanacan }\end{array}$ & 20.000 & $260.423,03$ \\
\hline Subtotal & & 20.000 & $260.423,03$ \\
\hline \multicolumn{4}{|c|}{ Febre Maculosa } \\
\hline Cloranfenicol Xarope & OPAS & 4.000 & $25.680,00$ \\
\hline Subtotal & & 4.000 & $25.680,00$ \\
\hline \multicolumn{4}{|c|}{ Influenza } \\
\hline Oseltamivir $75 \mathrm{mg}$ & Produtos Roche & 114.000 & $321.480,00$ \\
\hline Oseltamivir, Pó & Produtos Roche & 9.254 & $152.228 .300,00$ \\
\hline Insumo Princípio Ativo Fosfato de Oseltamivir & F-HOFFMAN & 4.000 & $80.193 .528,00$ \\
\hline Oseltamivir $75 \mathrm{mg}$ & ROCHE & 62.500 & $271.543,75$ \\
\hline Oseltamivir S12 mg solução oral & ROCHE & 6.250 & $353.437,50$ \\
\hline Oseltamivir S12 mg solução oral & ROCHE & 7.453 & 0,00 \\
\hline Subtotal & & 203.457 & 233.368.289,25 \\
\hline Total & & 4.097 .984 & 254.078.686 \\
\hline
\end{tabular}

Fonte: Produção própria.

Para o tratamento das endemias focais o Ministério da Saúde adquiriu 891.185.612 unidades farmacêuticas e gastou $R \$ 1.552 .577 .496,76$. Os laboratórios 
oficiais foram os que mais produziram seguidos dos laboratórios nacionais. Conforme dados do Quadro 29.

\section{continua}

Quadro 29 - Consolidação da produção dos laboratórios oficiais, nacionais e internacionais em número de Unidades Farmacêuticas (UF) e valor pago pelo Ministério da Saúde para tratamento das endemias focais, no período de 2003 a 2013

\begin{tabular}{|c|c|c|}
\hline Laboratório & $\begin{array}{l}\text { Produção (Unidades comprimidos, } \\
\text { cápsulas e frascos) } 2003 \text { a } 2013\end{array}$ & $\begin{array}{l}\text { Total pago pelo Ministério da Saúde } \\
\text { (R\$) } 2003 \text { a } 2013\end{array}$ \\
\hline \multicolumn{3}{|c|}{ Anti-Málaricos } \\
\hline Oficiais & 163.811 .200 & $9.137 .638,29$ \\
\hline Nacionais & 688.700 & $486.711,00$ \\
\hline Internacionais & 3.631 .390 & $2.162 .492,97$ \\
\hline Subtotal & 168.131 .290 & $11.786 .842,26$ \\
\hline \multicolumn{3}{|c|}{ Leishmaniose } \\
\hline Nacionais & 19.450 .279 & $66.695 .549,46$ \\
\hline Internacionais & 239.137 & $18.261 .800,48$ \\
\hline Subtotal & 19.689 .416 & $84.957 .349,94$ \\
\hline \multicolumn{3}{|c|}{ Meningite } \\
\hline Oficiais & 3.057 .700 & $821.922,80$ \\
\hline Internacionais & 20.000 & $260.423,03$ \\
\hline Subtotal & 3.077 .700 & $1.082 .345,83$ \\
\hline \multicolumn{3}{|c|}{ Peste } \\
\hline Oficiais & 22.100 & $6.538,37$ \\
\hline Subtotal & 22.100 & $6.538,37$ \\
\hline \multicolumn{3}{|c|}{ Tracoma } \\
\hline Oficiais & 70.000 & $27.944,00$ \\
\hline Nacionais & 965.238 & $1.015 .526,40$ \\
\hline Subtotal & 1.035 .238 & $1.043 .470,40$ \\
\hline \multicolumn{3}{|c|}{ Esquistossomose } \\
\hline Oficiais & 13.946 .000 & $3.540 .889,40$ \\
\hline Subtotal & 13.946 .000 & $3.540 .889,40$ \\
\hline
\end{tabular}


continuação

Quadro 29 - Consolidação da produção dos laboratórios oficiais, nacionais e internacionais em número de Unidades Farmacêuticas (UF) e valor pago pelo Ministério da Saúde para tratamento das endemias focais, no período de 2003 a 2013

\begin{tabular}{|c|c|c|}
\hline Laboratório & $\begin{array}{l}\text { Produção (Unidades comprimidos, } \\
\text { cápsulas e frascos) } 2003 \text { a } 2013\end{array}$ & $\begin{array}{l}\text { Total pago pelo Ministério da Saúde } \\
\text { (R\$) } 2003 \text { a } 2013\end{array}$ \\
\hline \multicolumn{3}{|c|}{ Doença de Chagas } \\
\hline Oficiais & 2.914 .400 & $754.100,16$ \\
\hline Nacionais & 815.200 & $10.262,56$ \\
\hline Subtotal & 3.729 .600 & $764.362,72$ \\
\hline \multicolumn{3}{|c|}{ Cólera } \\
\hline Oficiais & 486.649 .200 & $239.871 .149,13$ \\
\hline Nacionais & 125.000 & $145.352,50$ \\
\hline Subtotal & 486.774.200 & $240.016 .501,63$ \\
\hline \multicolumn{3}{|c|}{ Febre Maculosa } \\
\hline Internacionais & 4.000 & $25.680,00$ \\
\hline Subtotal & 4.000 & $25.680,00$ \\
\hline \multicolumn{3}{|c|}{ Filariose } \\
\hline Oficiais & 8.991 .000 & $129.470,40$ \\
\hline Subtotal & 8.991 .000 & $129.470,40$ \\
\hline \multicolumn{3}{|c|}{ Dengue } \\
\hline Oficiais & 11.935 .391 & $1.186 .248,27$ \\
\hline Nacionais & 2.700 .000 & $2.682 .900,00$ \\
\hline Subtotal & 14.635 .391 & $3.869 .148,27$ \\
\hline \multicolumn{3}{|c|}{ Influenza } \\
\hline Oficiais & 23.565 .490 & $85.442 .287,80$ \\
\hline Nacionais & 145.942 .630 & $863.988 .341,50$ \\
\hline Internacionais & 203.457 & $233.368 .289,25$ \\
\hline Subtotal & 169.711 .577 & $1.182 .798 .918,55$ \\
\hline \multicolumn{3}{|c|}{ Micoses Sistêmicas } \\
\hline Oficiais & 3.000 & $1.256,20$ \\
\hline Nacionais & 1.435 .100 & $22.554 .722,80$ \\
\hline Subtotal & 1.438 .100 & $22.555 .979,00$ \\
\hline
\end{tabular}


conclusão

Quadro 29 - Consolidação da produção dos laboratórios oficiais, nacionais e internacionais em número de Unidades Farmacêuticas (UF) e valor pago pelo Ministério da Saúde para tratamento das endemias focais, no período de 2003 a 2013

\begin{tabular}{|l|c|c|}
\hline \multicolumn{1}{|c|}{ Laboratório } & $\begin{array}{c}\text { Produção (Unidades comprimidos, } \\
\text { cápsulas e frascos) 2003 a 2013 }\end{array}$ & $\begin{array}{c}\text { Total pago pelo Ministério da Saúde } \\
\text { (R\$) 2003 a 2013 }\end{array}$ \\
\hline & Consolidação & \\
Oficiais & 714.965 .481 & $340.919 .444,82$ \\
Nacionais & 172.122 .147 & $957.579 .366,22$ \\
Internacionais & 4.097 .984 & $254.078 .685,72$ \\
\multicolumn{1}{|c|}{ Total Geral } & $\mathbf{8 9 1 . 1 8 5 . 6 1 2}$ & $\mathbf{1 . 5 5 2 . 5 7 7 . 4 9 6 , 7 6}$ \\
\hline
\end{tabular}

Fonte: Produção própria.

Em relação à quantidade produzida por unidade farmacêutica os laboratórios oficiais produziram no período pesquisado a quantia de 714.965 .481 de unidades farmacêuticas (comprimidos, cápsulas, seringas e frascos) para o tratamento das endemias focais, esta quantidade representa $80,23 \%$ da produção total. Receberam apenas $21,96 \%$ da verba orçamentária destinada ao tratamento.

Os laboratórios nacionais produziram 19,31\% (172.122.147UF) da produção e receberam $61,68 \%$ da verba orçamentária. Os laboratórios internacionais produziram apenas $0,46 \%$ (4.097.984 de UF) receberam $16,36 \%$ da verba orçamentária

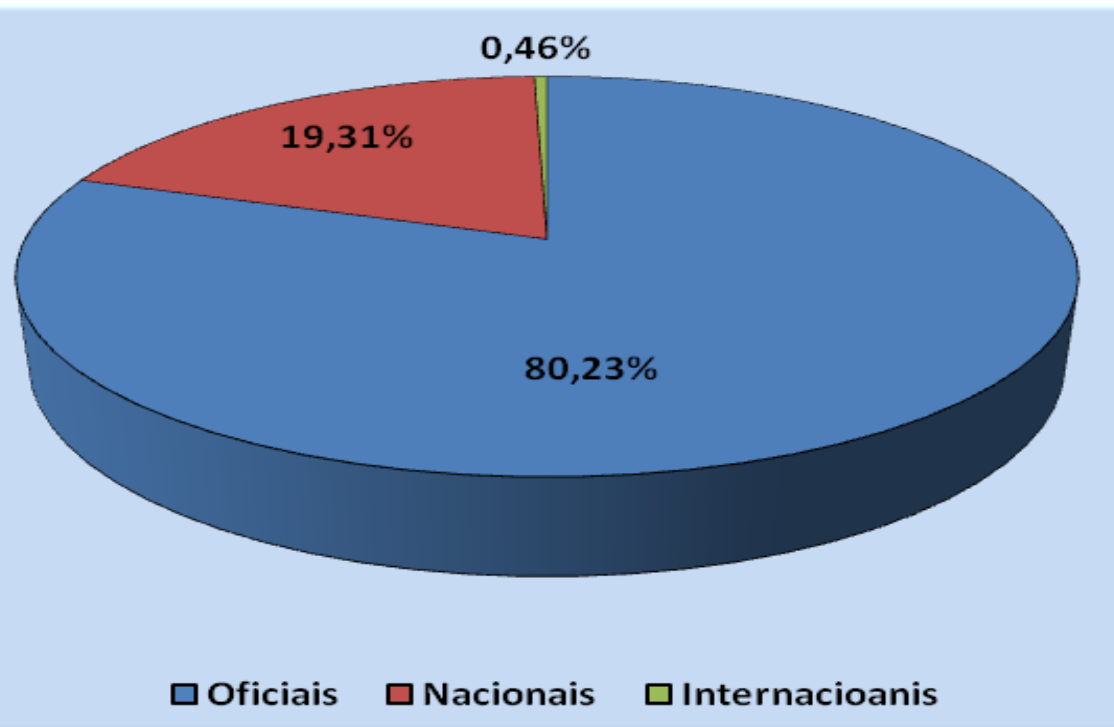

Figura 19 - Participação percentual da quantidade produzida pelos laboratórios oficiais, nacionais e internacionais em número de Unidades Farmacêuticas (UF) para o tratamento das endemias focais, no período de 2003 a 2013.

Fonte: Produção própria. 


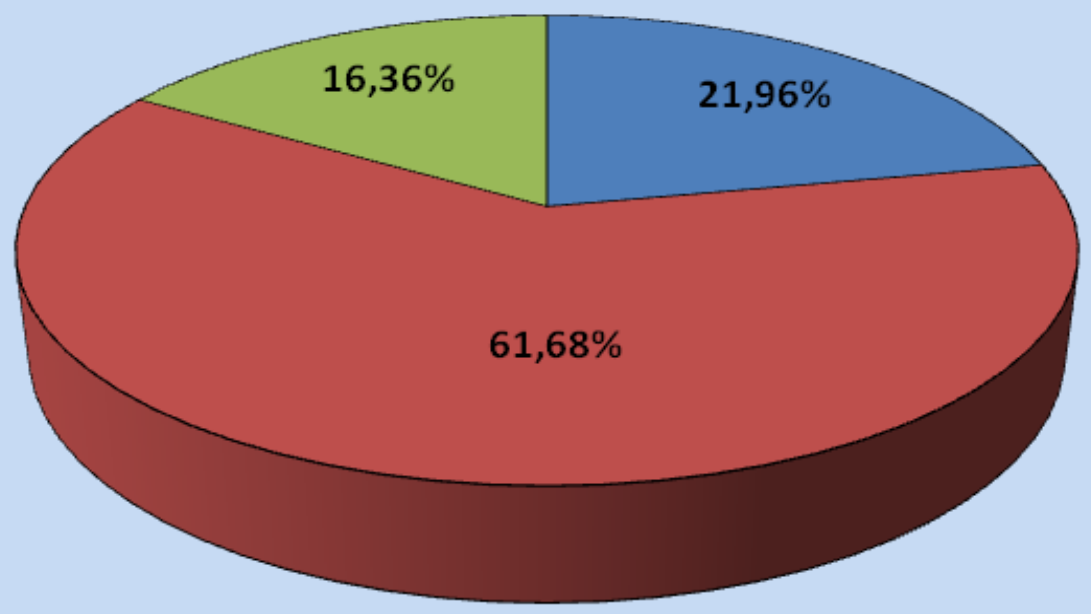

口Oficiais $\mathbf{n}$ Nacionais $\mathbf{\text { Internacioanis }}$

Figura 20 - Participação percentual da quantidade no gasto com os laboratórios oficiais, nacionais e internacionais pelo Ministério da Saúde com o tratamento das endemias focais, no período de 2003 a 2013.

Fonte: Produção própria.

Dos 29 laboratórios farmacêuticos oficiais apenas 6 laboratórios participaram da produção do elenco de medicamentos para o tratamento das endemias focais: FIOCRUZ, FURP, IQUEGO, LAFEPE, LFM e LQFEX, o que corresponde a 20,69\% dos laboratórios oficiais, no período de 2003 a 2013.

Dos 6 laboratórios farmacêuticos oficiais a FIOCRUZ foi o que mais produziu para o tratamento das endemias focais, com produção de 16 medicamentos. Dos 11 programas/tratamento esta produziu para 8 , ficando com uma participação de $50,00 \%$ do elenco de medicamentos produzidos pelos LO. Foi verificado que não houve sua participação para o tratamento da meningite, doença de chagas e cólera.

O LAFEPE teve uma participação de $21,88 \%$ do elenco de medicamentos, com a produção de 7 medicamentos. A FURP ficou com $12,50 \%$, com a produção com 4 medicamentos. O IQUEGO e o LQFEX produziram 2 medicamentos cada um, o que representa $6,25 \%$ do elenco. O laboratório LFM produziu apena 1 medicamento, o que representa $3,13 \%$. 
Quadro 30 - Quantidade de medicamentos produzidos por laboratório oficial para o tratamento das endemias focais, no período de 2003 a 2013

\begin{tabular}{|c|c|c|c|c|c|c|c|c|c|c|c|c|c|}
\hline Laboratório & $\begin{array}{c}\text { Anti- } \\
\text { Málaricos }\end{array}$ & Meningite & Peste & Tracoma & Esquistossomose & Doença de Chagas & Cólera & Filariose & Dengue & Influenza & $\begin{array}{c}\text { Micoses } \\
\text { Sistêmicas }\end{array}$ & Total & $\begin{array}{l}\text { Participação \% em } \\
\text { relação ao elenco de } \\
\text { medicamentos }\end{array}$ \\
\hline LFM & 1 & & & & & & & & & & & 1 & 3,13 \\
\hline LQFEX & 1 & 1 & & & & & & & & & & 2 & 6,25 \\
\hline IQUEGO & 1 & & & & & & & & 1 & & & 2 & 6,25 \\
\hline FURP & & 2 & 1 & & & & & & & & 1 & 4 & 12,50 \\
\hline LAFEPE & & 1 & & & & 2 & 1 & & 3 & & & 7 & 21,88 \\
\hline FIOCRUZ & 5 & & 3 & 1 & 1 & & & 1 & 3 & 1 & 1 & 16 & 50,00 \\
\hline Total & 8 & 4 & 4 & 1 & 1 & 2 & 1 & 1 & 7 & 1 & 2 & 32 & 100 \\
\hline
\end{tabular}

Fonte: Produção própria. 
Quadro 31 - Quantidade de Unidades farmacêuticas e participação percentual da quantidade produzida pelos laboratórios oficiais para o Ministério da Saúde para o tratamento das endemias focais, no período de 2003 a 2013

\begin{tabular}{|c|c|c|c|c|c|c|c|c|c|c|c|c|}
\hline \multirow[b]{2}{*}{ Ano } & \multicolumn{2}{|c|}{ FIOCRUZ } & \multicolumn{2}{|c|}{ FURP } & \multicolumn{2}{|c|}{ IQUEGO } & \multicolumn{2}{|c|}{ LAFEPE } & \multicolumn{2}{|c|}{ LFM } & \multicolumn{2}{|c|}{ LQFEX } \\
\hline & $\begin{array}{c}\text { Quantidade } \\
\text { de UF } \\
\text { Produzida }\end{array}$ & $\begin{array}{c}\text { Participação } \\
\text { Percentual } \\
(\%)\end{array}$ & $\begin{array}{l}\text { Quantidade } \\
\text { de UF } \\
\text { Produzida }\end{array}$ & $\begin{array}{c}\text { Participação } \\
\text { Percentual } \\
(\%)\end{array}$ & $\begin{array}{l}\text { Quantidade } \\
\text { de UF } \\
\text { Produzida }\end{array}$ & $\begin{array}{c}\text { Participação } \\
\text { Percentual } \\
(\%)\end{array}$ & $\begin{array}{l}\text { Quantidade } \\
\text { de UF } \\
\text { Produzida }\end{array}$ & $\begin{array}{c}\text { Participação } \\
\text { Percentual } \\
(\%)\end{array}$ & $\begin{array}{l}\text { Quantidade } \\
\text { de UF } \\
\text { Produzida }\end{array}$ & $\begin{array}{c}\text { Participação } \\
\text { Percentual } \\
\text { (\%) }\end{array}$ & $\begin{array}{l}\text { Quantidade } \\
\text { de UF } \\
\text { Produzida }\end{array}$ & $\begin{array}{c}\text { Participação } \\
\text { Percentual } \\
(\%)\end{array}$ \\
\hline 2003 & 3.794 .500 & 1,86 & 40.550 & 5,69 & & 0,00 & 22.798 .750 & 4,61 & 170.000 & 10,02 & 70.000 & 0,81 \\
\hline 2004 & 19.555 .000 & 9,61 & 35.850 & 5,03 & 935.700 & 15,47 & 328.000 & 0,07 & 286.000 & 16,86 & 1.368 .000 & 15,90 \\
\hline 2005 & 19.751 .500 & 9,71 & 97.000 & 13,61 & 1.725 .000 & 28,52 & 30.232 .500 & 6,12 & 600.000 & 35,37 & 2.230 .500 & 25,93 \\
\hline 2006 & 23.754 .000 & 11,67 & 94.000 & 13,19 & 2.200 .000 & 36,37 & 44.455 .300 & 8,99 & 440.000 & 25,94 & 2.774 .000 & 32,25 \\
\hline 2007 & 23.402 .000 & 11,50 & 55.000 & 7,72 & & 0,00 & 49.199 .000 & 9,95 & 200.500 & 11,82 & 184.000 & 2,14 \\
\hline 2008 & 6.190 .000 & 3,04 & & 0,00 & & 0,00 & 52.685 .900 & 10,66 & & 0,00 & & 0,00 \\
\hline 2009 & 35.249 .881 & 17,32 & 50.400 & 7,07 & 188.000 & 3,11 & 58.307 .100 & 11,79 & & 0,00 & 512.000 & 5,95 \\
\hline 2010 & 30.788 .000 & 15,13 & 50.000 & 7,01 & 1.000 .000 & 16,53 & 57.649 .300 & 11,66 & & 0,00 & 608.000 & 7,07 \\
\hline 2011 & 20.769 .000 & 10,21 & 50.000 & 7,01 & & 0,00 & 64.447 .350 & 13,04 & & 0,00 & 413.000 & 4,80 \\
\hline 2012 & 8.468 .000 & 4,16 & 50.000 & 7,01 & & 0,00 & 57.144 .950 & 11,56 & & 0,00 & & 0,00 \\
\hline 2013 & 11.790 .000 & 5,79 & 190.000 & 26,66 & & 0,00 & 57.144 .950 & 11,56 & & 0,00 & 443.000 & 5,15 \\
\hline $\begin{array}{l}\text { Total } \\
2003 \text { a } \\
2013\end{array}$ & 203.511.881 & 100 & 712.800 & 100 & 6.048 .700 & 100 & 494.393 .100 & 100 & 1.696 .500 & 100 & 8.602 .500 & 100 \\
\hline
\end{tabular}




\subsection{PROGRAMA MULTIDROGA-RESISTÊNCIA}

Este programa tem por objetivo a redução da resistência do bacilo tuberculoso aos principais quimioterápicos usados no tratamento da tuberculose dispensados pelo Programa Nacional de Controle da Tuberculose.

A pesquisa exploratória levantou que 24 medicamentos foram adquiridos para abastecimento do Programa Multidroga-Resistência, no período de 2003 a 2013, conforme arrolado no Quadro 32.

Do elenco acima relacionado os laboratórios oficiais foram responsáveis pela produção de 8 medicamentos. Esta produção para o Programa MultidrogaResistência representa uma participação percentual de 33,33\% do elenco adquirido pelo Ministério da Saúde. Os laboratórios nacionais produziram 9 medicamentos $(37,50 \%)$ e os internacionais produziram 13 medicamentos $(54,17 \%)$.

\section{continua}

Quadro 32 - Elenco de medicamentos produzidos pelos laboratórios para o Programa MultidrogaResistência, no período de 2003 a 2013

\begin{tabular}{|c|c|c|c|}
\hline \multirow{2}{*}{ Medicamentos } & \multicolumn{3}{|c|}{ Laboratórios } \\
\hline & Oficiais & Nacionais & Internacionais \\
\hline Amicacina (SULFATO) 250 mg solução injetável & & $x$ & \\
\hline Amicacina $1 \mathrm{~g}$ & & $x$ & \\
\hline Amicacina $500 \mathrm{mg}$ & & $x$ & \\
\hline Capreomicina $1 \mathrm{~g}$ & & $x$ & $x$ \\
\hline Claritromicina $500 \mathrm{mg}$ & & $x$ & $\mathrm{x}$ \\
\hline Clofazimina $100 \mathrm{mg}$ & & $x$ & $x$ \\
\hline Estreptomicina $1 \mathrm{~g}$ solução injetável & $x$ & & \\
\hline Etambutol $400 \mathrm{mg}$ & $x$ & & \\
\hline Isoniazida $100 \mathrm{mg}$ & $x$ & & \\
\hline Isoniazida $100 \mathrm{mg}$ + Rifampicina $150 \mathrm{mg}$ & $x$ & & \\
\hline Isoniazida 200 mg + Rifampicina 300 mg & $x$ & & \\
\hline Levofloxacino $250 \mathrm{mg}$ & & $x$ & $x$ \\
\hline Levofloxacino $500 \mathrm{mg}$ & & $x$ & \\
\hline
\end{tabular}




\section{conclusão}

Quadro 32 - Elenco de medicamentos produzidos pelos laboratórios para o Programa MultidrogaResistência, no período de 2003 a 2013

\begin{tabular}{|c|c|c|c|}
\hline \multirow{2}{*}{ Medicamentos } & \multicolumn{3}{|c|}{ Laboratórios } \\
\hline & Oficiais & Nacionais & Internacionais \\
\hline Linezolida 2mg Solução Injetável & & & $x$ \\
\hline Linezolida $600 \mathrm{mg}$ & & & $x$ \\
\hline Moxifloxacino $400 \mathrm{mg}$ & & $x$ & $x$ \\
\hline Ofloxacino $400 \mathrm{mg}$ & $x$ & & \\
\hline Para-Amino-Salicilico & & & $x$ \\
\hline Pirazinamida $500 \mathrm{mg}$ & $\mathrm{x}$ & & $x$ \\
\hline Piridoxina $100 \mathrm{mg}$ & & & $x$ \\
\hline Rifabutina $150 \mathrm{mg}$ & & & $\mathrm{x}$ \\
\hline Rifampicina $300 \mathrm{mg}$ & $\mathrm{x}$ & & \\
\hline Terizidona $250 \mathrm{mg}$ & & & $x$ \\
\hline Tuberculina PPD - RT 23 & & & $\mathrm{x}$ \\
\hline Total & 8 & 9 & 13 \\
\hline
\end{tabular}

Fonte: Produção Própria.

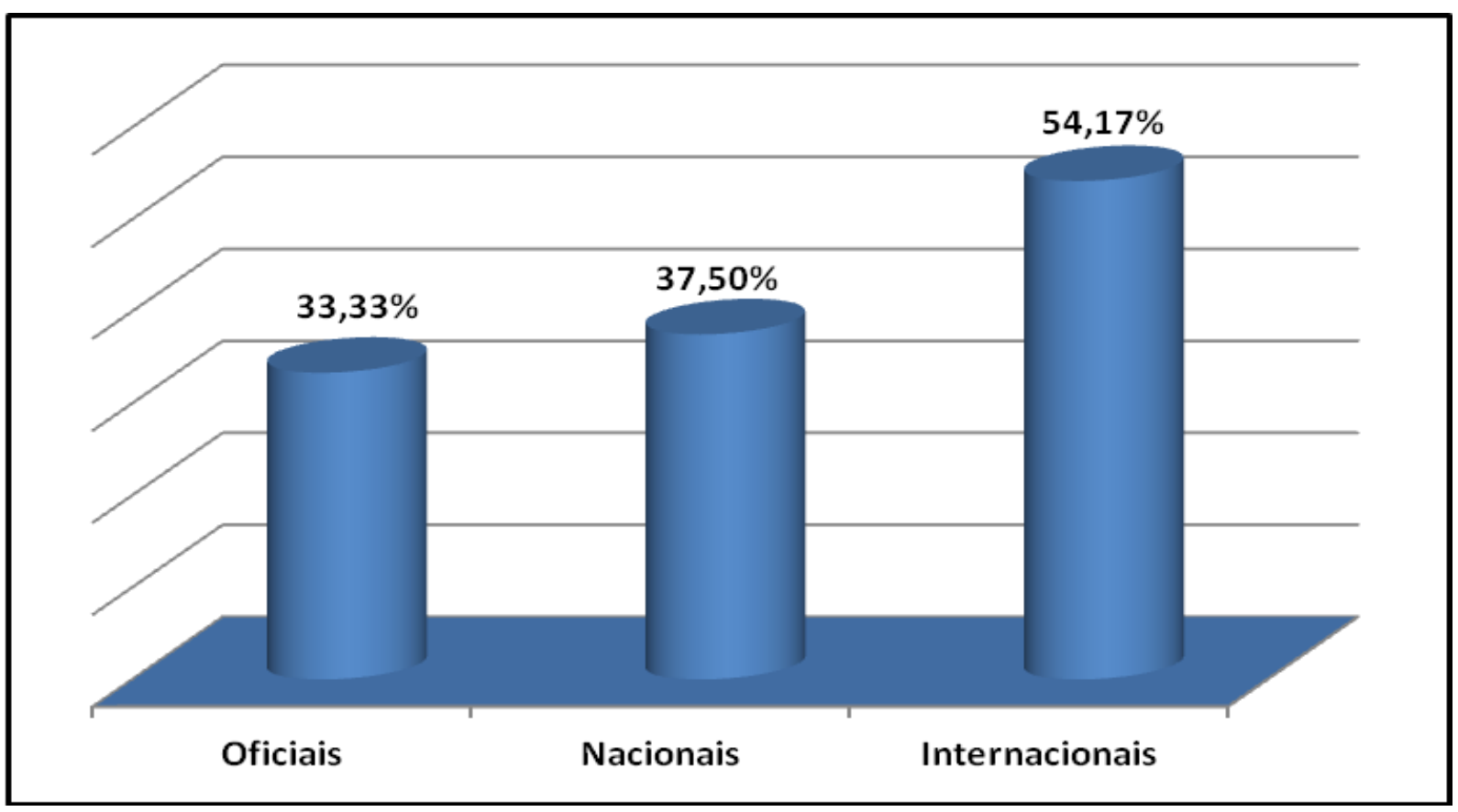

Figura 21 - Representação gráfica da participação percentual dos laboratórios na produção do elenco de medicamentos produzidos para o Programa Multidroga-Resistência, no período de 2003 a 2013. Fonte: Produção Própria. 
Dos 29 laboratórios farmacêuticos oficiais apenas a FIOCRUZ, FURP, IQUEGO, LAFEPE, LFM, LQFA e LQFEX participaram da produção pública para o Programa Multidroga-Resistência, no período de 2003 a 2013. O que corresponde apenas a $24,14 \%$ dos laboratórios públicos.

O laboratório do Exército (LQFEX) foi o que mais participou da produção pública com 5 medicamentos o que representa $31,25 \%$ dos medicamentos do elenco produzidos pelos laboratórios oficiais. A FIOCRUZ produziu 3 medicamentos $(18,75 \%)$. Os laboratórios LQFA, LFM e LAFEPE produziram 2 medicamento $(12,50 \%)$ cada ume a FURP e o LAFEPE produziram 1 medicamento $(6,25 \%)$ cada um.

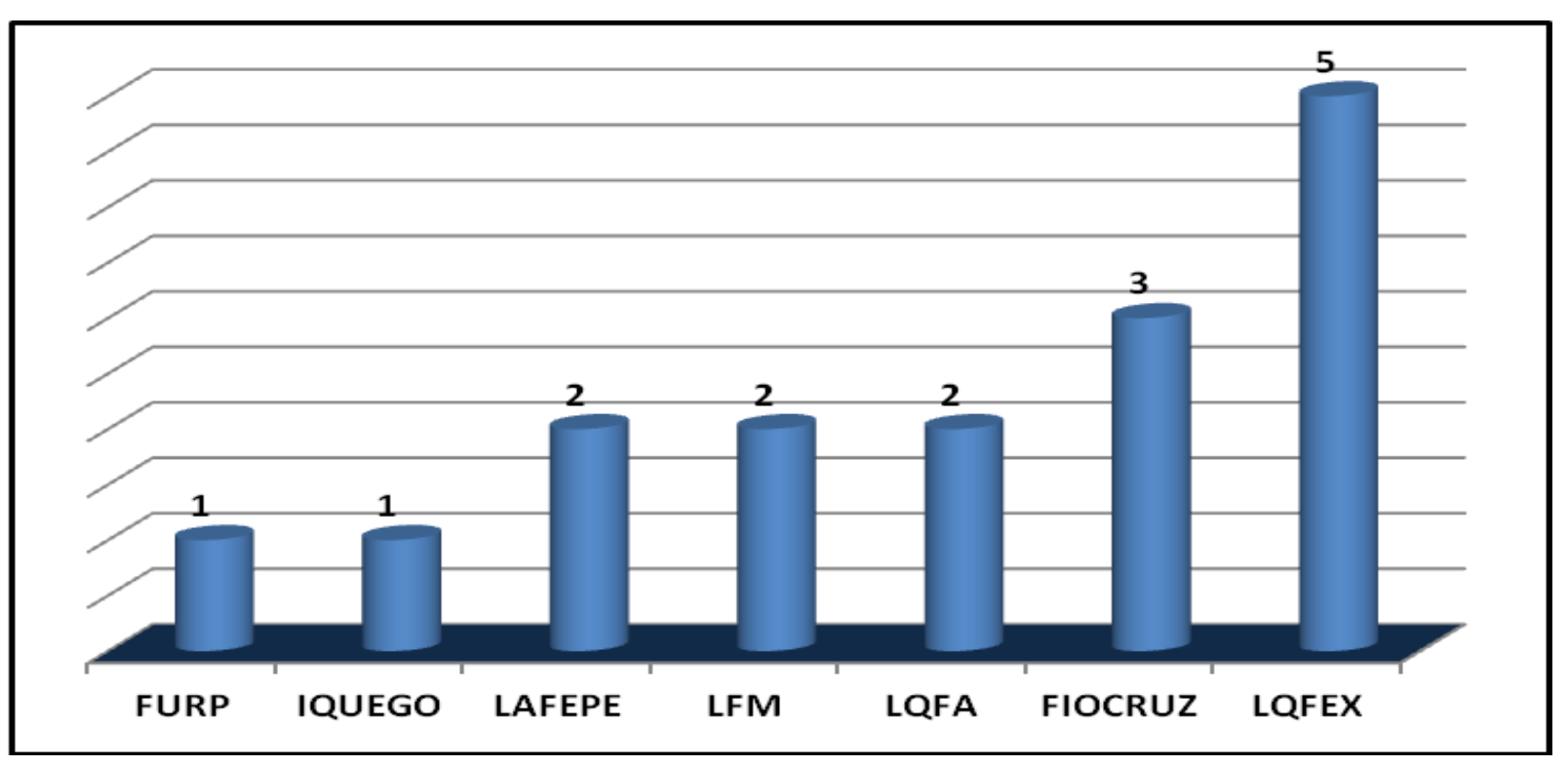

Figura 22 - Representação gráfica da quantidade de medicamentos produzidos pelos laboratórios oficiais para o Programa Multidrogas Resistência, no período de 2003 a 2013.

Fonte: Produção própria.

Nos Quadros 33, 34 e 35 está consolidada a série histórica da quantidade produzida de unidades farmacêuticas e o valor pago pelo Ministério da Saúde em reais, para cada tipo de laboratório, no período de 2003 a 2013. 
continua

Quadro 33 Consolidação da produção dos laboratórios oficiais em número de Unidades Farmacêuticas (UF) e valor pago pelo Ministério da Saúde para Programa Multidrogas Resistência, no período de 2003 a 2013

\begin{tabular}{|c|c|c|c|}
\hline Medicamentos & Unidade & $\begin{array}{l}\text { Quantidade de Unidades } \\
\text { Farmacêuticas } \\
\text { (comprimidos e cápsulas) } \\
\text { produzidas }\end{array}$ & $\begin{array}{c}\text { Valor pago pelo Ministério } \\
\text { da Saúde }(\mathbf{R} \$)\end{array}$ \\
\hline \multicolumn{4}{|c|}{ FIOCRUZ } \\
\hline Etambutol $400 \mathrm{mg}$ & Comp. & 3.059 .000 & $307.212,60$ \\
\hline Isoniazida 100 mg + Rifampicina 150 mg & Cáps. & 3.000 & 297,60 \\
\hline Isoniazida 200 mg + Rifampicina 300 mg & Caps & 25.000 & $4.135,00$ \\
\hline Subtotal & & 3.087 .000 & $311.645,20$ \\
\hline \multicolumn{4}{|c|}{ FURP } \\
\hline Estreptomicina $1 \mathrm{~g}$ solução injetável & $\mathrm{F} / \mathrm{A}$ & 356.800 & $43.201,04$ \\
\hline Subtotal & & 356.800 & $43.201,04$ \\
\hline \multicolumn{4}{|c|}{ IQUEGO } \\
\hline Etambutol $400 \mathrm{mg}$ & Comp. & 798.500 & $77.997,90$ \\
\hline Subtotal & & 798.500 & $77.997,90$ \\
\hline \multicolumn{4}{|c|}{ LAFEPE } \\
\hline Isoniazida 100 mg + Rifampicina 150 mg & Cáps. & 1.000 & 99,20 \\
\hline Rifampicina $300 \mathrm{mg}$ & Cáps. & 36.500 & $5.164,75$ \\
\hline Subtotal & & 37.500 & $5.263,95$ \\
\hline \multicolumn{4}{|c|}{ LFM } \\
\hline Ofloxacino $400 \mathrm{mg}$ & Comp. & 4.253 .000 & $1.616 .140,00$ \\
\hline Pirazinamida $500 \mathrm{mg}$ & Comp. & 1.405 .000 & $429.126,50$ \\
\hline Subtotal & & 5.658 .000 & $2.045 .266,50$ \\
\hline \multicolumn{4}{|c|}{ LQFA } \\
\hline Isoniazida $100 \mathrm{mg}$ & Comp. & 88.500 & $1.451,40$ \\
\hline Pirazinamida $500 \mathrm{mg}$ & Comp. & 128.000 & $15.526,40$ \\
\hline Subtotal & & 216.500 & $16.977,80$ \\
\hline
\end{tabular}




\section{conclusão}

Quadro 33 Consolidação da produção dos laboratórios oficiais em número de Unidades Farmacêuticas (UF) e valor pago pelo Ministério da Saúde para Programa Multidrogas Resistência, no período de 2003 a 2013

\begin{tabular}{|c|c|c|c|}
\hline Medicamentos & Unidade & $\begin{array}{c}\text { Quantidade de Unidades } \\
\text { Farmacêuticas } \\
\text { (comprimidos e cápsulas) } \\
\text { produzidas }\end{array}$ & $\begin{array}{c}\text { Valor pago pelo Ministério } \\
\text { da Saúde (R\$) }\end{array}$ \\
\hline \multicolumn{4}{|c|}{ LQFEX } \\
\hline Isoniazida 100 mg + Rifampicina 150 mg & Cáps. & 5.000 & 496,00 \\
\hline Isoniazida 200 mg + Rifampicina 300 mg & Cáps. & 8.000 & $1.323,20$ \\
\hline Ofloxacino $400 \mathrm{mg}$ & Comp. & 246.000 & $88.560,00$ \\
\hline Rifampicina $300 \mathrm{mg}$ & Cáps. & 79.500 & $11.249,25$ \\
\hline Ofloxacino, Comp. 400mg & Comp. & 10.000 & 0,00 \\
\hline \multicolumn{2}{|l|}{ Subtotal } & 348.500 & $101.628,45$ \\
\hline \multicolumn{2}{|l|}{ Total } & 10.502 .800 & $2.601 .980,84$ \\
\hline
\end{tabular}

Fonte: Produção própria.

\section{continua}

Quadro 34 - Consolidação da produção dos laboratórios nacionais em número de Unidades Farmacêuticas (UF) e valor pago pelo Ministério da Saúde para Programa Multidrogas Resistência, no período de 2003 a 2013

\begin{tabular}{|l|c|c|c|c|}
\hline \multicolumn{1}{|c|}{ Medicamentos } & Unidade & Laboratório & $\begin{array}{c}\text { Quantidade de } \\
\text { Unidades } \\
\text { Farmacêuticas } \\
\text { (comprimidos e } \\
\text { cápsulas) } \\
\text { produzidas }\end{array}$ & $\begin{array}{l}\text { Valor pago pelo } \\
\text { Ministério da } \\
\text { Saúde (R\$) }\end{array}$ \\
\hline Amicacina (SULFATO) $250 \mathrm{mg}$ solução injetável & Amp. & PHARLAB & 30.000 & $18.150,00$ \\
Amicacina $1 \mathrm{~g}$ & F/A & HIPOLABOR & 18.000 & $57.960,00$ \\
Amicacina $500 \mathrm{mg}$ & F/A & Blausiegel - Ata SP & 156.000 & $93.600,00$ \\
Amicacina $500 \mathrm{mg}$ & F/A & Dinalmed & 156.000 & $112.320,00$ \\
Amicacina $500 \mathrm{mg}$ & F/A & HIPOLABOR & 122.500 & $105.250,00$ \\
Amicacina $500 \mathrm{mg}$ & F/A & NOVAFARMA & 363.600 & $242.400,00$ \\
Capreomicina $1 \mathrm{~g}$ & F/A & OPAS & 28.000 & $395.578,52$ \\
Claritromicina $500 \mathrm{mg}$ & Comp. & Rioclarense & 186.200 & $123.860,24$ \\
Claritromicina $500 \mathrm{mg}$ & Comp. & EMS. & 59.100 & $92.250,00$ \\
Claritromicina $500 \mathrm{mg}$ & Comp. & Laboris & 852.100 & $548.158,00$ \\
Claritromicina $500 \mathrm{mg}$ & Comp. & OPAS & 300.000 & $199.560,00$ \\
\hline
\end{tabular}




\section{conclusão}

Quadro 34 - Consolidação da produção dos laboratórios nacionais em número de Unidades Farmacêuticas (UF) e valor pago pelo Ministério da Saúde para Programa Multidrogas Resistência, no período de 2003 a 2013

\begin{tabular}{|l|l|c|c|c|}
\hline \multicolumn{1}{|c|}{ Medicamentos } & Unidade & Laboratório & $\begin{array}{c}\text { Quantidade de } \\
\text { Unidades } \\
\text { Farmacêuticas } \\
\text { (comprimidos e } \\
\text { cápsulas) } \\
\text { produzidas }\end{array}$ & $\begin{array}{l}\text { Valor pago pelo } \\
\text { Ministério da } \\
\text { Saúde (R\$) }\end{array}$ \\
\hline Clofazimina $100 \mathrm{mg}$ & Cáps. & OPAS & 118.000 & $368.281,64$ \\
Levofloxacino $250 \mathrm{mg}$ & Comp. & A7 DIST. & 300.000 & $753.000,00$ \\
Levofloxacino $500 \mathrm{mg}$ & Comp. & E.M.S & 808.000 & $331.280,00$ \\
Levofloxacino $500 \mathrm{mg}$ & Comp. & HOSPFAR & 1.000 .000 & $480.000,00$ \\
Levofloxacino $500 \mathrm{mg}$ & Comp. & LICIMED & 200.000 & $96.000,00$ \\
Moxifloxacino $400 \mathrm{mg}$ & Tomp. & Bayer & 56.600 & $569.200,00$ \\
\hline
\end{tabular}

Fonte: Produção própria.

\section{continua}

Quadro 35 - Consolidação da produção dos laboratórios internacionais em número de Unidades Farmacêuticas (UF) e valor pago pelo Ministério da Saúde para o Programa Multidrogas Resistência, no período de 2003 a 2013

\begin{tabular}{|c|c|c|c|c|}
\hline Medicamentos & Unidade & Laboratório & $\begin{array}{l}\text { Quantidade de Unidades } \\
\text { Farmacêuticas (comprimidos e } \\
\text { cápsulas) produzidas }\end{array}$ & $\begin{array}{l}\text { Valor pago pelo } \\
\text { Ministério da } \\
\text { Saúde (R\$) }\end{array}$ \\
\hline Moxifloxacino $400 \mathrm{mg}$ & Comp. & MEDCOMERCE & 23.000 & $188.830,00$ \\
\hline Capreomicina $1 \mathrm{~g}$ & $\mathrm{~F} / \mathrm{A}$ & OPAS & 49.000 & $1.078 .477,40$ \\
\hline Clofazimina $100 \mathrm{mg}$ & Cáps. & OPAS & 96.000 & $42.720,00$ \\
\hline Para-Amino-Salicilico & Sachê & OPAS & 120.000 & $798.864,00$ \\
\hline Para-Amino-Salicilico & Sachê & OPAS & 353.010 & $1.215 .662,70$ \\
\hline Pirazinamida $500 \mathrm{mg}$ & Comp. & OPAS & 300 & 478,80 \\
\hline Piridoxina $100 \mathrm{mg}$ & Comp. & OPAS & 352.000 & $706.242,96$ \\
\hline Piridoxina $100 \mathrm{mg}$ & blister & OPAS & 360.000 & $22.074,00$ \\
\hline Rifabutina $150 \mathrm{mg}$ & Comp. & OPAS & 2.880 .000 & $2.439 .653,76$ \\
\hline Linezolida 2mg Solução Injetável & Bolsa & PFIZER & 5.110 & $978.462,80$ \\
\hline Linezolida $600 \mathrm{mg}$ & Comp. & PFIZER & 45.990 & $6.622 .560,00$ \\
\hline
\end{tabular}




\section{conclusão}

Quadro 35 - Consolidação da produção dos laboratórios internacionais em número de Unidades Farmacêuticas (UF) e valor pago pelo Ministério da Saúde para o Programa Multidrogas Resistência, no período de 2003 a 2013

\begin{tabular}{|c|c|c|c|c|}
\hline Medicamentos & Unidade & Laboratório & $\begin{array}{l}\text { Quantidade de Unidades } \\
\text { Farmacêuticas (comprimidos e } \\
\text { cápsulas) produzidas }\end{array}$ & $\begin{array}{l}\text { Valor pago pelo } \\
\text { Ministério da } \\
\text { Saúde (R\$) }\end{array}$ \\
\hline Claritromicina $500 \mathrm{mg}$ & Comp. & PHARLAB & 300.000 & $181.500,00$ \\
\hline Levofloxacino $250 \mathrm{mg}$ & Comp. & PRODIET & 225.000 & $447.750,00$ \\
\hline Moxifloxacino $400 \mathrm{mg}$ & Comp. & PRODIET & 80.000 & $656.000,00$ \\
\hline Terizidona 250 mg & Cáps. & UNO & 1.900 .000 & $6.942 .410,00$ \\
\hline Terizidona 250 mg & Cáps. & UNO & 1.500 .000 & $4.804 .731,16$ \\
\hline Terizidona 250 mg & Cáps. & UNO & 3.600 .000 & $11.597 .040,00$ \\
\hline Tuberculina - PPD-RT 23 & $\mathrm{~F} / \mathrm{A}$ & UNO & 145.000 & $1.328 .925,00$ \\
\hline Terizidona 250 mg & Cáps. & FLOMED & 4.661 .670 & $21.643 .428,48$ \\
\hline Terizidona $250 \mathrm{mg}$ & Cáps. & Flomed & 600.000 & $2.304 .703,80$ \\
\hline Tuberculina PPD - RT 23 & $\mathrm{~F} / \mathrm{A}$ & FLOMED & 127.470 & $1.282 .220,73$ \\
\hline \multicolumn{3}{|c|}{ Total } & 17.423 .550 & 65.282 .736 \\
\hline
\end{tabular}

Fonte: Produção própria.

No período pesquisado o Ministério da Saúde adquiriu 32.680.450 unidades farmacêuticas para o Programa Multidrogas Resistência e gastou R $\$ 72.471 .564,83$, no período de 2003 a 2013.'

Quadro 36 - Consolidação da produção dos laboratórios oficiais, nacionais e internacionais em número de Unidades Farmacêuticas (UF) e valor pago pelo Ministério da Saúde para o Programa Multidrogas Resistência, no período de 2003 a 2013.

\begin{tabular}{|c|c|c|}
\hline Laobratórios & $\begin{array}{c}\text { Quantidade de Unidades } \\
\text { Farmacêuticas (comprimidos e } \\
\text { cápsulas) produzidas }\end{array}$ & $\begin{array}{l}\text { Valor pago pelo Ministério da Saúde } \\
\qquad(\mathbf{R} \$)\end{array}$ \\
\hline Oficiais & 10.502 .800 & $2.601 .980,84$ \\
\hline Nacionais & 4.754 .100 & 4.586 .848 \\
\hline Internacionais & 17.423 .550 & 65.282 .736 \\
\hline Total & 32.680 .450 & $72.471 .564,83$ \\
\hline
\end{tabular}

Fonte: Produção própria. 
Os laboratórios farmacêuticos oficiais produziram $32,14 \%$ das unidades farmacêuticas adquiridas pelo Ministério da Saúde. Os laboratórios nacionais foram responsáveis por $14,55 \%$ da produção e os internacionais produziram $53,11 \%$.

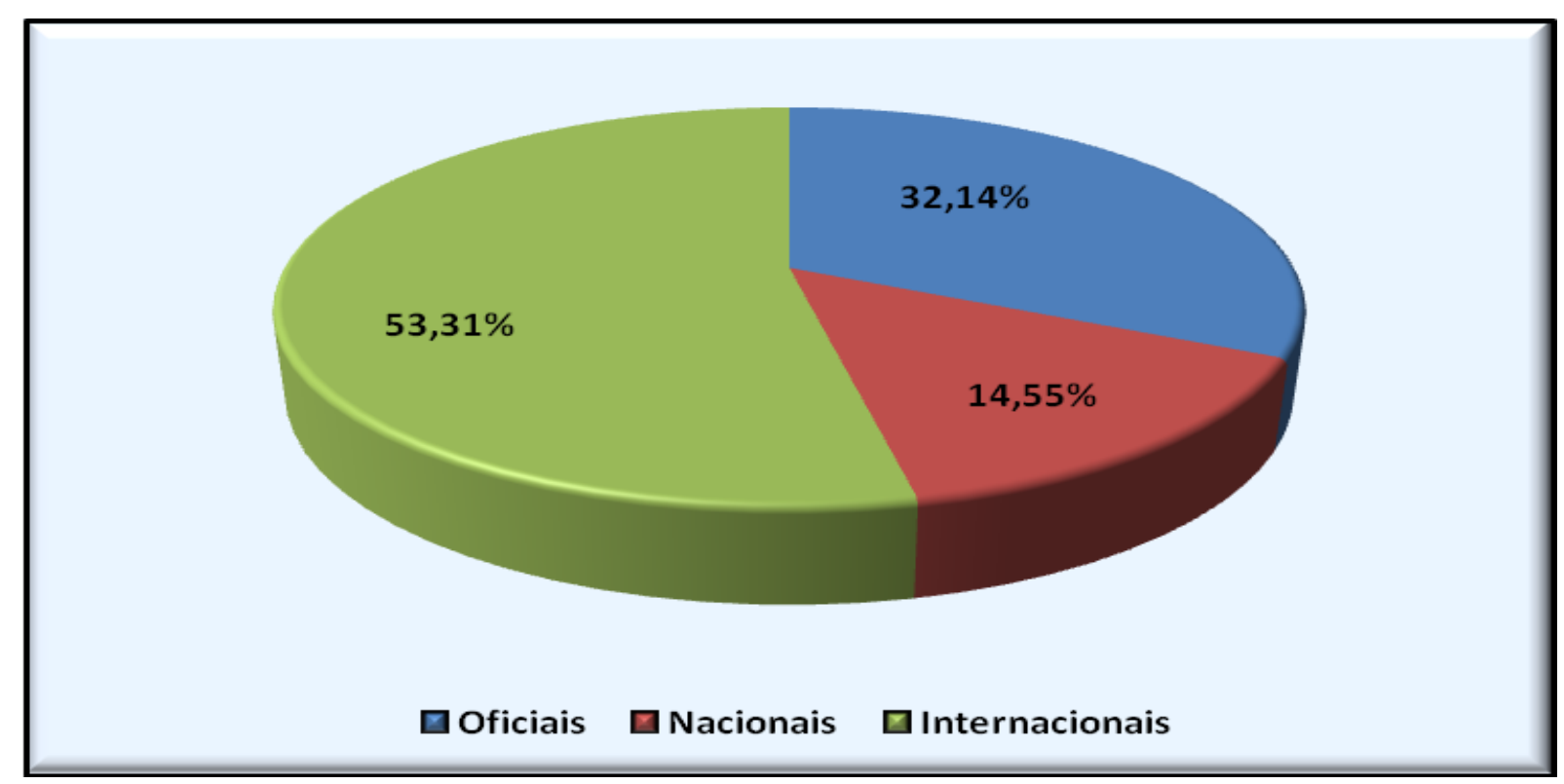

Figura 23 - Participação percentual da quantidade produzida pelos laboratórios oficiais, nacionais e internacionais em número de unidades farmacêuticas (UF) para o Ministério da Saúde para o Programa Multidrogas Resistência, no período de 2003 a 2013.

Fonte: Produção própria.

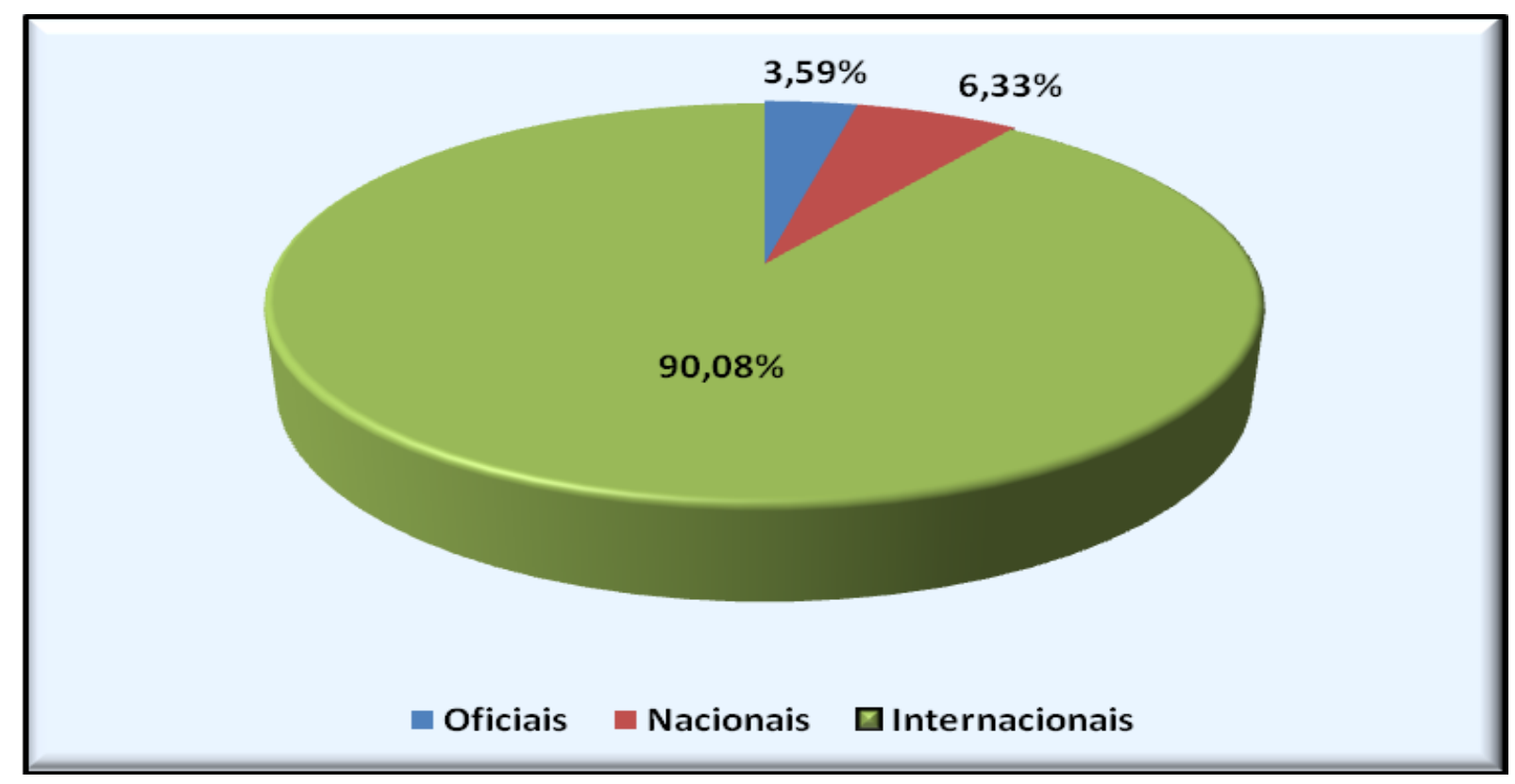

Figura 24 - Participação percentual do gasto do Ministério da Saúde com a produção dos laboratórios oficiais, nacionais e internacionais para o Programa Multidrogas Resistência, no período de 2003 a 2013.

Fonte: Produção própria. 


\subsection{MEDICAMENTOS DO COMPONENTE ESPECIALIZADO DA ASSISTÊNCIA FARMACÊUTICA}

O Componente Farmacêutico Especializado é uma estratégia implementada pelo Ministério da Saúde para fortalecer o acesso a medicamentos no âmbito do Sistema Único de Saúde (SUS) pela população brasileira.

Este componente tem como objetivo garantir a integralidade do tratamento medicamentoso em nível ambulatorial, cujas linhas de cuidado estão definidas em Protocolos Clínicos e Diretrizes Terapêuticas (PCDT), publicados pelo Ministério da Saúde.

No período de 2003 a 2013 a pesquisa identificou um elenco de 80 medicamentos.

Do elenco acima os laboratórios oficiais foram responsáveis pela produção de 20 medicamentos, o que representa $25 \%$ do elenco. Os laboratórios internacionais ficaram com a produção de 9 medicamentos $(11,25 \%)$. Os laboratórios nacionais foram os que mais produziram. Foram responsáveis pela produção de 61 medicamentos do elenco, que representa $76,25 \%$.

Dos 20 medicamentos produzidos pelos laboratórios oficiais, 18 medicamentos foram produzidos exclusivamente por eles e 2 medicamentos, tracolimo de $5 \mathrm{mg}$ e $10 \mathrm{mg}$, ooorreu produção delaboratórios nacionais. Foi observado ainda, que todos os medicamentos produzidos pelos laboratórios internacionais também foram produzidos por laboratórios nacionais.

continua

Quadro 37 - Elenco de medicamentos produzidos pelos laboratórios oficiais, nacionais e internacionais parao Componente Especializado da Assistência Farmacêutica, no período de 2003 a 2013

\begin{tabular}{|c|c|c|c|c|}
\hline \multirow{2}{*}{ Medicamentos } & \multirow{2}{*}{ Unidade } & \multicolumn{3}{|c|}{ Laboratórios } \\
\hline & & Oficiais & Nacionais & Internacionais \\
\hline Abatacepte 250mg & & & $x$ & \\
\hline Adalimumabe 40mg Solução Injetável & Seringa & & $x$ & \\
\hline Adefovir $10 \mathrm{mg}$ & Comp. & & $x$ & $x$ \\
\hline Alfaepoetina $2000 \mathrm{UI}$ & $\mathrm{F} / \mathrm{A}$ & $x$ & & \\
\hline Alfaepoetina $4000 \mathrm{UI}$ & $\mathrm{F} / \mathrm{A}$ & $x$ & & \\
\hline
\end{tabular}




\section{continuação}

Quadro 37 - Elenco de medicamentos produzidos pelos laboratórios oficiais, nacionais e internacionais parao Componente Especializado da Assistência Farmacêutica, no período de 2003 a 2013

\begin{tabular}{|c|c|c|c|c|}
\hline \multirow{2}{*}{ Medicamentos } & \multirow{2}{*}{ Unidade } & \multicolumn{3}{|c|}{ Laboratórios } \\
\hline & & Oficiais & Nacionais & Internacionais \\
\hline Alfainterferona $10.000 .000 \mathrm{UI}$ & $\mathrm{F} / \mathrm{A}$ & $x$ & & \\
\hline Alfainterferona $3.000 .000 \mathrm{UI}$ & $\mathrm{F} / \mathrm{A}$ & $x$ & & \\
\hline Alfainterferona $5.000 .000 \mathrm{UI}$ & $\mathrm{F} / \mathrm{A}$ & $x$ & & \\
\hline Alfapeginterferona $100 \mathrm{mcg}$ & $\mathrm{F} / \mathrm{A}$ & & $x$ & \\
\hline Alfapeginterferona $120 \mathrm{mcg}$ & $\mathrm{F} / \mathrm{A}$ & & $x$ & \\
\hline Alfapeginterferona $180 \mathrm{mcg}$ & Seringa & & $x$ & \\
\hline Alfapeginterferona $180 \mathrm{mcg}$ & F/A e Seringa & & $x$ & $x$ \\
\hline Alfapeginterferona $2 \mathrm{a}-180 \mathrm{mcg}$ & Fr. & & $x$ & \\
\hline Alfapeginterferona $2 b-100 \mathrm{mcg}$ & $\mathrm{F} / \mathrm{A}$ & & $x$ & \\
\hline Alfapeginterferona $2 b-120 \mathrm{mcg}$ & $\mathrm{F} / \mathrm{A}$ & & $x$ & \\
\hline Alfapeginterferona $2 \mathrm{~b}-80 \mathrm{mcg}$ & $\mathrm{F} / \mathrm{A}$ & & $x$ & \\
\hline Alfapeginterferona $80 \mathrm{mcg}$ & $\mathrm{F} / \mathrm{A}$ & & $x$ & \\
\hline $\begin{array}{l}\text { Alfapoetina Humana Recombinante } \\
2000 \mathrm{UI}\end{array}$ & & $x$ & & \\
\hline $\begin{array}{l}\text { Alfavelaglicerase } 200 \mathrm{U} / 400 \mathrm{U} \text { ou } \\
\text { imiglucerase } 200 \mathrm{U} / 400 \mathrm{U}\end{array}$ & $U$ & & $x$ & \\
\hline $\begin{array}{l}\text { Betainterferona 1A } 12.000 .000 \mathrm{UI}(44 \\
\mathrm{mcg})\end{array}$ & Seringa & & $x$ & \\
\hline $\begin{array}{l}\text { Betainterferona 1A 6.000.000 UI (22 } \\
\text { mcg) }\end{array}$ & Seringa & & $x$ & \\
\hline $\begin{array}{l}\text { Betainterferona 1A } 6.000 .000 \mathrm{UI}(30 \\
\mathrm{mcg})\end{array}$ & Seringa & & $x$ & \\
\hline $\begin{array}{l}\text { Betainterferona 1B } 9.600 .000 \mathrm{UI} \\
(300 \mathrm{mcg})\end{array}$ & Seringa & & $x$ & \\
\hline Boceprevir $200 \mathrm{mg}$ & Cáps. & & $x$ & \\
\hline Certolizumabe 200 mg & & & $x$ & \\
\hline Clozapina 100 mg & Comp. & $x$ & & \\
\hline Clozapina $25 \mathrm{mg}$ & Comp. & $x$ & & \\
\hline Donepezila $10 \mathrm{mg}$ & Comp. & & $x$ & \\
\hline Donepezila $5 \mathrm{mg}$ & Comp. & & $x$ & \\
\hline Entecavir $0,5 \mathrm{mg}$ & Comp. & & $x$ & $x$ \\
\hline Entecavir $1,0 \mathrm{mg}$ & Comp. & & $x$ & $x$ \\
\hline Eritropoetina/Interferon & Teste & $x$ & & \\
\hline
\end{tabular}




\section{continuação}

Quadro 37 - Elenco de medicamentos produzidos pelos laboratórios oficiais, nacionais e internacionais parao Componente Especializado da Assistência Farmacêutica, no período de 2003 a 2013

\begin{tabular}{|c|c|c|c|c|}
\hline \multirow{2}{*}{ Medicamentos } & \multirow{2}{*}{ Unidade } & \multicolumn{3}{|c|}{ Laboratórios } \\
\hline & & Oficiais & Nacionais & Internacionais \\
\hline Etanercepte 25 mg & $F / A$ & & $x$ & \\
\hline Etanercepte $50 \mathrm{mg}$ & $F / A$ & & $x$ & \\
\hline Everolimo 0,5 mg & Comp. & & $x$ & \\
\hline Everolimo $0,75 \mathrm{mg}$ & Comp. & & $x$ & \\
\hline Everolimo $1,0 \mathrm{mg}$ & Comp. & & $x$ & \\
\hline Glatirâmer 20 mg Injetável & Seringa & & $x$ & \\
\hline Golimumabe 50 mg & & & $x$ & \\
\hline Imatinibe (Mesilato) 100 mg (ONCO) & Comp. & & $x$ & \\
\hline Imatinibe (Mesilato) 400 mg & Comp. & & $x$ & \\
\hline Imiglucerase 200 UI & Fr. & & $x$ & $x$ \\
\hline Imiglucerase $400 \mathrm{UI}$ & $\mathrm{F} / \mathrm{A}$ & & & $x$ \\
\hline $\begin{array}{l}\text { Imunoglobulina Anti-B } 1000 \mathrm{UI} \text { (200 UI } \\
\text { amp 5ml) }\end{array}$ & Amp. & & $x$ & \\
\hline $\begin{array}{l}\text { Imunoglobulina Anti-B } 600 \text { UI (200 UI } \\
\text { amp 3ml) }\end{array}$ & Amp. & & $x$ & $\mathrm{x}$ \\
\hline Imunoglobulina Anti-Hepatite B 100 UI & Fr. & & $x$ & \\
\hline Imunoglobulina Humana 5,0 g & Ampola & & $x$ & $x$ \\
\hline Infliximabe 10 mg injetável & $\mathrm{F} / \mathrm{A}$ & & $x$ & \\
\hline Interferon $10.000 .000 \mathrm{UI}$ & $\mathrm{F} / \mathrm{A}$ & $x$ & & \\
\hline Interferon 3.000.000 UI & F/A & $x$ & & \\
\hline Interferon 5.000.000 UI & $\mathrm{F} / \mathrm{A}$ & $x$ & & \\
\hline L-Asparaginase $10.000 \mathrm{UI} / 10 \mathrm{ml}$ & $\mathrm{F} / \mathrm{A}$ & & $x$ & \\
\hline Leflunomida 20 mg & Comp. & & $x$ & \\
\hline Micofenolato de Mofetila 500 mg & Comp. & & $x$ & \\
\hline Micofenolato de Sódio 180 mg & Comp. & & $x$ & \\
\hline Micofenolato de Sódio 360 mg & Comp. & & $x$ & \\
\hline Miglustate $100 \mathrm{mg}$ & Cáps. & & $x$ & \\
\hline $\begin{array}{l}\text { Natalizumabe } 300 \text { mg Solução } \\
\text { Injetável }\end{array}$ & $\mathrm{F} / \mathrm{A}$ & & $x$ & \\
\hline Olanzapina 10 mg & Comp. & $x$ & & \\
\hline
\end{tabular}




\section{conclusão}

Quadro 37 - Elenco de medicamentos produzidos pelos laboratórios oficiais, nacionais e internacionais parao Componente Especializado da Assistência Farmacêutica, no período de 2003 a 2013

\begin{tabular}{|c|c|c|c|c|}
\hline \multirow{2}{*}{ Medicamentos } & \multirow{2}{*}{ Unidade } & \multicolumn{3}{|c|}{ Laboratórios } \\
\hline & & Oficiais & Nacionais & Internacionais \\
\hline Olanzapina 5 mg & Comp. & $x$ & & \\
\hline Quetiapina $100 \mathrm{mg}$ & Comp. & $x$ & & \\
\hline Quetiapina 200 mg & Comp. & $x$ & & \\
\hline Quetiapina $25 \mathrm{mg}$ & Comp. & $x$ & & \\
\hline Ribavirina $250 \mathrm{mg}$ & Cáps. & $x$ & & \\
\hline Rituximabe 500 mg & & & $x$ & \\
\hline Rivastigmina $1,5 \mathrm{mg}$ & Cáps. & & $x$ & \\
\hline Rivastigmina 3 mg & Cáps. & & $x$ & \\
\hline Rivastigmina $4,5 \mathrm{mg}$ & Cáps. & & $x$ & \\
\hline Rivastigmina 6 mg & Cáps. & & $x$ & \\
\hline Sevelamer (Cloridrato) 800 mg & Comp. & & $x$ & \\
\hline Sirolimo $1 \mathrm{mg}$ & Drágea & & $x$ & \\
\hline Sirolimo $1 \mathrm{mg} / \mathrm{ml}$ & Fr. & & $x$ & \\
\hline Sirolimo 2 mg & Drágea & & $x$ & \\
\hline Tacrolimo $1 \mathrm{mg}$ & Cáps. & $x$ & $x$ & \\
\hline Tacrolimo 5 mg & & $x$ & $x$ & \\
\hline Taliglucerase Alfa $200 \mathrm{UI}$ & F/A & & $x$ & $x$ \\
\hline Telaprevir 375 mg & Comp. & & $x$ & \\
\hline Tocilizumabe 20mg & F/A & & $x$ & \\
\hline Traztuzumabe 150 mg & F/A & & $x$ & \\
\hline Traztuzumabe 440 mg & $\mathrm{F} / \mathrm{A}$ & & $x$ & \\
\hline Total & & 20 & 61 & 9 \\
\hline
\end{tabular}




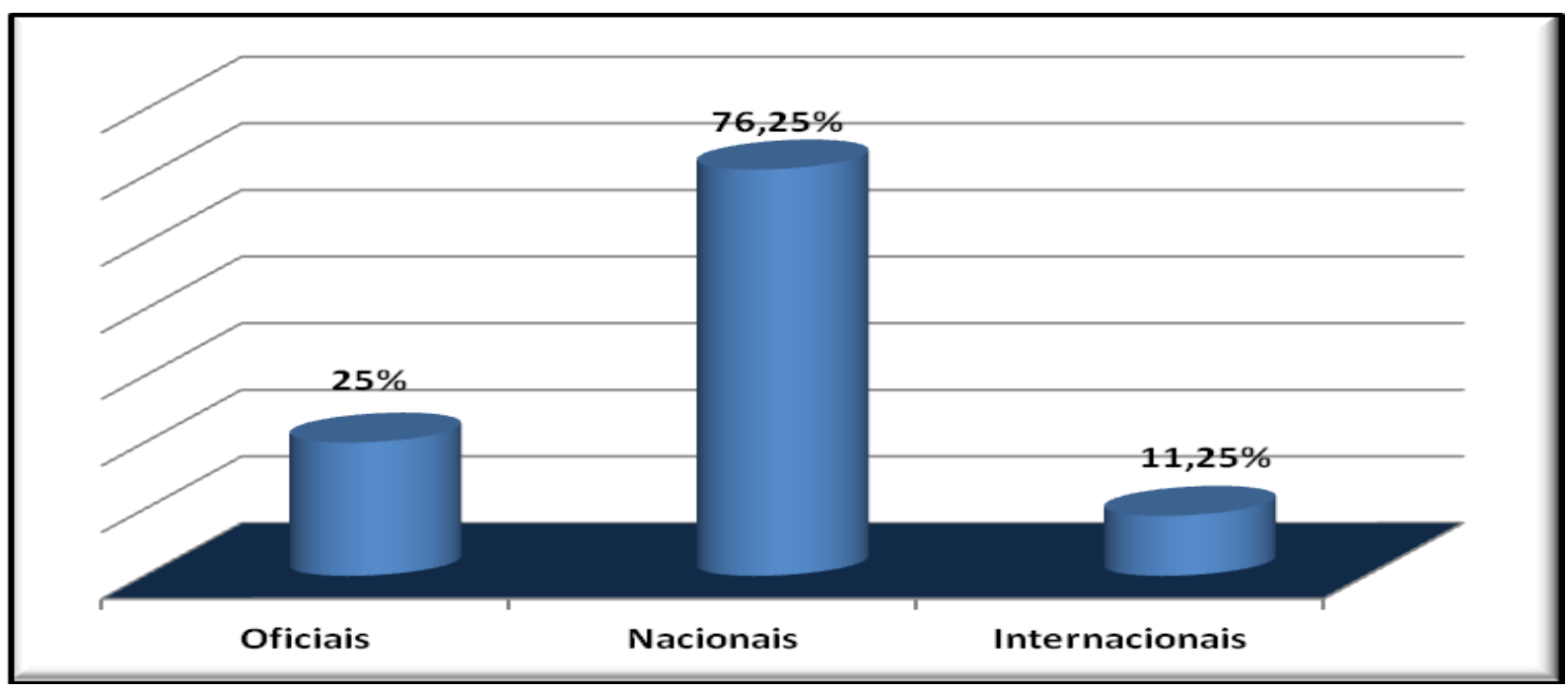

Figura 25 - Representação gráfica da participação percentual dos laboratórios na produção de medicamentos para o Componente Especializado da Assistência Farmacêutica, no período de 2003 a 2013.

Fonte: Produção própria.

Dos 29 laboratórios oficiais apenas a FIOCRUZ e o LFEPE participaram da produção pública para o Componente Especializado. A participação dos LFO foi de apenas $6,9 \%$.

A FIOCRUZ produziu 13 medicamentos (13,00\%) e o LAFEPE ficou responsável pela produção de 7 medicamentos $(7,00 \%)$.

Nos Quadros 38, 39 e 40 está consolidada a quantidade produzida de unidades farmacêuticas e o valor pago pelo Ministério da Saúde, para cada segmento da indústria farmacêutica.

\section{continua}

Quadro 38 - Consolidação da produção dos laboratórios oficiais em número de Unidades Farmacêuticas (UF) e valor pago pelo Ministério da Saúde para o Componente Especializado da Assistência Farmacêutica, no período de 2003 a 2013

\begin{tabular}{|l|c|c|c|c|}
\hline \multicolumn{1}{|c|}{ Medicamentos } & Unid. & Fornecedor & $\begin{array}{c}\text { Quantidade de } \\
\text { Unidades } \\
\text { Farmacêuticas } \\
\text { (comprimido, } \\
\text { cápsula, seringas e } \\
\text { frascos) produzidas }\end{array}$ & $\begin{array}{c}\text { Valor pago pelo } \\
\text { Ministério da Saúde } \\
\text { (R\$) }\end{array}$ \\
\hline Alfaepoetina 2000 UI & F/A & FIOCRUZ & 2.037 .749 & $18.691 .982,02$ \\
Alfaepoetina 4000 UI & F/A & FIOCRUZ & 15.136 .333 & $260.557 .094,69$ \\
Alfainterferona 10.000.000 UI & F/A & FIOCRUZ & 6.269 & $430.993,75$ \\
Alfainterferona 3.000.000 UI & F/A & FIOCRUZ & 120.158 & $2.411 .571,06$ \\
Alfainterferona 5.000.000 UI & F/A & FIOCRUZ & 32.268 & $1.091 .626,44$
\end{tabular}




\section{conclusão}

Quadro 38 - Consolidação da produção dos laboratórios oficiais em número de Unidades Farmacêuticas (UF) e valor pago pelo Ministério da Saúde para o Componente Especializado da Assistência Farmacêutica, no período de 2003 a 2013

\begin{tabular}{|c|c|c|c|c|}
\hline Medicamentos & Unid. & Fornecedor & $\begin{array}{c}\text { Quantidade de } \\
\text { Unidades } \\
\text { Farmacêuticas } \\
\text { (comprimido, } \\
\text { cápsula, seringas e } \\
\text { frascos) produzidas }\end{array}$ & $\begin{array}{c}\text { Valor pago pelo } \\
\text { Ministério da Saúde } \\
(R \$)\end{array}$ \\
\hline $\begin{array}{l}\text { Alfapoetina Humana Recombinante } \\
2000 \text { UI }\end{array}$ & & FIOCRUZ & 38.637 .612 & $540.153 .815,76$ \\
\hline Interferon $10.000 .000 \mathrm{UI}$ & F/A & FIOCRUZ & 6.326 & $416.187,54$ \\
\hline Interferon $3.000 .000 \mathrm{UI}$ & $\mathrm{F} / \mathrm{A}$ & FIOCRUZ & 138.992 & $2.670 .036,32$ \\
\hline Interferon $5.000 .000 \mathrm{UI}$ & $\mathrm{F} / \mathrm{A}$ & FIOCRUZ & 29.258 & $947.081,46$ \\
\hline Ribavirina $250 \mathrm{mg}$ & Cáps. & FIOCRUZ & 100.222 .748 & $14.031 .184,72$ \\
\hline Tacrolimo $1 \mathrm{mg}$ & & FIOCRUZ & 136.074 .200 & $392.158 .470,00$ \\
\hline Tacrolimo $5 \mathrm{mg}$ & & FIOCRUZ & 6.950 .100 & $96.864 .483,00$ \\
\hline Subtotal & & & 299.392.013 & 1.330 .424 .527 \\
\hline Clozapina $100 \mathrm{mg}$ & Comp. & LAFEPE & 54.258 .448 & $88.345 .489,28$ \\
\hline Clozapina $25 \mathrm{mg}$ & Comp. & LAFEPE & 35.024 .788 & $55.975 .965,54$ \\
\hline Olanzapina 5 mg & Comp. & LAFEPE & & \\
\hline Olanzapina $10 \mathrm{mg}$ & Comp. & LAFEPE & & \\
\hline Quetiapina $100 \mathrm{mg}$ & Comp. & LAFEPE & 55.380 .472 & $165.400 .436,83$ \\
\hline Quetiapina $200 \mathrm{mg}$ & Comp. & LAFEPE & 51.541 .812 & $364.031 .555,32$ \\
\hline Quetiapina $25 \mathrm{mg}$ & Comp. & LAFEPE & 39.793 .532 & $34.806 .469,86$ \\
\hline Subtotal & & & 235.999.052 & 708.559 .917 \\
\hline \multicolumn{3}{|l|}{ Total } & 535.391 .065 & 2.038.984.443,59 \\
\hline
\end{tabular}

Fonte: Produção própria. 


\section{continua}

Quadro 39 - Consolidação da produção dos laboratórios nacionais em número de Unidades Farmacêuticas (UF) e valor pago pelo Ministério da Saúde para o Componente Especializado da Assistência Farmacêutica, no período de 2003 a 2013

\begin{tabular}{|c|c|c|c|c|}
\hline Medicamentos & Unid. & Fornecedor & \begin{tabular}{|c} 
Quantidade de \\
Unidades \\
Farmacêuticas \\
(comprimido, cápsula, \\
seringas e frascos) \\
produzidas
\end{tabular} & $\begin{array}{l}\text { Valor pago pelo } \\
\text { Ministério da Saúde } \\
\text { (R\$) }\end{array}$ \\
\hline Adalimumabe 40mg Solução Injetável & Seringa & ABBOTT & 1.580 .600 & $1.978 .722 .184,16$ \\
\hline Micofenolato de Mofetila $500 \mathrm{mg}$ & Comp. & ACCORD & 6.706 .450 & $2.816 .709,00$ \\
\hline Miglustate $100 \mathrm{mg}$ & Cáps. & ACTELION & 90.360 & $10.029 .960,00$ \\
\hline Certolizumabe $200 \mathrm{mg}$ & & ASTRAZENECA & 21.740 & $11.740 .252,20$ \\
\hline L-Asparaginase $10.000 \mathrm{Ul} / 10 \mathrm{ml}$ & $\mathrm{F} / \mathrm{A}$ & BAGÓ & 52.300 & $17.640 .790,00$ \\
\hline $\begin{array}{l}\text { Betainterferona 1B } 9.600 .000 \mathrm{UI} \\
\text { (300mcg) }\end{array}$ & Seringa & BAYER & 1.630 .020 & $264.683 .814,30$ \\
\hline $\begin{array}{l}\text { Betainterferona } 1 \mathrm{~A} 6.000 .000 \mathrm{UI}(30 \\
\mathrm{mcg})\end{array}$ & Seringa & BIOGEN & 539.640 & 293.600.971,68 \\
\hline $\begin{array}{l}\text { Natalizumabe } 300 \text { mg Solução } \\
\text { Injetável }\end{array}$ & $\mathrm{F} / \mathrm{A}$ & BIOGEN & 46.355 & $112.949 .512,00$ \\
\hline Imunoglobulina Humana 5,0 g & $\mathrm{F} / \mathrm{A}$ & BLAUSIEGEL & 62.525 & $23.694 .630,31$ \\
\hline Abatacepte $250 \mathrm{mg}$ & & BRISTOL & 76.088 & $57.935 .685,84$ \\
\hline Entecavir $0,5 \mathrm{mg}$ & Comp. & BRISTOL & 604.110 & $6.246 .497,40$ \\
\hline Entecavir $1,0 \mathrm{mg}$ & Comp. & BRISTOL & 63.000 & $811.377,00$ \\
\hline Alfapeginterferona $2 \mathrm{a}$ - $180 \mathrm{mcg}$ & Fr. & $\begin{array}{l}\text { F.Hoffmann-La } \\
\text { Roche }\end{array}$ & 194.056 & $104.887 .268,00$ \\
\hline Adefovir $10 \mathrm{mg}$ & Comp. & GSK & 1.642 .080 & $10.799 .429,40$ \\
\hline $\begin{array}{l}\text { Alfavelaglicerase } 200 \mathrm{U} / 400 \mathrm{U} \text { ou } \\
\text { imiglucerase } 200 \mathrm{U} / 400 \mathrm{U}\end{array}$ & $U$ & GENZYME & 46.706 .400 & $171.253 .686,24$ \\
\hline Sevelamer (Cloridrato) $800 \mathrm{mg}$ & Comp. & GENZYME & 380.417 .013 & $465.876 .601,10$ \\
\hline Imiglucerase $200 \mathrm{UI}$ & Fr. & Genzyme Doação & 67.652 & 0,00 \\
\hline Micofenolato de Mofetila $500 \mathrm{mg}$ & Comp. & GERMED & 22.494 .934 & $10.122 .720,30$ \\
\hline Donepezila $5 \mathrm{mg}$ & Comp. & GLAXO & 4.525 .920 & $1.345 .556,02$ \\
\hline Imunoglobulina Anti-Hepatite B $100 \mathrm{UI}$ & Fr. & GRIFOLS & 21.591 & $2.930 .600,28$ \\
\hline $\begin{array}{l}\text { Imunoglobulina Anti-B } 1000 \text { UI (200 UI } \\
\text { amp 5ml) }\end{array}$ & Amp. & GRIFOLS & 1.043 & $398.590,79$ \\
\hline Imunoglobulina Anti-B $100 \mathrm{UI}$ & Amp. & GRIFOLS & 1.750 & $120.551,20$ \\
\hline $\begin{array}{l}\text { Imunoglobulina Anti-B } 600 \mathrm{UI} \text { (200 UI } \\
\text { amp 3ml) }\end{array}$ & Amp. & GRIFOLS BRASIL & 3.662 & $1.149 .269,38$ \\
\hline Imunoglobulina Humana 5,0 g & Amp. & GRIFOLS BRASIL & 79.362 & $64.918 .112,86$ \\
\hline Imatinibe (Mesilato) $100 \mathrm{mg}$ & & IVB & 268.080 & $4.694 .080,80$ \\
\hline Imatinibe (Mesilato) $400 \mathrm{mg}$ & & IVB & 1.680 .000 & $117.667 .200,00$ \\
\hline
\end{tabular}


continuação

Quadro 39 - Consolidação da produção dos laboratórios nacionais em número de Unidades Farmacêuticas (UF) e valor pago pelo Ministério da Saúde para o Componente Especializado da Assistência Farmacêutica, no período de 2003 a 2013

\begin{tabular}{|c|c|c|c|c|}
\hline Medicamentos & Unid. & Fornecedor & $\begin{array}{c}\text { Quantidade de } \\
\text { Unidades } \\
\text { Farmacêuticas } \\
\text { (comprimido, cápsula, } \\
\text { seringas e frascos) } \\
\text { produzidas } \\
\end{array}$ & $\begin{array}{l}\text { Valor pago pelo } \\
\text { Ministério da Saúde } \\
\text { (R\$) }\end{array}$ \\
\hline Rivastigmina $1,5 \mathrm{mg}$ & Cáps. & IVB & 6.325 .500 & $13.220 .295,00$ \\
\hline Rivastigmina $3 \mathrm{mg}$ & Cáps. & IVB & 8.663 .790 & $20.706 .458,10$ \\
\hline Rivastigmina $4,5 \mathrm{mg}$ & Cáps. & IVB & 4.431 .240 & $12.097 .285,20$ \\
\hline Rivastigmina 6 mg & Cáps. & IVB & 7.145 .820 & $19.936 .837,80$ \\
\hline Golimumabe $50 \mathrm{mg}$ & & JANSSEN & 21.740 & $45.817 .919,60$ \\
\hline Infliximabe 10 mg injetável & $\mathrm{F} / \mathrm{A}$ & JANSSEN & 368.250 & $398.253 .302,64$ \\
\hline Telaprevir 375 mg & Comp. & JANSSEN & 2.144 .520 & $187.602 .609,60$ \\
\hline Tacrolimo $1 \mathrm{mg}$ & Cáps. & JANSSEN-CILAG & 86.740 .708 & $299.479 .667,20$ \\
\hline Entecavir $0,5 \mathrm{mg}$ & Comp. & LAWRENCE & 4.334 .400 & $43.269 .205,12$ \\
\hline Entecavir $0,5 \mathrm{mg}$ & & LAWRENCE/ & 1.947.270 & $19.277 .973,00$ \\
\hline Infliximabe 10 mg injetável & Fa. & Mantecorp & 6.000 & $9.562 .680,00$ \\
\hline Tacrolimo $5 \mathrm{mg}$ & Cáps. & MEIZLER & 5.581 .200 & $93.007 .305,00$ \\
\hline Imunoglobulina Humana 5,0 g & Ampola & MEIZLER & 144.000 & $117.791 .994,30$ \\
\hline $\begin{array}{l}\text { Betainterferona 1A } 12.000 .000 \mathrm{UI}(44 \\
\mathrm{mcg} \text { ) }\end{array}$ & Seringa & MERCK & 1.415 .268 & $351.426 .532,80$ \\
\hline $\begin{array}{l}\text { Betainterferona 1A 6.000.000 UI (22 } \\
\text { mcg) }\end{array}$ & Seringa & MERCK & 730.020 & $153.737 .301,36$ \\
\hline Boceprevir $200 \mathrm{mg}$ & Cáps. & MERCK & 4.633 .696 & $51.170 .443,63$ \\
\hline Everolimo $0,5 \mathrm{mg}$ & Comp. & NOVARTIS & 2.913 .480 & $21.896 .445,60$ \\
\hline Everolimo $0,75 \mathrm{mg}$ & Comp. & NOVARTIS & 2.445 .360 & $28.125 .033,60$ \\
\hline Everolimo $1,0 \mathrm{mg}$ & Comp. & NOVARTIS & 2.938 .740 & $44.550 .962,40$ \\
\hline Imatinibe (Mesilato) $100 \mathrm{mg}$ (ONCO) & Comp. & NOVARTIS & 1.956 .900 & $40.312 .140,00$ \\
\hline Imatinibe (Mesilato) $400 \mathrm{mg}$ (ONCO) & Comp. & NOVARTIS & 4.169 .580 & $343.573 .392,00$ \\
\hline Micofenolato de Sódio 180 mg & Comp. & NOVARTIS & 10.964 .040 & $30.587 .924,40$ \\
\hline Micofenolato de Sódio 360 mg & Comp. & NOVARTIS & 105.821 .520 & $590.508 .670,40$ \\
\hline Taliglucerase Alfa $200 \mathrm{UI}$ & $\mathrm{F} / \mathrm{A}$ & PFIZER & 54.400 & $57.813 .600,00$ \\
\hline Donepezila $10 \mathrm{mg}$ & Comp. & RANBAXY & 20.683 .920 & $6.618 .835,20$ \\
\hline
\end{tabular}


conclusão

Quadro 39 - Consolidação da produção dos laboratórios nacionais em número de Unidades Farmacêuticas (UF) e valor pago pelo Ministério da Saúde para o Componente Especializado da Assistência Farmacêutica, no período de 2003 a 2013

\begin{tabular}{|c|c|c|c|c|}
\hline Medicamentos & Unid. & Fornecedor & $\begin{array}{c}\text { Quantidade de } \\
\text { Unidades } \\
\text { Farmacêuticas } \\
\text { (comprimido, cápsula, } \\
\text { seringas e frascos) } \\
\text { produzidas } \\
\end{array}$ & $\begin{array}{l}\text { Valor pago pelo } \\
\text { Ministério da Saúde } \\
\text { (R\$) }\end{array}$ \\
\hline Alfapeginterferona $2 \mathrm{a}-180 \mathrm{mcg}$ & Fr. & Roche & 1.567 .047 & $589.043 .624,38$ \\
\hline Alfapeginterferona $180 \mathrm{mcg}$ & Seringa & ROCHE & 685.995 & 215.693.301,00 \\
\hline Rituximabe $500 \mathrm{mg}$ & & ROCHE & 15.944 & $32.685 .200,00$ \\
\hline Tocilizumabe $20 \mathrm{mg}$ & $\mathrm{F} / \mathrm{A}$ & ROCHE & 167.412 & $53.997 .066,48$ \\
\hline Traztuzumabe $150 \mathrm{mg}$ & $\mathrm{F} / \mathrm{A}$ & ROCHE & 58.587 & $82.373 .907,87$ \\
\hline Traztuzumabe $440 \mathrm{mg}$ & $\mathrm{F} / \mathrm{A}$ & ROCHE & 19.047 & $65.201 .690,40$ \\
\hline Leflunomida $20 \mathrm{mg}$ & Comp. & Sanofi & 63.340 & $501.500,00$ \\
\hline Alfapeginterferona $120 \mathrm{mcg}$ & $\mathrm{F} / \mathrm{A}$ & SCHERING & 73.103 & $32.116 .415,45$ \\
\hline Alfapeginterferona $80 \mathrm{mcg}$ & $\mathrm{F} / \mathrm{A}$ & SCHERING & 590.456 & $242.187 .729,38$ \\
\hline Alfapeginterferona $100 \mathrm{mcg}$ & $\mathrm{F} / \mathrm{A}$ & SCHERING & 148.692 & $65.270 .744,00$ \\
\hline Infliximabe 10 mg injetável & $\mathrm{F} / \mathrm{A}$ & SCHERING & 312.453 & $406.644 .840,00$ \\
\hline Alfapeginterferona $2 \mathrm{~b}-100 \mathrm{mcg}$ & $\mathrm{F} / \mathrm{A}$ & Shering Plough & 358.637 & $157.043 .315,50$ \\
\hline Alfapeginterferona $2 \mathrm{~b}-120 \mathrm{mcg}$ & $\mathrm{F} / \mathrm{A}$ & Shering Plough & 112.322 & $56.748 .674,88$ \\
\hline Alfapeginterferona $2 b-80 \mathrm{mcg}$ & $\mathrm{F} / \mathrm{A}$ & Shering Plough & 746.458 & $290.078 .813,80$ \\
\hline Glatirâmer 20 mg Injetável & Seringa & TEVA & 4.324 .124 & $299.137 .134,24$ \\
\hline Donepezila $10 \mathrm{mg}$ & Comp. & WYETH & 10.012 .680 & $8.609 .903,53$ \\
\hline Donepezila $5 \mathrm{mg}$ & Comp. & WYETH & 9.162 .960 & $7.787 .599,70$ \\
\hline Etanercepte $25 \mathrm{mg}$ & $\mathrm{F} / \mathrm{A}$ & WYETH & 1.242 .368 & $431.866 .491,20$ \\
\hline Etanercepte $50 \mathrm{mg}$ & $\mathrm{F} / \mathrm{A}$ & WYETH & 1.773 .940 & $1.091 .327 .868,80$ \\
\hline Sirolimo $1 \mathrm{mg}$ & Drágea & WYETH & 15.922 .800 & $195.257 .188,50$ \\
\hline Sirolimo $1 \mathrm{mg} / \mathrm{ml}$ & Fr. & WYETH & 5.900 & $4.813 .456,00$ \\
\hline Sirolimo $2 \mathrm{mg}$ & Drágea & WYETH & 4.168 .560 & $103.170 .226,98$ \\
\hline \multicolumn{3}{|c|}{ Subtotal } & 807.690 .918 & $11.168 .937 .556,29$ \\
\hline
\end{tabular}

Fonte: Produção própria. 
Quadro 40 - Consolidação da produção dos laboratórios internacionais em número de Unidades Farmacêuticas (UF) e valor pago pelo Ministério da Saúde para o Componente Especializado da Assistência Farmacêutica, no período de 2003 a 2013

\begin{tabular}{|c|c|c|c|c|}
\hline Medicamentos & Unid. & Fornecedor & \begin{tabular}{|c} 
Quantidade de \\
Unidades \\
Farmacêuticas \\
(comprimido, cápsula, \\
seringas e frascos) \\
produzidas
\end{tabular} & $\begin{array}{l}\text { Valor pago pelo } \\
\text { Ministério da } \\
\text { Saúde (R\$) }\end{array}$ \\
\hline Imunoglobulina Humana Endovenosa $5 \mathrm{~g}$ & $\mathrm{~F} / \mathrm{A}$ & Blau & 61.456 & $26.447 .970,63$ \\
\hline Entecavir $1,0 \mathrm{mg}$ & Comp. & Bristol & 63.000 & $811.377,00$ \\
\hline Imunoglobulina Humana Endovenosa $5 \mathrm{~g}$ & $\mathrm{~F} / \mathrm{A}$ & CSL Behring & 61.451 & $26.445 .818,85$ \\
\hline Imunoglobulina Humana Endovenosa $5 \mathrm{~g}$ & $\mathrm{~F} / \mathrm{A}$ & BPL/Meizler & 10.000 & $8.518 .750,00$ \\
\hline Adefovir $10 \mathrm{mg}$ & Comp. & GSK & 558.060 & $3.482 .294,40$ \\
\hline Imiglucerase $200 \mathrm{UI}$ & Fr. & Genzyme & 33.053 .493 & $13.042 .398 .588,50$ \\
\hline Imiglucerase $400 \mathrm{UI}$ & $\mathrm{F} / \mathrm{A}$ & GENZYME & 20.610 .301 & $210.795 .122,56$ \\
\hline Imiglucerase $400 \mathrm{UI}$ & $\mathrm{F} / \mathrm{A}$ & $\begin{array}{c}\text { GENZYME } \\
\text { doação }\end{array}$ & 33.826 & 0,00 \\
\hline Adefovir $10 \mathrm{mg}$ & Comp. & GLAXO & 1.674 .930 & $10.683 .195,80$ \\
\hline Imunoglobulina Humana 5,0 g & $\mathrm{F} / \mathrm{A}$ & GRIFOLS & 306.813 & $181.866 .265,53$ \\
\hline Imunoglobulina Anti-Hepatite B 600 UI & Ampola & GRIFOLS & 5.980 & $1.881 .175,84$ \\
\hline Entecavir $0,5 \mathrm{mg}$ & Comp. & Lawrence & 1.066 .290 & $10.687 .424,67$ \\
\hline Entecavir $1,0 \mathrm{mg}$ & Comp. & Lawrence & 349.950 & $5.425 .099,88$ \\
\hline Imunoglobulina Humana $5,0 \mathrm{~g}$ & Fa. & LFB & 30.000 & $18.792 .188,00$ \\
\hline Imunoglobulina Humana Endovenosa $5 \mathrm{~g}$ & $\mathrm{~F} / \mathrm{A}$ & LFB & 20.000 & $12.525 .500,00$ \\
\hline Imunoglobulina Humana $5,0 \mathrm{~g}$ & $\mathrm{~F} / \mathrm{A}$ & MEIZLER & 82.000 & $67.414 .750,00$ \\
\hline Taliglucerase Alfa $200 \mathrm{UI}$ & frasco & Pfizer & 54.400 & $57.813 .600,00$ \\
\hline Alfapeginterferona $180 \mathrm{mg}$ & Seringa & Roche & 913.524 & $432.662 .063,56$ \\
\hline Imunoglobulina Humana 5,0 g & $\mathrm{F} / \mathrm{A}$ & OCTAPHARMA & 610.407 & $378.096 .337,15$ \\
\hline Total & & & 59.565 .881 & 14.496.747.522,37 \\
\hline
\end{tabular}

Fonte: Produção própria.

O Ministério da Saúde, no período de 2003 a 2013, adquiriu 1.402.647.864 unidades farmacêuticas (comprimidos, cápsulas, frascos, seringas e frascosampolas) para abastecer o Componente Especializado da Assistência Farmacêutica. Teve um gasto de $\mathrm{R} \$ 27.704 .669 .522,25$. 
Os laboratórios oficiais foram responsáveis pela produção de 535.391 .065 de unidades farmacêutica, que representa $38,17 \%$ da aquisição do Componente Especializado. Os laboratórios internacionais produziram 59.565.881 UF, que representa uma participação percentual de $4,25 \%$. Os laboratórios nacionais foram os que mais participaram da produção do Componente, produziram 807.690.918 unidades farmacêticas, ou seja, $57,58 \%$ da aquisição.

Vale ressaltar que os laboratórios farmacêuticos oficiais só começaram a produção para o Componente Especialiado no ano de 2009, com a FIOCRUZ produzindo os medicamentos: alfaepoetina $2000 \mathrm{UI}$, alfaepoetina $4000 \mathrm{UI}$, interferon 10.000.000 Ul, interferon 3.000.000 Ul, interferon 5.000.000 Ul e ribavirina $250 \mathrm{mg}$. Em 2010 a FIOCRUZ passou a produzir os medicamentos alfainterferona 10.000.000 UI, alfainterferona 3.000.000 UI e alfainterferona 5.000.000 UI. Em 2013 começou a produzir os medicamentos tacrolimo $1 \mathrm{mg}$ e tacrolimo $5 \mathrm{mg}$. Somente no ano de 2013 passou a produizir o medicamento alfapoetina humana recombinante 2000 Ul.

O LAFEPE só começou a participar da produção de medicamentos para o Componente Especializado em 2011, com a produção dos medicamentos: clozapina $100 \mathrm{mg}$, clozapina $25 \mathrm{mg}$, quetiapina $100 \mathrm{mg}$, quetiapina $200 \mathrm{mg}$ e quetiapina 25 mg. No ano de 2012 passou a produzir os medicamentos olanzapina $5 \mathrm{mg}$ e olanzapina $10 \mathrm{mg}$.

A produção pública foi de 535.391 .065 unidades farmacêuticas. A FIOCRUZ produziu 299.392.013 UF, que representa $55,92 \%$ da aquisição e o LAFEPE produziu 235.999 .052 U.F, que representa $44,08 \%$.

Quadro 41 - Consolidação da produção dos laboratórios oficiais, nacionais e internacionais em número de Unidades Farmacêuticas (UF) e o valor pago pelo Ministério da Saúde para o Componente Especializado da Assistência Farmacêutica, no período de 2003 a 2013.

\begin{tabular}{|l|c|c|}
\hline \multicolumn{1}{|c|}{ Laboratórios } & $\begin{array}{c}\text { Quantidade de Unidades Farmacêuticas } \\
\text { (comprimido, cápsula, seringas e } \\
\text { frascos) produzidas }\end{array}$ & Valor pago pelo Ministério da Saúde (R\$) \\
\hline Oficiais & 535.391 .065 & $2.038 .984 .443,59$ \\
Nacionais & 807.690 .918 & $11.168 .937 .556,29$ \\
Internacionais & 59.565 .881 & $14.496 .747 .522,37$ \\
\multicolumn{1}{|c|}{ Total } & $\mathbf{1 . 4 0 2 . 6 4 7 . 8 6 4}$ & $\mathbf{2 7 . 7 0 4 . 6 6 9 . 5 2 2 , 2 5}$ \\
\hline
\end{tabular}

Fonte: Produção própria. 


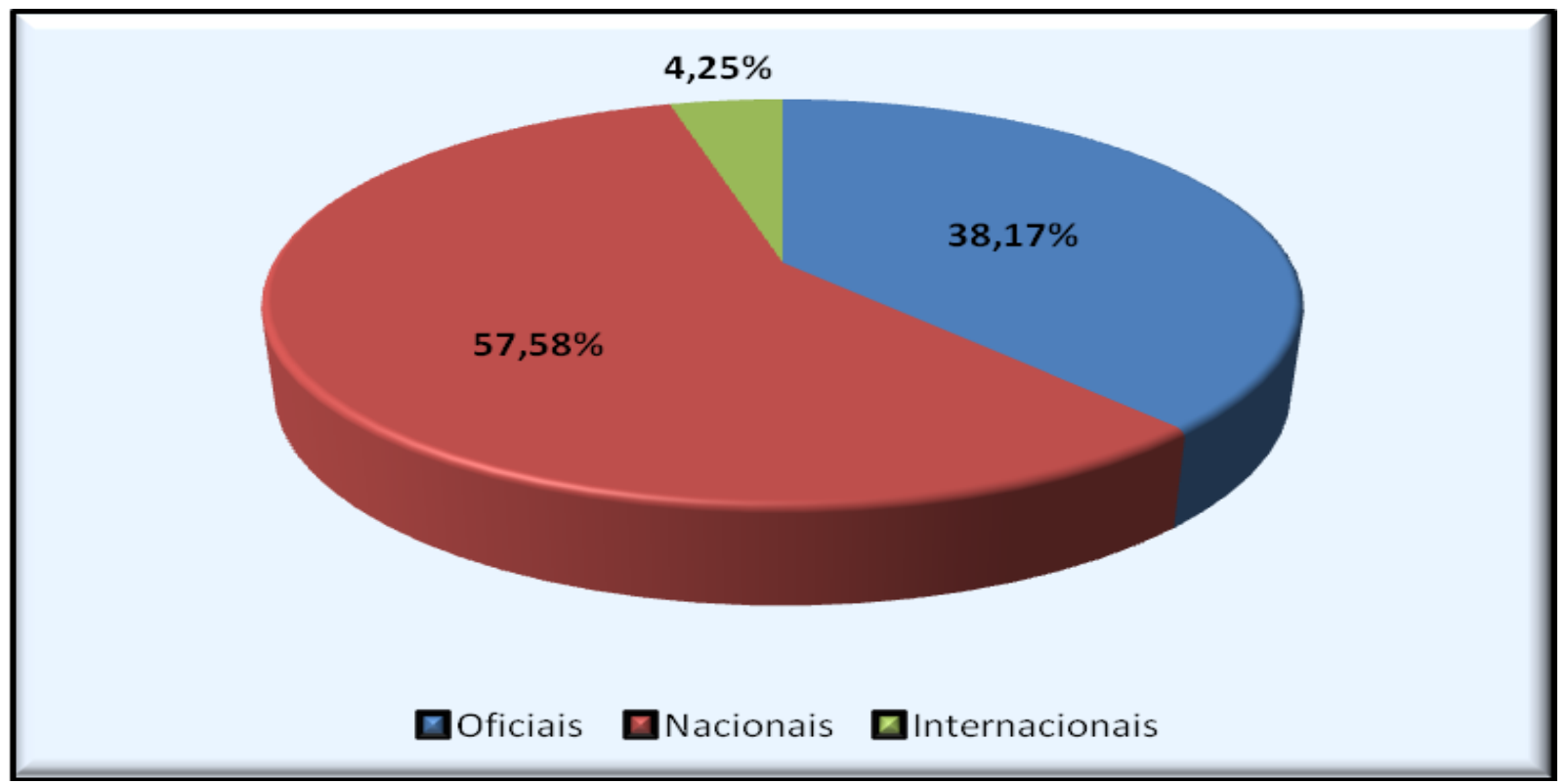

Figura 26 - Participação percentual da quantidade produzida pelos laboratórios oficiais, nacionais e internacionais em número de unidades farmacêuticas (UF) para o Ministério da Saúde para o Componente Especializado da Assistência Farmacêutica, no período de 2003 a 2013.

Fonte: Produção própria.

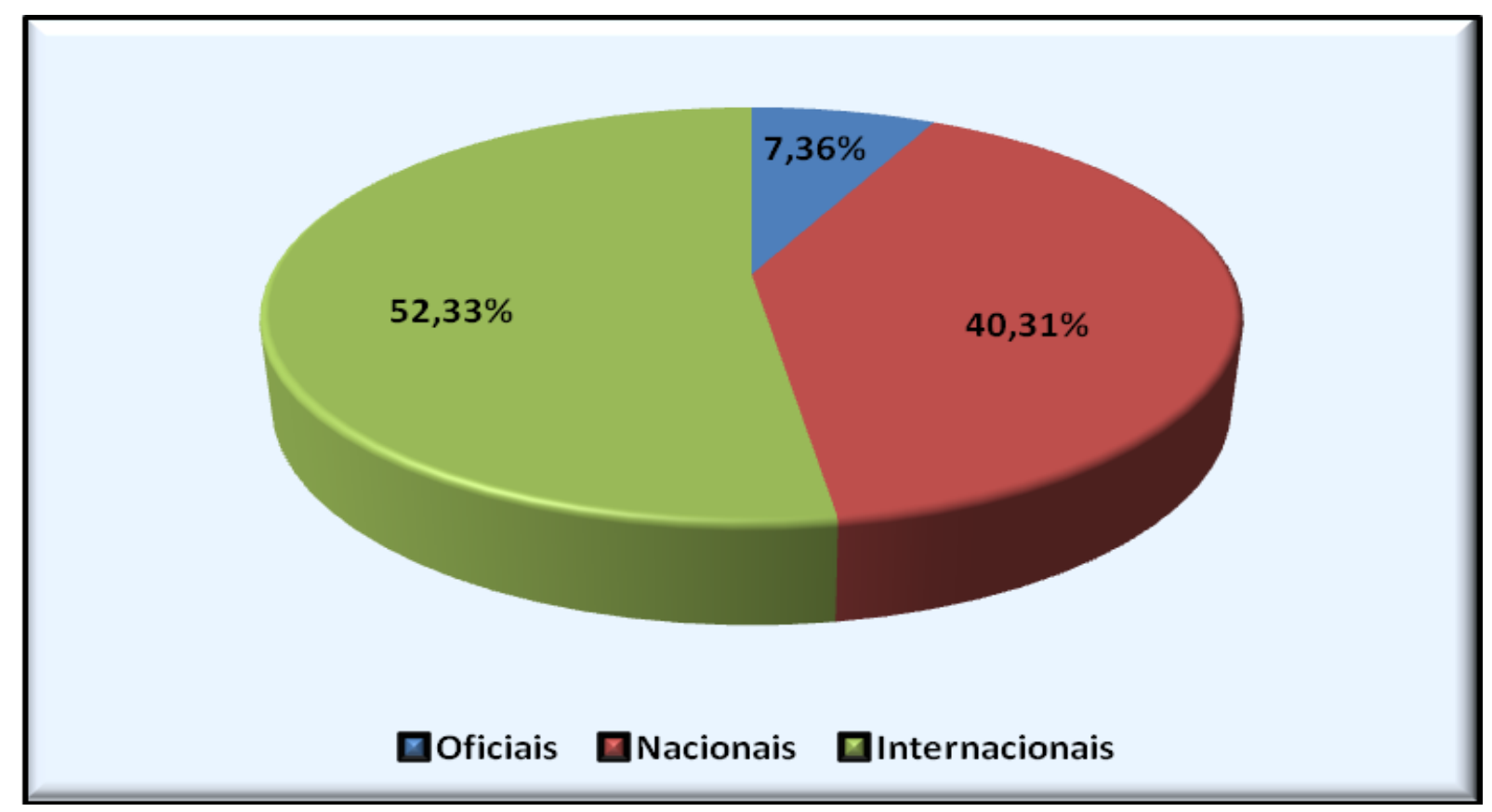

Figura 27 - Participação percentual do gasto do Ministério da Saúde com a produção dos laboratórios oficiais, nacionais e internacionais para o Componente Especializado da Assistência Farmacêutica, no período de 2003 a 2013.

Fonte: Produção própria. 


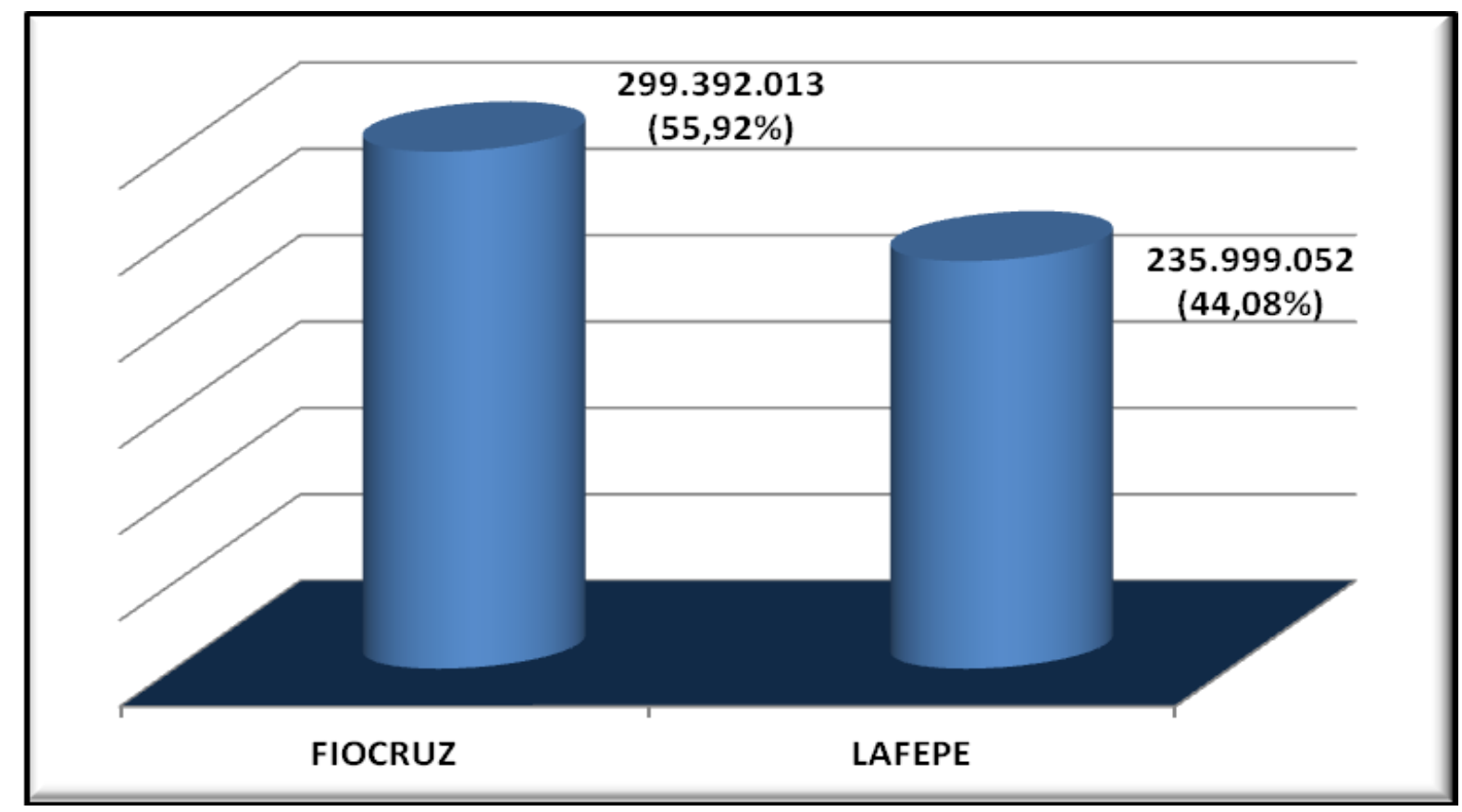

Figura 28 - Representação gráfica da produção pública por laboratório, no período de 2003 a 2013. Fonte: Produção própria.

\subsection{CONSOLIDAÇÃO DA PRODUÇÃO PARA OS COMPONENTES DA ASSISTÊNCIA FARMACÊUTICA DO MINISTÉRIO DA SAÚDE}

Após a analise detalhada de cada programa/tratamento foi organizada uma consolidação para que fosse possível ter uma visão global de toda a produção e o valor pago pelo Ministério da Saúde, no período de 2003 a 2013 para os Componentes da Assistência Farmacêutica.

No período de 2003 a 2013 o Ministério da Saúde adquiriu 9.900.448.968 unidades farmacêuticas para atender todos os seus Componentes da Assistência Farmacêutica que foram distribuídas no âmbito do SUS. Para esta aquisição o Ministério gastou $\mathrm{R} \$ 37.724 .621 .857,64$.

Do total das unidades produzidas os laboratórios oficiais fabricaram 6.620.024.457 unidades e receberem a importância de $\mathrm{R} \$ 5.262 .089 .372,20$. Foram os que mais produiziram no período pesquisado. Os laboratórios nacionais foram responsáveis pela produção de 1.459.799.480 unidades farmacêuticas e receberam a importância de $\mathrm{R} \$ 13.151 .644 .267,40$. Os laboratórios internacionais produziram 1.820.625.031 unidades farmacêuticas e receberam $R \$ 19.310 .888 .218,04$. 
A produção pública está representada pelos laboratórios: FIOCRUZ, FUNED, FURP, IQUEGO, IVB, LAFEPE, LFM, LIFAL, LQFA, LQFEX e NUPLAN. Dos 29 laboratórios oficiais apenas 11 laboratórios participaram da produção pública, então somente $37,93 \%$ dos laboratórios produiziram medicamentos para o Ministério da Saúde na fabricação de medicamentos para os Componentes da Assistência Farmacêutica.

No período de 2003 a 2013, o Ministério adquiriu 260 medicamentos (apresentações) para os Componentes da Assistência Farmacêutica. Juntos os laboratórios oficiais produziram 101 medicamentos (apresentações) para todos os Componentes da Assistência Farmacêutica. 
Quadro 42 - Consolidação da quantidade produzida para os Componentes da Assistência Farmacêutica do Ministério da Saúde, no período de 2003 a 2013

\begin{tabular}{|c|c|c|c|c|c|c|c|c|c|c|c|c|c|c|c|c|c|c|}
\hline \multirow[t]{2}{*}{ Laboratório } & \multicolumn{2}{|c|}{$\begin{array}{l}\text { Programa Nacional de } \\
\text { Doenças Sexualmente } \\
\text { Transmissiveis e AIDS }\end{array}$} & \multicolumn{2}{|c|}{$\begin{array}{l}\text { tratamento das } \\
\text { doenças crônico- } \\
\text { degenerativas } \\
\text { (lúpus eritematoso, } \\
\text { doença enxerto- } \\
\text { versus-hospedeiro } \\
\text { e mieloma múltiplo) }\end{array}$} & \multicolumn{2}{|c|}{$\begin{array}{l}\text { Programa Nacional } \\
\text { de Controle da } \\
\text { Hanseníase }\end{array}$} & \multicolumn{2}{|c|}{$\begin{array}{l}\text { Programa Nacional de } \\
\text { Alimentação e Nutrição }\end{array}$} & \multicolumn{2}{|c|}{$\begin{array}{l}\text { Programa Nacional } \\
\text { do Controle da } \\
\text { Tuberculose }\end{array}$} & \multicolumn{2}{|c|}{ Endemias Focais } & \multicolumn{2}{|c|}{$\begin{array}{l}\text { Programa Multidroga- } \\
\text { Resistência }\end{array}$} & \multicolumn{2}{|c|}{$\begin{array}{l}\text { Medicamentos do } \\
\text { Componente Especializado } \\
\text { da Assistencia } \\
\text { Farmacêutica }\end{array}$} & \multicolumn{2}{|c|}{ Total 2003 a 2013} \\
\hline & $\begin{array}{c}\text { Quantidade } \\
\text { de UF } \\
\text { produzida }\end{array}$ & (\%) & $\begin{array}{c}\text { Quantidade } \\
\text { de UF } \\
\text { produzida }\end{array}$ & (\%) & $\begin{array}{c}\text { Quantidade } \\
\text { de UF } \\
\text { produzida }\end{array}$ & (\%) & $\begin{array}{l}\text { Quantidade } \\
\text { de UF } \\
\text { produzida }\end{array}$ & (\%) & $\begin{array}{l}\text { Quantidade } \\
\text { de UF } \\
\text { produzida }\end{array}$ & $(\%)$ & $\begin{array}{c}\text { Quantidade } \\
\text { de UF } \\
\text { produzida }\end{array}$ & (\%) & $\begin{array}{l}\text { Quantidade } \\
\text { de UF } \\
\text { produzida }\end{array}$ & (\%) & $\begin{array}{l}\text { Quantidade } \\
\text { de UF } \\
\text { produzida }\end{array}$ & (\%) & $\begin{array}{c}\text { Quantidade } \\
\text { de UF } \\
\text { produzida }\end{array}$ & (\%) \\
\hline Oficiais & 2.362 .148 .798 & 55,03 & 21.533 .760 & 100,00 & 189.204.940 & 98,28 & 2.109 .065 .373 & 99,51 & 677.212 .240 & 71,46 & 714.965 .481 & 80,23 & 10.502 .800 & 32,14 & 535.391 .065 & 38,17 & 6.620 .024 .457 & 66,87 \\
\hline Nacionais & 462.779 .725 & 10,78 & & 0,00 & 2.079 .910 & 1,08 & 10.372 .680 & 0,49 & & 0,00 & 172.122.147 & 19,31 & 4.754 .100 & 14,55 & 807.690 .918 & 57,58 & 1.459 .799 .480 & 14,74 \\
\hline Internacionais & 1.467 .766 .858 & 34,19 & & 0,00 & 1.238 .020 & 0,64 & & 0,00 & 270.532 .738 & 28,54 & 4.097 .984 & 0,46 & 17.423 .550 & 53,31 & 59.565 .881 & 4,25 & 1.820 .625 .031 & 18,39 \\
\hline Total & 4.292.695.381 & 100 & 21.533 .760 & 100 & 192.522.870 & 100 & 2.119 .438 .053 & 100 & 947.744.978 & 100 & 891.185 .612 & 100 & 32.680 .450 & 100 & 1.402 .647 .864 & 100 & 9.900 .448 .968 & 100 \\
\hline
\end{tabular}

Fonte: Produção própria.

Quadro 43 - Consolidação do valor pago pelo Ministério da Saúde para os Componentes da Assistência Farmacêutica, no período de 2003 a 2013

\begin{tabular}{|c|c|c|c|c|c|c|c|c|c|c|c|c|c|c|c|c|c|c|}
\hline \multirow[t]{2}{*}{ Laboratório } & \multicolumn{2}{|c|}{$\begin{array}{l}\text { Programa Nacional de } \\
\text { Doenças Sexualmente } \\
\text { Transmissíveis e AIDS }\end{array}$} & \multicolumn{2}{|c|}{$\begin{array}{l}\text { tratamento das } \\
\text { doenças crônico- } \\
\text { degenerativas (lúpus } \\
\text { eritematoso, doença } \\
\text { enxerto-versus-- } \\
\text { hospedeiroe } \\
\text { mieloma múltiplo) }\end{array}$} & \multicolumn{2}{|c|}{$\begin{array}{l}\text { Programa Nacional } \\
\text { de Controle da } \\
\text { Hanseníase }\end{array}$} & \multicolumn{2}{|c|}{$\begin{array}{l}\text { Programa Nacional de } \\
\text { Alimentação e } \\
\text { Nutrição }\end{array}$} & \multicolumn{2}{|c|}{$\begin{array}{l}\text { Programa Nacional } \\
\text { do Controle da } \\
\text { Tuberculose }\end{array}$} & \multicolumn{2}{|c|}{ Endemias Focais } & \multicolumn{2}{|c|}{$\begin{array}{l}\text { Programa } \\
\text { Multidroga- } \\
\text { Resistência }\end{array}$} & \multicolumn{2}{|c|}{$\begin{array}{l}\text { Medicamentos do } \\
\text { Componente Especializado } \\
\text { da Assistência Farmacêutica }\end{array}$} & \multicolumn{2}{|c|}{ Total 2003 a 2013} \\
\hline & $\begin{array}{l}\text { Valor pago pelo } \\
\text { MS (R\$) }\end{array}$ & $(\%)$ & $\begin{array}{l}\text { Valor pago } \\
\text { pelo MS } \\
\text { (R\$) }\end{array}$ & $(\%)$ & $\begin{array}{c}\text { Valor pago } \\
\text { pelo MS (R\$) }\end{array}$ & (\%) & $\begin{array}{l}\text { Valor pago } \\
\text { pelo MS (R\$) }\end{array}$ & $(\%)$ & $\begin{array}{l}\text { Valor pago } \\
\text { pelo MS (R\$) }\end{array}$ & (\%) & $\begin{array}{l}\text { Valor pago } \\
\text { pelo MS (R\$) }\end{array}$ & (\%) & $\begin{array}{l}\text { Valor pago } \\
\text { pelo MS } \\
\text { (R\$) }\end{array}$ & $(\%)$ & $\begin{array}{l}\text { Valor pago pelo } \\
\text { MS (R\$) }\end{array}$ & $(\%)$ & $\begin{array}{l}\text { Valor pago pelo } \\
\text { MS (R\$) }\end{array}$ & $(\%)$ \\
\hline
\end{tabular}

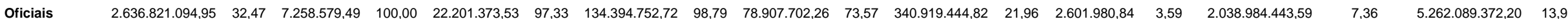

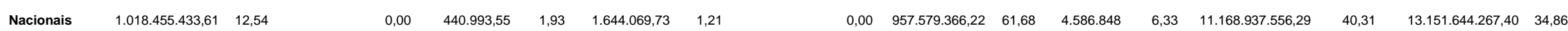

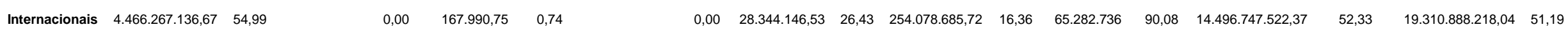

Fonte: Produção própria. 
A FIOCRUZ foi responsável pela produção de 54 medicamentos. O LAFEPE ficou em segundo lugar com a produção de 36 medicamentos. A FURP foi responsável pela produção 21 medicamentos. O IQUEGO produziu 17 medicamentos. A FUNED produziu 7 medicamentos. O NUPLAN e o LIFAL produziram 3 medicamentos cada um e o IVB apenas 1 medicamento. Os laboratórios oficiais milatares produziram 32 medicamentos, sendo 15 medicamentos pelo LQFEX produziu 15 medicamentos, o LFM 10 medicamentos e o LQFA. 
Quadro 44 - Consolidação da evolução da produção por Programa/Tratamento da Assistência Farmacêutica do Ministério da Saúde, no período de 2003 a 2013

\begin{tabular}{|c|c|c|c|c|c|c|c|c|c|c|c|c|c|c|c|c|c|c|}
\hline \multirow{4}{*}{ Laboratório } & \multirow{2}{*}{\multicolumn{2}{|c|}{$\begin{array}{l}\text { Programa Nacional de } \\
\text { Doenças Sexualmente } \\
\text { Transmissíveis e AIDS }\end{array}$}} & \multirow{2}{*}{\multicolumn{2}{|c|}{\begin{tabular}{|c|}
$\begin{array}{c}\text { tratamento das } \\
\text { doenças crônico- } \\
\text { degenerativas (lúpus } \\
\text { eritematoso, doença } \\
\text { enxerto-versus- } \\
\text { hospedeiro e mieloma } \\
\text { múltiplo) }\end{array}$ \\
$\begin{array}{c}\text { Total de medicamentos } \\
\text { por } \\
\text { programa/tratmento }\end{array}$ \\
\end{tabular}}} & \multirow{2}{*}{\multicolumn{2}{|c|}{$\begin{array}{l}\text { Programa Nacional de } \\
\text { Controle da } \\
\text { Hanseníase }\end{array}$}} & \multicolumn{2}{|c|}{$\begin{array}{l}\text { Programa Nacional de } \\
\text { Alimentaçãoo e } \\
\text { Nutriçẫo }\end{array}$} & \multicolumn{2}{|c|}{$\begin{array}{l}\text { Programa Nacional do } \\
\text { Controle da } \\
\text { Tuberculose }\end{array}$} & \multicolumn{2}{|c|}{ Endemias Focais } & \multicolumn{2}{|c|}{$\begin{array}{c}\text { Programa Multidroga- } \\
\text { Resistência }\end{array}$} & \multicolumn{2}{|c|}{$\begin{array}{l}\text { Medicamentos do } \\
\text { Componente } \\
\text { Especializado da } \\
\text { Assistência } \\
\text { Farmacêutica }\end{array}$} & \multirow{2}{*}{\multicolumn{2}{|c|}{ Total de medicamentos }} \\
\hline & & & & & & & \multicolumn{2}{|c|}{$\begin{array}{c}\text { Total de } \\
\text { medicamentos por } \\
\text { programa/tratmento }\end{array}$} & \multicolumn{2}{|c|}{$\begin{array}{c}\text { Total de } \\
\text { medicamentos por } \\
\text { programa/tratmento }\end{array}$} & \multicolumn{2}{|c|}{$\begin{array}{c}\text { Total de } \\
\text { medicamentos por } \\
\text { programa/tratmento }\end{array}$} & \multicolumn{2}{|c|}{$\begin{array}{c}\text { Total de } \\
\text { medicamentos por } \\
\text { programa/tratmento }\end{array}$} & \multicolumn{2}{|c|}{$\begin{array}{c}\text { Total de } \\
\text { medicamentos por } \\
\text { programa/tratmento }\end{array}$} & & \\
\hline & \multicolumn{2}{|l|}{59} & \multicolumn{2}{|l|}{1} & \multicolumn{2}{|l|}{12} & \multicolumn{2}{|l|}{6} & \multicolumn{2}{|l|}{13} & \multicolumn{2}{|l|}{65} & \multicolumn{2}{|l|}{24} & \multicolumn{2}{|l|}{80} & \multicolumn{2}{|l|}{260} \\
\hline & $\begin{array}{c}\text { Quantidade de } \\
\text { medicamentos } \\
\text { produzidos }\end{array}$ & (\%) & $\begin{array}{l}\text { Quantidade de } \\
\text { medicamentos } \\
\text { produzidos }\end{array}$ & (\%) & $\begin{array}{c}\text { Quantidade de } \\
\text { medicamentos } \\
\text { produzidos }\end{array}$ & (\%) & $\begin{array}{l}\text { Quantidade de } \\
\text { medicamentos } \\
\text { produzidos }\end{array}$ & $(\%)$ & $\begin{array}{c}\text { Quantidade de } \\
\text { medicamentos } \\
\text { produzidos }\end{array}$ & (\%) & $\begin{array}{l}\text { Quantidade de } \\
\text { medicamentos } \\
\text { produzidos }\end{array}$ & (\%) & $\begin{array}{l}\text { Quantidade de } \\
\text { medicamentos } \\
\text { produzidos }\end{array}$ & (\%) & $\begin{array}{c}\text { Quantidade de } \\
\text { medicamentos } \\
\text { produzidos }\end{array}$ & (\%) & $\begin{array}{l}\text { Quantidade de } \\
\text { medicamentos } \\
\text { produzidos }\end{array}$ & (\%) \\
\hline Oficiais & 18 & 30,51 & 1 & 100,00 & 8 & 66,67 & 5 & 83,33 & 11 & 84,62 & 30 & 46,15 & 8 & 33,33 & 20 & 25,00 & 101 & 38,85 \\
\hline Nacionais & 22 & 37,29 & & 0,00 & 5 & 41,67 & 1 & 16,67 & & 0,00 & 34 & 52,31 & 9 & 37,50 & 61 & 76,25 & 132 & 50,77 \\
\hline Internacionais & 31 & 52,54 & & 0,00 & 3 & 25,00 & & 0,00 & 3 & 23,08 & 13 & 20,00 & 13 & 54,17 & 9 & 11,25 & 72 & 27,69 \\
\hline
\end{tabular}




\section{DISCUSSÃO}

Ao longo da nossa história os Laboratórios Farmacêuticos Oficiais tiveram e ainda têm uma relevante e destacada participação na produção de medicamentos, nas mais diversas patologias que existem, para que a população brasileira tenha acesso a medicamentos. Não se pode negar que eles possuem relevante papel para o aprimoramento da qualidade de vida dos brasileiros, pois o medicamento é um componente da prevenção ou de cura de doenças, seja como meio de diminuição dos sofrimentos por elas causados.

A Política Nacional de Medicamentos, Portaria no 3.916, de 30 de outubro de 1998, orienta o setor público para a contratação dos Laboratórios Farmacêuticos Oficias para produção de medicamentos para serem distribuídos no âmbito do SUS, com o intuito de aproveitar a capacidade instalada destes laboratórios. Estes laboratórios configuram um verdadeiro patrimônio nacional e deverá ser utilizada preferencialmente, para atender a produção de medicamentos destinados ao tratamento de patologias cujos resultados tenham impacto sobre a saúde pública ou que são adquiridos em sua quase totalidade pelo setor público.

Mesmo com a grande desigualdade tecnológica ainda existente nos processos e produtos dos laboratórios oficiais, estes conseguiram ampliar a capacidade produtiva para atender parte da demanda dos medicamentos dos Componentes da Assistência Farmacêutica do Ministério da Saúde.

No período pesquisado alguns laboratórios oficiais conseguiram destaque na produção de medicamentos para os Componentes da Assistência Farmacêutica, como a FIOCRUZ, LAFEPE, FUNED E IQUEGO.

Apesar de pouco conhecidos e às vezes até questionados, os laboratórios oficiais militares também tiveram destaque na produção pública para o Programa Nacional de Controle da Hanseníase, Programa Nacional de Controle da Tuberculose, tratamento das Endemias Focais e para o Programa Multidroga Resistência.

Os laboratórios oficiais produziram mais para o Programa Nacional de Doenças Sexualmente Transmissíveis e AIDS, tratamento das doenças crônicodegenerativas, Programa Nacional de Controle da Hanseníase, Programa Nacional 
de Alimentação e Nutrição, Programa Nacional do Controle da Tuberculose e para as Endemias Focais.

Em relação aos Medicamentos do Componente Especializado da Assistência Farmacêutica os laboratórios nacionais foram os que mais produziram e na produção do elenco de medicamentos para o Programa Multidroga-Resistência os laboratórios internacionais foram os que mais produziram.

Mesmo com uma produção bem superior aos dos laboratóriros nacionais e internacionais, os laboratórios oficiais, tiveram uma renumeração bem inferior. Isto demonstra que o custo unitário médio dos medicamentos fornecidos pelos laboratórios oficiais é menor do que aquele dos laboratórios nacionais e internacionais. Podemos inferir que a atuação dos Laboratórios Oficiais também representa importante instrumento de regulação de preços.

Os laboratórios oficiais recebem menos pelo valor da unidade farmacêutica produzida, pois foram criados com a missão de suprir medicamentos essenciais a baixo custo para os programas de políticas públicas de saúde e também como suporte à regulação de mercados (preço) e de promoverem o acesso da população aos medicamentos de que ela necessita.

Por outro lado a incorporação de novos medicamentos com alto valor agregado no elenco de medicamentos adquiridos pelo Ministério da Saúde, com proteção patentária e com um único fabricante, ocasiona um gasto mais elevado, levando assim uma participação percentual mais elevada dos laboratórios internacionais. 


\section{CONCLUSÃO}

Pelo resultado da pesquisa conclui-se que a produção de medicamentos dos laboratórios oficiais ainda não é suficiente para atender a demanda de todos os programas de assistência farmacêutica do Ministério da Saúde. Há necessidade de serem pró-ativos e rápidos na atualização de seus protifólios e de terem a capacidade de reagirem no momento da incorporação de novos medicamentos.

O Ministério da Saúde vem adotando medidas estratégicas de incentivo à inovação dos laboratórios oficiais. Mas, além dos incentivos de fomento à produção de medicamentos para os laboratórios oficiais, já implementados pelo governo federal, ainda, há necessidade de investimentos dos governos estaduais junto aos laboratórios oficiais para modernização de suas plantas industriais e realização de certificação de suas Boas Práticas de Fabricação e Controle para que estes venham a atender na sua totalidade as demandas do SUS.

Antes das Parcerias para o Desenvolvimento Produtivo (PDPs) os laboratórios oficiais produziam apenas medicamentos que não eram de interesse dos grandes laboratórios de capital privado, para as doenças negligenciadas (malária, esquistossomose, doença de chagas). Este cenário está gradativamente aalterado.

Com a formalização de Projetos Executivos de Parcerias para o Desenvolvimento Produtivo, o Ministério da Saúde fomenta a produção pública de tecnologias estratégicas para o Sistema Único de Saúde e consolida a estratégia nacional de fomento, desenvolvimento e inovação no âmbito do Complexo Industrial da Saúde.

No entanto, há necessidade de reestruturação do modelo institucional dos laboratórios oficiais abrangendo uma política flexível de compras e administração, de contratação de profissionais inseridos no conhecimento científico e tecnológico e há a necessidade de uma maior articulação com a comunidade científica, com as instituições de ensino superior, com as agências de fomento, com o setor produtivo. E ampliação do seu elenco de produção frente às novas necessidades e demandas de medicamentos do Sistema Único de Saúde. 
Devem ainda, empreenderem esforços para criação de um centro de pesquisa, por meio de consórcio, com a participação exclusiva de laboratórios oficiais, com instalações e equipamentos adequados às finalidades de pesquisa, que contará com apoio de instituições atuantes na área de Saúde, Ciência e Tecnologia: as Universidades.

Após análise da produção de medicamentos para os Componentes da Assistência Farmacêutica conclui-se que o papel dos laboratórios oficiais é de vital importância para 0 atendimento de Programas de Saúde coordenados nacionalmente pelo Ministério da Saúde. 


\section{REFERÊNCIAS}

ABAJO, F.J. El medicamiento como solución y como problema para la salud pública. Una breve incursión a los objetivos de la farmacoepidimiología. Revista Española de Salud Pública, v. 75, n. 21, p. 281-284, 2001.

AITH, F. Curso de Direito Sanitário - a proteção do direito à saúde no Brasil. Editora Quartier Latin, 2007, p. 342.

ALOB. Associação dos Laboratórios Farmacêuticos Oficiais do Brasil. Endereço eletrônico: http://www.alfob.org/portugues/site/index. Acessado em: 20 de maio de 2014.

ARRAIS PSD, BRITO L.L, BARRETO ML, COELHO H.L.L. Prevalência e fatores determinantes do consumo de medicamentos no Município de Fortaleza, Ceará, Brasil. Cad Saúde Pública 2005; 21:1737-46.

BADIM, Silvia: A relação do sistema jurídico e do sistema político na garantia do direito social à assistência farmacêutica: o caso do Estado de São Paulo. Dissertação apresentada ao Programa de Pós-Graduação em Saúde Pública para obtenção do título de Mestre em Saúde Pública. Orientadora: Profa. Titular Sueli Gandolfi Dallari - São Paulo - 2005.

BARROSO, L.R. Da falta de efetividade à judicialização excessiva: direito à saúde, fornecimento gratuito de medicamentos e parâmetros para a atuação judicial. In MARTEL, Letícia de Campos Velho. (Org.) Estudos Contemporâneos de Direitos Fundamentais. Rio de Janeiro: Lumen Juris, 2009.

BOECHAT. N., Palestra: Os principais desafios da produção pública de medicamentos no Brasil proferida na mesa: "Desafios da Indústria Farmacêutica no Brasil" - XIII Encontro Regional da SBQ-Rio, julho 2011. Disponível em: http://www.portaldosfarmacos.ccs.ufrj.br/atualidades_desafios_ind.html. Acessado em: 10 de janeiro de 2014.

BONAVIDES, P. Curso de Direito Constitucional. $8^{\underline{a}}$ edição. Malheiros Editores Ltda. - pag. 514-516 - 1999.

BRASIL. Congresso Nacional. Relatório Final da CPI dos Medicamentos. Comissão Parlamentar de Inquérito destinada a investigar os reajustes de preços e a falsificação de medicamentos, materiais hospitalares e insumos de laboratórios. Brasília, 2000. Acessado em: 12 de junho de 2014. Disponível em: http://www.crfmt.org.br/arqs/materia/1362_a.pdf

_. Constituição (1988). Constituição da República Federativa do Brasil. Brasília, $\overline{\mathrm{DF}}$ Senado, $\quad 1998 . \quad$ Disponível em: http://www.planalto.gov.br/ccivil_03/constituicao/constituicaocompilado.htm. Acessado em 17 de maio de 2014.

. Constituição da República dos Estados Unidos do Brasil (de 16 de julho de 1934). Disponível em: http://bd.camara.gov.br/bd/handle/bdcamara/1558. Acessada em 04 de abril de 2014.

Constituição da República Federativa do Brasil de 1967. Disponível em: file:///C:/Users/Eliana/Downloads/constituicao_1967_texto.pdf. Acessada em: Acessada em: 04 de abril de 2014. 
. Constituição dos Estados Unidos do Brasil (de 10 de novembro de 1937). Disponível em: file:///C:/Users/Eliana/Downloads/constituicao_1937_texto.pdf. Acessada em: Acessada em: 04 de abril de 2014.

Constituição dos Estados Unidos do Brasil (de 18 de setembro de 1946). Disponível em: file:///C:/Users/Eliana/Downloads/constituicao_1946_texto.pdf. Acessada em: Acessada em: 04 de abril de 2014.

. Constituição dos Estados Unidos do Brazil: publicada com o Decreto n. 914 A de 23 de outubro de 1890. Disponível em: file://C:/Users/Eliana/Downloads/constitui\%C3\%A7\%C3\%A30_1890_brasil_ex1. pdf. Acessada em: 04 de abril de 2014.

Constituição Politica do Imperio do Brazil (de 25 de março de 1824). Disponível em: file:///C:/Users/Eliana/Downloads/constituicao_1824_texto.pdf. Acessada em 04 de abril de 2014.

Ministério da Saúde. Conselho Nacional de Saúde. Resolução № 338, de 06 de maio de 2004. Aprova a Política Nacional de Assistência Farmacêutica. Disponível em: HTTP://BVSMS.SAUDE.GOV.BR/BVS/SAUDELEGIS/CNS/2004/RES0338_06_0 5_2004.HTML. Acessada em 17 de maio de 2014.

- Ministério da Saúde. Departamento de Ciência e Tecnologia. Doenças negligenciadas: estratégias do Ministério da Saúde. Rev Saúde Pública 2010;44(1):200-2. Disponível em: http://www.scielosp.org/pdf/rsp/v44n1/23.pdf. Acessado: em 20 de março de 2014.

. Ministério da Saúde. Departamento de Ciência e Tecnologia, Secretaria de Ciência, Tecnologia e Insumos Estratégicos. Doenças negligenciadas: estratégias do Ministério da Saúde - informes técnicos institucionais. Rev. Saúde Pública vol.44 no.1 São Paulo fev. 2010 http://dx.doi.org/10.1590/S003489102010000100023.

em:http://bvsms.saude.gov.br/bvs/publicacoes/AGENDA_PORTUGUES_MONTA DO.pdf

. Ministério da Saúde. Portaria GM/MS no 204, de 29 de janeiro de 2007. Regulamenta o financiamento e a transferência dos recursos federais para as ações e os serviços de saúde, na forma de blocos de financiamento, com o respectivo monitoramento e controle. Publicada Diário Oficial da União de 14 de março de 2007, Disponível em: http://bvsms.saude.gov.br/bvs/saudelegis/gm/2007/prt0204_29_01_2007_comp.html (SAÚDE LEGIS - Sistema de Legislação da Saúde). Acessado em 17 de maio de 2014.

Ministério da Saúde. Portaria GM/MS no 3.916, de 30 de outubro de 1998. Dispõe sobre a aprovação da Política Nacional de Medicamentos. Publicada Diário Oficial da União de 10 de novembro de 1998. Disponível em: http://portal2.saude.gov.br/saudelegis/leg_norma_pesq_consulta.cfm. Acessado em 17 de maio de 2014.

. Ministério da Saúde. Portaria GM/MS no 3.925, de novembro de 1998, que Aprovar o Manual para Organização da Atenção Básica no Sistema Único de Saúde. 
http://www.brasilsus.com.br/index.php?option=com_content\&view=article\&id=15986. Acessada em 12 de maio de 2014.

. Ministério da Saúde. Portaria Interministerial no 128, de 29 de maio de 2008. Estabelece Diretrizes para a Contratação Pública de Medicamentos e Fármacos pelo Sistema Único de Saúde. Acessada em 13 de outubro de 2014. Disponível em: http://www.comprasnet.gov.br/legislacao/portarias/p128_08.htm

. Ministério da Saúde. Portaria no 1.554, de 30 de julho de 2013, que dispõe sobre as regras de financiamento e execução do Componente Especializado da Assistência Farmacêutica no âmbito do Sistema Único de Saúde (SUS). Diário Oficial da União, Poder Executivo, DF, 31 de julho de 2013b.

. Ministério da Saúde. Portaria no 1.555, de 30 de julho de 2013. Dispõe sobre as normas de financiamento e de execução do Componente Básico da Assistência Farmacêutica no âmbito do Sistema Único de Saúde (SUS). Diário Oficial da União, Poder Executivo, DF, 31 de julho de 2013a.

Ministério da Saúde. Portaria n 2.438/GM, de 7 de dezembro de 2005, Cria a Rede Brasileira de Produção Pública de Medicamentos. Publicada no Diário Oficial da União no 236, de 9 de dezembro de 2005, Seção 1, página 80. Disponível em: http://bvsms.saude.gov.br/bvs/saudelegis/gm/2005/prt2438_07_12_2005.html. Acessada em: 23 de março de 2014.

. Ministério da Saúde. Portaria № 3.031, 16 de dezembro de 2008. Dispõe sobre critérios a serem considerados pelos Laboratórios Oficiais de produção de medicamentos em suas licitações para aquisição de matéria-prima. Acessada em 13 de outubro de 2014. Disponível em: http://dtr2001.saude.gov.br/sas/PORTARIAS/Port2008/GM/GM-3031.htm

. Ministério da Saúde. Portaria no 374 de 28 de fevereiro de 2008. Institui no âmbito do Sistema Único de Saúde - SUS, o Programa Nacional de Fomento à Produção Pública e Inovação no Complexo Industrial da Saúde. Acessada em 13 de outubro de 2014.2 Disponível em: http://dtr2001.saude.gov.br/sas/PORTARIAS/Port2008/GM/GM-374.htm

Ministério da Saúde. Portaria no 374, de 28 de fevereiro de 2008, Institui no âmbito do Sistema Único de Saúde - SUS, o Programa Nacional de Fomento à Produção Pública e Inovação no Complexo Industrial da Saúde. Publicada no Diário Oficial da União de 29 de fevereiro de 2008, Seção 1, página 118. Disponível em: http://bvsms.saude.gov.br/bvs/saudelegis/gm/2008/prt0374_28_02_2008.html. Acessado em: 23 de março de 2014.

. Ministério da Saúde. Portaria no 375 DE 28 de fevereiro de 2008. Institui, no âmbito do Sistema Único de Saúde - SUS, o Programa Nacional para Qualificação, Produção e Inovação em Equipamentos e Materiais de Uso em Saúde no Complexo Industrial da Saúde. Acessada em 13 de outubro de 2014. Disponível em: http://dtr2001.saude.gov.br/sas/PORTARIAS/Port2008/GM/GM375.htm

. Ministèrio da Saùde. Portaria no 837, de 18 de abril de 2012, que definiu as diretrizes e os critérios de constituição das PDP. Acessada em 11 de outubro de 2014. em: http://bvsms.saude.gov.br/bvs/saudelegis/gm/2012/prt0837_18_04_2012.html 
- Ministério da Saúde. Secretaria de Políticas de Saúde. Departamento de Atenção Básica. Política nacional de medicamentos 2001/Ministério da Saúde, Secretaria de Políticas de Saúde, Departamento de Atenção Básica. - Brasília : Ministério da Saúde, 2001. 40 p. : il - (Série C. Projetos, Programas e Relatórios, n.25). 1. Medicamentos - Política Nacional. I. Título. II. Série.

Ministério da Saúde/Organização Pan-Americana da Saúde/Organização Mundial da Saúde. Avaliação da assistência farmacêutica no Brasil: estrutura, processo e resultados. Brasília: Ministério da Saúde; 2005.

. Presidência da República. Decreto N 4.726, de 09 de junho de 2003. Aprova a Estrutura Regimental e o Quadro Demonstrativo dos Cargos em Comissão e das Funções Gratificadas do Ministério da Saúde, e dá outras providências. Disponível em: http://www.planalto.gov.br/ccivil_03/decreto/2003/D4726.htm. Acessado em 15 de maio de 2014.

. Presidência da República. Decreto no 6.860, de 27 de maio de 2009: Aprova a Estrutura Regimental e o Quadro Demonstrativo dos Cargos em Comissão e das Funções Gratificadas do Ministério da Saúde, integra o Centro de Referência Professor Hélio Fraga à estrutura da Fundação Oswaldo Cruz - FIOCRUZ, altera e acresce artigo ao Anexo I e altera o Anexo II ao Decreto no 4.725, de 9 de junho de 2003, que aprova o Estatuto e o Quadro Demonstrativo dos Cargos em Comissão e das Funções Gratificadas da FIOCRUZ, e dá outras providências.

. Presidência da República. Decreto no 68.806, de 25 de junho de 1971. Institui a Central de Medicamentos (CEME). Disponível em: http://www.planalto.gov.br/ccivil_03/decreto/1970-1979/D68806.htm. Acessado em 08 de maio de 2014.

Presidência da República. Decreto no 7.713, de 3 de abril de 2012. Estabelece a aplicação de margem de preferência nas licitações realizadas no âmbito da Administração Pública Federal para aquisição de fármacos e medicamentos descritos no Anexo I, para fins do disposto no art. $3^{\circ}$ da Lei no 8.666, de 21 de junho de 1993. Diário Oficial da União, Brasília, DF, 4 de abril de 2012, p.13, Col. 2. Acessado em 12 de outubro de 2014. Disponível em: <http://www6.senado.gov.br/legislacao/DetalhaDocumento.action?id=264782>

Presidência da República. DECRETO № 8.065, DE 7 DE AGOSTO DE 2013. Aprova a Estrutura Regimental e o Quadro Demonstrativo dos Cargos em Comissão e das Funções Gratificadas do Ministério da Saúde e remaneja cargos em comissão. Acessado em 15 de agosto de 2013. Disponível em: http://www.planalto.gov.br/ccivil_03/_Ato2011-2014/2013/Decreto/D8065.htm

Presidência da República. Lei no 12.349, de 15 de dezembro de 2010. Altera as Leis no 8.666, de 21 de junho de 1993, 8.958, de 20 de dezembro de 1994, e 10.973, de 2 de dezembro de 2004; e revoga o $\S 1^{\circ}$ do art. 2 da Lei $\mathrm{n}^{\circ}$ 11.273, de 6 de fevereiro de 2006. Diário Oficial da União, Brasília, DF, 16 de dezembro de 2010, Seção I, p. 2. Acessada em 10 de outubro de 2014. Disponível em: <http://www.planalto.gov.br/ccivil_03/_Ato2007-2010/2010/Lei/L12349.htm>. Acesso em: 17 de fevereiro de 2012.

Presidência da República. Lei no 12.349/10, de 15/12/2010 Altera as Leis $\mathrm{n}^{\text {os }}$ 8.666, de 21 de junho de 1993, 8.958, de 20 de dezembro de 1994, e 10.973, de 2 de dezembro de 2004; e revoga o $\S 1^{\circ}$ do art. $2^{\circ}$ da Lei $n^{\circ} 11.273$, de 6 de fevereiro de 2006. 
. Presidência da República. Lei no 8.080, de 19 de setembro de 1990. Dispõe sobre as condições para a promoção, proteção e recuperação da saúde, a organização e o funcionamento dos serviços correspondentes e dá outras providências. Publicada no Diário Oficial da União de 20 de setembro de 1990. Acessada em 17 de maio de 2014. Disponível em: http://www.planalto.gov.br/ccivil_03/Leis/L8080.htm.

CARVALHO, Gilson. SUS 20 anos: deficiências reconhecidas à parte, houve o resgate do direito dos cidadãos ao atendimento básico de saúde. SER MÉDICO - Revista do CREMESP-SP. Edição 45 - Outubro - Novembro/Dezembro de 2008, p. 28.

COMPARATO, F.K. A afirmação Histórica dos Direitos Humanos. 3 ed. São Paulo: Saraiva, 2003. 577 p.

GOMES A.P.; CHAVES J.G e NINOMYA T. Os laboratórios Farmacêuticos Oficiais e a Produção Pública de Medicamentos. In Medicamentos no Brasil: Inovação \& Acesso. Organizadores Paulo Marchiori Buss, José da Rocha Carvalheiro e Carmen Phang Romero Casas - Rio de Janeiro - RJ : Editora FIOCRUZ, 2008, pag 251-267.

GOMES, CAP. Os laboratórios farmacêuticos oficias e a produção pública de medicamentos: avanços e desafios. Medicamentos no Brasil: Inovações e acesso. Organizado por Paulo Marchiori Buss, José da Rocha Cavalheiro e Carmen Phang Romero Casas. - Rio de Janeiro: Editora FIOCRUZ, 2008. Pag. 251-267.

. C.A.P, CHAVES J.G, NINOMYA T. Os laboratórios Farmacêuticos Oficiais e a Produção Pública de Medicamentos - avanços e desafios. In: BUSSS, P.M; CARVALHEIROS, J.R; CASAS. C.P.R. organizadores. Medicamentos no Brasil: inovação e acesso. Rio de Janeiro; FIOCRUZ, 2008.

HANSENCLEVER, L et al. Diagnóstico e papel dos laboratórios públicos na capacitação tecnológica $e$ atividade de $P \& D$ da indústria farmacêutica brasileira. Medicamentos no Brasil: Inovações e acesso. Organizado por Paulo Marchiori Buss, José da Rocha Cavalheiro e Carmen Phang Romero Casas. - Rio de Janeiro: Editora FIOCRUZ, 2008. Pag. 199-231.

HUNT, P.; KHOSLA, R. Acesso a medicamentos como um direito humano. Revista Internacional de Diretos Humanos, Número 8, São Paulo, Junho de 2008, p. 101-121.

JARAMILLO, Nelly Marin; IVAMA, Adriana Mitsue; BARBANO, Dirceu B. A.; SANTOS, Manoel R. Cruz e LUIZA, Vera Lucia (Orgs.). Avaliação da Assistência Farmacêutica no Brasil: Estrutura, Processo e Resultados. Ministério da Saúde, OPAS/OMS, Brasília-DF, 2005.

LOYOLA, M.A. Medicamentos e saúde pública em tempos de AIDS: metamorfoses de uma política dependente. Ciência e Saúde Coletiva, Rio de Janeiro, v.13, suppl. 0, p.763- 778, abr. 2008.

MAGALHÃES, JL et al. Laboratórios farmacêuticos oficiais e sua relevância para saúde pública do Brasil. RECIIS - Revista Eletrônica de Comunicação, Informação \& Inovação em Saúde (RECIIS). Rio de Janeiro, v5, n.1, p.85-99, Mar., 201. Disponível em: [www.reciis.cict.fiocruz.br] e-ISSN 1981-6278. Acessada em; 20 de janeiro de 2014. 
MARMELSTEIN, G. Curso de direitos fundamentais. São Paulo: Atlas, 2008.

MARQUES, RM et al. A problemática do financiamento da saúde pública brasileira: de 1985 a 2008. Economia e Sociedade [online]. 2012, vol.21, n.2, pp. 345-362. ISSN 0104-0618. Disponível em: http://dx.doi.org/10.1590/S010406182012000200005. Acessado em: 14 de março de 2014.

OLIVEIRA, E.; LABRA, M.; BERMUDEZ, J. A produção pública de medicamentos no Brasil: uma visão geral. Cadernos de Saúde Pública, Rio de Janeiro/RJ, 22 (11): 2379-2389, nov., 2006.

OLIVEIRA, EA et al. A produção pública de medicamentos no Brasil: uma visão geral. Artigo 2379. Cad. Saúde Pública, Rio de Janeiro, 22(11):2379-2389, nov, 2006

OLIVEIRA, M.A.; BERMUDEZ, J.A.Z.; OSORIO-DE-CASTRO, C.G.S. Assistência farmacêutica e acesso a medicamentos. Rio de Janeiro: Fiocruz, 2007, p. 33-62.

PAIM, J. S. \& ALMEIDA FILHO, N., 1998. Saúde coletiva: uma "nova saúde pública" ou campo aberto a novos paradigmas?. In: Revista saúde pública. 32. p. 299-316.

PORTAL BRASIL. Presidência da República. SAÚDE - SUS democratiza o acesso do cidadão aos serviços de saúde. Publicado: 31/10/2009 22h20. Disponível em: http://www.brasil.gov.br/saude/2009/11/sus-democratiza-o-acesso-do-cidadao-aosservicos-de-saude. Acessado em 10 de maio de 2014.

RAMOS, E.M.R. Evolução histórica os direitos sociais. Disponível em http://ww3.Ifg.com.br/public_html/article.php?story=2008121611074897\&mode=print. Acessado em 17 de junho de 2014.

RODRIGUES, MS. Produção pública de medicamentos no Brasil: uma análise sob a ótica da assistência farmacêutica no sistema único de saúde. Acessada em: 16 de abril de 2014. Disponível em: http://www6.ensp.fiocruz.br/visa/files/MAYARA_RODRIGUES.pdf

SILVA, J.A. Curso de Direito Constitucional Positivo. 16 edição. Malheiros Editores Ltda. - pag. 288-290 e 458-467 - 1999a.

SOUZA, W. Doenças negligenciadas. Wanderley de Souza, coordenador. - Rio de Janeiro: Academia Brasileira de Ciências, 2010. 56 p. :il. - (Ciência e tecnologia para o desenvolvimento nacional. Estudos estratégicos)

TEIXEIRA, HV et al. Financiamento da saúde pública no Brasil: a experiência do Siops. Ciência e Saúde Coletiva 8(2): 379-391, 2003.

UNESCO. Declaração Universal dos Direitos Humanos - Adotada e proclamada pela resolução 217 A (III) da Assembléia Geral das Nações Unidas em 10 de dezembro de $1948 . \quad$ Disponível em http://unesdoc.unesco.org/images/0013/001394/139423por.pdf. Acessada em 15 de junho de 2014.

Vera Maria Vieira PANIZ; Anaclaudia Gastal FASSA; Luiz Augusto FACCHINI; Andréa Dâmaso BERTOLDI; Roberto Xavier PICCINI; Elaine TOMASI; Elaine THUMÉ; Denise Silva da SILVEIRA; Fernando Vinholes SIQUEIRA; Maria Aparecida RODRIGUES. - Acesso a medicamentos de uso contínuo em adultos e idosos nas regiões Sul e Nordeste do Brasil. Cad. Saúde Pública vol.24 no.2 Rio de 
Janeiro Feb. 2008. Disponível em: http://dx.doi.org/10.1590/S0102311X2008000200005. Acessado em: 20 de maio de 2014.

VIANA, ALA et al. Políticas e Sistemas de Saúde no Brasil. Organizado por Lígia Giovanella, Sarah Escorel, Lenaura de Vassconcelos Costa Lobato, et al. Rio de Janeiro: Editora FIOCRUZ, 2008. Pag. 65-105.

VIEIRA, FS et al. Financiamento da Assistência Farmacêutica no Sistema Único de Saúde. Saúde Soc. São Paulo, v.22, n.1, p.73-84, 2013. 
Apêndices 
Apêndice 1 - Produção Pública, em número de Unidades Farmacêuticas (UF) para o Programa Nacional de Doenças Sexualmente Transmissíveis e AIDS, no período de 2003 a 2013.

\begin{tabular}{|c|c|c|c|c|c|c|c|c|c|c|c|c|c|c|c|c|c|c|c|c|c|c|c|c|c|c|}
\hline \multirow{3}{*}{ Medicamentos } & \multirow{3}{*}{ Unid. } & \multirow{3}{*}{ Formecedor } & \multicolumn{2}{|c|}{2003} & \multicolumn{2}{|c|}{2004} & \multicolumn{2}{|c|}{2005} & \multicolumn{2}{|c|}{2006} & \multicolumn{2}{|c|}{2007} & \multicolumn{2}{|c|}{2008} & \multicolumn{2}{|c|}{2009} & \multicolumn{2}{|c|}{2010} & \multicolumn{2}{|c|}{2011} & \multicolumn{2}{|c|}{2012} & \multicolumn{2}{|c|}{2013} & \multicolumn{2}{|c|}{ Total } \\
\hline & & & Alocaạāo & custo & Alocąăo & custo & Alocaạâa & custo & Alocaạāo & custo & Alocaạāo & custo & Alocacáa & custo & \begin{tabular}{|l} 
Alocaáä \\
\end{tabular} & custo & Alocąạo & custo & Alocąăo & custo & Alocacáa & custo & Alocaąăo & custo & \multirow{2}{*}{ UF } & \multirow{2}{*}{ RS } \\
\hline & & & Quant. & (Rs) & ouant. & (Rs) & Quant. & (Rs) & Quant. & (Rs) & Quant. & (Rs) & Quant. & (RS) & Ouant. & (RS) & Ouant. & (Rs) & ouant. & (Rs) & Quant. & (Rs) & ouant. & (RS) & & \\
\hline $\begin{array}{l}\text { Didanosina } 100 \\
\mathrm{mg}\end{array}$ & comp. & FIOCRUZ & 5.778 .000 & 5.328.477,60 & 2.440 .800 & $2.250 .905,76$ & 5.989.460 & $5.523 .480,01$ & & & & & & & & & & & & & & & & & $14.208 .260,00$ & 13.102.857,37 \\
\hline $\begin{array}{l}\text { Didanosina } 25 \\
\mathrm{mg}\end{array}$ & comp. & FIOCRUZ & 1.820 .700 & $393: 271,20$ & 917.700 & $198.223,20$ & 798.000 & 172.368,00 & 266.100 & $57.47,60$ & & & & & & & & & & & & & & & $3.802 .500,00$ & $821.340,00$ \\
\hline $\begin{array}{l}\text { Etaurienz } 600 \\
\mathrm{mg}\end{array}$ & comp. & FIOCRUZ & & & & & & & & & & & 15.000 .000 & 20.250.000,00 & 15.000.000 & 20.250.000,00 & 27.000 .000 & $36.450 .000,00$ & 21.015 .000 & $28.370 .250,00$ & 57.000 .000 & $76.950 .000,00$ & 51.030 .000 & 68.890.500,00 & $186.045 .000,00$ & $251.160,750,00$ \\
\hline $\begin{array}{l}\text { Estavudina } 40 \\
\mathrm{mg}\end{array}$ & Cáps. & FIOCRUZ & 8.230 .800 & $4.362 .324,00$ & & & 5.535.000 & $2.933 .550,00$ & & & 5.700 .000 & \begin{tabular}{|l} 
3.021.000,00 \\
\end{tabular} & & & & & & & 169.320 & 38.943.60 & & & & & 19.635.120,00 & 10.355.817,60 \\
\hline $\begin{array}{l}\text { Estavdina, } \\
\text { Caps } 30 \text { mg }\end{array}$ & Cáps. & FIOCRUZ & 3.858 .000 & 1.041.660,00 & 6.922 .740 & $4.769 .767,86$ & \begin{tabular}{|l|l|}
4.390 .000 \\
\end{tabular} & $1.244 .565,00$ & $\begin{array}{l}2.718 .000 \\
\end{array}$ & $770.553,00$ & 3.480 .000 & $986,580,00$ & 8.580 .000 & 1.973.400,00 & & & 3.852 .000 & $885.960,00$ & & & & & & & $33.800 .740,00$ & 11.672.485,86 \\
\hline Indinavir $400 \mathrm{mg}$ & Caps. & FIOCBUZ & 6.287 .580 & 7.387.906,50 & & & 1.734 .570 & $20229.46,90$ & & & & & & & & & & & & & & & & & $8.022 .150,00$ & $9.477 .35,40$ \\
\hline $\begin{array}{l}\text { Lamivudina } 150 \\
\mathrm{mg}\end{array}$ & comp. & FIOCRUZ & 7.180.080 & $4.947 .075,12$ & & & 8.812 .500 & 6.071.812,50 & 7.110 .000 & $4.898 .790,00$ & 22.050 .000 & \begin{tabular}{|l|l}
$155.192 .450,00$ \\
\end{tabular} & 19.800.000 & \begin{tabular}{|l}
$10.890 .000,00$ \\
\end{tabular} & 15.150.000 & \begin{tabular}{|l|l}
$8.332 .500,00$ \\
\end{tabular} & 31.500 .000 & $17.325 .000,00$ & 48.024 .000 & $26.413 .200,00$ & \begin{tabular}{|l|l}
49.008 .000 \\
\end{tabular} & $26.954 .400,00$ & 50.400 .000 & $27.720 .000,00$ & $259.034 .580,00$ & $148.755 .227,62$ \\
\hline $\begin{array}{l}\text { Nevirapina } \\
\text { 200mg }\end{array}$ & comp. & FiocuUz & 15.877 .420 & 13.174.998,60 & 6.100 .200 & $5,0.033 .166,00$ & \begin{tabular}{|l|l|} 
& 3.360 .000 \\
\end{tabular} & $2,788.800,000$ & 3.624 .000 & $3.007 .920,00$ & 4.800 .000 & \begin{tabular}{|l}
$3.984 .000,00$ \\
\end{tabular} & 6.000 .000 & 3.960.000,00 & 7.272 .000 & \begin{tabular}{|l|l|} 
& $4.799 .52,00$ \\
\end{tabular} & 7.200 .000 & $4.811 .400,00$ & 60 & $3.960 .000,00$ & 7.002 .000 & $4.621 .320,00$ & 12.000 .000 & $7.920 .000,00$ & $79.321 .6220,00$ & $58.091 .064,60$ \\
\hline $\begin{array}{l}\text { Zidooudina } 100 \\
\text { mg }\end{array}$ & Caps. & FIOCBUZ & 5.249 .700 & $1.736 .075,79$ & 1.389 .200 & $459.408,44$ & 5.812 .500 & $1.922 .193,75$ & 3.165 .000 & $1.046 .665,50$ & 4.500 .000 & \begin{tabular}{|l|l}
$1.488 .150,00$ \\
\end{tabular} & 4.925 .000 & \begin{tabular}{|l}
$1.280 .50,00$ \\
\end{tabular} & 2.200 .000 & $572.000,00$ & 6.200 .000 & $1.612 .000,00$ & 4.500 .000 & $1.170 .000,00$ & 3.300 .000 & $858.000,00$ & 4.600 .000 & 1.196.000,00 & $45.841 .400,00$ & $13.340 .993,48$ \\
\hline $\begin{array}{l}\text { Zidovudina } 300 \\
\text { mo } \\
150 \mathrm{mg} \text { mivdudina }\end{array}$ & comp. & FIOCAUZ & 15.000 .000 & $20.550 .000,00$ & 14.316 .240 & 19.613.248,80 & \begin{tabular}{|l|l|}
15.375 .000 \\
\end{tabular} & $21.063 .750,00$ & 35.040.000 & $48.004 .800,00$ & 45.000.000 & \begin{tabular}{|l|l|}
$61.290 .0000,00$ \\
\end{tabular} & \begin{tabular}{|l|l|}
40.050 .000 \\
\end{tabular} & \begin{tabular}{|l|l}
$44.055 .000,00$ \\
\end{tabular} & \begin{tabular}{|l|l|}
60.399 .980 \\
\end{tabular} & \begin{tabular}{|l|l|}
$66.384 .978,00$ \\
\end{tabular} & $54,375.000$ & $59.812 .500,00$ & 55.899.600 & $61.489 .560,00$ & \begin{tabular}{|l|l|}
56.6110 .000 \\
\end{tabular} & $62.271 .000,00$ & 67.271 .400 & 73.998.540,00 & $459.287 .220,000$ & 538.533.376.80 \\
\hline \multicolumn{3}{|c|}{ subtotal } & 69.278 .280 & 58.921.722,81 & 32.086 .880 & 32.354.720,06 & 51.807.030 & 43.749.966,16 & 51.923.100 & 57.786.206,10 & 85.530.000 & \begin{tabular}{|l|l|} 
& 85.962.180,00 \\
\end{tabular} & \begin{tabular}{|l|} 
94.355.000 \\
\end{tabular} & \begin{tabular}{|l|l} 
& $82.48 .900,00$ \\
\end{tabular} & \begin{tabular}{|l|}
99.971 .980 \\
\end{tabular} & \begin{tabular}{|l|l|}
$100.338 .998,00$ \\
\end{tabular} & 130.277.000 & 120.896.866,00 & $\begin{array}{l}135.607 .920 \\
\end{array}$ & 121.441.953,60 & 172.922.000 & $171.654 .722,00$ & 185.301.400 & $179.725 .040,00$ & 1.108.998.590,00 & 1.055.241.266,73 \\
\hline $\begin{array}{l}\text { Didanosina } 100 \\
\mathrm{mg}\end{array}$ & comp. & FUNED & 2.082 .240 & $1.920 .241,73$ & & & & & & & & & & & & & & & & & & & & & $2.082 .240,00$ & $1.920 .241,73$ \\
\hline $\begin{array}{l}\text { Nevirapina } \\
\text { 200mg }\end{array}$ & comp. & FUNED & & & 4.692 .420 & $3.894 .708,60$ & 6.660 .000 & $5.527 .800,00$ & 3.624 .000 & $3.007 .920,00$ & 2.760 .000 & 2.290.800,00 & 6.000 .000 & \begin{tabular}{|l|}
$.960 .000,00$ \\
\end{tabular} & 4.848 .000 & \begin{tabular}{|l|}
$.199 .680,00$ \\
\end{tabular} & 9.112 .500 & $6.014 .250,00$ & 6.000 .000 & $3.960 .000,00$ & 3.498 .000 & $2.308 .680,00$ & & & 47.194.920,00 & 34.163.838,60 \\
\hline $\begin{array}{l}\text { Talidomida } 100 \\
\text { mg }\end{array}$ & comp. & FUNED & 240.000 & $43,080,00$ & 60.000 & 11.526 .00 & 48.000 & 14.452,80 & 76.800 & $23.124,48$ & 1220.000 & $36.132,00$ & 96,000 & $24,000,00$ & & & & & & & & & & & $640.800,00$ & ${ }_{1522.315,28}$ \\
\hline $\begin{array}{l}\text { Tenotovir } 300 \\
\text { mg }\end{array}$ & comp. & FUNED & & & & & & & & & & & & & & & & & 28.800.000 & $115.776 .000,00$ & $\begin{array}{l}19.800 .000 \\
\end{array}$ & $79.596 .000,00$ & 16.500.000 & $63.013 .50,00$ & $65.100 .000,00$ & $258.385 .500,00$ \\
\hline 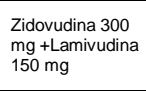 & Fr. & FUNED & & & & & & & $\begin{array}{l}6.000 .000 \\
\end{array}$ & $8.220 .000,00$ & 9.000 .000 & \begin{tabular}{|l|l}
$12.330 .000,00$ \\
\end{tabular} & \begin{tabular}{|l|l|} 
& 4.005 .000 \\
\end{tabular} & \begin{tabular}{|l|l} 
& $4.405 .500,00$
\end{tabular} & \begin{tabular}{|l|l|} 
& 8.280 .000 \\
\end{tabular} & \begin{tabular}{|l|l} 
& $9.108 .000,00$ \\
\end{tabular} & 12.500 .040 & $13.750 .044,00$ & \begin{tabular}{|l}
6.800 .100 \\
\end{tabular} & $7.480 .110,00$ & \begin{tabular}{|l|}
9.996 .000 \\
\end{tabular} & $10.995 .600,00$ & 11.802.000 & $12.982 .200,00$ & 68.383.140,00 & $79.271 .454,00$ \\
\hline \multicolumn{3}{|c|}{ subtotal } & 2.322 .240 & $1.963 .321,73$ & 4.752 .420 & $3.900 .234,60$ & \begin{tabular}{|c|}
6.708 .000 \\
\end{tabular} & $5.542 .252,80$ & 9.700 .800 & 11.251.044,48 & 11.880.000 & 14.656.932,00 & 10.101.000 & \begin{tabular}{|l|l} 
& $8.389 .500,00$ \\
\end{tabular} & \begin{tabular}{|l|l|} 
& 13.128 .000 \\
\end{tabular} & \begin{tabular}{|l|l|}
$12.307 .680,00$ \\
\end{tabular} & 21.612.540 & $19.764 .294,00$ & 41.600.100 & 127.216.1110,00 & 33.294.000 & 92.900.280,00 & 28.3020.000 & 75.995.700,00 & 183.401.100,00 & 373.993.349,61 \\
\hline $\begin{array}{c}\text { Didanosina } 100 \\
\mathrm{mg}\end{array}$ & \begin{tabular}{|c|} 
comp. \\
\end{tabular} & FURP & 2.780 .460 & $2.564 .140,21$ & 1.139 .040 & 1.050.422,69 & 1.050 .000 & $968.310,00$ & & & & & & & & & & & & & & & & & $4.996 .500,00$ & $4.582 .872,90$ \\
\hline $\begin{array}{l}\text { Estavudina } 40 \\
\mathrm{mg}\end{array}$ & Cáps. & FURP & 3.999 .960 & $2.119 .978,80$ & & & \begin{tabular}{ll|}
5.535 .000 \\
\end{tabular} & $2.933 .550,00$ & 5.856.000 & $3.103 .880,00$ & & & & & & & & & & & & & & & $15.390 .960,00$ & $8.157 .208,80$ \\
\hline $\begin{array}{l}\text { Estavduna, } \\
\text { Capps.30 ma }\end{array}$ & Cáps. & FURP & 2.000 .160 & $540.043,20$ & 4.711 .980 & 2.177.870,61 & & & & & & & & & & & & & & & & & & & $6.712 .140,00$ & 2.717.913,81 \\
\hline $\begin{array}{l}\text { Lamivudina } 150 \\
\text { m }\end{array}$ & comp. & FURP & 4.352.280 & $2.999 .720,92$ & 5.800 .200 & $3.500 .257,80$ & \begin{tabular}{|l|}
8.812 .500 \\
\end{tabular} & 6.071.812,50 & $\begin{array}{l}7.110 .000 \\
\end{array}$ & $4.898 .790,00$ & 7.350.000 & \begin{tabular}{|l|l} 
& $5.064 .150,00$
\end{tabular} & \begin{tabular}{|l|}
8.250 .000 \\
\end{tabular} & \begin{tabular}{|l|l}
$4.537 .500,00$ \\
\end{tabular} & \begin{tabular}{|l|l|}
10.3020 .000 \\
\end{tabular} & \begin{tabular}{|l}
$5.666 .100,00$ \\
\end{tabular} & 21.420 .000 & $11.781 .000,00$ & \begin{tabular}{|l|l|}
9.62 .500 \\
\end{tabular} & $5.325 .3755,00$ & \begin{tabular}{|l|l}
159.996 .000 \\
\end{tabular} & 8.797.800,00 & 16:800.000 & $9240.000,00$ & $115.155 .480,00$ & \begin{tabular}{|l}
$67.88 .506,22$ \\
\end{tabular} \\
\hline
\end{tabular}




\begin{tabular}{|c|c|c|c|c|c|c|c|c|c|c|c|c|c|c|c|c|c|c|c|c|c|c|c|c|c|c|}
\hline $\begin{array}{l}\text { Zidoovudina } 1000 \\
\text { mg }\end{array}$ & \begin{tabular}{|l|} 
Canss. \\
\end{tabular} & FURP & 3.425 .040 & 1.1.132.660,73 & 1.466 .190 & $484.869,03$ & 3.600 .000 & $1.190 .520,00$ & 3.186 .000 & 1.053.610,20 & & & & & & & & & & & & & & & $11.677 .230,00$ & 3.861.1599.96 \\
\hline 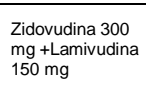 & Comp. & FURP & 8.612 .940 & 11.799.727,80 & 11.134 .500 & $15.254 .347,20$ & 15.375 .000 & $21.063 .75,000$ & 17.040 .000 & 23.344.800,00 & 9.000 .000 & 12.330.000,00 & 14.025 .000 & $15.427 .500,00$ & 15.007 .500 & 16.388.190,00 & 26.637 .540 & $29.301 .294,00$ & 8.250 .000 & $9.075 .000,00$ & 12.000.000 & $13.200 .000,00$ & 14.162 .400 & $15.578 .640,00$ & 151.244.949,000 & $182.763 .249,00$ \\
\hline $\begin{array}{l}\text { Zidovudina } 50 \\
\text { mg soluyá oral }\end{array}$ & Fr. & FURP & 73.121 & $649.431,47$ & 64,995 & $576.726,70$ & & & & & & & & & & & & & & & & & & & 138.055,00 & 1.226.158,17 \\
\hline \multicolumn{3}{|c|}{ subtotal } & 25.243.961 & $21.804 .703,13$ & 23.596.905 & $23.044,494,03$ & 34.372 .500 & $32,227.942,50$ & 33.192 .000 & 32.400.880,20 & 16.3550 .000 & $17.394,150,00$ & 22275.000 & $19.965 .00,000$ & 25.500.500 & $22.054 .290,00$ & 48.057.540 & $41.082 .294,00$ & 17.932 .500 & $14,400.375,00$ & 27.996 .000 & 21.997.800,00 & 30.962 .400 & $24.818 .644,00$ & $300.288 .306,00$ & $277.190 .568,86$ \\
\hline $\begin{array}{c}\text { Didanosina } 25 \\
\text { mg }\end{array}$ & Comp. & IQUEGO & & & & & 360.000 & 777660,00 & & & & & & & & & & & & & & & & & $360.000,00$ & $777.760,00$ \\
\hline $\begin{array}{l}\text { Didanosina } 100 \\
\text { mg }\end{array}$ & Comp. & IQUEGO & 2.780 .460 & $2.564 .140,21$ & 1.139.940 & $1.050 .422,69$ & 2046.620 & $1.887 .392,96$ & & & & & & & & & & & & & & & & & $5.966 .120,00$ & $5.501 .955,86$ \\
\hline $\begin{array}{l}\text { Estavudina } 40 \\
\text { mg }\end{array}$ & \begin{tabular}{|l|} 
Cáps. \\
\end{tabular} & laUEGo & 4.000.020 & 2.120.010,60 & 3.415 .920 & $1.810 .477,60$ & 5.5355 .000 & $2.933 .550,000$ & 4.3920 .000 & $2.327 .760,000$ & & & & & & & & & & & & & & & 17.3429.940,000 & 9.191.758,20 \\
\hline $\begin{array}{l}\text { Lamivudina } 150 \\
\text { m } 90\end{array}$ & Comp. & IQUEGO & 4.3552280 & $2.998,720,92$ & 5.080 .200 & $3.500 .257,80$ & 8.812500 & 6.071.1212.50 & 7.110 .000 & $4.8998 .790,00$ & 7.350 .000 & $5.064 .150,00$ & 5.038 .000 & $4.545 .560,00$ & 4.848 .000 & $2.666 .400,00$ & 10.0800000 & $5.544 .000,00$ & $5,793.000$ & $3.186 .150,00$ & 12.000 .000 & $6.600 .000,00$ & ${ }_{12.600 .000}$ & $6.930 .000,00$ & $830.063 .980,000$ & $520066.141,22$ \\
\hline $\begin{array}{l}\text { Lamivudinatio } \\
\text { molm solugâ } \\
\text { oral }\end{array}$ & Fr. & IQUEGO & ${ }^{65.047}$ & $1.585 .845,86$ & 45.640 & $1.112 .703,20$ & 71.900 & $1.752 .922,00$ & 59.500 & $1.450 .610,00$ & 88.000 & $2.145 .44,00$ & & & 80.000 & 1.243.200,00 & & & 78.000 & 1.616.160,00 & 86.000 & $1.781 .920,00$ & 96.000 & 1.989.120,00 & $650.087,00$ & 14.677.921,06 \\
\hline $\begin{array}{c}\text { Zidoundina } \\
\text { mg }\end{array}$ & cans. & IQUEGO & 3.425 .040 & 1.132.660,73 & 1.4662800 & $484,998,80$ & 5.962 .500 & $1.971 .798,75$ & 3.078 .000 & $1.017 .894,60$ & & & & & & & & & 28.450 .200 & $31.2955220,00$ & & & & & 4233820202,00 & 35.902 .472 .87 \\
\hline $\begin{array}{l}\text { Zidovudina a } 300 \\
\text { mg } \\
150 \mathrm{manivudina}\end{array}$ & Comp. & IQUEGO & 8.612880 & $11.799 .645,60$ & 11.134 .560 & $15.254 .347,20$ & 15.375 .000 & $21.063 .750,00$ & 17.040 .000 & $23.344 .800,00$ & 9.000 .000 & $12.330 .000,00$ & 10.022 .0000 & $11.022 .000,00$ & 10.350.000 & $11.385 .000,00$ & 9.787 .500 & $10.766 .250,00$ & 5.825 .100 & $6.407 .610,00$ & 9.996 .000 & $10.995 .600,00$ & 11.802.000 & $12.988 .200,00$ & $118.943 .044,00$ & $147.351 .202,80$ \\
\hline $\begin{array}{l}\text { Didanosina } 100 \\
\text { mg }\end{array}$ & Comp. & 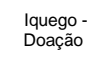 & & & & & & & 101.400 & 0,00 & & & & & & & & & & & & & & & $101.400,00$ & 0,00 \\
\hline \multicolumn{3}{|c|}{ subtotal } & 23.235.727 & 22.201.023,92 & 22281.640 & $23.213 .067,28$ & 38. 163.520 & 35.758.966,21 & 31.780 .900 & $33.039 .854,60$ & 16.438 .000 & $19.599 .50,000$ & 15.055 .000 & 15.567.860,00 & 15.55.000 & $15.294 .600,00$ & 19.867.500 & $16.310 .250,00$ & 40.146.300 & 42.505.140,00 & 22.002.000 & $19.377 .520,00$ & 24.998.000 & $21.901 .320,00$ & $268.009 .587,00$ & 264.709.212,02 \\
\hline \multirow[t]{2}{*}{$\begin{array}{l}\text { Lamivudina } 150 \\
\mathrm{mg}\end{array}$} & comp. & INB & & & 4.064 .160 & 2.800.206,.24 & & & & & & & & & & & 106.910 .000 & $138.737 .161,75$ & & & & & & & $110.974 .160,00$ & $141.577 .367,99$ \\
\hline & & & & & 4.064 .160 & $2.800 .206,24$ & & & & & & & & & & & 106.910.000 & 138.777.161,75 & & & & & & & 110.974. 160,00 & 141.537.367,99 \\
\hline 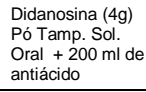 & $\mathrm{Fr}$ & LAFEPE & 38.790 & $2.999 .346,72$ & 33.011 & $2.547 .392,85$ & 39.000 & $3.009 .552,00$ & 36.600 & $2.824 .348,80$ & 27,000 & $2.083 .536,00$ & 16.000 & $987,680,00$ & 7.500 & $462.975,00$ & 9.000 & $555.570,00$ & 6.600 & $407.418,00$ & & & 5.400 & 333.342,00 & $218.901,00$ & $16.205 .161,37$ \\
\hline $\begin{array}{l}\text { Didanosina } 100 \\
\text { mg }\end{array}$ & Comp. & LAFEPE & 2.780 .460 & $2.564 .140,21$ & 1.139.940 & $1.050 .422,69$ & 3.982 .980 & $3.673 .104,16$ & & & & & & & & & & & & & & & & & $7.902 .480,00$ & $7.287 .667,06$ \\
\hline $\begin{array}{l}\text { Etaurienz } 600 \\
\text { mg }\end{array}$ & Comp. & LAFEPE & & & & & & & & & & & 15.000 .000 & $20.250 .000,00$ & & & 9.000 .000 & $12.150 .000,00$ & & & & & & & $24.000 .000,00$ & $32.400 .000,00$ \\
\hline $\begin{array}{l}\text { Estavudina } 40 \\
\text { mg }\end{array}$ & Caps. & LAFEPE & 4.000 .020 & 2.120.010,60 & & & 5.535 .000 & $2.933 .550,00$ & 4.392.000 & $2.327 .760,00$ & & & & & & & & & & & & & & & $13.927 .020,00$ & $7.381 .320,60$ \\
\hline $\begin{array}{l}\text { Estavdina, } \\
\text { Caps } 30 \text { m } \mathrm{mg}\end{array}$ & Cáps. & LAFEPE & 2.000 .220 & $540.059,40$ & 4.711.980 & $2.177 .870,61$ & 3.590 .000 & $1.017 .765,00$ & 2.718 .000 & $770.553,00$ & & & 6.145 .920 & $1.413 .561,60$ & & & & & 3.960 .000 & $910.800,00$ & 3.204 .000 & $736.920,00$ & & & $26.330 .120,00$ & $7.567 .529,61$ \\
\hline Indinavir $400 \mathrm{mg}$ & Caps. & LAFEPE & 450.000 & $528.750,00$ & & & 6.804 .900 & $7.961 .733,00$ & 3.321.000 & $3.885 .570,00$ & 3.330 .000 & $3.896 .100,00$ & 2.6110 .000 & $2.453 .400,00$ & 1.288 .800 & $1.211 .472,00$ & 1.980 .000 & $1.861 .200,00$ & & & & & 476.910 & $448.295,40$ & $20.261 .610,00$ & $22.246 .520,40$ \\
\hline $\begin{array}{l}\text { Lamivudina } 150 \\
\mathrm{mg} g\end{array}$ & Comp. & LAFEPE & 7.352 .280 & $5.065 .720,92$ & 5.000 .200 & $3.500 .257,80$ & 8.812500 & $6.071 .812,50$ & 7.110 .000 & $4.898 .790,00$ & 7.350 .000 & $5.064 .150,00$ & & & & & 91.000 & $1.885 .520,00$ & 1.600 .500 & $880.275,00$ & 3.996 .000 & $2.197 .800,00$ & 4.200 .000 & $2.3110 .000,00$ & $45.592 .480,00$ & 31.877.326,22 \\
\hline Ritonavir $100 \mathrm{mg}$ & cáps. & LAFEPE & ${ }^{789.938}$ & 1.227.960,48 & & & 5.880 .000 & $9.210 .432,00$ & & & & & & & & & & & & & & & & & $6.663 .938,00$ & 10.438.3924.48 \\
\hline$\underset{\substack{\text { Tenonouri } \\
\text { mg } 000}}{0}$ & comp. & LAFEPE & & & & & & & & & & & & & & & & & 7.200 .000 & $28.944,000,00$ & 19.800.000 & $79.5960 .000,00$ & 16.500 .000 & $63.017 .500,000$ & 43.500:000,000 & $177.55535000,00$ \\
\hline
\end{tabular}




\begin{tabular}{|c|c|c|c|c|c|c|c|c|c|c|c|c|c|c|c|c|c|c|c|c|c|c|c|c|c|c|}
\hline $\begin{array}{l}\text { Zidoovulina } 10 \\
\text { mg axarope }\end{array}$ & Fr. & LAFEPE & & & & & & & & & & & 150.000 & $1.066 .500,00$ & & & & & & & & & & & $150.000,00$ & $1.066 .50,00$ \\
\hline $\begin{array}{l}\text { Zidovudina } 100 \\
\text { mg }\end{array}$ & caps. & LAFEPE & 3.425 .000 & 1.1.132.647,50 & 1.466.500 & $484.971,55$ & 5.875 .000 & $1.942 .862,50$ & 3.111 .000 & $1.028 .807,70$ & & & 3.280 .000 & 852.800 .00 & 50.000 & $355.500,00$ & & & & & & & & & $17.207 .500,00$ & $5.797 .589,25$ \\
\hline 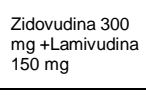 & Comp. & $\begin{array}{l}\text { LAFEPE } \\
\text {. }\end{array}$ & 8.612 .880 & $11.799 .645,50$ & 11.134 .560 & $15.254 .347,20$ & 15.375 .000 & $21.063 .750,00$ & 17.040 .000 & $23.344 .800,00$ & 9.000 .000 & $12.330 .000,00$ & 12.000 .000 & $132000.000,00$ & & & 17.400 .0000 & $19.140 .000,00$ & 7.575 .000 & $8.332 .500,00$ & 21.996 .000 & $24.195 .600,00$ & 12.982200 & $14.280 .4220,00$ & $133.115 .644,00$ & $162.941 .062,80$ \\
\hline $\begin{array}{l}\text { Zidovudina } 50 \\
\text { mg soluçáal oral }\end{array}$ & Fr. & LAFEPE & ${ }^{73.121}$ & $649,431,47$ & 64.935 & $576.726,70$ & 147.000 & $1.305 .595,20$ & ${ }_{1322.000}$ & 1.1.172.371,20 & 150.000 & $1.332 .240,00$ & & & & & 129.000 & $917.190,00$ & 90.000 & $639.900,00$ & 115.000 & $817.650,00$ & 130.000 & $924.300,00$ & $1.031 .056,00$ & 8.335.404,57 \\
\hline \multicolumn{3}{|c|}{ subtotal } & 29.516.709 & 28.621.712,91 & 23.530 .226 & 25.591.989,39 & 56.04 .380 & 58.190.156,36 & 37.860.600 & $40.253 .000,70$ & 19.957.000 & $24,706.026,00$ & 39.201 .920 & 40.223.941,60 & 1.346 .300 & $2.029 .947,00$ & 28.609 .000 & $36.509 .480,00$ & 20.432 .100 & $40.14 .9393,00$ & 49.111.000 & $107.5439 .97,00$ & 34.294 .510 & $81.309 .857,40$ & $339.900 .745,00$ & 485.094.974,36 \\
\hline $\begin{array}{l}\text { Didanosina } 100 \\
\text { mg }\end{array}$ & Comp. & LIFAL & & & 1.139.940 & $1.050 .422,69$ & 6.500 .000 & $5.994 .300,00$ & & & & & & & & & & & & & & & & & $7.639 .040,00$ & 7.044.72,69 \\
\hline Indinavir $400 \mathrm{mg}$ & \begin{tabular}{|l|l|} 
cans. \\
\end{tabular} & LFFLL & 1.799.000 & $2.104,425,00$ & & & 10.210.410 & 11.965.549,70 & 3.321 .000 & $3.8855 .57,000$ & 3.330 .000 & 3.8996.100,00 & 2.142.000 & $2.013 .480,00$ & 1.9932200 & $1.817 .208,00$ & 2.970 .000 & $2,791.800,00$ & 1.647 .000 & $1.548 .180,00$ & & & & & $27.344 .611,000$ & $30.022 .112,70$ \\
\hline 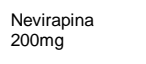 & comp. & LIFAL & & & & & 3.360 .000 & $2.788 .800,00$ & 3.624000 & $3.007 .920,00$ & $2,760.000$ & $2290.800,00$ & & & & & & & & & & & & & $9.744 .000,00$ & $8.087 .520,00$ \\
\hline $\begin{array}{l}\text { Nevirapina } 200 \\
\text { mg }\end{array}$ & Comp. & $\begin{array}{l}\text { LIFAL- } \\
\text { Doaçáo }\end{array}$ & & & & & & & & & & & & & & & 48.660 & 0,00 & & & & & & & $48.60,00$ & 0,00 \\
\hline \multicolumn{3}{|c|}{ Total } & 1.7991.000 & 2.104 .425 & 1.1.139.040 & 1.050.423 & 20.070 .410 & 20.748 .450 & 6.945 .000 & 6.893 .90 & 6.090.000 & 6.186 .900 & 2.142 .000 & 20.13 .480 & 1.933.200 & 1.817 .208 & 3.017 .660 & 2.791 .800 & $\begin{array}{l}1.647 .000 \\
\end{array}$ & 1.548 .180 & & & & & 44.776 .310 & 45.154.355,39 \\
\hline
\end{tabular}


Apêndice 2 - Produção dos laboratórios nacionais, em número de Unidades Farmacêuticas (UF) para o Programa Nacional de Doenças Sexualmente Transmissíveis e AIDS, no período de 2003 a 2013.

\begin{tabular}{|c|c|c|c|c|c|c|c|c|c|c|c|c|c|c|c|c|c|c|c|c|c|c|c|c|c|c|}
\hline \multirow{3}{*}{ Medicamentos } & \multirow{3}{*}{\begin{tabular}{|l|} 
Unid. \\
\end{tabular}} & \multirow{3}{*}{ Fornecedor } & \multicolumn{2}{|c|}{2003} & \multicolumn{2}{|c|}{2004} & \multicolumn{2}{|c|}{2005} & \multicolumn{2}{|c|}{2006} & \multicolumn{2}{|c|}{2007} & \multicolumn{2}{|c|}{2008} & \multicolumn{2}{|c|}{2009} & \multicolumn{2}{|c|}{2010} & \multicolumn{2}{|c|}{2011} & \multicolumn{2}{|c|}{2012} & \multicolumn{2}{|c|}{2013} & \multicolumn{2}{|c|}{ Total } \\
\hline & & & Alocaçăo & custo & Alocąago & custo & Alcacąa & custo & Alocaąåo & custo & Aocaa̧ä & custo & Alocacąo & custo & Alocasaio & Custo & Alocąąo & custo & Aocaa̧ä & custo & Alocagago & custo & Alocaạăo & custo & \multirow{2}{*}{ UF } & \multirow{2}{*}{ RS } \\
\hline & & & ouant. & (RS) & ouant. & (RS) & ouant. & (RS) & ouant. & (RS) & ouant. & (RS) & ouant. & (RS) & ouant. & (Rs) & ouant. & (Rs) & ouant. & (RS) & ouant. & (Rs) & Quant. & (RS) & & \\
\hline $\begin{array}{l}\text { Nevitapina } 10 \mathrm{mg} \\
\text { suspersisa oral }\end{array}$ & Fr. & воEнRINGER & 9.071 & $906.918,58$ & ${ }^{233.250}$ & 2.159.925,00 & 9.000 & 751.500,00 & 15000 & $1.395 .000,00$ & & & 25.000 & $469.750,00$ & & & & & & & & & & & $81.321,100$ & $5.683 .093,58$ \\
\hline Tipranavir $550 \mathrm{mg}$ & Cáps. & BOEHRINGER & & & & & & & & & & & & & & & ${ }_{136.080}$ & 1.166.205.50 & & & 24000 & $205.680,00$ & 1590000 & $1.362 .530,00$ & $319.080,00$ & $2.734 .515,60$ \\
\hline $\begin{array}{l}\text { Didanosina EC } \\
400 \mathrm{mg}\end{array}$ & \begin{tabular}{|l|} 
Cáps. \\
\end{tabular} & BristoL & & & 810.000 & $6.075 .000,00$ & & & \begin{tabular}{l|l}
4.269 .000 \\
\end{tabular} & $15.449 .511,00$ & 3270.000 & $11.834 .130,00$ & & & & & & & & & & & & & $8.349 .000,00$ & $33.358 .641,00$ \\
\hline $\begin{array}{l}\text { Estavudina } 20 \mathrm{mg} g \\
\text { potorat sulusaco } \\
\text { oral }\end{array}$ & Fr. & CRISTÁLAA & 89.637 & $5.019 .672,00$ & ${ }^{75.936}$ & 4.252.416,00 & 85.000 & \begin{tabular}{|l}
$4.632 .500,00$ \\
\end{tabular} & 76.400 & $4.162 .272,00$ & 44,000 & $2.384 .800,00$ & 40.000 & 2.204.000,00 & & & 20.000 & $1.1677 .018,00$ & 15.000 & $675.000,00$ & 19.000 & \begin{tabular}{|l|l} 
& $855.000,00$
\end{tabular} & & & $464.973,00$ & $25.352 .678,00$ \\
\hline Ritonavir $100 \mathrm{mg}$ & Cáps. & CRISTÁLAA & 8.912 .736 & 122999.575 .68 & & & 6.5220 .000 & \begin{tabular}{|l|l}
$8.345,60,00$ \\
\end{tabular} & & & & & & & & & & & & & 25875.000 & 21. $1.05 .625,00$ & 20.700 .000 & $17.139 .600,00$ & $62.007 .73,00$ & $59.930 .400,68$ \\
\hline $\begin{array}{l}\text { Ritionaxir } 80 \mathrm{mg} \\
\text { soluchaco oral }\end{array}$ & Fr. & CRISTT́LAA & & & & & 900 & 171.000,00 & 14.817.600 & 18.966.52,.00 & & & & & & & & & & & & & & & $14.818 .50,00$ & 19.137.528,00 \\
\hline $\begin{array}{l}\text { Saquinavir } 200 \\
\text { mg }\end{array}$ & \begin{tabular}{|l|l|} 
Cáps. \\
\end{tabular} & Cristalia & & & & & 7275.000 & 11.276.250,00 & $5.184,000$ & $8.035 .200,00$ & & & 4.800,000 & $7.641 .540,00$ & & & 1.0152200 & $1.705 .536,00$ & 1.692000 & $2.842 .560,00$ & 1.602 .000 & \begin{tabular}{|l}
$2.691 .360,00$ \\
\end{tabular} & 1.170 .000 & $2.161 .107,00$ & $22.744 .200,00$ & $36.35 .553,00$ \\
\hline $\begin{array}{l}\text { Nevirapina } 200 \\
\text { mg }\end{array}$ & Comp. & 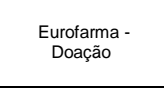 & 66.840 & 0,00 & & & & & & & & & & & & & & & & & & & & & $66.84,00$ & 0,00 \\
\hline 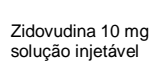 & FAA & Cisstalia & 10.936 & $45.931,20$ & 12.480 & $52.416,00$ & 27.600 & $199.977,20$ & 30.000 & $130.410,00$ & & & 30.000 & $133.002,00$ & 10.000 & $48.132,00$ & 18.000 & $88.369,20$ & 30.000 & $147.282,00$ & 22.000 & 108.006,80 & 29.000 & $156.53,20$ & $220.016,00$ & $1.030 .062,60$ \\
\hline 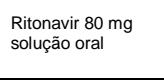 & $\mathrm{Fr}$. & Cirstalia - Doagáa & & & & & 900 & & & & & & & & & & & & & & & & & & 900,00 & 0,00 \\
\hline $\begin{array}{l}\text { Maravirouve } \\
\text { 1500mg }\end{array}$ & comp. & GLAXO & & & & & & & & & & & & & & & & & & & & & 276.000 & $4.876 .920,00$ & $276.000,00$ & $4.876 .922,00$ \\
\hline $\begin{array}{l}\text { Abacavir, Comp. Comp } \\
3000 \mathrm{mg}\end{array}$ & comp. & Glaxo Wellome & 1.132 .440 & $6.307 .90,80$ & 1.991:220 & $11.091 .095,40$ & 1.680 .000 & \begin{tabular}{|l|l}
$9.357 .60,00$ \\
\end{tabular} & & & & & & & & & & & & & & & & & $4.803 .660,00$ & $26.756 .386,20$ \\
\hline 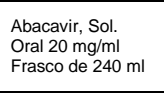 & Fr. & Giaxo Wellome & 2.862 & 292.152,96 & 3.316 & $338.49,28$ & 4.550 & 495.088,00 & & & & & & & & & & & & & & & & & $11.028,00$ & $1.125,738,24$ \\
\hline 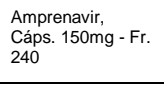 & Cáps. & Glaxo Wellome & & & 2.520 .000 & $5.166 .000,00$ & 2226.960 & 4.565.268,00 & & & & & & & & & & & & & & & & & $4.746 .960,00$ & $\begin{array}{l}9.731 .268,00 \\
0\end{array}$ \\
\hline 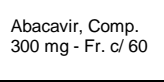 & comp. & GiaxoSmithkKine & & & & & & & $1.777,500$ & $9.7335575,00$ & 9.000 & $918.7220,00$ & & & & & & & & & & & 3.720 .000 & $1.589 .794,00$ & $5.476 .500,00$ & $12.2420 .099,00$ \\
\hline 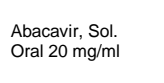 & Fr. & GlaxosnithkKine & & & & & & & 4.125 & $421.080,00$ & & & & & & & & & & & & & 5.500 & $281.51,25$ & $9.625,00$ & $702.611,25$ \\
\hline 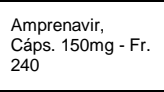 & Cáps. & GlaxoSminhkline & & & & & & & 2.136 .000 & $4.378 .800,00$ & & & & & & & & & & & & & & & $2.136 .000,00$ & $4.378 .800,00$ \\
\hline 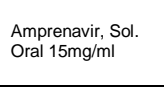 & Fr. & GiaxoSmithkine & & & & & 1.775 & $443,217,50$ & 2.500 & $624.250,00$ & & & 751 & $175.095,65$ & & & & & & & & & & & $5.026,00$ & 1.242 .563 .15 \\
\hline $\begin{array}{l}\text { Darunavi, comp. } \\
\text { istomg, }\end{array}$ & comp. & JANSSEN & & & & & & & & & & & & & & & & & 166.560 & $602.114,40$ & & & 73.440 & $214.250,83$ & $240.000,00$ & $816.365,23$ \\
\hline $\begin{array}{l}\text { Darunavi, Comp. } \\
75 \text {. }\end{array}$ & comp. & JANSSEN & & & & & & & & & & & & & & & & & 28.800 & 52.041,60 & & & 95.040 & $137.963,52$ & $123.840,00$ & $190.005,12$ \\
\hline Etravirinan 100mg & comp. & JANSSEN & & & & & & & & & & & & & & & 403.200 & $4.209 .408,00$ & 600.000 & 6.000.000,00 & 1.278 .000 & \begin{tabular}{|l}
$.555 .000,00$ \\
\end{tabular} & 1.870 .080 & 13.279.806,00 & $4.151 .280,00$ & $33.074214,00$ \\
\hline
\end{tabular}




\begin{tabular}{|c|c|c|c|c|c|c|c|c|c|c|c|c|c|c|c|c|c|c|c|c|c|c|c|c|c|c|}
\hline $\begin{array}{l}\text { Darunavir, Comp. } \\
\text { 3oommg }\end{array}$ & Comp. & Janssen-Cilag & & & & & & & & & & & 2288.000 & 21.913.650,00 & 3.351.360 & 30.631.430,40 & \begin{tabular}{|l|}
12.960 .000 \\
\end{tabular} & $103.161 .600,00$ & 12.960.000 & $93.700 .800,00$ & 10.000.0080 & $59.300 .47,40$ & \begin{tabular}{|l|l|}
13.000 .0800 \\
\end{tabular} & $74.083 .555,90$ & $54.551 .522,00$ & $382.791 .510,70$ \\
\hline Indinavirit $40 \mathrm{mg}$ & Cáps. & ¿AOB & 23.899 .420 & $29.193 .000,00$ & & & & & & & & & & & & & & & & & & & & & $23.889 .4220,00$ & $29.193 .000,00$ \\
\hline $\begin{array}{l}\text { Zidoovudina } 100 \\
\text { mg }\end{array}$ & Cáps. & MEDAPI & & & & & 5.000 .000 & $1.653 .500,00$ & & & & & & & & & & & & & & & & & $5.000 \cdot 000,00$ & $1.653 .500,00$ \\
\hline 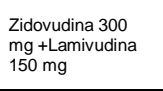 & Fr. & MEDAPI & & & & & 10.500 .000 & $14.280 .000,00$ & & & & & & & & & & & & & & & & & $10.500 .000,00$ & $14.280 .000,00$ \\
\hline Neffinauri $250 \mathrm{mg}$ & Caps. & ROCHE & 78.036.750 & $124.737 .900,75$ & 45.550 .050 & \begin{tabular}{|l}
$64.786 .120,65$ \\
\end{tabular} & 48.060 .000 & 56.230.200,00 & 33.169 .500 & 35.569.268,86 & 32.670 .000 & $31.036 .500,00$ & & & & & & & & & & & & & $237.786 .300,00$ & $312.359 .990,26$ \\
\hline & Subtotal & & 112.150.692 & 178.802.842 & 51.286 .252 & 93.921.470 & 81.391.985 & 112.321 .701 & 61.451.625 & 98.865.995 & 35.993 .000 & 46.174.150 & 7.181 .751 & 32.537.038 & 3.361.360 & 30.679 .562 & \begin{tabular}{|l|}
14.552 .480 \\
\end{tabular} & 111.498.137 & 15.992.350 & \begin{tabular}{|l}
104.019 .798 \\
\end{tabular} & 38.820.080 & 94.351.146 & \begin{tabular}{|l|l|}
41.098 .140 \\
\end{tabular} & 115.283.695 & 462.779 .725 & 1.018.455.433,61 \\
\hline
\end{tabular}


Apêndice 3 - Produção dos laboratórios internacionais, em número de Unidades Farmacêuticas (UF) para o Programa Nacional de Doenças Sexualmente Transmissíveis e AIDS, no período de 2003 a 2013.

\begin{tabular}{|c|c|c|c|c|c|c|c|c|c|c|c|c|c|c|c|c|c|c|c|c|c|c|c|c|c|c|}
\hline \multirow{3}{*}{ Medicamentos } & \multirow{3}{*}{ Unid. } & \multirow{3}{*}{ Fornecedor } & \multicolumn{2}{|c|}{2003} & \multicolumn{2}{|c|}{2004} & \multicolumn{2}{|c|}{2005} & \multicolumn{2}{|c|}{2006} & \multicolumn{2}{|c|}{2007} & \multicolumn{2}{|c|}{2008} & \multicolumn{2}{|c|}{2009} & \multicolumn{2}{|c|}{2010} & \multicolumn{2}{|c|}{2011} & \multicolumn{2}{|c|}{2012} & \multicolumn{2}{|c|}{2013} & \multicolumn{2}{|c|}{ Total } \\
\hline & & & Alocasâa & custo & \begin{tabular}{|l|l|} 
Alocąăo \\
\end{tabular} & custo & \begin{tabular}{|l|l|} 
Alocaāó \\
\end{tabular} & custo & Alocạāo & custo & \begin{tabular}{|l|} 
Alocaạăo \\
\end{tabular} & custo & \begin{tabular}{|l|} 
Alocąáa \\
\end{tabular} & custo & \begin{tabular}{|l|l|} 
Alocaăäo \\
\end{tabular} & custo & Alocaạâa & custo & \begin{tabular}{|l|l|} 
Alocąăo \\
\end{tabular} & custo & Alocaạăo & custo & Alocacāo & custo & \multirow{2}{*}{ UF } & \multirow{2}{*}{ RS } \\
\hline & & & ouant. & (As) & auant. & (Rs) & Quant. & (As) & Quant. & (RS) & Quant. & (RS) & Quant. & (As) & Quant. & (As) & Quant. & (As) & Quant. & (As) & Quant. & (AS) & ouant. & (AS) & & \\
\hline $\begin{array}{l}\text { Lopinavir 100 } \\
\text { mg tritonair } \\
25 \mathrm{mg}\end{array}$ & Comp. & АвВотт & 0 & & & & & & & & & & & & & 0,00 & & & \begin{tabular}{|l|l|}
1.008 .000 \\
\end{tabular} & 74.601,57 & \begin{tabular}{|l|l|} 
& $1.56,0.000$ \\
\end{tabular} & 955.464,00 & & & 2.634.000,00 & \begin{tabular}{|l}
$1.705 .065,57$ \\
\end{tabular} \\
\hline 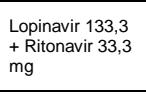 & \begin{tabular}{|l|} 
Capss. \\
\end{tabular} & АвВотт & 17.955.447 & \begin{tabular}{|l|l|}
$53.352 .019,58$ \\
\end{tabular} & 39.555.000 & $154.264 .500,00$ & \begin{tabular}{|l|l|}
81.492 .480 \\
\end{tabular} & 230.389.960,50 & \begin{tabular}{|l|l}
$\mid 67.889 .880$ \\
\end{tabular} & $100.510 .967,34$ & & & & & & & & & & & & & & & 206.872.807,00 & 538.517.447,42 \\
\hline $\begin{array}{l}\text { Lopinavir } 200 \\
\text { myt+fitonavi } \\
50 \mathrm{mg}\end{array}$ & \begin{tabular}{|c|} 
comp. \\
\end{tabular} & АвВОтт & & & & & & & & & \begin{tabular}{|l|l|}
34.099 .920 \\
\end{tabular} & |60.348.023,15 & \begin{tabular}{|l|l|}
80.750 .400 \\
\end{tabular} & \begin{tabular}{|l|l|}
$11.762 .860,32$ \\
\end{tabular} & 75.120.000 & \begin{tabular}{|l|l}
$128.629 .854,00$ \\
\end{tabular} & & & 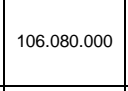 & |108.185.688,00 & 79.920.000 & \begin{tabular}{|l|l|}
$74.727 .198,00$ \\
\end{tabular} & & & 375.970.320,00 & |485.653.623,47 \\
\hline 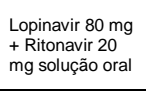 & Fr. & АвВотT & & & & & & & & & & & & & 13.000 & \begin{tabular}{|l|l}
$1.3533 .625,00$ \\
\end{tabular} & & & 24000 & \begin{tabular}{|l|l}
$1.468 .584,00$ \\
\end{tabular} & 16.000 & 897.936,00 & & & $53.000,00$ & \begin{tabular}{|l|l} 
& $3.720 .145,00$
\end{tabular} \\
\hline $\begin{array}{c}\text { Ritionaviri } 100 \\
\text { mg }\end{array}$ & Caps. & АвВОтT & & & & & & & & & \begin{tabular}{|l|l|}
11.425 .008 \\
\end{tabular} & 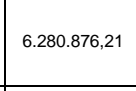 & \begin{tabular}{|l|l|}
14.952 .000 \\
\end{tabular} & \begin{tabular}{|l|l}
$7.355 .26,929$ \\
\end{tabular} & \begin{tabular}{|l|l|}
$15,300.0000$ \\
\end{tabular} & \begin{tabular}{|l|l}
$9.0000 .000,00$ \\
\end{tabular} & \begin{tabular}{|l|l|}
20.400 .000 \\
\end{tabular} & \begin{tabular}{|l|l}
$11.453 .000,00$ \\
\end{tabular} & \begin{tabular}{|l|l|}
18.000 .000 \\
\end{tabular} & \begin{tabular}{|l}
$9.922 .176,00$ \\
\end{tabular} & & & & & $\begin{array}{l}80.077 .008,00 \\
\end{array}$ & 43.991.279,13 \\
\hline $\begin{array}{l}\text { Ritionari } 80 \mathrm{mg} \\
\text { solusfio oral }\end{array}$ & Fr. & Аввотт & 13.347 & 2.282.737.41 & & & & & & & & & & & & & 530 & $61.131,92$ & & & 280 & $29.80,68$ & & & $14.157,00$ & 2.374.052,01 \\
\hline 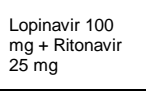 & Comp. & ABBVVE & & & & & & & & & & & & & & & & & & & & & 2.044 .000 & \begin{tabular}{|l|l}
$1.257 .945,60$ \\
\end{tabular} & \begin{tabular}{|l|l|}
$2.044 .000,00$ \\
\end{tabular} & \begin{tabular}{|l|l}
$1.257 .945,60$ \\
\end{tabular} \\
\hline $\begin{array}{l}\text { Lopinavir } 200 \\
\text { mytrititonair } \\
50 \mathrm{mg}\end{array}$ & Comp. & ABBUVE & & & & & & & & & & & & & & & & & & & & & $97,200.000$ & 89.806.482,00 & $\begin{array}{l}97.200 .0000,00 \\
\end{array}$ & \begin{tabular}{|l|l}
$89.800 .482,00$ \\
\end{tabular} \\
\hline 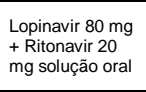 & Fr. & ABBVIE & & & & & & & & & & & & & & & & & & & & & 28.000 & 1.552.853,68 & $28.000,00$ & \begin{tabular}{|l|l}
$1.552 .253,68$ \\
\end{tabular} \\
\hline 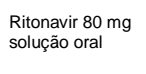 & Fr. & ABBVIE & & & & & & & & & & & & & & & & & & & & & 300 & $31.552,70$ & 300,00 & $31.552,70$ \\
\hline 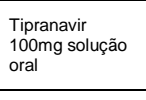 & Fr. & BOEHRINGER & & & & & & & & & & & & & & & 1.676 & \begin{tabular}{|l|l|} 
& $623.472,00$ \\
\end{tabular} & & & 280 & $104,160,00$ & 900 & 334.800,00 & $2.856,00$ & \begin{tabular}{|l|l|}
$1.062 .4322,00$ \\
\end{tabular} \\
\hline $\begin{array}{c}\text { Alazanauxir } 150 \\
\text { ma c caps }\end{array}$ & Caps. & BRisToL & & & \begin{tabular}{|l|l|}
2.404 .800 \\
\end{tabular} & \begin{tabular}{|l}
$23.446 .800,00$ \\
\end{tabular} & \begin{tabular}{|l|l|}
9.457 .980 \\
\end{tabular} & \begin{tabular}{|l}
$70.934 .850,00$ \\
\end{tabular} & \begin{tabular}{|l|l|}
15.000 .000 \\
\end{tabular} & 105.750.000,00 & 12.900.000 & $88.216 .650,00$ & & & & & & & & & & & & & 39.762.780,00 & 288.348.300,00 \\
\hline $\begin{array}{l}\text { Alazanauxir } 200 \\
\text { my C Caps }\end{array}$ & Caps. & BRISTOL & \begin{tabular}{|l|}
509.400 \\
\end{tabular} & 5.756.400,00 & \begin{tabular}{|l|l|}
3.516 .300 \\
\end{tabular} & \begin{tabular}{|l}
$34.283 .925,00$ \\
\end{tabular} & \begin{tabular}{|l|l|}
11.538 .420 \\
\end{tabular} & \begin{tabular}{|l}
$90.288 .136,50$ \\
\end{tabular} & \begin{tabular}{|l|l|}
7.200 .000 \\
\end{tabular} & 52.959.600,00 & \begin{tabular}{|l|l|}
6.480 .000 \\
\end{tabular} & 46.293.120,00 & \begin{tabular}{|l|}
4.410 .000 \\
\end{tabular} & \begin{tabular}{|l|}
$20.109 .600,00$ \\
\end{tabular} & & & & & & & & & & & 33.735.120,00 & $249.690 .781,50$ \\
\hline $\begin{array}{l}\text { Didanosina EC } \\
250 \mathrm{mg}\end{array}$ & Caps. & BrisToL & & & \begin{tabular}{|l|l|}
123.000 \\
\end{tabular} & $575.640,00$ & \begin{tabular}{|l|l|}
1.920 .000 \\
\end{tabular} & \begin{tabular}{|l|l|l|}
$7.109 .250,00$ \\
\end{tabular} & \begin{tabular}{|l|l|}
496.530 \\
\end{tabular} & \begin{tabular}{|l|}
$1.458 .55,88$ \\
\end{tabular} & \begin{tabular}{|l|l|}
1.140 .000 \\
\end{tabular} & 3.348.750,00 & \begin{tabular}{|l|l|}
1.795 .500 \\
\end{tabular} & 3.375.540,00 & & & & & & & & & & & \begin{tabular}{|l|l}
$5.475 .030,00$ \\
\end{tabular} & \begin{tabular}{|l|l}
$55867.736,88$ \\
\end{tabular} \\
\hline $\begin{array}{c}\text { Tenoforir } \\
\text { mg }\end{array}$ & comp. & GILEAD & \begin{tabular}{|l|l|} 
& 27.000 \\
\end{tabular} & $7.238 .880,00$ & \begin{tabular}{|l|l|}
1.986 .000 \\
\end{tabular} & $45.757 .440,00$ & & & \begin{tabular}{|l|l|} 
& 8100.000 \\
\end{tabular} & 72.33.000.00 & \begin{tabular}{|l|l|}
10.500 .000 \\
\end{tabular} & 89.775.000,00 & 11.400.000 & \begin{tabular}{|l|}
$73.515 .000,00$ \\
\end{tabular} & \begin{tabular}{|l|}
18.000 .000 \\
\end{tabular} & 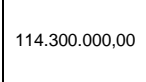 & |30.000.000 & $120.750 .000,00$ & & & & & & & $80.262 .000,00$ & $523.6093220,00$ \\
\hline 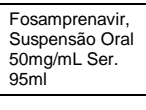 & \begin{tabular}{|l|} 
\\
\end{tabular} & GLAXO & & & & & & & & & & & & & & & 1.480 & $287.157,00$ & & & 550 & \begin{tabular}{ll|}
$96.042,38$ \\
\end{tabular} & & & $2.030,00$ & 383.199,38 \\
\hline 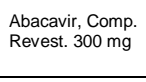 & Comp. & Gilaxo Group & & & & & & & & & \begin{tabular}{|l|l|}
3.600 .0000 \\
\end{tabular} & \begin{tabular}{|l|l}
$162200.000,000$ \\
\end{tabular} & \begin{tabular}{|l|l|} 
& 1.555 .000 \\
\end{tabular} & 4.482000,000 & & & & & & & & & & & 5.135.000,000 & 20.682.000,00 \\
\hline $\begin{array}{l}\text { Amprenavir, Sol. } \\
\text { Oral } 15 \mathrm{mig} / \mathrm{mI}\end{array}$ & Fr. & Glaxo Group & & & & & & & & & & & 3.849 & $658.179,00$ & & & & & & & & & & & $3.849,00$ & $658.179,00$ \\
\hline 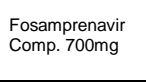 & comp. & Gilaxo Group & & & & & & & & & 672.000 & 5.221.440,00 & 1.932 .000 & 10.862.190,00 & 1.404 .000 & 8.010.990,00 & 1.800 .000 & 6.913:800,00 & 2.250.000 & 7.2.53:955,75 & 3.360 .000 & 10.352.160,00 & 5.196 .000 & 17.240.328,00 & 16.614,000,00 & 65.854.766,75 \\
\hline 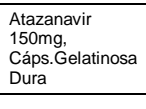 & Caps. & Lawerence & & & & & & & & & & & \begin{tabular}{|l|l|} 
& 8250.000 \\
\end{tabular} & \begin{tabular}{|l|}
$35.970 .000,00$ \\
\end{tabular} & & & & & & & & & & & \begin{tabular}{|l|l|}
$8.250 .000,00$ \\
\end{tabular} & 35.970.000,00 \\
\hline 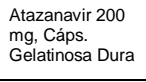 & Cáps. & Lawerence & & & & & & & & & & & 9.990 .000 & \begin{tabular}{|l|}
$40.998 .960,00$ \\
\end{tabular} & & & |4.80.0000 & 19.955.400,00 & \begin{tabular}{|l|l|}
6.975 .000 \\
\end{tabular} & 25.162312,50 & 5.000 .100 & 16.672.833,45 & & & 26.765.100,00 & 102.792.505,95 \\
\hline
\end{tabular}




\begin{tabular}{|c|c|c|c|c|c|c|c|c|c|c|c|c|c|c|c|c|c|c|c|c|c|c|c|c|c|c|}
\hline 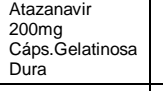 & Caps. & LAWRENCE & & & & & & & & & & & & & 2.004 .000 & $10.470 .900,00$ & & & & & & & & & $2.004 .000,00$ & $10.470 .900,00$ \\
\hline 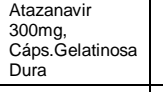 & Cáps. & Lawrence & & & & & & & & & & & 4.125 .000 & 35.977.000,00 & 8.970 .000 & $90.148 .500,00$ & \begin{tabular}{|l|l|}
102020.0000 \\
\end{tabular} & $76.683 .000,00$ & 19.800 .000 & 18.108.000,00 & \begin{tabular}{|l|l|}
12.499 .920 &
\end{tabular} & \begin{tabular}{|l|}
$\mid 68.249 .563,20$ \\
$\mid$
\end{tabular} & & & $55.594 .920,00$ & $379.159 .663,20$ \\
\hline $\begin{array}{l}\text { Didanosina EC } \\
\text { 250 mg }\end{array}$ & Cáps. & LAWRENCE & & & & & & & & & & & & & 1.251 .000 & $2.689 .650,00$ & \begin{tabular}{|l|}
1.200 .000 \\
\end{tabular} & $2.058 .840,00$ & 900.000 & $1.361 .880,00$ & & & 9960.000 & $1.452 .672,00$ & $4.311 .000,00$ & $7.563 .042,00$ \\
\hline $\begin{array}{l}\text { Didanosina EC } \\
4000 \mathrm{mg}\end{array}$ & \begin{tabular}{l|l|} 
Cáps. & \\
\end{tabular} & LAWRENCE & & & & & & & & & & & & & 801.000 & $2.843 .550,00$ & \begin{tabular}{|l|}
1.376 .250 \\
\end{tabular} & $3.095 .901,90$ & 1.800.000 & $4.464 .720,00$ & 1.200 .000 & $2.827 .656,00$ & 1.020.000 & $2.403 .57,60$ & $6.197 .250,00$ & $15.635 .335,50$ \\
\hline Indinavirit $40 \mathrm{mg}$ & \begin{tabular}{|l|l|} 
Cáps. & \\
\end{tabular} & LKM & & & & & 800.100 & $920.115,00$ & & & & & & & & & & & & & & & & & $800.100,00$ & $920.115,00$ \\
\hline $\begin{array}{l}\text { Laminudina } 150 \\
\text { mg }\end{array}$ & Cáps. & LKM & & & & & 1.000 .020 & 375.007,50 & & & & & & & & & $\mid \begin{array}{l}\mid 06.080 .000 \\
\mid\end{array}$ & 137.65.72.80 & & & & & & & $107.080 .0220,00$ & 138.030.780,30 \\
\hline $\begin{array}{l}\text { Zidovudina } 100 \\
\text { mg }\end{array}$ & Cáps. & LKM & & & & & 2.800 .000 & 630.000,00 & & & & & & & & & & & & & & & & & $2.800 .000,00$ & 630.000,00 \\
\hline $\begin{array}{l}\text { Rategravir } \\
\text { Aloomg }\end{array}$ & comp. & $\begin{array}{l}\text { MERCA } \\
\text { SHARP }\end{array}$ & & & & & & & & & & & & & 2.868 .000 & $62.460 .186,00$ & \begin{tabular}{|l|l|}
5.100 .000 \\
\end{tabular} & $86.134 .104,00$ & 5.112 .000 & $75.062 .052,00$ & \begin{tabular}{|l|l|}
4.600 .000 \\
\end{tabular} & 62.790.000,00 & 5.166 .000 & $70.434 .000,00$ & $22.840 .000,00$ & $356.880 .342,00$ \\
\hline $\begin{array}{l}\text { Eavirenz } \\
\text { 200mg }\end{array}$ & Fr. & $\begin{array}{l}\text { MERECK } \\
\text { SHARP }\end{array}$ & & & & & & & 382.680 & $576.450,02$ & & & & & & & & & & & & & & & $382.680,00$ & $576.450,02$ \\
\hline $\begin{array}{c}\text { Elaviren } 2000 \\
\text { my }\end{array}$ & \begin{tabular}{ll|} 
Cáps. \\
\end{tabular} & $\begin{array}{c}\text { MERACK } \\
\text { SHARP }\end{array}$ & 15.479 .670 & 92.609 .609 .49 & \begin{tabular}{|l|}
22.514 .400 \\
\end{tabular} & $107,528.774,40$ & 29.700 .000 & $118,206.000,00$ & \begin{tabular}{|l|l|}
21.825 .000 \\
\end{tabular} & $81.55 .1990,00$ & & & & & & & & & & & & & & & $89.519 .070,00$ & $400.077 .77,8398$ \\
\hline 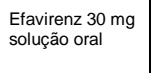 & Fr. & $\begin{array}{l}\text { MERCA } \\
\text { SHARP }\end{array}$ & 16.998 & $1.468 .117,26$ & 16.500 & $1.079 .100,00$ & 20.000 & \begin{tabular}{|l|l|} 
& $1.090 .000,00$ \\
\end{tabular} & 26.250 & $1.344 .787,50$ & 15.045 & $495.085,82$ & 15.826 & $466.388,15$ & 25.800 & 1.010.715,00 & 24.500 & $747.201,00$ & & & 7.000 & $213.486,00$ & 15.500 & $472.719,00$ & $183.419,00$ & $8.367 .599,73$ \\
\hline Indinavir $400 \mathrm{mg}$ & Capse. & Merck Sharp & & & & & \begin{tabular}{l|l|}
1.600 .020 \\
\end{tabular} & \begin{tabular}{|l|l|} 
& $1.984 .024,80$ \\
\end{tabular} & & & & & & & & & & & 600.300 & $564.288,00$ & & & & & $2.200 .320,00$ & $2.548 .306,80$ \\
\hline $\begin{array}{l}\text { Eativienz } \\
\text { 2000mg }\end{array}$ & Cáps. & OPAS & & & & & & & & & & & & & & & & & & & 203.940 & $40.021,21$ & & & $203.044,00$ & $40.021,21$ \\
\hline $\begin{array}{l}\text { Nevirapina } 10 \\
\text { moguluspensäo } \\
\text { oral }\end{array}$ & Fr. & OPAS & & & & & & & & & & & & & & & & & & & 5.774 & $52.55,52$ & & & $5.774,00$ & 52.35,52 \\
\hline $\begin{array}{c}\text { Eavarien } 2000 \\
\text { my }\end{array}$ & comp. & $\begin{array}{c}\text { OPAS } \\
\text { (Rarbaxy) }\end{array}$ & & & & & & & & & 13.515.000 & $12.019 .456,00$ & & & & & & & & & & & & & $13.515 .000,00$ & 12.019.456,00 \\
\hline $\begin{array}{l}\text { Enturitida } \\
\text { Somangma }\end{array}$ & \begin{tabular}{|l|l|}
$\mathrm{kt}$ \\
\end{tabular} & ROCHE & & & & & 13.000 & \begin{tabular}{|l|l}
$45.726 .456,00$ \\
\end{tabular} & 11.100 & $34.774 .696,05$ & 16.000 & $50.125 .688,00$ & 16.000 & 38.165.601,60 & 25.550 & 74.867.098, 16 & 21.750 & 54.403.779,19 & & & 1.025 & 1.114.718,25 & 4.393 & 10.988.294,36 & 108.918,00 & 310.166.331,61 \\
\hline 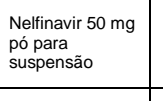 & Fr. & ROCHE & 10.540 & $1.331 .202,00$ & & & & & & & & & & & & & & & & & & & & & 10.540,00 & $1.331 .202,00$ \\
\hline $\begin{array}{c}\text { Saquinauri } 200 \\
\mathrm{~m}\end{array}$ & cás. & Roche & & & |10.800.000 & $17.184 .960,00$ & & & & & 7.560 .000 & $11.793 .600,000$ & & & & & & & & & & & & & 18.356.000,00 & $28.978 .560,00$ \\
\hline 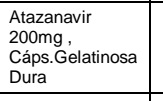 & Cáps. & $\underset{L A B}{\text { SWORDS LA }}$ & & & & & & & & & & & & & & & & & & & & & 27.630.000 & $141.237 .180,00$ & $27.630 .000,00$ & $\begin{array}{lll}141.237 .180,00 \\
\end{array}$ \\
\hline $\begin{array}{c}\substack{\text { abacauri } \\
\text { Comprimido } 300 \\
\text { mg }} \\
\end{array}$ & Comp. & UNICEF & & & & & & & & & & & & & 5.100 .000 & $5.136 .975,00$ & & & & & \begin{tabular}{|l|l|}
2520.0000 \\
\end{tabular} & $\mid 1.589 .794,00$ & & & $7.620 .000,00$ & $6.726 .769,00$ \\
\hline 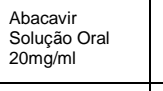 & Fr. & UNICEF & & & & & & & & & & & & & 6.500 & $272.528,75$ & & & 5.200 & $250.283,12$ & & & & & $11.700,00$ & $522.811,87$ \\
\hline $\begin{array}{l}\text { Eativenz } \\
\text { 20omg }\end{array}$ & cás. & UNICEF & & & & & & & & & & & & & & & $\begin{array}{l}330.030 \\
\end{array}$ & $119.052,00$ & 504.000 & $103.638,00$ & 495.000 & 188.149,50 & 480.000 & $225.411,00$ & $1.809 .030,00$ & $6332.24,50$ \\
\hline $\begin{array}{l}\text { Etavirenz } 600 \\
\text { mg }\end{array}$ & comp. & UNICEF & & & & & & & & & & & & & & & \begin{tabular}{|l|}
18.000 .000 \\
\end{tabular} & $7.386 .981,00$ & & & & & & & $18.000 .000,00$ & $7.386 .981,00$ \\
\hline $\begin{array}{l}\text { Lamivudina } 150 \\
\mathrm{mg}\end{array}$ & Cáps. & UNICEF & & & & & $\begin{array}{l}10.622 .000 \\
\end{array}$ & \begin{tabular}{|l|l|} 
& $2.389 .500,00$ \\
\end{tabular} & & & & & & & & & 825.000 & $692.113,95$ & & & & & & & $11.445 .000,00$ & $3.081 .613,95$ \\
\hline
\end{tabular}




\begin{tabular}{|c|c|c|c|c|c|c|c|c|c|c|c|c|c|c|c|c|c|c|c|c|c|c|c|c|c|c|}
\hline $\begin{array}{l}\text { Nevirapina 10 } 10 \\
\text { mo suspensao } \\
\text { oral }\end{array}$ & $\mathrm{Fr}$. & UNCEF & & & & & & & & & & & & & 20.000 & $113.500,00$ & & & 10.000 & $62.401,50$ & 13.000 & $83.811,00$ & 28.000 & $248.150,00$ & 71.000,00 & $507.862,50$ \\
\hline $\begin{array}{l}\text { Novitapina } \\
\text { 200mg }\end{array}$ & comp. & UNCEF & & & & & \begin{tabular}{|l|}
4.530 .000 \\
\end{tabular} & $1.226 .497,50$ & & & & & & & & & & & & & & & & & $4.530 .000,00$ & 1.226.497,50 \\
\hline $\begin{array}{l}\text { Zidovudina } 100 \\
\text { mg }\end{array}$ & Cáps. & UNCEF & & & & & \begin{tabular}{|l|l|}
8.000 .000 \\
\end{tabular} & $1.400 .000,00$ & & & & & & & & & & & & & & & & & $8.000 .000,00$ & $1.400 .000,00$ \\
\hline $\begin{array}{l}\text { Zidovudina } 300 \\
\text { mg tuanivadina } \\
1500 \mathrm{mg}\end{array}$ & $\mathrm{Fr}$. & UNICEF & & & & & \begin{tabular}{|l|}
21.840 .000 \\
\end{tabular} & $11.848 .200,00$ & & & & & & & & & & & & & & & & & $21.844 .000,00$ & $11.848 .200,00$ \\
\hline $\begin{array}{l}\text { Eatavienz } \\
\text { 2000mg }\end{array}$ & Cáps. & $\begin{array}{c}\text { UNMCEF } \\
\text { (Aurobinoo) }\end{array}$ & & & & & & & & & $\begin{array}{l}432.000 \\
\end{array}$ & 206.856 .50 & 954,000 & $342.653,22$ & & & & & & & & & & & $1.386 .000,00$ & $549.509,72$ \\
\hline $\begin{array}{l}\text { Etavirenz } 6000 \\
\text { mg }\end{array}$ & comp. & $\begin{array}{c}\text { UNMCEF } \\
\text { (Aurobinoo) }\end{array}$ & & & & & & & & & 13.515 .000 & 12:106.715,09 & 31.959.900 & $23.544 .563,37$ & & & & & & & & & & & 45.474.900,00 & $35.661 .278,47$ \\
\hline $\begin{array}{l}\text { Abacavir. Comp. } \\
\text { Revest. } 300 \mathrm{mg}\end{array}$ & comp. & $\begin{array}{c}\text { UNMCEF } \\
\text { (Aurobinoo) }\end{array}$ & & & & & & & & & & & 1.680 .000 & $1.275 .324,96$ & & & & & & & & & & & $1.680 .000,00$ & 1.275.324,96 \\
\hline $\begin{array}{l}\text { Abacauri, Sol: } \\
\text { Oral } 20 \text { mglmi }\end{array}$ & $\mathrm{Fr}$ & $\begin{array}{c}\text { UNMCEF } \\
\text { (Aurobinolo) }\end{array}$ & & & & & & & & & & & 6.500 & $210.059,40$ & & & & & & & & & & & $6.500,00$ & $210.059,40$ \\
\hline 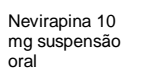 & $\mathrm{Fr}_{\mathrm{s}}$ & 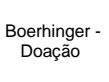 & & & & & 407 & 0,00 & & & & & & & 422 & 0,00 & & & & & & & & & 829,00 & 0,00 \\
\hline $\begin{array}{l}\text { Tenofovir } 300 \\
\text { mg }\end{array}$ & comp. & $\begin{array}{c}\text { Gil EAD- } \\
\text { Doagaio }\end{array}$ & & & & & \begin{tabular}{|l|l|}
5.778 .000 \\
\end{tabular} & 106.959.600,00 & & & & & & & & & & & & & & & & & $5.778 .000,00$ & 106.959.600,00 \\
\hline $\begin{array}{l}\text { Etavirenz } 6000 \\
\text { mg }\end{array}$ & Cáps. & $\begin{array}{l}\text { MERCK. } \\
\text { Doageio }\end{array}$ & & & 525.000 & & & & & & & & & & & & & & & & & & & & $5225.000,00$ & 0,00 \\
\hline 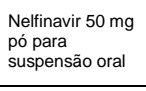 & $\mathrm{Fr}$ & 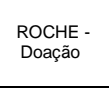 & & & 25.620 & 0,00 & 10.000 & 0,00 & 15.200 & 0,00 & & & & & & & & & & & & & & & $50.820,00$ & 0,00 \\
\hline $\begin{array}{l}\text { Nelfinavir } 50 \mathrm{mg} \\
\text { potbara } \\
\text { suspensáa oral }\end{array}$ & Fr. & 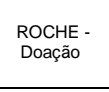 & 1.581 & 0,00 & & & & & & & 7.500 & 0.00 & & & & & & & & & & & & & $9.081,00$ & 0,00 \\
\hline $\begin{array}{l}\text { Nevirigaina } \\
\text { lolug } \\
\text { suspensăo orat }\end{array}$ & $\mathrm{Fr}$ & $\begin{array}{l}\text { UncCE. } \\
\text { Doagéio }\end{array}$ & & & & & & & & & & & & & 3.500 & 0,00 & & & & & & & & & $3.500,00$ & 0,00 \\
\hline $\begin{array}{l}\text { Tenofovir } 300 \\
\text { mg }\end{array}$ & comp. & 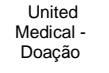 & & & 3.510 & 0,00 & & & & & & & & & & & & & & & & & & & $3.510,00$ & 0,00 \\
\hline 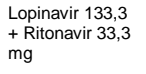 & Cáps. & 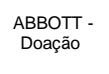 & 194.820 & 0,00 & 11.250 & & 15.414 & & 1.030.194 & 0,00 & & & & & & & & & & & & & & & $1.251 .678,00$ & 0,00 \\
\hline $\begin{array}{l}\text { Lopinavir } 200 \\
\text { mg +tithouar } \\
50 \mathrm{mg} \text {. }\end{array}$ & comp. & 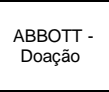 & & & & & & & & & \begin{tabular}{|l|l|}
3.600 .0000 \\
\end{tabular} & 0.00 & & & 24.000 & 0,00 & & & & & & & & & $3.624 .000,00$ & 0,00 \\
\hline 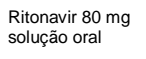 & $\mathrm{Fr}$ & 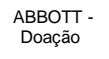 & 0 & & & & 1.152 & 0,00 & & & 1.750 & 0,00 & & & & & & & & & & & & & $2.902,00$ & 0,00 \\
\hline & Total & & 34.518.803 & 164.119 .966 & 81.481.380 & 384.122.1.139 & \begin{tabular}{|c|}
$\mid 91.136 .993$ \\
\end{tabular} & 691.477 .598 & 121.976.834 & 455.1399 .748 & \begin{tabular}{|l|}
$\mid 19.479 .223$ \\
$\mid$
\end{tabular} & 402.243.261 & 173.775 .975 & 411.034 .147 & 130.936 .872 & 511.308 .072 & | 200.161:216 & 529.024 .689 & 163.158 .500 & 342.716 .470 & \begin{tabular}{|l|}
$\mid 11.37 .37 .969$ \\
\end{tabular} & 240.988 .152 & 139.763 .093 & 337.685 .995 & 1.467 .766 .858 & 4.466 .267 .137 \\
\hline
\end{tabular}


Apêndice 4 - Produção Pública, em número de Unidades Farmacêuticas (UF) para o Programa Nacional de Controle da Hanseníase, período 2003 a 2013.

\begin{tabular}{|c|c|c|c|c|c|c|c|c|c|c|c|c|c|c|c|c|c|c|c|c|c|c|c|c|c|c|}
\hline \multirow{3}{*}{ Medicamentos } & \multirow{3}{*}{\begin{tabular}{|l|} 
Unida. \\
\end{tabular}} & \multirow{3}{*}{ Fornecedor } & \multicolumn{2}{|c|}{2003} & \multicolumn{2}{|c|}{2004} & \multicolumn{2}{|c|}{2005} & \multicolumn{2}{|c|}{2006} & \multicolumn{2}{|c|}{2007} & \multicolumn{2}{|c|}{2008} & \multicolumn{2}{|c|}{2009} & \multicolumn{2}{|c|}{2010} & \multicolumn{2}{|c|}{2011} & \multicolumn{2}{|c|}{2012} & \multicolumn{2}{|c|}{2013} & \multicolumn{2}{|c|}{ Total } \\
\hline & & & Alocagáa & custo & Alocacáa & custo & Alocacäo & custo & Alocaaga & custo & \begin{tabular}{|l|} 
Alocaăa \\
\end{tabular} & custo & Alocąāo & Custo & Alocacäo & custo & Alocasâa & custo & Alocacäo & custo & Alocąąa & custo & Alocasăao & custo & \multirow{2}{*}{ UF } & \multirow{2}{*}{ RS } \\
\hline & & & Ouant. & (RS) & ouant. & (RS) & Quant. & (AS) & ouant. & (AB) & ouant. & (AS) & ouant. & (AS) & ouant. & (RS) & ouant. & (AS) & Quant. & (RS) & ouant. & (PS) & ouant. & (RS) & & \\
\hline Dapsona 100 mg & \begin{tabular}{|c|} 
\\
\end{tabular} & FIOCAUZ & 275.500 & $3.306,00$ & 631.500 & $7.578,00$ & & & & & & & & & & & & & & & & & & & $907.000,00$ & $10.884,00$ \\
\hline Preddisisna $20 \mathrm{mg}$ & \begin{tabular}{|l|} 
Comp. \\
\end{tabular} & Fiocauz & 2.347 .500 & $146,484,00$ & 3.677 .500 & $240.614,25$ & 7.5355500 & $478.414,70$ & 7.2180000 & $472.79,00$ & \begin{tabular}{|l|l|} 
& 7.159 .500 \\
\end{tabular} & $468.97,25$ & 5.192000 & $340.076,00$ & & & 8.576 .000 & $561.728,00$ & 1220.500 & $805.027,75$ & & & & & $53.992 .500,00$ & $3.514 .077,95$ \\
\hline Preddisiona $5 \mathrm{mg}$ & \begin{tabular}{|l|} 
\\
\end{tabular} & Fiocauz & 2.194 .500 & $477.800,10$ & 2.411 .500 & $\begin{array}{l}52.570,70 \\
\end{array}$ & 6.740 .500 & 146.942,90 & & & \begin{tabular}{|l|} 
\\
\end{tabular} & $38.150,00$ & & & & & & & & & & & & & $13.090 .500,00$ & $285.503,70$ \\
\hline \multicolumn{3}{|c|}{ Subtotal } & 4.817 .500 & 197.630 & 6.716 .500 & 300.763 & 14.276 .000 & 625.358 & 7.218 .000 & 472.779 & \begin{tabular}{|l|}
8.909 .500 \\
\end{tabular} & 507.097 & $\begin{array}{l}5.192 .000 \\
\end{array}$ & 340.076 & 0 & 0 & 8.576 .000 & 561.728 & 1220.500 & 805.028 & 0 & 0 & 0 & 0 & 67.996.000 & 3.810 .459 \\
\hline Talidonidia $100 \mathrm{mg}$ & \begin{tabular}{|l|} 
Comp. \\
\end{tabular} & FUNED & 2.766 .720 & $\begin{array}{l}496,626,24 \\
\end{array}$ & 4.455 .840 & $855.966,86$ & 4.444800 & $1.338 .3229,28$ & 3.754560 & $\begin{array}{l}1.130 .498,02 \\
\end{array}$ & \begin{tabular}{|l|l|} 
& 3.133920 \\
\end{tabular} & $943.623,31$ & 3.740 .640 & $935.160,00$ & 4.199 .400 & $1.721 .600,40$ & 3.512640 & $1.440 .182,40$ & 1.338 .720 & $548,875,20$ & 2.164 .800 & $887.568,00$ & 4.469 .760 & $1.832 .601,60$ & $37.981 .440,00$ & 12.131.037,31 \\
\hline \multicolumn{3}{|c|}{ subtotal } & 2.766 .720 & $\begin{array}{l}496,622,24 \\
\end{array}$ & 4.455.840 & $855.966,86$ & 4.444.800 & $1.338 .3229,28$ & 3.754 .560 & $\begin{array}{l}1.130 .498,02 \\
\end{array}$ & \begin{tabular}{|l|l|} 
& 3.133 .9220 \\
\end{tabular} & $943.623,31$ & 3.740 .540 & $935.160,00$ & 4.199 .400 & $1.721 .600,40$ & 3.512 .640 & $1.440 .182,40$ & 1.338 .720 & $548.875,20$ & 2.164 .800 & $887.568,00$ & 4.469.760 & $1.832 .601,60$ & 37.981.440,00 & 12.131.037,31 \\
\hline 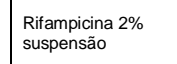 & Frasco & FURP & 450 & 355,68 & 7.650 & ${ }_{6.348,74}$ & & & & & & & & & & & & & & & & & & & $8.100,00$ & $6.704,42$ \\
\hline \multicolumn{3}{|c|}{ Subtotal } & 450 & 355,68 & 7.650 & $\begin{array}{l}6.348,74 \\
\end{array}$ & & & & & & & & & & & & & & & & & & & $8.100,00$ & $6.704,42$ \\
\hline 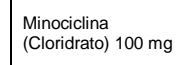 & comp. & IQUEGO & 38.000 & $29,427,20$ & 27.000 & 20.908 .80 & 156.000 & $120.000,40$ & 172.500 & $133.584,00$ & & & & & & & & & 500.000 & $430.000,00$ & & & 420.000 & $483.000,00$ & $1.313 .500,00$ & $1.217 .726,40$ \\
\hline \multicolumn{3}{|c|}{ Subtotal } & 38.000 & $29,427,20$ & 27.000 & $20.908,80$ & 156.000 & $\begin{array}{l}120.80,40 \\
\end{array}$ & 172.500 & $133.584,00$ & & & & & & & & & 500.000 & $430.000,00$ & & & 420.000 & $\begin{array}{l}483.000,00 \\
\end{array}$ & $1.313 .500,00$ & $1.217 .726,40$ \\
\hline $\begin{array}{c}\text { Ritampicina } 300 \\
\mathrm{mg}\end{array}$ & Caps. & LAFEPE & 225.000 & 31.837,50 & 197.500 & $27.946,25$ & 84000 & $11.886,00$ & & & & & & & & & & & & & & & & & $500.500,00$ & $71.669,75$ \\
\hline \multicolumn{3}{|c|}{ subbotal } & 225.000 & ${ }^{31.837,50}$ & $\begin{array}{r}197.500 \\
\end{array}$ & $27.94,25$ & 84.000 & $11.886,00$ & & & & & & & & & & & & & & & & & $506.500,00$ & $71.69,75$ \\
\hline Olloxacino $400 \mathrm{mg}$ & \begin{tabular}{|l} 
Comp. \\
\end{tabular} & LFM & 164.500 & $\begin{array}{l}59,220,00 \\
\end{array}$ & 210.000 & 75.600 .00 & 368.000 & $\begin{array}{l}139.840,00 \\
\end{array}$ & 204.000 & $77.520,00$ & 116.500 & $44.277,00$ & 189.000 & $71.820,00$ & 140.500 & $53.390,00$ & 315.500 & $119.980,00$ & 3550.000 & $133.000,00$ & & & & & 2.058.000,00 & $774.550,00$ \\
\hline Predonisona 20 mg & \begin{tabular}{|l|} 
Comp. \\
\end{tabular} & LFM & 1.125 .000 & $70.200,00$ & 2.971 .000 & $194,600,50$ & 2.650 .000 & $\begin{array}{l}173.575 .00 \\
\end{array}$ & & & \begin{tabular}{|l|l|} 
& 7.159 .500 \\
\end{tabular} & $468.97,25$ & & & & & & & & & 5.686 .000 & $369.158,00$ & 120820000 & $\begin{array}{l}791.371,00 \\
\end{array}$ & $31.623 .500,00$ & $2.067 .851,75$ \\
\hline Predonisona 20 mg & \begin{tabular}{|l|} 
Comp. \\
\end{tabular} & LFM & & & & & & & 7.218 .000 & $472.79,00$ & & & & & & & & & & & & & & & $7.218 .000,00$ & $472.79,00$ \\
\hline Prodonisona 5 mg & \begin{tabular}{|l} 
Comp. \\
\end{tabular} & LFM & 1.0240000 & 22.2323,20 & & & & & & & & & 1.396 .500 & $30.443,70$ & 2.793500 & 60.898,30 & 3.104 .000 & $67.667,20$ & 1.000 .000 & $21.800,00$ & 6.356 .500 & $138.571,70$ & 3.550 .500 & $76.964,90$ & 19.205.000,00 & $418.699,00$ \\
\hline \multicolumn{3}{|c|}{ Subtotal } & 2.313 .500 & 151.743 & 3.181 .000 & 270.201 & 3.018 .000 & 313.415 & 7.422 .000 & 550.299 & \begin{tabular}{|l|}
7.276 .000 \\
\end{tabular} & 513.217 & 1.565 .500 & 102264 & $\begin{array}{l}2.934 .000 \\
\end{array}$ & 114.288 & 3.419 .500 & 187.557 & 1.350 .000 & 154.800 & 11.992 .500 & 507.730 & 15.612 .500 & 866.336 & 60.104 .500 & 3.733 .550 \\
\hline Predonisona 5 mg & \begin{tabular}{|l|} 
Comp. \\
\end{tabular} & LQFA & & & & & & & & & & & 1.396 .500 & $30.443,70$ & & & & & & & & & & & $1.396 .500,00$ & $30.443,70$ \\
\hline Prodenisona 20 mg & \begin{tabular}{|l} 
Comp. \\
\end{tabular} & LQFA & 1.125 .000 & $70.200,00$ & & & 2.650 .000 & $173.575,00$ & 5.000 .000 & $327.500,00$ & \begin{tabular}{|l|} 
\\
\end{tabular} & $468.97,25$ & & & & & & & & & & & & & $15.934 .500,00$ & $1.044 .222,25$ \\
\hline Prodonisona 5 mg & \begin{tabular}{|l|} 
Comp. \\
\end{tabular} & LQFA & 1.0240000 & 22.2323,20 & 2.724 .500 & $59.394,10$ & & & & & & & & & & & & & & & & & & & $3.748 .500,00$ & $81.717,30$ \\
\hline \multicolumn{3}{|c|}{ Subtotal } & 2.149 .000 & 92.523 & 2.724 .500 & 59.394 & 2.650 .000 & 173.575 & 5.000 .000 & 327.500 & \begin{tabular}{|l|l|} 
& 7.159 .500 \\
\end{tabular} & 466.947 & 1.396 .500 & 30.444 & o & 0 & 0 & o & 0 & 0 & 0 & 0 & 0 & 。 & 21.079.500 & ${ }_{1.152 .333}$ \\
\hline
\end{tabular}




\begin{tabular}{|c|c|c|c|c|c|c|c|c|c|c|c|c|c|c|c|c|c|c|c|c|c|c|c|c|c|c|}
\hline Olloxacino $400 \mathrm{mg}$ & comp. & LOFEX & 191.900 & $69.084,00$ & 23.500 & $8.460,00$ & & & & & & & & & & & & & & & & & & & $215.400,00$ & $77.54,00$ \\
\hline & subtotal & & 191.900 & $69.044,00$ & 23.500 & $8.460,00$ & & & & & & & & & & & & & & & & & & & $215,400,00$ & $7.544,00$ \\
\hline & Total & & 24.812 240 & 2.069 .370 & 34.643.480 & 3.091 .516 & $49.25,6000$ & 5.166 .779 & 47.134.120 & 5.229 .320 & 52.957 .840 & 4.865 .770 & 23.829.280 & 2.815 .887 & 14.266 .080 & 3.677 .789 & 31.016.280 & 4.378 .9355 & 30.958 .40 & 3.877 .406 & 28.314 .600 & 2.790 .595 & 41.004 .520 & 6.367 .775 & 378.99 .480 & ${ }_{44,325.5203}$ \\
\hline
\end{tabular}


Apêndice 5 - Produção dos laboratórios nacionais, em número de Unidades Farmacêuticas (UF) para o Programa Nacional de Controle da Hanseníase, período 2003 a 2013.

\begin{tabular}{|c|c|c|c|c|c|c|c|c|c|c|c|c|c|c|c|c|c|c|c|c|c|c|c|c|c|c|}
\hline \multirow{3}{*}{ Medicamentos } & \multirow{3}{*}{ Unid. } & \multirow{3}{*}{ Formecedor } & \multicolumn{2}{|c|}{2003} & \multicolumn{2}{|c|}{2004} & \multicolumn{2}{|c|}{2005} & \multicolumn{2}{|c|}{2006} & \multicolumn{2}{|c|}{2007} & \multicolumn{2}{|c|}{2008} & \multicolumn{2}{|c|}{2009} & \multicolumn{2}{|c|}{2010} & \multicolumn{2}{|c|}{2011} & \multicolumn{2}{|c|}{2012} & \multicolumn{2}{|c|}{2013} & \multicolumn{2}{|c|}{ Total } \\
\hline & & & Alocaçâa & Custo & Alocasăo & custo & Alocaăäo & Custo & Aocacaso & custo & Alocarāo & custo & Alocasăo & Custo & Alocasăo & custo & Alocaạăo & custo & Alocąậo & custo & Alocąạa & custo & Alocąăoo & custo & \multirow{2}{*}{ UF } & \multirow{2}{*}{ RS } \\
\hline & & & Quant. & (RS) & Quant. & (RS) & Quant. & (RS) & ouant. & (AS) & Quant. & (AS) & ouant. & (Rs) & Quant. & (RS) & Quant. & (AS) & Quant. & (RS) & ouant. & (As) & Quant. & (AS) & & \\
\hline 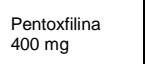 & comp. & AVENTIS & 44.530 & 12.383,10 & 202240 & $48.537,60$ & & & & & & & & & 1638900 & $36.026,25$ & & & & & & & & & $410,60,000$ & $96,944,95$ \\
\hline $\begin{array}{c}\text { cloazimina } \\
\text { iotomg }\end{array}$ & Câps. & Cristatila & 838.600 & $117.544,60$ & & & & & & & & & & & & & & & & & & & & & $838.600,00$ & $117.54,60$ \\
\hline $\begin{array}{l}\text { Pentoxtiina } \\
400 \text { milg }\end{array}$ & comp. & MEZLER & 40.000 & $\begin{array}{l}12,000,000 \\
0\end{array}$ & & & 261.400 & $65.550,00$ & & & & & & & & & & & & & & & & & $301.400,00$ & $77.550,00$ \\
\hline 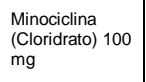 & comp. & Mienio & & & & & & & & & 141.000 & $96,48,30$ & & & & & & & & & & & & & $141.000,00$ & $96,486,30$ \\
\hline $\begin{array}{l}\text { Clotazamina } 50 \\
\text { mg }\end{array}$ & Cáps. & N. .uuimica & 169.700 & 17.988,20 & & & & & & & & & & & & & & & & & & & & & $169,700,00$ & 17.988,20 \\
\hline $\begin{array}{l}\text { Pentoxtinan } \\
4000 \mathrm{mg}\end{array}$ & comp. & PROOIET & & & & & & & & & & & & & & & 138.550 & $34.637,50$ & & & & & & & $138.550,00$ & $34,67,50$ \\
\hline 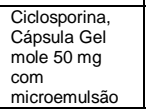 & Cáps. & 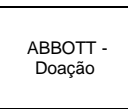 & 80.000 & 0,00 & & & & & & & & & & & & & & & & & & & & & $80.000,00$ & 0,00 \\
\hline & Total & & 1.172.830 & ${ }_{159.956}$ & 202240 & 48.538 & 261.400 & 65.350 & 。 & 0 & 141.000 & 96.486 & 。 & 。 & 163.890 & 36.026 & 138.55 & 34.638 & 。 & 0 & 0 & 0 & 。 & 0 & 20.79 .910 & 440.994 \\
\hline
\end{tabular}


Apêndice 6 - Produção dos laboratórios internacionais, em número de Unidades Farmacêuticas (UF) para o Programa Nacional de Controle da Hanseníase, período 2003 a 2013.

\begin{tabular}{|c|c|c|c|c|c|c|c|c|c|c|c|c|c|c|c|c|c|c|c|c|c|c|c|c|c|c|}
\hline \multirow{3}{*}{ Medicamentos } & \multirow{3}{*}{ Unid. } & \multirow{3}{*}{ Fornecedor } & \multicolumn{2}{|c|}{2003} & \multicolumn{2}{|c|}{2004} & \multicolumn{2}{|c|}{2005} & \multicolumn{2}{|c|}{2006} & \multicolumn{2}{|c|}{2007} & \multicolumn{2}{|c|}{2008} & \multicolumn{2}{|c|}{2009} & \multicolumn{2}{|c|}{2010} & \multicolumn{2}{|c|}{2011} & \multicolumn{2}{|c|}{2012} & \multicolumn{2}{|c|}{2013} & \multicolumn{2}{|c|}{ Total } \\
\hline & & & Alocąąa & custo & Alocąąa & Custo & Alocacąo & custo & Alocąąa & Custo & Alocąāo & custo & Alocąąo & custo & Alocąăo & Custo & Alocacăo & Custo & Alocąąa & Custo & Alocasąio & custo & Alocąāo & Custo & \multirow{2}{*}{ uF } & \multirow{2}{*}{ RS } \\
\hline & & & ouant. & (AB) & ouant. & (RS) & Quant. & (RS) & Quant. & (RS) & Quant. & (RS) & ouant. & (RS) & Quant. & (RS) & Quant. & (RS) & ouant. & (RS) & ouant. & (RS) & Quant. & (BS) & & \\
\hline Pentoxtilina $400 \mathrm{mg}$ & comp. & LA. VIDAL & & & & & & & & & & & & & & & & & & & 217.020 & $62.935,80$ & & & $217.020,00$ & $62.95,50$ \\
\hline Clofazimina $100 \mathrm{mg}$ & Caps. & opas & & & & & 266.500 & $39.708,50$ & & & & & & & & & & & & & & & & & $266.500,00$ & 39.70 .50 \\
\hline Clofazaimina 50 mg & Cáps. & opas & & & & & 604.500 & $65.346,45$ & & & & & & & & & & & & & & & & & $604.500,00$ & 65.34 .45 \\
\hline Pentoxtilina $400 \mathrm{mg}$ & comp. & SANOFI & & & & & & & & & & & & & & & & & & & 150.000 & 0,00 & & & $150.000,00$ & 0,00 \\
\hline & Total & & 。 & 0,00 & 。 & 0,00 & 87.000 & $105.054,95$ & o & 0,00 & 。 & 0,00 & 。 & 0.00 & 。 & 0,00 & 。 & 0.00 & 。 & 0.00 & 367.020 & $62.295,80$ & 。 & 0,00 & 1.238 .020 .00 & $167.909,75$ \\
\hline
\end{tabular}


Apêndice 7 - Produção Pública, em número de Unidades Farmacêuticas (UF) para o Programa Nacional de Alimentação e Nutrição, período de 2003 a 2013.

\begin{tabular}{|c|c|c|c|c|c|c|c|c|c|c|c|c|c|c|c|c|c|c|c|c|c|c|c|c|c|c|}
\hline \multirow{3}{*}{ Medicamentos } & \multirow{3}{*}{ Unid. } & \multirow{3}{*}{ Formecedor } & \multicolumn{2}{|c|}{2003} & \multicolumn{2}{|c|}{2004} & \multicolumn{2}{|c|}{2005} & \multicolumn{2}{|c|}{2006} & \multicolumn{2}{|c|}{2007} & \multicolumn{2}{|c|}{2008} & \multicolumn{2}{|c|}{2009} & \multicolumn{2}{|c|}{2010} & \multicolumn{2}{|c|}{2011} & \multicolumn{2}{|c|}{2012} & \multicolumn{2}{|c|}{2013} & \multicolumn{2}{|c|}{ Total } \\
\hline & & & \begin{tabular}{|l|} 
Alocąăao \\
\end{tabular} & custo & Alocacăo & Custo & Alccaăāo & custo & Alocasăo & custo & Alocacāo & custo & Alocacăa & custo & Alocacăa & custo & Alocacāo & custo & Alocacāo & custo & Alocacăa & custo & Alccąąa & custo & & \multirow{2}{*}{ Rs } \\
\hline & & & Ouant. & (RS) & ouant. & (RS) & Quant. & (RS) & ouant. & (RS) & ouant. & (RS) & Quant. & (RS) & Quant. & (Rs) & Ouant. & (RS) & ouant. & (Rs) & ouant. & (Rs) & \begin{tabular}{|l|} 
ouant. \\
\end{tabular} & (Rs) & & \\
\hline Ácido Fblico. $5 \mathrm{mg}$ & comp. & FIOCRUz & & & 60.600 .000 & $830,220,00$ & 55.105 .900 & 754.949,46 & 125.900 .250 & $1.724 .433,43$ & 125.900 .250 & $1.724,433,43$ & 138.566.594 & $1.898 .637,71$ & 143.457.000 & $1.966 .560,90$ & 137.054.000 & $1.877 .699,80$ & 34.54.000 & $473.252,80$ & & & & & $8221.147 .994,00$ & 11.249,727,52 \\
\hline $\begin{array}{l}\text { uutatat erroso } \\
40 \mathrm{mg}\end{array}$ & Comp. & FIOCRUz & & & 60.60 .0000 & 1.636.200,00 & 55.105.800 & 1.487.856,60 & 251.800.500 & 6.798.613,50 & & & 308.269 .000 & $8.323 .263,00$ & 214.955.000 & $5.8007731,00$ & 218.255.000 & $5.992 .885,00$ & 55.163 .000 & $1.489 .401,00$ & & & & & $1.164 .146 .300,00$ & 31.431.950,10 \\
\hline $\begin{array}{l}\text { Sultato erroso } \\
\text { xaropee }\end{array}$ & $\mathrm{Fr}$ & FIOCRUZ & & & 4.100 .000 & $7.764 .170,00$ & 1.780 .236 & \begin{tabular}{|l|l}
$3.371 .232,91$ \\
\end{tabular} & 8.820 .300 & $16.703 .002,11$ & & & 9.152200 & 17.331.521,14 & 7.222 .793 & 12.309:806,11 & 7.175.600 & 12.229.375,08 & 2.662 .800 & 4.538.210,04 & & & & & 40.913:929,900 & 74:247.317,39 \\
\hline 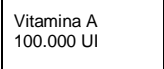 & Cáps. & FIOCRUz & 1.200 .000 & $126.000,00$ & 600.000 & $69.720,00$ & 800.000 & 124,720,00 & 1.000 .000 & $168.400,00$ & 1.012000 & $170,420,80$ & 1.499 .450 & $252.507,38$ & 1.594 .750 & $266.555,90$ & 987,150 & 166.235,06 & 1.688 .700 & $284,377,08$ & 2.033.150 & $342.382,46$ & \begin{tabular}{|l|l}
1.080 .000 \\
\end{tabular} & 181.872,00 & $13.495,200,00$ & 2.155.191, 188 \\
\hline 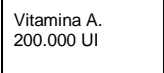 & \begin{tabular}{|l|} 
Cáps. \\
\end{tabular} & FIOCAUZ & 8.800 .000 & $1.349 .920,00$ & 3.500 .000 & $593.600,00$ & 3.75 .000 & $818.590,00$ & 5.000 .000 & 1.1.177.000,00 & 2.764 .800 & $650.83,92$ & 7.027 .950 & $1.654 .379,43$ & 8.0692 .200 & 1.899.489,68 & 5.889 .300 & 1.386.341,22 & 8.001 .250 & $1.883 .494,25$ & 10.994.,550 & $2.588 .069,99$ & 5.560 .100 & $1.308 .847,54$ & 69936.1950,00 & 15.310.566,03 \\
\hline \multicolumn{3}{|c|}{ subtotal } & \begin{tabular}{|l|l|}
10.000 .000 \\
\end{tabular} & 1.475.5292,00 & 129.400.000 & 10.893.910,00 & 116.546 .636 & 6.557.389,97 & 392.52 .050 & 26.577 .899 .94 & 129.677.050 & $2.546 .088,15$ & 464.535.294 & 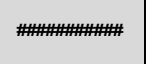 & 375.296.743 & $22246.943,59$ & 369.361.050 & 21.552.477, 16 & 1020.59.750 & 8.666.735,17 & 13.027.500 & 2.930 .452 .45 & 6.640 .100 & 1.990.719,54 & $2.100 .065 .373,00$ & 134.994,752,72 \\
\hline
\end{tabular}


Apêndice 8 - Produção dos laboratórios nacionais, em número de Unidades Farmacêuticas (UF) para o Programa Nacional de Alimentação e Nutrição, período de 2003 a 2013.

\begin{tabular}{|c|c|c|c|c|c|c|c|c|c|c|c|c|c|c|c|c|c|c|c|c|c|c|c|c|c|c|}
\hline \multirow{3}{*}{ Medicamentios } & \multirow{3}{*}{ Unid. } & \multirow{3}{*}{ Fornecedor } & \multicolumn{2}{|c|}{2003} & \multicolumn{2}{|c|}{2004} & \multicolumn{2}{|c|}{2005} & \multicolumn{2}{|c|}{2006} & \multicolumn{2}{|c|}{2007} & \multicolumn{2}{|c|}{2008} & \multicolumn{2}{|c|}{2009} & \multicolumn{2}{|c|}{2010} & \multicolumn{2}{|c|}{2011} & \multicolumn{2}{|c|}{2012} & \multicolumn{2}{|c|}{2013} & \multicolumn{2}{|c|}{ Total } \\
\hline & & & Alocąāo & custo & Alocąąo & custo & Alocąąo & custo & Alocąago & custo & Alocąąo & custo & Alcacą̧o & custo & Alocąąo & custo & Alocąąo & custo & Alocąąa & custo & Alocacąo & custo & Alocacąo & custo & \multirow{2}{*}{ uF } & \multirow{2}{*}{ As } \\
\hline & & & Quant. & (RS) & Quant. & (RS) & Quant. & (Rs) & Quant. & (RS) & Quant. & (RS) & ouant. & (RS) & ouant. & (RS) & Quant. & (RS) & Quant. & (Rs) & Quant. & (RS) & Quant. & (Rs) & & \\
\hline 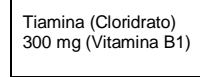 & comp. & Teuto & & & & & & & & & 10.022 .680 & 1.599.619,73 & & & & & & & & & & & & & $10.022 .680,00$ & $1.599 .619,73$ \\
\hline 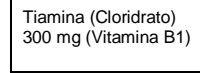 & comp. & DIMEBEL & & & & & & & 350.000 & $44,450,00$ & & & & & & & & & & & & & & & $350.000,00$ & $44,450,00$ \\
\hline & Total & & 。 & 0 & 。 & 0 & 。 & 0 & 350.000 & $44,450,00$ & 10.022 .680 & 1.599.619.73 & & & & & & & & & & & & & $10.372 .680,00$ & $1.644 .069,73$ \\
\hline
\end{tabular}


Apêndice 9 - Produção Pública, em número de Unidades Farmacêuticas (UF), para o Programa Nacional de Controle da Tuberculose, no período de 2003 a 2013.

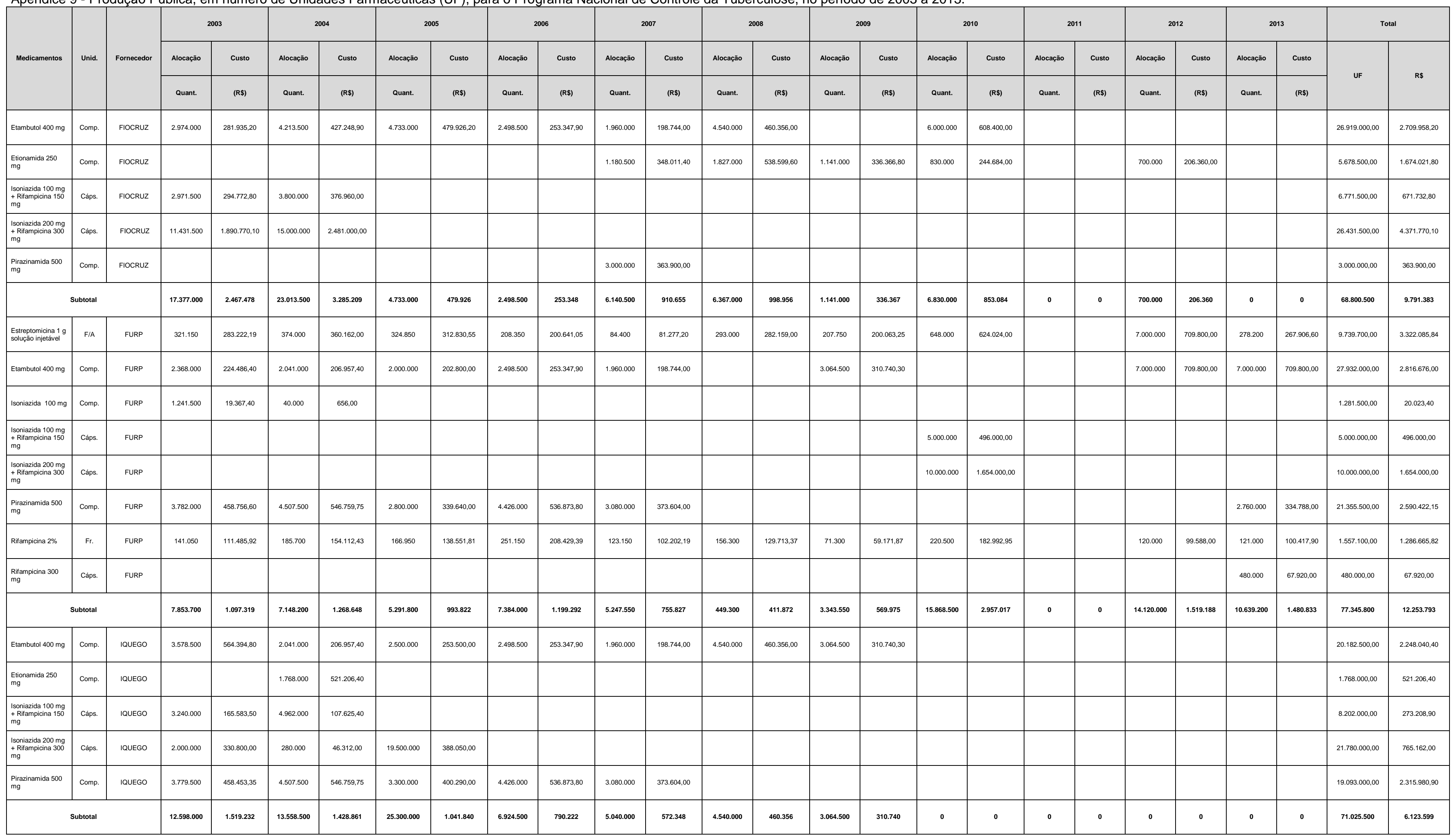




\begin{tabular}{|c|c|c|c|c|c|c|c|c|c|c|c|c|c|c|c|c|c|c|c|c|c|c|c|c|c|c|}
\hline Isoniazida $100 \mathrm{~mm}$ & comp. & LAFEPE & 3.746000 & $57.75,90$ & 4.786 .500 & $78.498,60$ & 6.000 .000 & 98400,00 & 4.445 .500 & $67.986,20$ & 2.820 .000 & $46.248,00$ & & & 3.054000 & $50.005,60$ & & & & & & & & & $24,552000,000$ & 398.975,30 \\
\hline 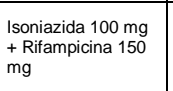 & Cáps. & LAFEPE & & & 1.101 .500 & 109.268 .80 & 1.000 .000 & $99.200,00$ & 3.662 .500 & 363,322,000 & 1.672 .500 & $165.912,00$ & & & & & & & & & & & & & $7.436 .500,00$ & $737.700,80$ \\
\hline 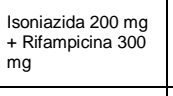 & Cáps. & LAFEPE & 8.845 .500 & $1.463 .045,70$ & 6.743 .000 & $1.115,292,20$ & 17.453 .000 & $2.886 .726,20$ & 16.725 .000 & $2.766 .315,00$ & 9.145 .000 & $1.512 .583,00$ & & & & & & & & & & & & & $58.911 .500,00$ & $9.743 .962,10$ \\
\hline 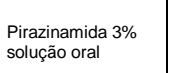 & Fr. & LAFEPE & & & 30.250 & $56.156,10$ & & & & & & & & & & & & & & & & & & & $30.250,00$ & $56.156,10$ \\
\hline 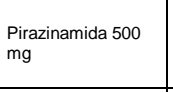 & comp. & LAFEPE & 6.122 .000 & $742.598,60$ & 4.507 .500 & $546.759,75$ & 3.300 .000 & $400.290,00$ & 4.426 .000 & $536.873,80$ & & & & & & & & & & & & & & & $18.3555000,00$ & $2.226 .52,15$ \\
\hline $\begin{array}{l}\text { Ritampicina } 300 \\
\text { mg }\end{array}$ & \begin{tabular}{|l|} 
Cáps. \\
\end{tabular} & LAFEPE & & & & & & & 2.958 .500 & $418.627,75$ & & & & & & & & & & & & & & & $2.958 .500,00$ & $418.627,75$ \\
\hline \multicolumn{3}{|c|}{ subtotal } & 18.713.500 & 2.263 .401 & 17.166.750 & 1.905 .975 & 27.753.000 & 3.488 .616 & 31.917 .500 & 4.153.123 & 13.637.500 & 1.724 .743 & 0 & $\circ$ & 3.054.000 & 50.086 & $\circ$ & 0 & 0 & 0 & 0 & 0 & 0 & 0 & 112.244 .250 & 13.581 .944 \\
\hline Isoniazida $100 \mathrm{mg}$ & \begin{tabular}{|l} 
Comp. \\
\end{tabular} & LFM & 1.741 .500 & $27.167,40$ & & & & & 4.145 .500 & $67.986,20$ & & & 2.418 .000 & $39.655,20$ & $3.054,000$ & $50.085,60$ & 8.000 .000 & $207.200,00$ & 6.000 .000 & $155.400,00$ & 7.500 .000 & $194,250,00$ & 25.000 .000 & $647,500,00$ & 57.859.000,00 & $1.389 .24,40$ \\
\hline 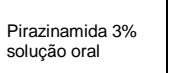 & Fr. & LFM & 54,100 & 95.648 .80 & 30.200 & 56.06328 & 48.100 & $93,75,00$ & 69.350 & ${ }_{135.232 .50}$ & 49.50 & $97.402,50$ & 59.200 & $115.440,00$ & 22.400 & 43.880,00 & & & & & & & 87.500 & $170.625,00$ & $420.800,00$ & $807.887,08$ \\
\hline 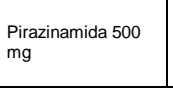 & comp. & LFM & 5.479 .500 & $664.663,35$ & 4.507 .500 & $546.759,75$ & 5.800 .000 & 7035.540,00 & 4.426 .000 & $549,266,60$ & 3.080 .000 & $373.604,00$ & 11.671 .500 & $1.415 .752,95$ & 16.487 .500 & $1.999 .933,75$ & 181.700 & $354,315,00$ & & & & & & & 51.633.700,00 & $6.607 .835,40$ \\
\hline \multicolumn{3}{|c|}{ Subtotal } & 7.275 .100 & 787.480 & 4.537 .700 & 602.223 & 5.848 .100 & 797.335 & 8.640 .950 & 752.485 & 3.129.950 & 477.007 & 14.148.700 & 1.57 .848 & 19.553.900 & 2.093 .699 & 8.181 .700 & 561.515 & 6.000 .000 & 155.400 & 7.500 .000 & 194,250 & 25.087 .500 & 818.125 & 109.913.500 & 8.804 .967 \\
\hline Isoniazida $100 \mathrm{mg}$ & comp. & LaFA & & & & & & & & & & & 2.418 .000 & $39.655,20$ & & & & & 6.000 .000 & $155.400,00$ & & & 15.000.000 & 388.500,00 & $23.418 .000,00$ & $583,555,20$ \\
\hline $\begin{array}{l}\text { Prizazanamida } 500 \\
\text { mag }\end{array}$ & comp. & LOFA & & & & & & & & & & & 11.671 .500 & $1.415 .752,95$ & & & & & & & & & & & $11.671 .500,00$ & 1.415 .752 .95 \\
\hline Boniazida $100 \mathrm{mg}$ & comp. & LOFA & 1.386 .500 & $21.542,40$ & 4.578 .000 & 75.079 .20 & 5.225 .500 & 85.988 .20 & 4.145 .500 & $67.986,20$ & 2.820 .000 & $46.248,00$ & & & & & 7.500 .000 & $194,250,00$ & & & & & & & $25.655 .50,00$ & $490.804,00$ \\
\hline $\begin{array}{l}\text { Prizazinarida } 500 \\
\text { mag }\end{array}$ & comp. & LOFA & 6.431 .000 & $780.080,30$ & 4.507 .000 & $546.699,10$ & & & 4.426 .500 & $536.934,45$ & 3.080 .000 & $373.604,00$ & & & & & & & & & & & & & $18.444 .50,00$ & 2.237.3717.85 \\
\hline \multicolumn{3}{|c|}{ subtotal } & 7.817.500 & 801.623 & 9.085 .000 & 621.778 & 5.225 .500 & 85.698 & 8.572 .000 & 604.921 & 5.900 .000 & 419.852 & 14.089 .500 & 1.455 .008 & 0 & 0 & 7.500 .000 & 194.250 & 6.000 .000 & 155.400 & 0 & 0 & 15.000.000 & 388.500 & 79.189 .500 & 4.727.4.430 \\
\hline $\begin{array}{l}\text { Etionanidida } 250 \\
\text { mg }\end{array}$ & comp. & LaFEX & 1.274 .500 & 357.879 .60 & & & 672.000 & 198.105.,60 & 1.099 .000 & 323,985,20 & & & & & & & & & & & & & & & $3.045 .500,00$ & $879.970,40$ \\
\hline 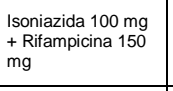 & Cáps. & LOFEXX & 1.366 .500 & ${ }_{135.556,80}$ & 1.0055 .500 & ${ }_{107,68,60}$ & 6.453 .000 & $640.137,60$ & 3.662 .500 & $363,320,00$ & 1.672.500 & $165.912,00$ & & & & & 5.000 .000 & $496.000,00$ & & & & & & & 19.240.000,00 & $1.908 .608,00$ \\
\hline 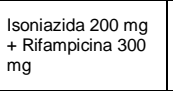 & Cáps. & LaFEX & 11.576 .690 & $1.914 .784,53$ & 10.904 .500 & $1.8003 .604,30$ & 10.000 .000 & $1.654 .000,00$ & 16.725 .000 & 2.766 .315 .00 & 9.145 .000 & $1.512 .583,00$ & & & & & 10.000 .000 & $1.654 .000,00$ & & & & & & & $68.351 .190,00$ & $11.305,286,83$ \\
\hline $\begin{array}{c}\text { Pirazinamida } 500 \\
\text { ma }\end{array}$ & comp. & LOFEX & 600.000 & $72.780,00$ & 4.507 .000 & $546.699,10$ & 11.988 .500 & $1.454 .205,05$ & 4.426 .000 & $536.873,80$ & 3.080 .000 & $373.604,00$ & & & & & & & & & & & & & $24.601 .500,00$ & $2.984,161,95$ \\
\hline $\begin{array}{l}\text { Ritampicina } 300 \\
\mathrm{mg}\end{array}$ & Cáps. & LOFEX & & & & & & & 2.959 .000 & $418.698,50$ & & & & & 1.000 .000 & $141.500,00$ & & & 1.440 .000 & $203.760,00$ & & & 600.000 & $84,900,00$ & $5.999 .000,00$ & $848.855,50$ \\
\hline \multicolumn{3}{|c|}{ subtotal } & 14.817.690 & 2.481 .001 & 16.497.000 & 2.457 .985 & 29.113.500 & 3.946.48 & 28.871.500 & 4.409 .193 & 13.897.500 & 2.052 .099 & 0 & 0 & 1.000 .000 & ${ }_{141.500}$ & 15.000.000 & 2.150 .000 & 1.400 .000 & 200.760 & 0 & 0 & 600.000 & 84.900 & 121.237 .190 & 17.926 .886 \\
\hline 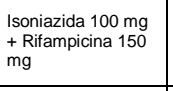 & Cáps. & NUPLAM & 91.500 & $9.076,80$ & & & & & & & 1.672.500 & $165.912,00$ & & & & & 2.500 .000 & $248.00,00$ & & & & & & & $4.264 .000,00$ & $422.988,80$ \\
\hline 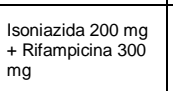 & Cáps. & NUPLAM & 48.000 & $7.999,20$ & & & & & & & 9.145 .000 & $1.512 .583,00$ & 10.371 .000 & $1.715 .363,40$ & & & 12.500 .000 & $1.902 .000,00$ & & & & & & & $32.064 .000,00$ & $5.137 .885,50$ \\
\hline
\end{tabular}




\begin{tabular}{|c|c|c|c|c|c|c|c|c|c|c|c|c|c|c|c|c|c|c|c|c|c|c|c|c|c|c|}
\hline $\begin{array}{l}\text { Pirazinamida } 500 \\
\text { mg }\end{array}$ & comp. & NuPLAM & 1.128 .000 & $136.826,40$ & & & & & & & & & & & & & & & & & & & & & $1.128 .000,00$ & $136.826,40$ \\
\hline \multicolumn{3}{|c|}{ subtotal } & 1.267 .500 & 153.842 & 0 & 0 & 0 & 0 & 0 & 0 & 10.817.500 & 1.678.495 & 10.371 .000 & 1.715 .533 & 0 & 0 & 15.000 .000 & 2.150 .000 & 0 & 0 & 0 & 0 & 0 & 0 & 37.456 .000 & 5.697 .701 \\
\hline \multicolumn{3}{|c|}{ Total } & 87.719 .990 & 11.571 .375 & 91.008 .550 & 11.571.279 & 103.264.900 & 10.829 .686 & 94.808.850 & 12.162 .583 & 63.810.500 & 8.555.026 & 49.965 .500 & 6.612 .204 & 31.166.950 & 3.5023 .367 & 68.380 .200 & 8.865 .866 & 13.440.000 & 514.560 & 22.320.000 & 1.919.798 & 51.326 .700 & 2.72 .358 & 677.212 .240 & 152.117 .704 \\
\hline
\end{tabular}


Apêndice 10 - Produção Internacional, em número de Unidades farmacêutica (UF) para o Programa Nacional de Controle da Tuberculose, no período de 2003 a 2013.

\begin{tabular}{|c|c|c|c|c|c|c|c|c|c|c|c|c|c|c|c|c|c|c|c|c|c|c|c|c|c|c|}
\hline \multirow{3}{*}{ Medicamentos } & \multirow{3}{*}{ Unid. } & \multirow{3}{*}{ Fornecedor } & \multicolumn{2}{|c|}{2003} & \multicolumn{2}{|c|}{2004} & \multicolumn{2}{|c|}{2005} & \multicolumn{2}{|c|}{2006} & \multicolumn{2}{|c|}{2007} & \multicolumn{2}{|c|}{2008} & \multicolumn{4}{|c|}{\begin{tabular}{|l|l}
2009 & 2010 \\
\end{tabular}} & \multicolumn{2}{|c|}{2011} & \multicolumn{2}{|c|}{2012} & \multicolumn{2}{|c|}{2013} & \multicolumn{2}{|c|}{ Total } \\
\hline & & & Alocąăao & custo & Alocąąa & Custo & Alocąăa & Custo & Alocaạăo & Custo & Alocaăăo & custo & Alocasāo & Custo & Alocasajo & custo & Alocacăâo & custo & Alocaąăo & custo & Alocacāoo & Custo & Alocaçä & Custo & \multirow{2}{*}{ UF } & \multirow{2}{*}{ RS } \\
\hline & & & Quant. & (Rs) & Quant. & (AS) & ouant. & (AS) & Quant. & (AS) & Quant. & (RS) & Quant. & (AS) & Quant. & (As) & Quant. & (As) & Quant. & (RS) & Quant. & (RS) & Quant. & (Rs) & & \\
\hline Tuberculina-PPD-At- & $\mathrm{Fr}$. & FLOMED & 72.738 & $1.963 .926,00$ & & & & & & & & & & & & & & & & & & & & & $72.738,00$ & $1.963 .926,00$ \\
\hline $\begin{array}{l}\text { soniazida } 75 \mathrm{mg}+ \\
\text { Ritampicina } 150 \mathrm{mg} \\
50 \mathrm{mg}\end{array}$ & comp. & OPAS & & & & & & & & & & & & & & & 80.640 .000 & $4.079 .14,00$ & & & & & & & $80.640 .000,00$ & 4.079.144,00 \\
\hline 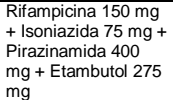 & comp. & OPAS & & & & & & & & & & & & & 40.320 .000 & $5.068 .256,00$ & & & 19.500 .000 & 1.947.057,08 & 30.000 .000 & $4.113 .558,45$ & 100.000 .000 & $11.171 .905,00$ & $189.820 .000,00$ & $22.301 .077,53$ \\
\hline & Subtotal & & 72.738 & 1.966 .926 & 0 & 0 & 0 & 0 & 0 & 0 & 0 & 0 & 0 & 0 & 40.3220 .000 & 5.068 .256 & 80.640 .000 & 4.079.144 & 19.500.000 & 1.947 .057 & 30.000 .000 & 4.113 .358 & 100.000 .000 & 11.171.905 & 270.532 .738 & 28.344.147 \\
\hline
\end{tabular}


Apêndice 11 - Produção Pública, em número de Unidades Farmacêuticas (UF) para o tratamento das Endemias Focais, no período de 2003 a 2013.

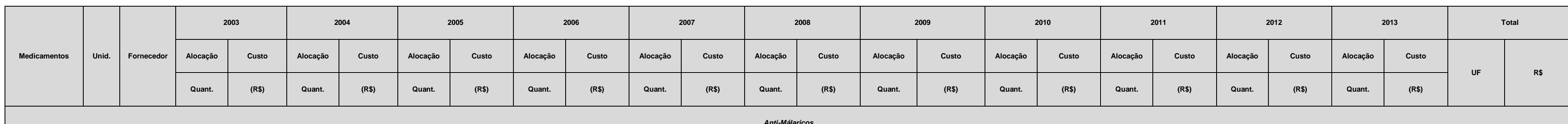

\begin{tabular}{|c|c|c|c|c|c|c|c|c|c|c|c|c|c|c|c|c|c|c|c|c|c|c|c|c|c|c|}
\hline 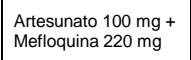 & comp. & FIOCAUZ & 0 & & & & & & & & & & & & 156.000 & $91.930,80$ & 276.000 & $162.646,80$ & 219.600 & 129.410,28 & & & & & 651.600 & 3839.987,88 \\
\hline \begin{tabular}{|l|}
$\begin{array}{l}\text { Artesunatia } 25 \mathrm{mg}+ \\
\text { Melioguina } 55 \mathrm{mg}\end{array}$ \\
\end{tabular} & Comp. & Flockuz & & & & & & & & & & & & & 54.000 & 7.86240 & 102.000 & $14.851,20$ & 119.400 & $17.384,64$ & & & & & 255.400 & $40.098,24$ \\
\hline $\begin{array}{l}\text { Cliorouina } 150 \mathrm{mg} \\
\end{array}$ & Comp. & FIOCAUZ & 21.000 & 642,60 & $5,700.000$ & $174,422,00$ & 6.000 .000 & 183.600,00 & 7.500 .000 & $229.500,00$ & 7.800 .000 & $238.680,00$ & 4.200.000 & $128.522,00$ & 1.211.000 & $37.056,60$ & 8.822 .500 & $269.966,50$ & 5.530.000 & $1692.18,00$ & 4.800.000 & 146.880,00 & 4.410.000 & 134.946,00 & 55.994.500 & $1.713 .431,70$ \\
\hline Primaquina $15 \mathrm{mg}$ & comp. & Fiocruz & 1.000 .000 & $19.900,00$ & 9.000 .000 & $179.100,00$ & 8.918 .000 & 177.468 .20 & 10.000 .000 & $199.000,00$ & 10.000 .000 & $199.000,00$ & & & 2.812 .000 & 55.958 .80 & 12.152.500 & $241.834,75$ & 9.630 .000 & $191.637,00$ & & & $4,900.000$ & $97.51,00$ & 68.412 .500 & 1.361.408,75 \\
\hline Pimaauina 5 mg & comp. & Fiochuz & 1.500 .000 & $20.400,00$ & 3.000 .000 & 40.800,00 & 2.229 .500 & $30.221,20$ & 4.000.000 & $54,400,00$ & 3.500 .000 & $47,600,00$ & 1.250 .000 & $17,000,00$ & 5322000 & $7.255,20$ & 3.533.500 & 48.055.60 & 2.225 .000 & 30.260 .00 & 2.000 .000 & $27,200,00$ & 980,000 & $13,328,00$ & 24,750.000 & $336,600,00$ \\
\hline \multicolumn{3}{|c|}{ subbotal } & 2.521.000 & 40.942,60 & 17.700.000 & 394,320,00 & 17.147.500 & 391.139,40 & 21.500.000 & $482.900,00$ & 21.300.000 & $485.280,00$ & 5.455 .000 & $145.522,00$ & 4.765.000 & 200.043,80 & 244886.500 & $737.356,85$ & 17.724.000 & 577.909,92 & 6.800 .000 & $174.080,00$ & 10.290.000 & $245.784,00$ & 150.084.000 & $3.335 .526,57$ \\
\hline \begin{tabular}{|l|} 
Doxicicina $100 \mathrm{mg}$ \\
\end{tabular} & comp. & laUEGo & & & 935.700 & $42.667,92$ & 1.725 .000 & $78.606,00$ & 2.200 .000 & 100.3220,00 & & & & & & & & & & & & & & & 4.860.700 & $221.64,92$ \\
\hline \begin{tabular}{|l|} 
Doxiciclina $100 \mathrm{mg}$ \\
\end{tabular} & comp. & 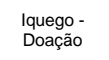 & & & & & & & & & & & & & 188.000 & 0.00 & & & & & & & & & 188.000 & 0,00 \\
\hline \multicolumn{3}{|c|}{ subtotal } & 0 & 0,00 & 935.700 & $42.667,92$ & 1.725 .000 & $78.660,00$ & 2.200 .000 & 100.3220,00 & 0 & 0,00 & 0 & 0,00 & 188.000 & 0,00 & 0 & 0,00 & 0 & 0,00 & 0 & 0,00 & 0 & 0,00 & 5.048.700 & 221.647,92 \\
\hline Melloquina $250 \mathrm{mg}$ & comp. & LFM & 170.000 & $279.344,00$ & 286.000 & $493.055,40$ & 600.000 & $1.034 .340,00$ & 440.000 & $819,280,00$ & 200.500 & $373.331,00$ & & & & & & & & & & & & & 1.69 .500 & $2.999 .330,40$ \\
\hline \multicolumn{3}{|c|}{ Subtotal } & 170.000 & $279.344,00$ & 268.000 & 493.035,40 & 600.000 & 1.034.340,00 & 440.000 & $819.280,00$ & 20.500 & 373.331,00 & & & & & & & & & & & & & $\begin{array}{l}1.696 .500 \\
\end{array}$ & 2.999.330,40 \\
\hline 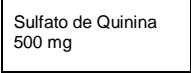 & comp. & LaFEX & 70.000 & $16.660,00$ & 1.368 .000 & $325.584,00$ & 2.070 .000 & $599.677,00$ & 2.550 .000 & $841.640,00$ & & & & & 224000 & 71.1.12,40 & 320.000 & 101.632,00 & 125.000 & 55.72 .50 & & & 155.000 & $69.083,50$ & 6.982 .000 & $2.081 .133,40$ \\
\hline \multicolumn{3}{|c|}{ subtotal } & 70.000 & $16.660,00$ & 1.368.000 & $325,584,00$ & 2.070.000 & $599.679,00$ & 2.550 .000 & $841.640,00$ & & & & & 224,000 & 71.142,40 & 320.000 & 101.632,00 & 125.000 & $55.712,50$ & & & 155.000 & $69.08,50$ & 6.982.000 & 2.081.133,40 \\
\hline \multicolumn{3}{|c|}{ Total } & 2.766.000 & $336.946,60$ & 20.289.700 & 1.255.607,32 & 21.542.500 & 2.104.068,40 & 26.790.000 & 2.244.140,00 & 21.500.500 & $858.61,00$ & 5.450 .000 & 145.52,000 & 5.177.000 & 277.186,20 & 25.206.500 & $838.988,85$ & 17.899.000 & $593.62,42$ & 6.800.000 & $174.080,00$ & 10.445.000 & $314.867,50$ & 163.811.200 & 9.137.638,29 \\
\hline
\end{tabular}

Meningite

\begin{tabular}{|c|c|c|c|c|c|c|c|c|c|c|c|c|c|c|c|c|c|c|c|c|c|c|c|c|c|c|}
\hline & & & & & & & \\
\hline Ritampicina $300 \mathrm{mg}$ & \begin{tabular}{|c|} 
Cáps. \\
\end{tabular} & LAFEPE & 209.000 & 29.573 .50 & 328.000 & $46,412,00$ & 192.500 & $27.238,75$ & & & & & & & & & & & & & & & & & 729.500 & 103224,25 \\
\hline \multicolumn{3}{|c|}{ Subtotal } & 209.000 & $29.577,50$ & 328.000 & $46.412,00$ & 192.500 & $27.238,75$ & & & & & & & & & & & & & & & & & 729.500 & $103.224,25$ \\
\hline Ritampicina $300 \mathrm{mg}$ & \begin{tabular}{|c|} 
Canss. \\
\end{tabular} & LOFEX & & & & & 160.500 & $22.710,75$ & 124.000 & $17.546,00$ & 184.000 & $26,036,00$ & & & 288.000 & $40.752,00$ & 288.000 & $40,752,00$ & 288.000 & $40.752,00$ & & & 288.000 & 40.752 .00 & 1.620 .500 & $229.900,75$ \\
\hline \multicolumn{3}{|c|}{ Subtotal } & & & & & 160.500 & 22.710,75 & 124.000 & $17.54,00$ & 184.000 & $26.036,00$ & & & 288.000 & 40.752,00 & 288.000 & $40,752,00$ & 288.000 & $40,752,00$ & & & 288.000 & $40.752,00$ & 1.620 .500 & $229.300,75$ \\
\hline $\begin{array}{l}\text { Rifampicina, Frasco } \\
\text { de } 50 \mathrm{ml}\end{array}$ & Frasco & FURP & 39.150 & $30.94,16$ & 35.150 & $29.170,99$ & 96.000 & $79.670,40$ & 93.000 & $77.180,70$ & 54.000 & $44,81,40$ & & & & & & & & & & & 140.000 & $19.810,00$ & 457.300 & $281.590,85$ \\
\hline 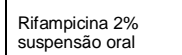 & Fr. & FURP & & & & & & & & & & & & & 50.400 & $41.826,96$ & 50.000 & $41.455,00$ & 50.000 & $41.455,00$ & 50.000 & $41.455,00$ & 50.000 & $41.495,00$ & 250.400 & $207.800,96$ \\
\hline \multicolumn{3}{|c|}{ Subtotal } & 39.150 & $30.944,16$ & 35.150 & 29.170,99 & 96.000 & $79.670,40$ & 93.000 & $77.180,70$ & 54.000 & 44.814,60 & 0 & 0,00 & 50.400 & 41.282,96 & 50.000 & $41.495,00$ & 50.000 & $41.495,00$ & 50.000 & $41.995,00$ & 190.000 & $61.305,00$ & 7007.700 & 499.997,81 \\
\hline
\end{tabular}




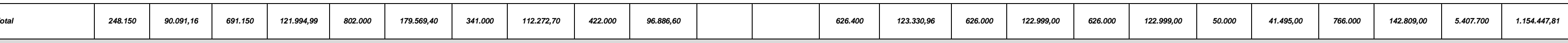

Peste

\begin{tabular}{|c|c|c|c|c|c|c|c|c|c|c|c|c|c|c|c|c|c|c|c|c|c|c|c|c|c|c|}
\hline 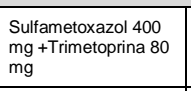 & Comp. & FIOCFuZ & 3.500 & 177,45 & 1.500 & 76,05 & 2.000 & 101,40 & 2.000 & 101,40 & & & & & 1.500 & 76,05 & & & & & & & & & 10.500 & 532,35 \\
\hline 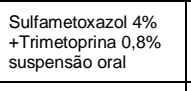 & Fr. & FIOCRUZZ & & & & & & & & & & & & & 1.000 & $1.154,80$ & & & & & & & & & 1.000 & $1.154,80$ \\
\hline Tetracicina 250mg & Cáps. & Filociuz & & & 2.500 & 125,00 & 2.000 & 100,00 & 2.000 & 100,00 & & & & & & & & & & & & & & & 6.500 & 325,00 \\
\hline \multicolumn{3}{|c|}{ subbotal } & 3.500 & 177,45 & 4.000 & 201,05 & 4.000 & 201,40 & 4.000 & 201,40 & 0 & 0,00 & 0 & 0,00 & 2.500 & $1.230,85$ & 0 & 0,00 & 0 & 0,00 & 0 & 0,00 & 0 & 0,00 & 18.000 & $2.012,15$ \\
\hline 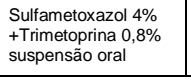 & Frasco & FURP & 1.400 & $1.408,26$ & 700 & 800,36 & 1.000 & 1.154,80 & 1.000 & $1.154,80$ & & & & & & & & & & & & & & & 4.100 & $4.526,22$ \\
\hline \multicolumn{3}{|c|}{ Subtotal } & 1.400 & $1.408,26$ & 700 & 808,36 & 1.000 & $1.154,80$ & 1.000 & $1.154,80$ & & & & & & & & & & & & & & & 4.100 & $4.526,22$ \\
\hline \multicolumn{3}{|c|}{ Total } & 4.900 & $1.585,71$ & 4.700 & $1.009,41$ & 5.000 & $1.356,20$ & 5.000 & $1.356,20$ & 0 & 0,00 & 0 & 0,00 & 2.500 & $1.230,85$ & 0 & 0,00 & 0 & 0,00 & 0 & 0,00 & 0 & 0,00 & 22.100 & $6.538,37$ \\
\hline
\end{tabular}

tracoma

\begin{tabular}{|c|c|c|c|c|c|c|c|c|c|c|c|c|c|c|c|c|c|c|c|c|c|c|c|c|c|c|}
\hline $\mid$\begin{tabular}{|l|} 
Tetracilina, Pomada \\
Offat $1 \% \%$
\end{tabular} & Bisn. & FioçUz & 70.000 & $27.94,00$ & & & & & & & & & & & & & & & & & & & & & 70.000 & $27.944,00$ \\
\hline & ubtotal & & 70.000 & $27.94,400$ & 0 & 0,00 & 0 & 0,00 & 0 & 0,00 & 0 & 0,00 & 0 & 0,00 & 0 & 0,00 & 0 & 0,00 & 0 & 0,00 & 0 & 0,00 & 0 & 0,00 & 70.000 & $27,94,000$ \\
\hline & Total & & 70.000 & $27,94,00$ & 0 & 0,00 & 0 & 0,00 & 0 & 0,00 & 0 & 0,00 & 0 & 0,00 & 0 & 0,00 & 0 & 0,00 & 0 & 0,00 & 0 & 0,00 & 0 & 0,00 & 70.000 & $27,94,00$ \\
\hline
\end{tabular}

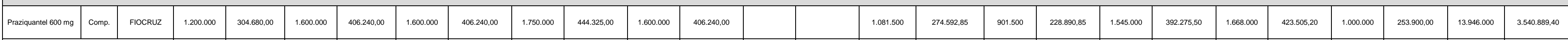

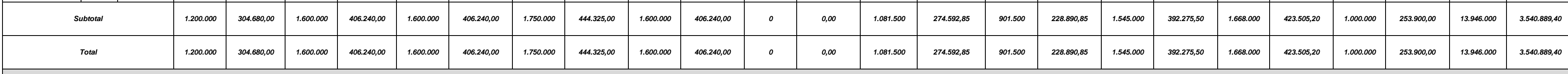

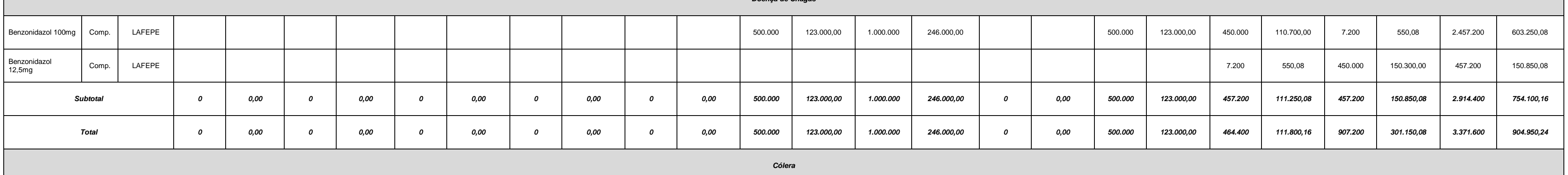

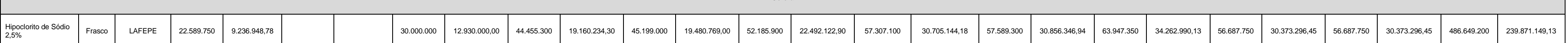

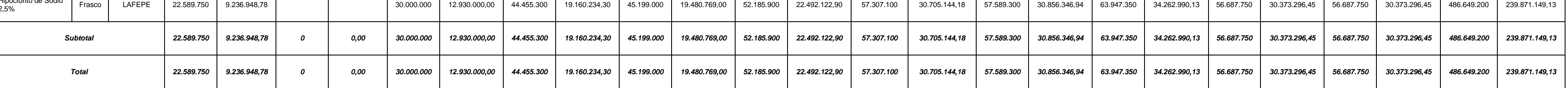




\begin{tabular}{|c|c|c|c|c|c|c|c|c|c|c|c|c|c|c|c|c|c|c|c|c|c|c|c|c|c|c|}
\hline $\begin{array}{l}\text { Dieitiataramazina, } \\
\text { comp: } 50 \text { ong }\end{array}$ & \begin{tabular}{|l|l|} 
comp. \\
\end{tabular} & Fiochuz & & & 251.000 & $3.614,40$ & 1.000 .000 & 14.400,00 & 500.000 & $7.200,00$ & 500.000 & $7.200,00$ & 740.000 & $10.055,00$ & 2.500 .000 & $36.000,00$ & 2.000 .000 & $28.800,00$ & 1.000 .000 & $14,400,00$ & & & 500.000 & $7.200,00$ & 8.991 .000 & $129.470,40$ \\
\hline \multicolumn{3}{|c|}{ subtotal } & & & 251.000 & $3.614,40$ & 1.000 .000 & $14,400,00$ & 500.000 & $7.200,00$ & 500.000 & $7.200,00$ & 790.000 & $10.555,00$ & 2.500 .000 & $36.000,00$ & 2.000 .000 & $28.800,00$ & 1.000 .000 & $14,400,00$ & & & 500.000 & 7.200,00 & 8.991 .000 & $129.470,40$ \\
\hline \multicolumn{3}{|c|}{ Total } & 0 & 0,00 & 25.000 & $3.614,40$ & 1.000.000 & $14.000,00$ & 500.000 & $7.200,00$ & 500.000 & $7.200,00$ & 740.000 & $10.65,00$ & 2.500 .000 & $36.00,00$ & 2.000 .000 & $28.800,00$ & 1.000 .000 & $19.400,00$ & 0 & 0,00 & 500.000 & $7.200,00$ & 8.991 .000 & 129.470,40 \\
\hline \multicolumn{27}{|c|}{ Dengue } \\
\hline Paracetamal 500mg & comp. & Fiocauz & & & & & & & & & & & & & 2.740 .060 & 109.876,41 & 2.000 .000 & 802000,00 & 500.000 & $9.955,00$ & & & & & 5.240 .060 & $200.026,41$ \\
\hline $\begin{array}{l}\text { Paractammal } 200 \\
\text { my g glatas }\end{array}$ & $\mathrm{Fr}$. & Fiocruz & & & & & & & & & & & & & 32.26 & 13.702,92 & & & & & & & & & 32.26 & 13.702.92 \\
\hline 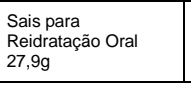 & Env. & Fiocruz & & & & & & & & & & & & & 562.705 & 270.210,94 & 1.000.000 & $480.200,00$ & & & & & & & 1.562 .705 & 750.410,94 \\
\hline \multicolumn{3}{|c|}{ subtotal } & 0 & 0,00 & 0 & 0,00 & 0 & 0,00 & 0 & 0,00 & 0 & 0,00 & 0 & 0,00 & 3.355.391 & $393.790,27$ & 3.000 .000 & $560.400,00$ & 500.000 & $9.950,00$ & 0 & 0,00 & 。 & 0,00 & 6.835.391 & $966,140,27$ \\
\hline Paracetamal 500mg & \begin{tabular}{|l|l|} 
comp. \\
\end{tabular} & laUEGo & & & & & & & & & & & & & & & 1.000 .000 & 40.100,00 & & & & & & & 1.000 .000 & $40.100,00$ \\
\hline \multicolumn{3}{|c|}{ Subtotal } & & & & & & & & & & & & & & & 1.000 .000 & $40.100,00$ & & & & & & & 1.000 .000 & $40.100,00$ \\
\hline $\begin{array}{c}\text { Metoclopranida } 100 \\
\text { me }\end{array}$ & comp. & $\angle A F E P E$ & & & & & 10.000 & 276,00 & & & & & & & & & & & & & & & & & 10.000 & 276,00 \\
\hline $\begin{array}{l}\text { Meloclopramida } \\
\text { solusca o oral }\end{array}$ & \begin{tabular}{|l|l|} 
Frasco \\
\end{tabular} & LAFEPE & & & & & 20.000 & $7.190,00$ & & & & & & & & & & & & & & & & & 20.000 & $7.190,00$ \\
\hline $\begin{array}{l}\text { Paracetamol } 2000 \\
\text { mog golatas }\end{array}$ & Frasco & LAFEEE & & & & & 10.000 & $5.342,00$ & & & 4.000.000 & $144.000,00$ & & & & & 60.000 & 25200,00 & & & & & & & 4.070.000 & $177.542,00$ \\
\hline \multicolumn{3}{|c|}{ subtotal } & $\circ$ & & & & 40.000 & 12.808,00 & & & 4.000.000 & $144.000,00$ & & & 6.670.782 & $787.500,53$ & 8.060 .000 & $1.226 .20,00$ & 1.000 .000 & 19.900,00 & & & & & 19.770.782 & $2.190 .488,53$ \\
\hline \multicolumn{3}{|c|}{ Total } & $\circ$ & 0,00 & $\circ$ & 0,00 & 40.000 & $12.000,00$ & 0 & 0,00 & 4.000.000 & $144.000,00$ & $\circ$ & 0,00 & 10.006.173 & 1.1.181.370,80 & 12.060.000 & $1.826 .70,00$ & 1.500.000 & $29.55,00$ & 0 & 0,00 & o & 0,00 & 27.606 .73 & $3.199 .728,80$ \\
\hline \multicolumn{27}{|c|}{ Influenza } \\
\hline oseltamivir $75 \mathrm{mg}$ & \begin{tabular}{|l|} 
Capps. \\
\end{tabular} & Fiocruz & & & & & & & & & & & & & 21.500.000 & $60.200 .000,00$ & & & & & & & & & 21.500.000 & $60.200 .000,00$ \\
\hline 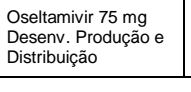 & comp. & Fiocruz & & & & & & & & & & & & & 2.065 .490 & 25.242.287,80 & & & & & & & & & 2.065 .490 & 25.242.287,80 \\
\hline \multicolumn{3}{|c|}{ Subtotal } & 0 & 0,00 & 0 & 0,00 & 0 & 0,00 & 0 & 0,00 & 0 & 0,00 & 0 & 0,00 & 23.565.490 & 85.442.287,80 & 0 & 0,00 & 0 & 0,00 & 0 & 0,00 & 0 & 0,00 & 23.565.490 & $85.442 .287,80$ \\
\hline \multicolumn{3}{|c|}{ Total } & 0 & 0,00 & $\circ$ & 0,00 & o & 0,00 & $\circ$ & 0,00 & $\circ$ & 0,00 & 0 & 0,00 & 25.630.980 & 110.684.575,60 & $\circ$ & 0,00 & $\circ$ & 0,00 & o & 0,00 & o & 0,00 & 25.630.980 & $110.684 .575,50$ \\
\hline \multicolumn{27}{|c|}{ Micoses Sistetemicas } \\
\hline $\begin{array}{l}\begin{array}{l}\text { Sutat a } 400 \mathrm{mg}+\mathrm{T} \text { ine } \\
80 \mathrm{~g}\end{array} \\
\end{array}$ & comp. & Fiocauz & & & & & & & & & 2.000 & 101,40 & & & & & & & & & & & & & 2.000 & 10,40 \\
\hline $\begin{array}{l}\text { Sulta } \% \text { \% Time } \\
0,8 \% \text { suspensáa oral }\end{array}$ & \begin{tabular}{|l|l|} 
Frasco \\
\end{tabular} & FURP & & & & & & & & & 1.000 & $1.154,80$ & & & & & & & & & & & & & 1.000 & 1.1.54,80 \\
\hline \multicolumn{3}{|c|}{ subtotal } & 0 & 0,00 & 0 & 0,00 & 0 & 0,00 & 0 & 0,00 & 3.000 & $1.256,20$ & 0 & 0,00 & 0 & 0,00 & 0 & 0,00 & 0 & 0,00 & 0 & 0,00 & 0 & 0,00 & 3.000 & $1.256,20$ \\
\hline \multicolumn{3}{|c|}{ Total } & 26.873.800 & $9.998 .196,25$ & 22.336.550 & 1.788.46, 12 & 54.999 .500 & $15.648 .442,00$ & 73.841.300 & $21.969 .528,20$ & 73.224.500 & 20.994.962,80 & 58.875.900 & 22.771.298,90 & 103.331.553 & \begin{tabular}{l|l|l}
$143.523 .431,44$ & \\
\end{tabular} & 98.383.300 & 33.902.725,64 & 86.967.350 & 35.539.137,05 & 65.670.150 & 31.124.176,81 & 70.305.950 & 31.393.223,03 & 735.50.9.53 & 368.55.588,23 \\
\hline
\end{tabular}


Apêndice 12 - Produção dos laboratórios nacionais, em número de Unidades Farmacêuticas (UF) para o tratamento das Endemias Focais, no período de 2003 a 2013.

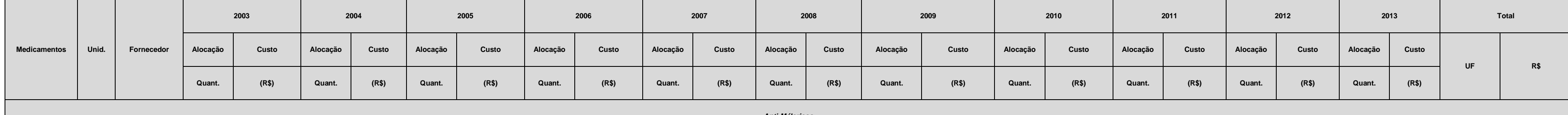

\begin{tabular}{|c|c|c|c|c|c|c|c|c|c|c|c|c|c|c|c|c|c|c|c|c|c|c|c|c|c|c|}
\hline $\begin{array}{l}\text { Artesunatio ode } \\
\text { Solod o o } \\
\text { injelavel }\end{array}$ & Amp. & ativus & 22.000 & $199.540,00$ & & & & & 11.000 & $13.189,00$ & & & & & & & & & & & & & & & 33.000 & $212: 729,00$ \\
\hline Artesunato $50 \mathrm{mg}$ & comp. & ativus & 50.000 & $31.000,00$ & & & & & & & & & & & & & & & & & & & & & 50.000 & $31.000,00$ \\
\hline 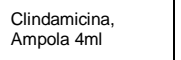 & Amp. & Cellofarm & & & & & & & & & 11.000 & $9.790,00$ & & & & & & & & & & & & & 11.000 & $9.790,00$ \\
\hline $\begin{array}{l}\text { lilindanicina } \\
\text { (Cloridratio) } 3000 \mathrm{mg}\end{array}$ & Cáps. & EM.S & & & & & & & & & & & & & 17.600 & $7.040,00$ & & & & & & & & & 17.600 & $7.040,00$ \\
\hline $\begin{array}{l}\text { Clinataricna, Amp. } \\
04 \mathrm{~m} \text {. }\end{array}$ & Amp. & EUROFARMA & 3.400 & $4.760,00$ & & & & & & & & & & & & & & & & & & & & & 3.400 & $4.760,00$ \\
\hline 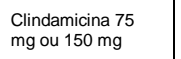 & Caps. & HPPOABOOR & 15.000 & 28800,00 & & & & & 20.000 & 12200,00 & & & & & & & & & & & & & & & 35.000 & 41.000,00 \\
\hline 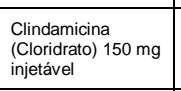 & Amp. & HYPOFARMA & & & & & & & & & & & & & & & 150.000 & $110.250,00$ & & & & & & & 150.000 & $110.250,00$ \\
\hline Doxiciclina 100mg & comp. & IMEX FARMA & & & & & & & & & & & & & & & & & 270.000 & $17.45,00$ & & & & & 270.000 & $17.45,00$ \\
\hline 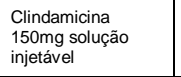 & Amp. & Novatama & & & & & & & & & & & 8.700 & $7.917,00$ & & & & & & & & & & & 8.700 & 7917,00 \\
\hline $\begin{array}{l}\text { Clindamicina } \\
\text { (Cloridrato) } 300 \mathrm{mg}\end{array}$ & Cáps. & PRODIET & & & & & & & & & & & & & & & 80.000 & $26.000,00$ & & & & & & & 80.000 & $26,000,00$ \\
\hline 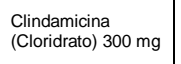 & Caps. & TEUTO & & & & & & & & & 20.000 & $4.580,00$ & & & & & & & & & & & & & 20.000 & 4.580,00 \\
\hline $\begin{array}{l}\text { cilindaninina, } \\
\text { Amponaliand }\end{array}$ & Amp. & UNÄ́o auímica & & & & & 10.000 & 14.500,00 & & & & & & & & & & & & & & & & & 10.000 & 1450,00,00 \\
\hline \multicolumn{3}{|c|}{ Subtotal } & 90.400 & $264,100,00$ & 0 & 0,00 & 10.000 & $14,500,00$ & 31.000 & $25.389,00$ & 31.000 & $14,370,00$ & 8.700 & $7.917,00$ & 17.600 & $7.040,00$ & 230.000 & ${ }_{136.250,00}$ & 270.000 & $17: 45,00$ & 0 & 0,00 & 0 & 0,00 & 688.700 & $486.711,00$ \\
\hline
\end{tabular}

\begin{tabular}{|c|c|c|c|c|c|c|c|c|c|c|c|c|c|c|c|c|c|c|c|c|c|c|c|c|}
\hline 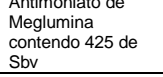 & Amp. & AvENTIS & 3.052 .473 & 12.783.655.50 & & & 3.080 .000 & $11.148 .000,000$ & & & & & & & & & & & & & & & 6.732473 & $239391.655,50$ \\
\hline $\begin{array}{l}\text { Antoterecina B } 50 \\
m g\end{array}$ & Frasco & CRISTALLA & 10.000 & $70.600,00$ & & & & & 20.000 & $218.000,00$ & 17.500 & $192.500,00$ & 27.500 & $314,600,00$ & & & & & 10.000 & $132.000,00$ & 26.500 & 339200,00 & 111.500 & 1.266.900,00 \\
\hline 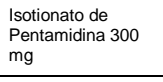 & $F / A$ & Haca Lab. & 10.000 & $410.000,00$ & 10.000 & $370.000,00$ & & & & & & & & & & & & & & & & & 20.000 & $780,000,00$ \\
\hline 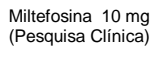 & Cáps. & PALADIN & & & & & & & & & & & & & & & 13,496 & $104.728,96$ & & & & & 13.496 & 104:728,96 \\
\hline 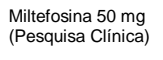 & Cáps. & PALADIN & & & & & & & & & & & & & & & 53.760 & $653.184,00$ & & & & & 53.760 & $653.184,00$ \\
\hline 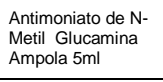 & Amp. & SANOFI & & & & & & & & & & & & & 1.000 .000 & $3.055 .000,00$ & 1.800.000 & $5.814 .000,00$ & 1.352000 & $4.123 .600,00$ & 2.527 .050 & 7126281,00 & 6.679 .050 & $20.113 .881,00$ \\
\hline $\begin{array}{l}\text { Meglumina } \\
\text { antinononiato }\end{array}$ & Amp. & $\begin{array}{l}\text { SANoFl } \\
\text { AVENTIS }\end{array}$ & & & & & & & 2.990 .000 & $11.152 .700,00$ & 2.850 .000 & $8.6025 .50,000$ & & & & & & & & & & & 5.840 .000 & $19.845 .200,00$ \\
\hline & subtotal & & 3.672473 & $13.264 .255,50$ & 10.000 & $370.000,00$ & 3.080.000 & $11.148 .000,00$ & 3.010 .000 & $11.370 .700,00$ & 2.867 .500 & $8.885 .000,00$ & 27.500 & $314.600,00$ & 1.000.000 & $3.050 .000,00$ & 1.667 .256 & $6.571 .912,96$ & 1.362000 & 4.255.600,00 & 2.553 .550 & 7465581,00 & 19.450 .279 & $66.699 .549,46$ \\
\hline
\end{tabular}




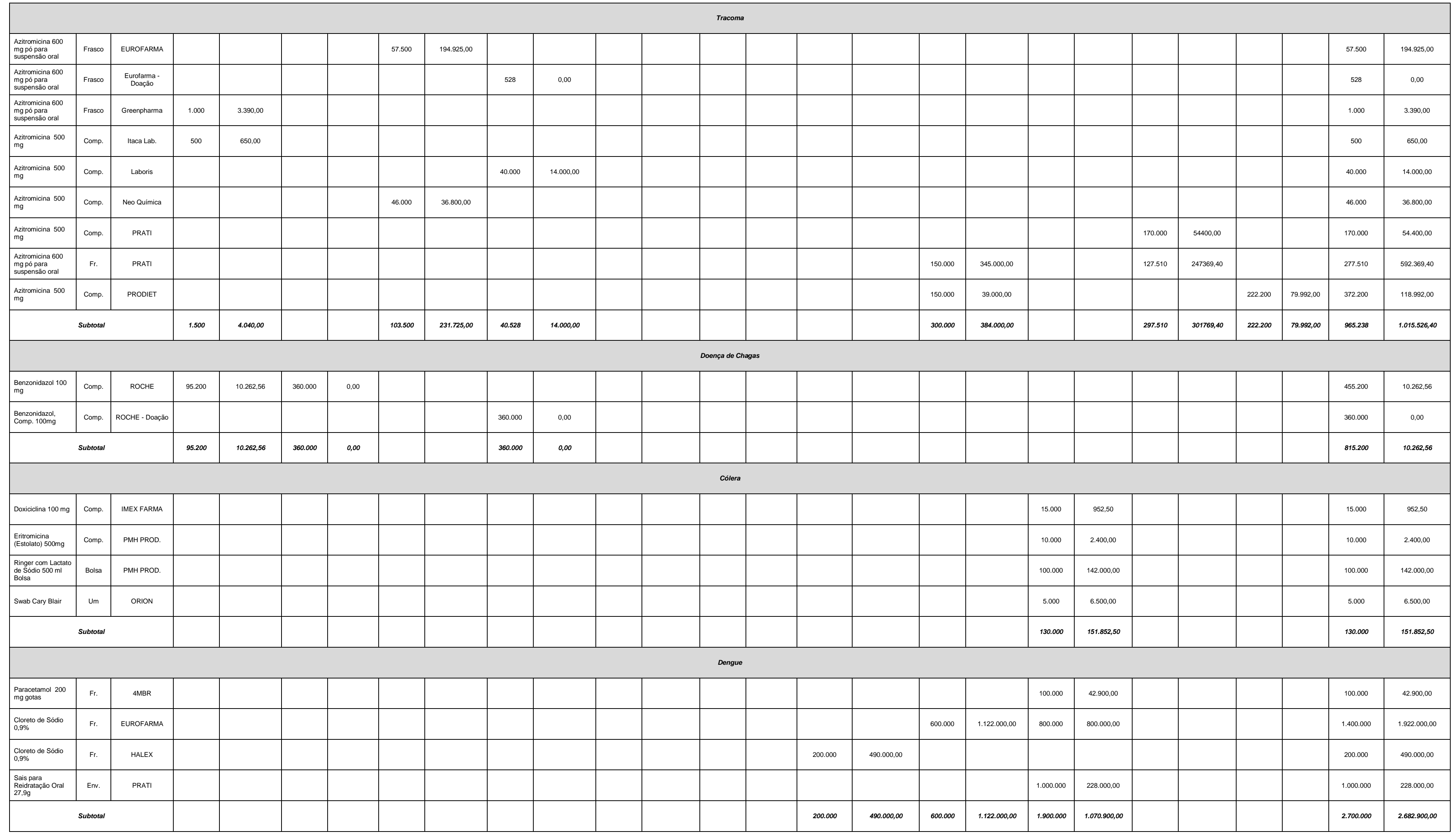




\begin{tabular}{|c|c|c|c|c|c|c|c|c|c|c|c|c|c|c|c|c|c|c|c|c|c|c|c|c|c|c|}
\hline \multicolumn{27}{|c|}{ Intuenza } \\
\hline 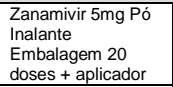 & $\mathrm{kit}$ & GLAXO & & & & & & & & & & & & & 200.000 & $8.312 .000,00$ & & & & & & & & & 200.000 & $8.312 .000,00$ \\
\hline 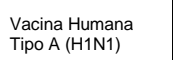 & Dose & 10 & & & & & & & & & & & & & 40.000 .000 & $465.532 .000,00$ & & & & & & & & & 40.000 .000 & $465.5252000,00$ \\
\hline oseltanivir $30 \mathrm{mg}$ & Cáps. & ROCHE & & & & & & & & & & & & & 16.000 .000 & $27.804 .800,00$ & & & & & & & & & 16.000 .000 & $27.804 .800,00$ \\
\hline oseltanivir 45 mm & Cáps. & ROCHE & & & & & & & & & & & & & 14.000.000 & $36.495 .200,00$ & & & & & & & & & 14.000 .000 & $36,455200,000$ \\
\hline oseltamivir $75 \mathrm{~mm}$ & Caps. & ROCHE & & & & & & & & & & & & & 75.242.250 & $325844,344,150$ & & & & & & & & & 75 2424.630 & $325.544 .341,50$ \\
\hline oseltanivit $75 \mathrm{mg}$ & comp. & ROCHE & & & & & & & & & & & & & 500.000 & & & & & & & & & & 500.000 & 0,00 \\
\hline & Subtotal & & & & & & & & & & & & & & 145.942.530 & 8683.988.341,50 & & & & & & & & & 145.942.630 & $863.88 .341,50$ \\
\hline \multicolumn{27}{|c|}{ Micoses Sistemicas } \\
\hline 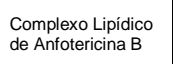 & $\mathrm{FAA}$ & BAGG & & & & & & & & & & & & & & & 22.500 & 11.182.500,00 & & & 140.040 & 10677739,20 & & & 36.540 & $21: 559693920$ \\
\hline Andotericina $B$ & Frasco & Cirstalia & & & & & & & & & 3.000 & 33000,00 & & & & & & & & & & & & & 3.000 & 33000,00 \\
\hline Fuluonazal $100 \mathrm{mg}$ & Cáps. & CRIISTALAA & & & & & & & & & & & & & & & 215.520 & $40.948,80$ & & & & & & & 215.520 & $40.948,80$ \\
\hline 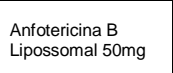 & F/A & Gilead & & & & & & & & & 600 & $285.525,00$ & & & & & & & & & & & & & 600 & $285.525,00$ \\
\hline 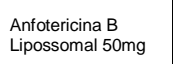 & Comp. & GileAdD- Doaçăo & & & & & & & & & & & 3.000 & 0,00 & & & & & & & & & & & 3.000 & 0.00 \\
\hline $\begin{array}{l}\text { Fluconazol } 2 \mathrm{mg} \\
\text { Injetavel }\end{array}$ & $\mathrm{Fr}$ & HALEX-ISTAR & & & & & & & & & & & & & & & 13.440 & $52.684,80$ & & & & & & & 13.40 & 52684,80 \\
\hline 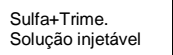 & Amp. & J.F GALLO & & & & & & & & & 18.000 & $7.200,00$ & & & & & & & & & & & & & 18.000 & $7.200,00$ \\
\hline Itraconazol. 100mg & Cáps. & Neo Química & & & & & & & & & 657.000 & $134.65,00$ & & & & & & & & & & & & & 657.000 & $134,655,00$ \\
\hline Itrazonazal 100mm & Cáps. & PRODIET & & & & & & & & & & & & & & & 486.000 & $140.940,00$ & & & & & & & 486.000 & 140.940,000 \\
\hline $\begin{array}{l}\text { Tetracicina } 250 \\
\text { mg }\end{array}$ & Cáps. & & & & & & & & & & 2.000 & 100,00 & & & & & & & & & & & & & 2.000 & 100,00 \\
\hline \multicolumn{3}{|c|}{ subtotal } & 0 & 0,00 & 0 & 0,00 & 0 & 0,00 & 0 & 0,00 & 680.600 & $460.510,00$ & 3.000 & 0,00 & 0 & 0,00 & 737.460 & 11.417.073,60 & 0 & 0,00 & 14.040 & 106771939,20 & 0 & 0,00 & 1.435 .100 & $22.554 .722,80$ \\
\hline
\end{tabular}


Apêndice 13 - Produção dos laboratórios internacionais, em número de Unidades Farmacêuticas (UF) para o tratamento das Endemias Focais, no período de 2003 a 2013.

\begin{tabular}{|c|c|c|c|c|c|c|c|c|c|c|c|c|c|c|c|c|c|c|c|c|c|c|c|c|c|c|}
\hline \multirow{3}{*}{ Medicamentos } & \multirow{3}{*}{ Unid. } & \multirow{3}{*}{ Fornecedor } & \multicolumn{2}{|c|}{2003} & \multicolumn{2}{|c|}{2004} & \multicolumn{2}{|c|}{2005} & \multicolumn{2}{|c|}{2006} & \multicolumn{2}{|c|}{2007} & \multicolumn{2}{|c|}{2008} & \multicolumn{2}{|c|}{2009} & \multicolumn{2}{|c|}{2010} & \multicolumn{2}{|c|}{2011} & \multicolumn{2}{|c|}{2012} & \multicolumn{2}{|c|}{2013} & \multicolumn{2}{|c|}{ Total } \\
\hline & & & Alocagâa & custo & Alocąâo & custo & Alocąąo & custo & Alccaạa & custo & Alocąâa & custo & Alocaạăo & custo & Alocạ̧ăo & custo & Alocąă̄o & custo & Alocą̧ăo & custo & Alocąąo & custo & Alocaçäo & custo & \multirow{2}{*}{ uF } & \multirow{2}{*}{ Rs } \\
\hline & & & Ouant. & (ABS) & Ouant. & (RS) & Ouant. & (RS) & Ouant. & (AS) & Ouant. & (RS) & ouant. & (Rs) & Quant. & (RS) & ouant. & (ABS) & ouant. & (Rs) & ouant. & (Rs) & ouant. & (RS) & & \\
\hline \multicolumn{27}{|c|}{ Ant:-Malaricos } \\
\hline Artemeter $80 \mathrm{mg}$ & Comp. & OPAS & 0 & & & & & & & & & & & & & & 10.000 & 22285,00 & & & & & & & $10.000,00$ & $22.255,00$ \\
\hline $\begin{array}{l}\text { Artemater } 80 \mathrm{mg} \\
\text { nifielvel }\end{array}$ & $F / A$ & OPAS & & & & & & & & & & & & & & & & & 76.500 & 53.779 .50 & 30.750 & $42,788,63$ & & & $107.250,00$ & $96.58,13$ \\
\hline 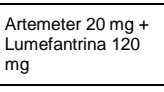 & Comp. & OPAS & & & & & & & & & & & & & & & 2.831.040 & $443.956,00$ & 202.200 & $400.276,80$ & 140.400 & 373.002 .24 & & & $3.173 .640,00$ & $1.217 .235,04$ \\
\hline 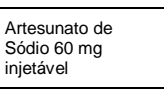 & $\mathrm{F} / \mathrm{A}$ & OPAS & . & & & & & & & & & & & & & & 30.000 & 107.50,50 & 82.300 & $250.192,00$ & 53.200 & $315.688,80$ & & & $165.500,00$ & 677.390,30 \\
\hline 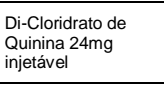 & Amp. & OPAS & 0 & & & & & & & & & & & & & & 85.000 & $90.499,50$ & & & & & 90.000 & $62.515,00$ & $175.00,00$ & $153.014,50$ \\
\hline \multicolumn{3}{|c|}{ subtotal } & 0 & 0 & 0 & 0 & 0 & o & 0 & 0 & 0 & 0 & 0 & 0 & 0 & 0 & 2.956 .040 & 664.250 & 36.000 & 704.248 & 224.350 & 73.480 & 90.000 & 62.515 & 3.631 .390 & 2.162 .493 \\
\hline \multicolumn{27}{|c|}{ Leistmaniose } \\
\hline 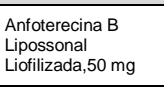 & Frasso & GILEAD & 1.200 & $763: 200,00$ & 800 & $508.800,00$ & 3.437 & $1.712 .157,75$ & 3.750 & $1.784 .531,25$ & 5.900 & $2.781 .337,50$ & 20.700 & $1.710 .676,80$ & 66.600 & $3.377 .619,00$ & 53.000 & $2.454 .165,00$ & 34.600 & $1.487 .713,50$ & & & 34.600 & $1.487 .713,50$ & $224.587,00$ & $18.067 .914,30$ \\
\hline $\begin{array}{l}\text { Pentanicinan } 3000 \\
\text { mal Injelavel }\end{array}$ & Amp. & OPAS & & & & & & & & & & & 5.000 & $63.644,18$ & & & 5.500 & $75,423,00$ & 4.000 & $544.89,00$ & & & & & $14.500,00$ & $193.866,18$ \\
\hline $\begin{array}{l}\text { Antritericina B B } \\
\text { lipossonal }\end{array}$ & $\mathrm{F} / \mathrm{A}$ & GILEAD - Doação & & & & & & & & & 50 & & & & & & & & & & & & & & 50,00 & 0,00 \\
\hline & Subtotal & & 1.200 & $763.200,00$ & 800 & $508.800,00$ & 3.437 & $1.7121 .15,75$ & 3.750 & $1.784 .531,25$ & 5.950 & $2.781 .377,50$ & 25.700 & 1.774.,320,98 & 66.600 & 3.377.619,00 & 58.500 & $2.529 .588,00$ & 38.600 & $1.542 .532,50$ & & & 34.600 & $1.487 .713,50$ & $239.137,00$ & 18.261.800,48 \\
\hline \multicolumn{27}{|c|}{ Meringte } \\
\hline $\begin{array}{l}\text { Vacinas contra } \\
\text { Menningte }\end{array}$ & Doses & $\begin{array}{c}\text { Vacuras } \\
\text { Filinayyunanaranan }\end{array}$ & & & 20.000 & $260.423,03$ & & & & & & & & & & & & & & & & & & & $20.000,00$ & $260.423,03$ \\
\hline & Subtotal & & & & 20.000 & $260.423,03$ & & & & & & & & & & & & & & & & & & & $20.000,00$ & $260.423,03$ \\
\hline \multicolumn{27}{|c|}{ Febre Maculoss } \\
\hline 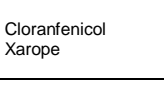 & $\mathrm{Fr}$ & OPAS & & & & & & & & & & & & & & & & & & & & & 4.000 & $25.680,00$ & 4.000 & $25.680,00$ \\
\hline & subtotal & & & & & & & & & & & & & & & & & & & & & & 4.000 & $25.680,00$ & 4.000 & $25.680,00$ \\
\hline \multicolumn{27}{|c|}{ Influenza } \\
\hline oseltamivir $75 \mathrm{mg}$ & Câps. & Produtos foche & & & & & & & 144.000 & $321.480,00$ & & & & & & & & & & & & & & & 114.000 & $321.480,00$ \\
\hline Osettamivir, Po & kg & Produltos foche & & & & & & & 9.254 & 152.228.300,00 & & & & & & & & & & & & & & & 9.254 & $152.228 .300,00$ \\
\hline 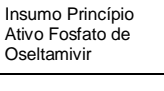 & $\mathrm{kg}$ & F-HOFFMAN & & & & & & & & & & & & & 4.000 & $80.193 .528,00$ & & & & & & & & & 4.000 & $80.193 .528,00$ \\
\hline oseltanivir $75 \mathrm{mg}$ & comp. & ROCHE & & & & & & & & & & & & & 62.500 & $271.543,75$ & & & & & & & & & 62.500 & $271.543,75$ \\
\hline
\end{tabular}




\begin{tabular}{|c|c|c|c|c|c|c|c|c|c|c|c|c|c|c|c|c|c|c|c|c|c|c|c|c|c|c|}
\hline 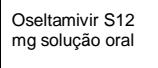 & $F$ & RоCHE & & & & & & & & & & & & & 6.250 & 355477,50 & & & & & & & & & 6.250 & 355437350 \\
\hline 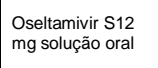 & $F$ & ROCHE & & & & & & & & & & & & & 7.453 & & & & & & & & & & 7.453 & 0,00 \\
\hline & sublora & & & & & & & & ${ }_{123.254}$ & $125298,780,000$ & & & & & 802023 & 8081715002025 & & & & & & & & & 200.457 & 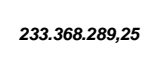 \\
\hline & Toat & & 1.200 & 7632200 & 20.800 & 769223 & 3.437 & 1.712:158 & $\begin{array}{l}127.004 \\
\end{array}$ & 1543393.311 & 5.950 & 2781.338 & 25.700 & 1.774 .321 & 1468038 & $\begin{array}{l}84,196.128 \\
8\end{array}$ & 3.0145 .50 & 3.1983938 & 399.500 & 22465791 & \begin{tabular}{|l|}
22,350 \\
\end{tabular} & 731.480 & 128.600 & 1.575.099 & 4.0979894 & 24arorasese \\
\hline
\end{tabular}


Apêndice 14 - Produção Pública, em número de Unidades Farmacêuticas (UF), para o Programa Multidrogas Resistência, no período de 2003 a 2013.

\begin{tabular}{|c|c|c|c|c|c|c|c|c|c|c|c|c|c|c|c|c|c|c|c|c|c|c|c|c|c|c|}
\hline \multirow{3}{*}{ Medicamentos } & \multirow{3}{*}{ Unid. } & \multirow{3}{*}{ Formecedor } & \multicolumn{2}{|c|}{2003} & \multicolumn{2}{|c|}{2004} & \multicolumn{2}{|c|}{2005} & \multicolumn{2}{|c|}{2006} & \multicolumn{2}{|c|}{2007} & \multicolumn{2}{|c|}{2008} & \multicolumn{2}{|c|}{2009} & \multicolumn{2}{|c|}{2010} & \multicolumn{2}{|c|}{2011} & \multicolumn{2}{|c|}{2012} & \multicolumn{2}{|c|}{2013} & \multicolumn{2}{|c|}{ Total } \\
\hline & & & Alocacäa & Custo & Alocacấo & Custo & Alocacąa & custo & Alocaçäo & custo & Alocacäa & Custo & Alocacăo & custo & Alocaçäo & custo & Alocacáa & custo & Alocacāo & custo & Alocaçăo & custo & Alocaạāo & custo & \multirow{2}{*}{ UF } & \multirow{2}{*}{ Rs } \\
\hline & & & ouant. & (RS) & ouant. & (RS) & ouant. & (RS) & ouant. & (RS) & ouant. & (RS) & Quant. & (BS) & ouant. & (RS) & Quant. & (RS) & Quant. & (AS) & Quant. & (RS) & Quant. & (Rs) & & \\
\hline Elambutol $400 \mathrm{~mm}$ & comp. & FIOCAUZ & 450.000 & 42.660,00 & 300.000 & $30,42,00$ & 432.000 & $43,800,80$ & 399.000 & $35.588,60$ & 1.528 .000 & 154939,20 & & & & & & & & & & & & & 3.0550 .000 & 307.212 .60 \\
\hline $\begin{array}{l}\begin{array}{l}\text { Isoniazida } 100 \mathrm{mg}+ \\
\text { Rifampicina } 150 \mathrm{mg}\end{array} \\
\text { Re }\end{array}$ & caps. & FIOCFuz & & & 3.000 & 297,60 & & & & & & & & & & & & & & & & & & & 3.000 & 29,60 \\
\hline 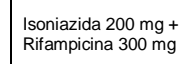 & caps & FIOCRUZZ & 10.000 & $1.654,00$ & 15.000 & $2.481,00$ & & & & & & & & & & & & & & & & & & & 25.000 & $4.135,00$ \\
\hline \multicolumn{3}{|c|}{ Subtotal } & 460.000 & ${ }^{44.314}$ & 318.000 & 33.199 & 432.000 & 43.005 & 399.000 & 35.389 & 1.528 .000 & 154.939 & 0 & 。 & o & o & 。 & o & o & 。 & 。 & 0 & 。 & 。 & 3.087 .000 & 311.645 \\
\hline 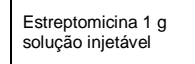 & $\mathrm{FFA}$ & FUAP & 1.600 & $1.411,04$ & 2.200 & $2.118,60$ & 4.500 & $4,333,50$ & 348.500 & $35.337,90$ & & & & & & & & & & & & & & & 356.800 & 432201,04 \\
\hline \multicolumn{3}{|c|}{ subtotal } & 1.600 & $1.411,04$ & 2.200 & $2.118,60$ & 4.500 & $4,333,50$ & 348.500 & 35.337,90 & & & & & & & & & & & & & & & 356.000 & $43.201,04$ \\
\hline Elambuto $1400 \mathrm{mg}$ & comp. & IQUEGo & 450.000 & $42.660,00$ & & & & & 348.500 & $35.337,90$ & & & & & & & & & & & & & & & 799.500 & $77.99,90$ \\
\hline \multicolumn{3}{|c|}{ Subtotal } & 450.000 & 42.660,00 & & & & & 348.500 & $35.337,90$ & & & & & & & & & & & & & & & 799.500 & $77.997,90$ \\
\hline 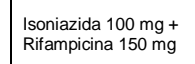 & caps. & LAFEPE & & & 1.000 & 99,20 & & & & & & & & & & & & & & & & & & & 1.000 & 99,20 \\
\hline \begin{tabular}{|l} 
Ritampicina $300 \mathrm{mg}$ \\
\end{tabular} & Cáps. & LAFEPE & & & 2.000 & 283,00 & & & 34.500 & $4.881,75$ & & & & & & & & & & & & & & & 36.500 & $5.164,75$ \\
\hline \multicolumn{3}{|c|}{ Subtotal } & 0 & 0 & 3.000 & 382 & 0 & 0 & 34.500 & 4.882 & 0 & 0 & 0 & 。 & 0 & 0 & 0 & o & 。 & 0 & 0 & 0 & 0 & 0 & 37.500 & 5.264 \\
\hline Ofloxacin $400 \mathrm{mg}$ & comp. & LFM & & & & & 720.000 & $273.600,00$ & 728.000 & $276.640,00$ & 441.500 & $167.770,00$ & 366.000 & 199,080,00 & 597.500 & 227.050,00 & & & 1.200 .000 & $456.000,00$ & & & 200.000 & $76,000,00$ & 4.255:000 & 1.616.140,00 \\
\hline $\begin{array}{l}\text { Pirazinamida } 500 \mathrm{mg} \\
\end{array}$ & comp. & LFM & & & & & & & & & & & & & 405.000 & $49.126,50$ & 1.000 .000 & $380,000,00$ & & & & & & & 1.405.000 & 429.126 .50 \\
\hline \multicolumn{3}{|c|}{ subtotal } & 0 & 0 & 0 & 。 & 720.000 & 273.600 & 728.000 & 276.640 & 441.500 & 167.770 & 366.000 & 139.080 & 1.002 .500 & 27.177 & 1.000 .000 & 380.000 & 1.200 .000 & 456.000 & 。 & 0 & 200.000 & 76.000 & 5.658 .000 & 2.045 .267 \\
\hline Isoniazida $100 \mathrm{mg}$ & comp. & LaFAE & & & & & 7.500 & 123,00 & 81.000 & $1.328,40$ & & & & & & & & & & & & & & & 88.500 & $1.451,40$ \\
\hline Pirazinamida $500 \mathrm{mg}$ & Comp. & LaFAE & 128.000 & $15.526,40$ & & & & & & & & & & & & & & & & & & & & & 128.000 & $15,526,40$ \\
\hline & Subtotal & & 128.000 & 15.526 & 0 & 0 & 7.500 & 123 & 81.000 & 1.328 & 0 & 0 & 0 & 0 & 0 & 0 & 0 & 0 & 0 & 0 & 0 & 0 & 0 & 0 & 216.500 & 16.978 \\
\hline 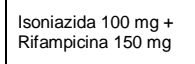 & Cáps. & LafEX & & & & & & & 5.000 & 496,00 & & & & & & & & & & & & & & & 5.000 & 499,00 \\
\hline 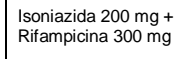 & Cáps. & LOFEX & & & & & & & 8.000 & $1.323,20$ & & & & & & & & & & & & & & & 8.000 & $1.323,20$ \\
\hline Ofloxacino 400 mg & comp. & LOFEX & 216.000 & $77.760,00$ & 30.000 & 10.800,00 & & & & & & & & & & & & & & & & & & & 246.000 & $88.560,00$ \\
\hline Rifampicina 300 mg & Cáps. & LofEx & & & & & 2000 & 283,00 & 77.500 & $10.966,25$ & & & & & & & & & & & & & & & 79.500 & $11.249,25$ \\
\hline 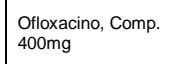 & comp. & 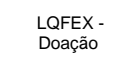 & & & & & 10.000 & & & & & & & & & & & & & & & & & & 10.000 & 0.00 \\
\hline & Subtotal & & 216.000 & 77.760 & 30.000 & 10.800 & 12000 & ${ }_{283}$ & 90.500 & 12.785 & 0 & 0 & 0 & 0 & 0 & 0 & 0 & 0 & 0 & 0 & 0 & 0 & 0 & 0 & 348.500 & 101.628 \\
\hline & Total & & 1.255 .600 & 181.671 & 355.200 & 46.499 & 1.176 .000 & 322.144 & 1.980 .000 & 401.700 & 1.969 .500 & 322.709 & 366.000 & 139.080 & 1.002 .500 & 27.177 & 1.000 .000 & 300.000 & 1.200 .000 & 456.000 & 。 & 0 & 200.000 & 76.000 & 10.502.800 & 2.601 .981 \\
\hline
\end{tabular}


Apêndice 15 - Produção dos laboratórios nacionais, em número de Unidades Farmacêuticas (UF), para o Programa Multidrogas Resistência, no período de 2003 a 2013.

\begin{tabular}{|c|c|c|c|c|c|c|c|c|c|c|c|c|c|c|c|c|c|c|c|c|c|c|c|c|c|c|}
\hline \multirow{3}{*}{ Medicamentos } & \multirow{3}{*}{ Unid. } & \multirow{3}{*}{ Fornecedor } & \multicolumn{2}{|c|}{2003} & \multicolumn{2}{|c|}{2004} & \multicolumn{2}{|c|}{2005} & \multicolumn{2}{|c|}{2006} & \multicolumn{2}{|c|}{2007} & \multicolumn{2}{|c|}{2008} & \multicolumn{2}{|c|}{2009} & \multicolumn{2}{|c|}{2010} & \multicolumn{2}{|c|}{2011} & \multicolumn{2}{|c|}{2012} & \multicolumn{2}{|c|}{2013} & \multicolumn{2}{|c|}{ Total } \\
\hline & & & Alocasăao & custo & Alocasâa & custo & Alocasâa & custo & Alocąăo & custo & Alocąâa & custo & Alocaçäa & custo & Alocąăa & custo & Alocaçāo & Custo & Alocaçăo & custo & Alocąăa & custo & Aocacasao & custo & \multirow{2}{*}{ UF } & \multirow{2}{*}{ Rs } \\
\hline & & & Quant. & (Rs) & Quant. & (As) & Quant. & (RS) & ouant. & (Rs) & Quant. & (AB) & ouant. & (RS) & ouant. & (BS) & auant. & (RS) & auant. & (Rs) & ouant. & (As) & ouant. & (RS) & & \\
\hline Claritromicina $500 \mathrm{mg}$ & comp. & Riocararnse & & & & & & & & & & & & & & & & & 1862200 & ${ }_{123.860,24}$ & & & & & 186.200 & 123.860.24 \\
\hline 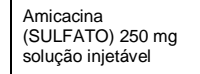 & Amp. & PHARLAB & & & & & & & & & & & & & & & & & & & & & 30.000 & $18.150,00$ & 30.000 & $18.150,00$ \\
\hline Levolloxacino $250 \mathrm{mg}$ & comp. & A7 DIST. & & & & & & & & & & & & & & & & & 300.000 & 753000,00 & & & & & 300.000 & 753000,00 \\
\hline Moxilitoxacino $400 \mathrm{mg}$ & comp. & Bayer & & & & & & & & & & & 21.600 & 2055200,00 & & & & & 35.000 & $364,000,00$ & & & & & 56.600 & 569200,00 \\
\hline Amicacina $500 \mathrm{mg}$ & $F / A$ & Blausiegl - Ata SP & 78.000 & $46,800,00$ & & & & & 78.000 & $46,800,00$ & & & & & & & & & & & & & & & 156.000 & $93,600,00$ \\
\hline Amicacina $500 \mathrm{mg}$ & $F / A$ & Dinalmed & 78.000 & 56.160,00 & & & & & 78.000 & $56,160,00$ & & & & & & & & & & & & & & & 156.000 & 112320,00 \\
\hline Levoflloxacino $500 \mathrm{mg}$ & comp. & EM.S & & & & & & & & & & & & & & & & & & & & & 800.000 & $331.280,00$ & 808.000 & $331.280,00$ \\
\hline Claritromicina $500 \mathrm{mg}$ & comp. & емS. & & & 24.500 & $49.000,00$ & 34.600 & 43250,00 & & & & & & & & & & & & & & & & & 59.100 & 92250,00 \\
\hline Amicacina $1 \mathrm{~g}$ & $F / A$ & HIPOLABOR & 18.000 & $57,960,00$ & & & & & & & & & & & & & & & & & & & & & 180.000 & $57.960,00$ \\
\hline Amicacina $500 \mathrm{mg}$ & $F / A$ & HIPOLABOR & 60.000 & 540000,00 & & & 62.500 & $51.250,00$ & & & & & & & & & & & & & & & & & 122.500 & $105.250,00$ \\
\hline Levoffloxacino $500 \mathrm{mg}$ & comp. & HOSPFAR & & & & & & & & & & & & & & & 1.000 .000 & $480,000,00$ & & & & & & & 1.000 .000 & $480.000,00$ \\
\hline Claritromicina $500 \mathrm{mg}$ & comp. & Laboris & & & & & & & 36.500 & $25,550,00$ & 415.600 & 282608,00 & 400.000 & $240.000,00$ & & & & & & & & & & & 852.100 & $588.158,00$ \\
\hline Levoffloxacin $500 \mathrm{mg}$ & comp. & LCIMED & & & & & & & & & & & & & & & 200.000 & 960000,00 & & & & & & & 200.000 & $96,000,00$ \\
\hline Amicacina $500 \mathrm{mg}$ & $F / A$ & NOVAFARMA & & & 57.600 & $51.840,00$ & & & & & & & & & & & 145.000 & $93.960,00$ & 161.000 & $90,600,00$ & & & & & 363.000 & $242,400,00$ \\
\hline Capromicicna 19 & $F / A$ & OPAS & & & & & & & & & & & & & & & & & & & & & 28.000 & 395.57 .52 & 28.000 & 395.57 .52 \\
\hline Clartromicina $500 \mathrm{mg}$ & comp. & OPAS & & & & & & & & & & & & & & & & & & & & & 300.000 & $199.560,00$ & 300.000 & 199.560,00 \\
\hline Clofazainina $100 \mathrm{mg}$ & cáps. & OPAS & & & & & & & & & & & & & & & & & & & & & 118.000 & $368.281,64$ & 118.000 & 368281,64 \\
\hline
\end{tabular}




\begin{tabular}{|c|c|c|c|c|c|c|c|c|c|c|c|c|c|c|c|c|c|c|c|c|c|c|c|c|c|c|}
\hline $\begin{array}{l}\text { Moxilloxacino } 400 \\
\text { mg }\end{array}$ & comp. & MEDOOMERCE & & & & & & & & & & & & & & & & & & & 23.000 & $188.830,00$ & & & 23.000 & 188.830,00 \\
\hline Capreomicina $1 \mathrm{~g}$ & $F / A$ & OPAS & & & & & & & & & & & & & & & 49.000 & $1.078 .477,40$ & & & & & & & 49.000 & $1.078 .477,40$ \\
\hline Clotazimina $100 \mathrm{mg}$ & Cáps. & OPAS & & & & & & & & & & & & & & & 96.000 & 42.720,00 & & & & & & & 96.000 & $42.720,00$ \\
\hline $\begin{array}{l}\text { Patal-amino- } \\
\text { Salcicico }\end{array}$ & Sache & OPAS & & & & & & & & & & & & & & & 120.000 & $798.864,00$ & & & & & & & ${ }_{120.000}$ & $798.864,00$ \\
\hline 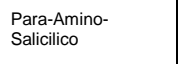 & Sache & OPAS & & & & & & & & & & & & & & & & & & & & & 355.010 & 1.215 .626270 & 355.010 & $1.215 .662,70$ \\
\hline 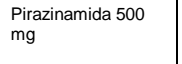 & comp. & OPAS & & & & & & & & & & & & & & & 300 & 478,80 & & & & & & & 300 & 478,80 \\
\hline Piridoxina $100 \mathrm{mg}$ & comp. & OPAS & & & & & & & & & & & & & & & & & 352.000 & $706.242,96$ & & & & & 352.000 & 706.242,96 \\
\hline Piridoxina $100 \mathrm{mg}$ & bister & OPAS & & & & & & & & & & & & & & & & & & & & & 360.000 & $22.074,00$ & 360.000 & 22.074,00 \\
\hline Rifabutina $150 \mathrm{mg}$ & Comp. & OPAS & & & & & & & & & & & & & & & 2.880 .000 & 2.439.653,76 & & & & & & & 2.880 .000 & $2.439 .653,76$ \\
\hline 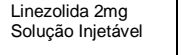 & Bolsa & PFIZER & & & & & & & & & & & & & & & & & & & & & 5.110 & $978.462,80$ & 5.110 & $978.462,30$ \\
\hline Linezolida $600 \mathrm{mg}$ & comp. & PFIZER & & & & & & & & & & & & & & & & & & & & & 45.990 & 6.622.560,00 & 45.900 & $6.622 .560,00$ \\
\hline 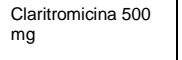 & comp. & PHARLAB & & & & & & & & & & & & & & & & & & & 300.000 & $181.500,00$ & & & 300.000 & 181.500,00 \\
\hline $\begin{array}{l}\text { Levolfoxacino } 250 \\
\text { mg }\end{array}$ & comp. & PRODET & & & & & & & & & & & & & & & & & & & & & 225.000 & $444.750,00$ & 225.000 & $447.750,00$ \\
\hline $\begin{array}{l}\text { Moxitilxacino } 400 \\
\text { my }\end{array}$ & comp. & PRODIET & & & & & & & & & & & & & & & & & & & & & 80.000 & 656.000,00 & 80.000 & $656.000,00$ \\
\hline Terizidona a $550 \mathrm{mg}$ & Cáps. & uno & & & & & & & & & & & & & & & & & & & & & 1.900 .000 & 6.942.410,00 & 1.900 .000 & 6.942.4110,00 \\
\hline Terizidona a $550 \mathrm{mg}$ & Caps. & uno & & & & & & & & & & & & & & & & & 1.500.000 & $4.804 .73,16$ & & & & & 1.500 .000 & $4.804 .731,16$ \\
\hline Terizidona $250 \mathrm{mg}$ & Caps. & uno & & & & & & & & & & & & & & & & & & & \begin{tabular}{l|l|l}
1.8000 .000 &
\end{tabular} & $5.799 .520,00$ & 1.800 .000 & $5.798 .520,00$ & 3.600 .000 & 11.597.040,00 \\
\hline 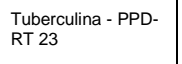 & FAA & uno & & & & & & & & & & & & & & & & & 145.000 & $1.328 .925,00$ & & & & & 145.000 & $1.328 .925,00$ \\
\hline Terizidona $250 \mathrm{mg}$ & Cáps. & FLLMED & 727.000 & $4.885 .440,00$ & & & 372.000 & $1.822 .800,00$ & 1.272 .000 & $5.858 .832,00$ & 761.000 & 3.132.276,00 & 25.670 & $415.554,00$ & 404.000 & $1.658 .79,1,68$ & 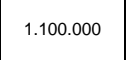 & $3.869 .444,80$ & & & & & & & 4.661 .670 & $21.643,428,48$ \\
\hline Terizidona $250 \mathrm{mg}$ & Caps. & Flomed & & & & & & & & & & & 600.000 & $2.304 .703,80$ & & & & & & & & & & & 600.000 & $2.304 .703,80$ \\
\hline $\begin{array}{l}\text { Tuberduina PPD- } \\
\text { RT } 23\end{array}$ & F/A & FLOMED & & & & & & & & & & & & & 127.470 & $1.282 .20,73$ & & & & & & & & & 127.70 & $1.282 .220,73$ \\
\hline & Subtotal & & 727.000 & $4.885 .440,00$ & 0 & 0,00 & 372.000 & $1.822 .80,00$ & 1.272 .000 & $5.858 .832,00$ & 761.000 & 3.132.276,00 & 625.670 & $2.720 .557,80$ & 53.470 & 2.941.012,41 & 4.245.500 & $8.229 .628,76$ & 1.997.000 & $6.839 .899,12$ & 2.123 .000 & $6.168 .850,00$ & 4.769.110 & $22.683 .439,50$ & 17.423.550 & 65.282.735,59 \\
\hline
\end{tabular}


Apêndice 16 - Produção dos laboratórios oficiais, em número de Unidades Farmacêuticas (UF), para o Componente Especializado da Assistência Farmaceutica, no período de 2003 a 2013.

\begin{tabular}{|c|c|c|c|c|c|c|c|c|c|c|c|c|c|c|c|c|c|c|c|c|c|c|c|c|c|c|}
\hline \multirow{3}{*}{ Medicamentos } & \multirow{3}{*}{ Unid. } & \multirow{3}{*}{ Fornecedor } & \multicolumn{2}{|c|}{2003} & \multicolumn{2}{|c|}{2004} & \multicolumn{2}{|c|}{2005} & \multicolumn{2}{|c|}{2006} & \multicolumn{2}{|c|}{2007} & \multicolumn{2}{|c|}{2008} & \multicolumn{2}{|c|}{2009} & \multicolumn{2}{|c|}{2010} & \multicolumn{2}{|c|}{2011} & \multicolumn{2}{|c|}{2012} & \multicolumn{2}{|c|}{2013} & \multicolumn{2}{|c|}{ Total } \\
\hline & & & Alocacáo & \multirow{2}{*}{$\begin{array}{l}\text { Custo } \\
\text { (RS) }\end{array}$} & \multirow{2}{*}{$\begin{array}{c}\text { Alocasâa } \\
\text { Ouant. }\end{array}$} & \multirow{2}{*}{$\begin{array}{c}\text { Custo } \\
\text { (RS) }\end{array}$} & Alocaăäo & custo & Alocaçăo & Custo & Alocąâá & custo & Alocaa̧a & custo & Alocasâio & custo & Alcacąa & custo & Alocąấ & custo & Alocąąo & custo & Alocasăa & custo & \multirow{2}{*}{ uF } & \multirow{2}{*}{ Rs } \\
\hline & & & \begin{tabular}{|l|} 
ouant. \\
\end{tabular} & & & & ouant. & (RS) & ouant. & (RS) & ouant. & (AB) & ouant. & (As) & ouant. & (AS) & ouant. & (AS) & ouant. & (RS) & Ouant. & (AS) & ouant. & (Rs) & & \\
\hline Aflaepoetina 2000 UI & $F / A$ & FIOCBUZ & & & & & & & & & & & & & 1.055.259 & 9.477 .225 .92 & 982490 & $9.215 .756,20$ & & & & & & & 2.037 .749 & 18.691.982,02 \\
\hline Altaposetina 4000 UI & $F / A$ & Fiocruz & & & & & & & & & & & & & 7.0899877 & 119.180.159,97 & 8.046 .496 & 141.376.934,72 & & & & & & & 15.136.333 & 260.557.094,69 \\
\hline $\begin{array}{l}\text { Alfainterferona } 10.000 .000 \\
\text { Ual }\end{array}$ & $F / A$ & FIOCRUZ & & & & & & & & & & & & & & & 6.269 & $430.993,75$ & & & & & & & 6.269 & 430.993,75 \\
\hline $\begin{array}{l}\text { Altainetererona 3.000.000 } \\
\text { U }\end{array}$ & $\mathrm{F} / \mathrm{A}$ & FIOCAUZ & & & & & & & & & & & & & & & ${ }^{120.158}$ & $2.411 .571,06$ & & & & & & & 120.158 & $2.411 .571,06$ \\
\hline $\begin{array}{l}\text { Altainitererena } 5.000 .000 \\
\text { U }\end{array}$ & $F / A$ & Fiocauz & & & & & & & & & & & & & & & 32.268 & 1.091.626,44 & & & & & & & 32.268 & 1.091.626,44 \\
\hline $\begin{array}{l}\text { Allaposednan Humana } \\
\text { Recomanninante } 2000 \mathrm{UI}\end{array}$ & & Fiocruz & & & & & & & & & & & & & & & & & & & & & 3.637.612 & $540.153 .815,76$ & 38.637.612 & $540.153 .815,76$ \\
\hline Eritropoetinallitereferon & Teste & FIOCRUZZ & & & & $33.121 .024,67$ & & $296.421 .005,17$ & & & & & & & & & & & & & & & & & 0 & $322.542 .029,84$ \\
\hline Intereferon 10.000.000 UI & $F / A$ & FIOCAUZ & & & & & & & & & & & & & 6.326 & $416.187,54$ & & & & & & & & & 6.326 & $416.187,54$ \\
\hline Intereferon $3.000 .000 \mathrm{UI}$ & $F / A$ & FIOCAUZ & & & & & & & & & & & & & 138.992 & $2.670 .036,32$ & & & & & & & & & 138.992 & $2.670 .036,32$ \\
\hline Intereferon 5.000.000 UI & $F / A$ & FIOCAUZ & & & & & & & & & & & & & 20.258 & $947.08,46$ & & & & & & & & & 29.258 & $947.081,46$ \\
\hline Ribavirina $250 \mathrm{mg}$ & Cáps. & FIOCAUZ & & & & & & & & & & & & & 85522.748 & 11.931.184,72 & 15.000 .000 & $2.100 .000,00$ & & & & & & & 100.222.748 & 14.031.184,72 \\
\hline Tacrolimo $1 \mathrm{mg}$ & & FIOCAUZ & & & & & & & & & & & & & & & & & & & 82.527.100 & 239.549.235, 00 & 53.577.100 & $152.609 .235,00$ & 136.074 .200 & $392.158 .477,00$ \\
\hline Tacorolimo $5 \mathrm{mg}$ & & FIOCAUZ & & & & & & & & & & & & & & & & & & & 3.985 .050 & $55.857 .841,50$ & 2.965 .550 & $41.006 .641,50$ & 6.950 .100 & $96.864 .483,00$ \\
\hline \multicolumn{3}{|c|}{ subtoal } & 0 & 0 & 0 & 33.121.025 & 0 & 296.422.005 & 0 & 0 & 0 & o & 0 & 0 & 93.5424220 & 144.620.876 & 24.187.681 & 156.626.882 & 0 & 0 & 86.512 .150 & 295.407.077 & $\begin{array}{l}95.199 .762 \\
\end{array}$ & 733.769 .692 & 299.392 .013 & 1.659.966.557 \\
\hline Clozzapina $100 \mathrm{mg}$ & Comp. & LAFEPE & & & & & & & & & & & & & & & & & 12.287.368 & 21.257. 146,64 & 20.700 .000 & $33.948 .000,00$ & 21.271 .080 & 33.140.342,64 & 544.258.448 & $88.345 .489,28$ \\
\hline Clozapina $25 \mathrm{mg}$ & Comp. & LAFEPE & & & & & & & & & & & & & & & & & 33.399.588 & $553770.034,64$ & 1.0123300 & $384,674,00$ & 612.900 & 221.255,90 & 35.024 .788 & 55.975.965,54 \\
\hline Olanzapina 5 mg & comp. & LAFEPE & & & & & & & & & & & & & & & & & & & 9.9056672 & $44.872 .694,16$ & & & & \\
\hline Olarzapina $10 \mathrm{mg}$ & comp. & LAFEPE & & & & & & & & & & & & & & & & & & & 17.826.816 & 163.650.170,88 & & & & \\
\hline Quetiapina $100 \mathrm{mg}$ & comp. & LAFEPE & & & & & & & & & & & & & & & & & 12.600.000 & $38.682 .000,00$ & 31.462.788 & $93.704,752,60$ & 11.377.684 & $33.013 .684,23$ & 55.380 .472 & $165.400 .436,83$ \\
\hline Quetiapina $200 \mathrm{mg}$ & comp. & LAFEPE & & & & & & & & & & & & & & & & & 16.300.000 & $89.8130000,00$ & 22.032.252 & $205.066 .508,72$ & ${ }_{132209.560}$ & $69.152 .044,60$ & 51.54.812 & 364.031.555,32 \\
\hline Quetiapina $25 \mathrm{mg}$ & comp. & LAFEPE & & & & & & & & & & & & & & & & & 8.700 .000 & $7.830 .000,00$ & 22.955 .968 & $19.796 .552,64$ & 8.397 .564 & $7.179 .917,22$ & 39.793 .532 & $34.806 .469,86$ \\
\hline
\end{tabular}




\begin{tabular}{|c|c|c|c|c|c|c|c|c|c|c|c|c|c|c|c|c|c|c|c|c|c|c|c|c|}
\hline subtoat & ${ }^{\circ}$ & $\circ$ & $\circ$ & 。 & 。 & $\circ$ & 0 & 。 & $\circ$ & $\circ$ & $\circ$ & $\circ$ & 。 & 。 & 。 & 。 & 832306556 & ${ }^{21295252181}$ & 125.6557 .766 & 566.1223353 & 54-18007788 & 1422707.248 & 2359000.052 & Toass59.977 \\
\hline Total & 。 & 0,00 & 。 & 66 66220.099,34 & 。 & 529282020101,34 & 。 & 0,000 & 。 & 0,00 & 。 & 0,00 & 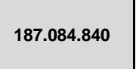 & 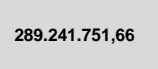 & 48375.562 & 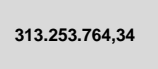 & 832205056 & 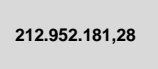 & 2086000086 & $1.15222737 .56,0,00$ & 205,108312 & 1.610.246.632:11 & 83473as:78 & 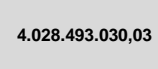 \\
\hline
\end{tabular}


Apêndice 17 - Produção dos laboratórios nacionais, em número de Unidades Farmacêuticas (UF), para o o Componente Especializado da Assistência Farmaceutica, no período de 2003 a 2013.

\begin{tabular}{|c|c|c|c|c|c|c|c|c|c|c|c|c|c|c|c|c|c|c|c|c|c|c|c|c|c|c|}
\hline \multirow{3}{*}{ Medicamentos } & \multirow{3}{*}{ Unid. } & \multirow{3}{*}{ Fornecedor } & \multicolumn{2}{|c|}{2003} & \multicolumn{2}{|c|}{2004} & \multicolumn{2}{|c|}{2005} & \multicolumn{2}{|c|}{2006} & \multicolumn{2}{|c|}{2007} & \multicolumn{2}{|c|}{2008} & \multicolumn{2}{|c|}{2009} & \multicolumn{2}{|c|}{2010} & \multicolumn{2}{|c|}{2011} & \multicolumn{2}{|c|}{2012} & \multicolumn{2}{|c|}{2013} & \multicolumn{2}{|c|}{ Total } \\
\hline & & & Alocąạa & custo & Alocąạa & custo & Alocasąio & custo & Alocasąa & custo & Alocaçăo & custo & Alocąago & custo & Alocasagó & custo & Alocacăo & custo & Alocazago & Custo & Alocaząio & custo & Alocasagó & custo & 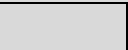 & 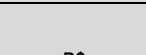 \\
\hline & & & Quant. & (RS) & Quant. & (RS) & Quant. & (RS) & Quant. & (RS) & Quant. & (R\$) & Ouant. & (AS) & Quant. & (PS) & Quant. & (RS) & Ouant. & (RS) & Ouant. & (Rs) & Quant. & (As) & $\mathrm{UF}_{\mathrm{f}}$ & RS \\
\hline $\begin{array}{l}\text { Adalimumabe tomm } \\
\text { Solusara nnitituvel }\end{array}$ & Seringa & АвВотт & 0 & & & & & & & & & & & & & & 154.532 & $239.524,600,00$ & 444.532 & $645.234 .600,00$ & 430.000 & $523.365 .900,00$ & 551.536 & $570.597 .084,16$ & 1.580.600 & 1.978.722. 184,16 \\
\hline $\begin{array}{l}\text { Micoternolato de } \\
\text { Mofitilia } 500 \mathrm{~mm}\end{array}$ & Comp. & ACСORD & 0 & & & & & & & & & & & & & & & & & & & & 6.700 .450 & $2.816 .709,00$ & 6.706 .450 & $2.816 .709,00$ \\
\hline Migusatat $100 \mathrm{mg}$ & Cáps. & ACTELON & 0 & & & & & & & & & & & & & & & & & & 90.360 & $10.029 .960,00$ & & & 90.360 & $10.029 .960,00$ \\
\hline $\begin{array}{c}\text { Cerdilumabe } 200 \\
\text { mg }\end{array}$ & & AStRAZENECA & 0 & & & & & & & & & & & & & & & & & & & & 21.740 & 11.740.255,20 & 21.740 & 11.740.252.20 \\
\hline 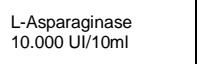 & $F A$ & BAGÓ & 。 & & & & & & & & & & & & & & & & & & & & 52.300 & $17.640 .790,00$ & 52.300 & $17.640 .790,00$ \\
\hline 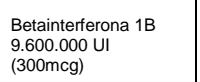 & Seringa & BAYYR & 0 & & & & & & & & & & & & & & 297.765 & 47.591.779.95 & 619.365 & 96.796.579.95 & 446.730 & $60.147 .727,20$ & 266.160 & $60.147 .727,20$ & 1.630 .020 & $264.638 .814,30$ \\
\hline $\mid$ & Seringa & BIOGEN & o & & & & & & & & & & & & & & 87.796 & $51.799 .640,00$ & 181.796 & $105.255 .640,00$ & 142.000 & $73,527.600,00$ & 128.048 & 62.988.091,68 & 539.440 & $293.600 .977,68$ \\
\hline $\begin{array}{l}\text { Natalizumabe } 300 \mathrm{mg} \\
\text { Solusaga liniftavel }\end{array}$ & $F / A$ & BIOGEN & 0 & & & & & & & & & & & & & & & & 35.556 & $87.667 .92,00$ & & & 10.499 & $25.281 .592,00$ & 46.355 & $112.949 .512,00$ \\
\hline $\begin{array}{l}\text { Imungoglobulina } \\
\text { Humana } 5,0 \mathrm{O}\end{array}$ & $F / A$ & Blausiegel & 0 & & & & & & & & & & & & & & & & 62.255 & $23,694,630,31$ & & & & & 62.525 & $23.694 .630,31$ \\
\hline Abatacopte 250mg & & Bristol & 0 & & & & & & & & & & & & & & & & & & & & 76.088 & $57.935 .685,84$ & 76.088 & $57.935 .685,84$ \\
\hline Enecaxir $0.5 \mathrm{mg}$ & Comp. & BвilstoL & 。 & & & & & & & & & & & & 195880 & 1.921.999,20 & 418.230 & $4.324,498,20$ & & & & & & & 604.110 & $6.244 .497,40$ \\
\hline Entecavir $1,0 \mathrm{mg}$ & Comp. & BristoL & 0 & & & & & & & & & & & & & & & & 63.000 & $811.377,00$ & & & & & 63.000 & $811.377,00$ \\
\hline $\begin{array}{l}\text { Alfapegintefferona } 2 a \\
-180 \mathrm{mcg}\end{array}$ & Fr. & $\begin{array}{l}\text { F.Hoffmann-La } \\
\text { Roche }\end{array}$ & 0 & & & & & & & & 194.056 & 104.887.268,00 & & & & & & & & & & & & & 194.56 & 104.887.268,00 \\
\hline Adetovir $10 \mathrm{mg}$ & Comp. & Gsk & 0 & & & & & & & & & & & & 542.010 & $3.658 .567,50$ & 542.010 & 3.658 .567 .50 & 558.060 & 3.488.294,40 & & & & & 1.642 .080 & $10.799 .429,40$ \\
\hline 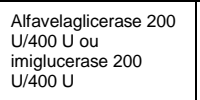 & u & GENZYME & 0 & & & & & & & & & & & & & & & & 46.706.400 & 171.255.666,24 & & & & & 46.706.400 & 171.253.686,24 \\
\hline $\begin{array}{l}\text { Sovelamer } \\
\text { (cloridatato) } 8000 \mathrm{mg}\end{array}$ & comp. & GENZYME & 0 & & & & & & & & & & & & 41.729.940 & $37.489 .369,54$ & 41.826.993 & $182.371 .009,54$ & 128.880 .000 & 102.988.008,00 & 80.042 .520 & $55.067 .212,80$ & 81.938 .520 & $87.961 .001,22$ & 380.47 .013 & $465.876 .601,10$ \\
\hline Imigucerasse 200 UI & $\mathrm{Fr}$. & Genryme Doasăa & 。 & & 8.123 & 0,00 & 11.100 & 0,00 & ${ }_{14,923}$ & 0,00 & 33.506 & 0.00 & & & & & & & & & & & & & 67.552 & 0,00 \\
\hline $\begin{array}{l}\text { Micotenolato de } \\
\text { Mofitila } 500 \text { mg }\end{array}$ & comp. & GERMED & 0 & & & & & & & & & & & & & & & & 22.449 .934 & 10.122.720.,30 & & & & & 22.449 .934 & 10.122.720,30 \\
\hline Donepezila $5 \mathrm{mg}$ & Comp. & GLAXO & 。 & & & & & & & & & & & & & & & & & & 2.262.960 & $672.778,01$ & 2.262.960 & 677.778 .01 & 4.525 .920 & 1.345.55,02 \\
\hline
\end{tabular}




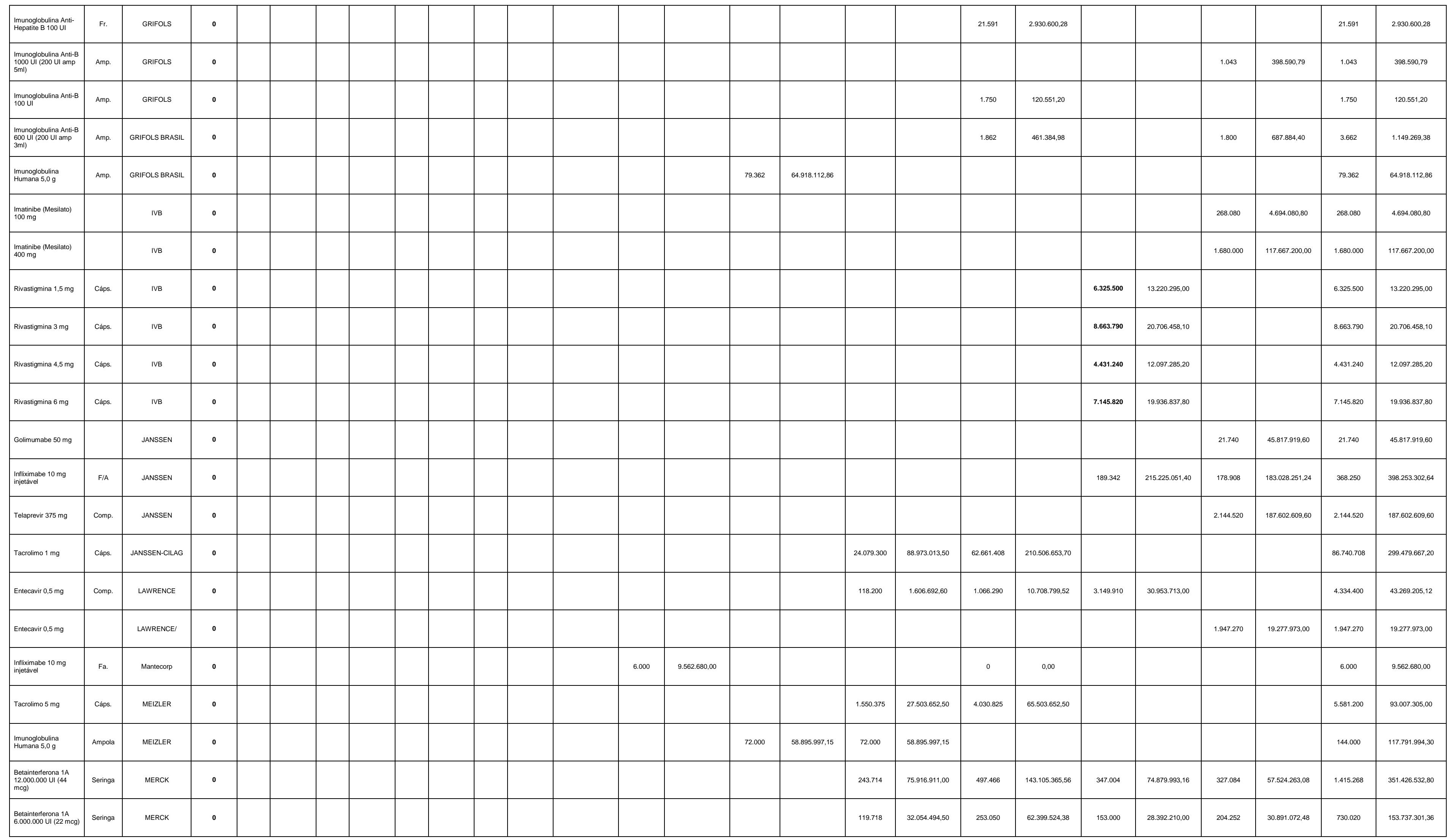




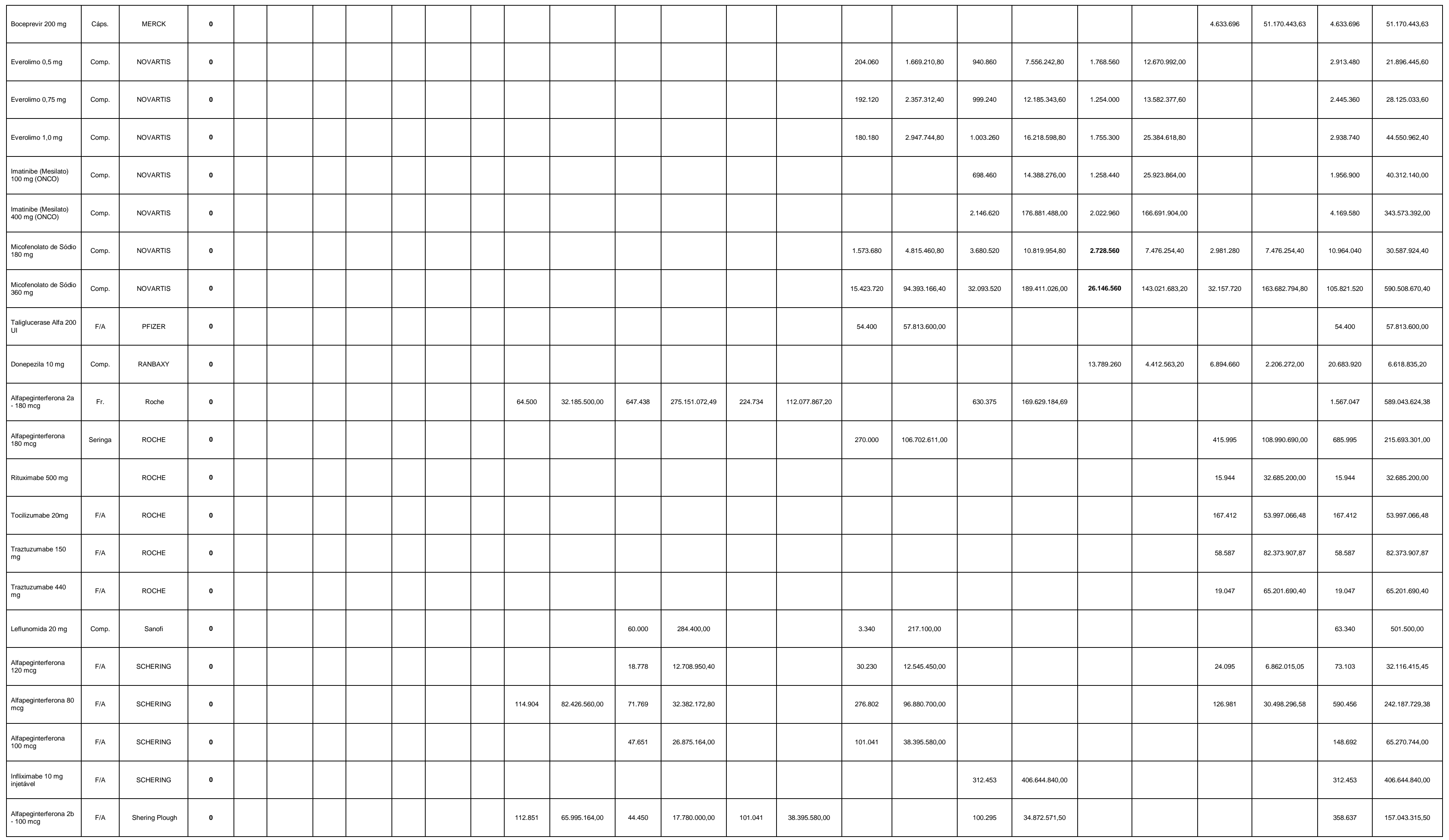




\begin{tabular}{|c|c|c|c|c|c|c|c|c|c|c|c|c|c|c|c|c|c|c|c|c|c|c|c|c|c|c|}
\hline $\begin{array}{l}\text { Altapeginteferona } 2 b \\
-120 \mathrm{mog}\end{array}$ & $F / A$ & Shering Plough & 0 & & & & & & & & 40.202 & $28.134 .230,40$ & 14.646 & 6.151.320,00 & 18.115 & $7.517 .725,00$ & & & 39.359 & 14.445.399,48 & & & & & 112.322 & $56.748 .674,88$ \\
\hline $\begin{array}{l}\text { Alfapeginterterona } 2 \mathrm{~b} \\
-80 \mathrm{mcg}\end{array}$ & $F / A$ & Sheing Plough & 0 & & & & & & & & 186673 & $87.536 .092,80$ & 236.724 & $93.269 .256,00$ & 195.401 & $68.390 .350,00$ & & & 127.660 & 40.883.115,00 & & & & & 746.458 & $290.078 .813,80$ \\
\hline $\begin{array}{l}\text { Giatitamer } 20 \mathrm{mg} \\
\text { Inititivel }\end{array}$ & Seringa & TEVA & 0 & & & & & & & & & & & & & & 532.056 & 39.372.144,00 & 1.42 .056 & 105.802:144,00 & 1.200 .024 & $80.593 .611,84$ & 1.149.9.98 & $73.369 .234,40$ & 4.324 .124 & $299.137 .134,24$ \\
\hline Donepezila $10 \mathrm{mg}$ & Comp. & WУЕтH & 0 & & & & & & & & & & & & & & & & 10.012.680 & 8.609:900.53 & & & & & 10.012 .680 & 8.609.900,53 \\
\hline Donepezila $5 \mathrm{mg}$ & Comp. & WУЕTH & 0 & & & & & & & & & & & & & & & & 9.162 .960 & $7.787 .599,70$ & & & & & 9.162980 & 7.787.599,70 \\
\hline Etanerecepte $25 \mathrm{mg}$ & $\mathrm{FAA}$ & WУETH & 0 & & & & & & & & & & & & & & 152356 & $63.684 .080,00$ & 749.940 & $272.734 .200,00$ & 187.984 & 57.89 .972 .00 & ${ }_{152.388}$ & $37.584 .403,20$ & ${ }^{1.242 .368}$ & $431.866 .491,20$ \\
\hline Etanercepte $50 \mathrm{mg}$ & $F / A$ & WYЕTH & 0 & & & & & & & & & & & & & & ${ }^{109.628}$ & $91.649 .088,00$ & 551.752 & 401.135.808, 00 & 408.064 & $251.367 .424,00$ & 704.496 & 347.175 .628 .80 & 1.773 .940 & 1.091 .327 .868 .80 \\
\hline Sirolimo $1 \mathrm{mg}$ & Drágea & WУЕTH & 0 & & & & & & & & & & & & & & 2.126 .220 & $30.677 .568,00$ & 8.848 .740 & 113.500:239,60 & 2.590 .980 & 28.177.233,00 & 2.350 .860 & $22.956 .147,90$ & 15.922 .800 & $195.257 .188,50$ \\
\hline Sirolimo $1 \mathrm{mg} / \mathrm{ml}$ & Fr. & WУЕTH & 0 & & & & & & & & & & & & & & 1.696 & $1.466 .736,00$ & 4.204 & 3.344.720,00 & & & & & 5.900 & $4.813 .455,00$ \\
\hline Sirdimo $2 \mathrm{mg}$ & Drágea & WУETH & 0 & & & & & & & & & & & & & & 7919.90 & 20.712 .672 .00 & 2.146 .770 & $555.945 .346,40$ & 488.50 & 10.607.077,1,80 & 814.020 & 15.005.136,.78 & 4.168 .560 & 103.170.226,98 \\
\hline \multicolumn{3}{|c|}{ Subtotal } & o & o & 8.123 & 。 & 11.100 & o & 14.923 & o & 746.992 & 400.1664 .815 & 1.147 .456 & 474.165 .016 & 43.147.583 & 3932.265 .568 & 91.466.292 & 1.480.463.729 & 344.272.134 & 3.806 .375 .998 & 175.425.448 & 1.966 .03 .692 & 15.1.456.167 & 2.647 .790 .739 & 807.690.918 & 11.166.937.556 \\
\hline
\end{tabular}


Apêndice 18 - Produção dos laboratórios internacionais, em número de Unidades Farmacêuticas (UF), para o Componente Especializado da Assistência Farmaceutica, no período de 2003 a 2013.

\begin{tabular}{|c|c|c|c|c|c|c|c|c|c|c|c|c|c|c|c|c|c|c|c|c|c|c|c|c|c|c|}
\hline \multirow{3}{*}{ Medicamentos } & \multirow{3}{*}{ Unid. } & \multirow{3}{*}{ Fornecedor } & \multicolumn{2}{|c|}{2003} & \multicolumn{2}{|c|}{2004} & \multicolumn{2}{|c|}{2005} & \multicolumn{2}{|c|}{2006} & \multicolumn{2}{|c|}{2007} & \multicolumn{2}{|c|}{2008} & \multicolumn{2}{|c|}{2009} & \multicolumn{2}{|c|}{2010} & \multicolumn{2}{|c|}{2011} & \multicolumn{2}{|c|}{2012} & \multicolumn{2}{|c|}{2013} & \multicolumn{2}{|r|}{ Total } \\
\hline & & & Alocąâa & custo & Alocaräo & custo & \begin{tabular}{|l|l|} 
Alocacăo \\
\end{tabular} & custo & Alocagagio & custo & Alocąagio & custo & Alocaráa & custo & Alocąăá & custo & Alocacáá & custo & Alocąăo & custo & Alocąăa & custo & Alocasăa & custo & \multirow{2}{*}{ UF } & \multirow[b]{2}{*}{ Rs } \\
\hline & & & ouant. & (AS) & ouant. & (RS) & Quant. & (RS) & Ouant. & (RS) & ouant. & (Rs) & Ouant. & (RS) & ouant. & (AB) & ouant. & (RS) & auant. & (Rs) & ouant. & (BRS) & ouant. & (Rs) & & \\
\hline 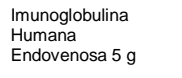 & $F / A$ & Blau & & & & & & & & & & & & & & & & & & & & & ${ }^{61.456}$ & $20.447 .97,63$ & 61.456 & 26.447 .970 .63 \\
\hline Enecauri $1,0 \mathrm{mg}$ & comp. & Bristol & & & & & & & & & & & & & & & & & 63.000 & $811.377,00$ & & & & & 63.000 & $811.377,00$ \\
\hline 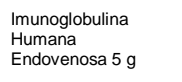 & $\mathrm{F} / \mathrm{A}$ & CSL Eeming & & & & & & & & & & & & & & & & & & & & & ${ }^{61.451}$ & 26.445 .818 .85 & 61.451 & $26.455 .818 ., 55$ \\
\hline $\begin{array}{l}\text { Mminnogoloulina } \\
\text { Mndovernosa } 59\end{array}$ & $F / A$ & BpLMeizer & & & & & & & & & 10.000 & $8.518 .750,00$ & & & & & & & & & & & & & 10.000 & $8.518 .750,00$ \\
\hline Adetovir $10 \mathrm{mg}$ & comp. & GsK & & & & & & & & & & & & & & & & & 558.060 & $3.4822294,40$ & & & & & 555.060 & 3.482.294,40 \\
\hline Imigucerase $200 \mathrm{UI}$ & Fr. & Genzyme & 12.540 & 27.838.800,00 & 66.435 & $147,455,700,00$ & \begin{tabular}{|l|l|l|}
16.305 .874 &
\end{tabular} & 195.584.886,00 & 70.000 & $121.730 .000,00$ & 143.775 & 250.024,725,00 & 130.000 & $135.000 .000,00$ & 165.119 & 229.102.612.50 & 130.000 & $180.375 .000,00$ & 16.029 .750 & 11.755.256.865,00 & & & & & 33.055 .493 & 13.042.398.58,.50 \\
\hline Imigucerase 400 uI & $\mathrm{F} / \mathrm{A}$ & GENZYME & & & & & & & & & & & & & 46.301 & $127,327,750,00$ & & & & & & & 20.564 .000 & 83.467 .372 .56 & 20.610.301 & $210.795 .122,56$ \\
\hline Imigucerase $400 \mathrm{UI}$ & $F / A$ & 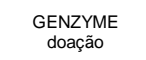 & & & & & & & & & 33.506 & 0,00 & & & 320 & 0,00 & & & & & & & & & 33826 & 0,00 \\
\hline Adefovir $10 \mathrm{mg}$ & comp. & gLaxo & & & & & & & & & & & & & & & 677.490 & $4.573 .057,50$ & 558.080 & $3.4882294,40$ & & & 439.980 & $2.627 .843,90$ & 1.674 .930 & 10.683.195,80 \\
\hline $\begin{array}{l}\text { Imungoglobulina } \\
\text { Humanan } 5.09\end{array}$ & $F / A$ & GRIFoLs & & & & & & & & & & & & & 79.962 & 64.918.116,00 & 79.362 & 64.918.116,00 & 148.089 & 52.030.033,53 & & & & & 306.813 & 181.866.265,53 \\
\hline $\begin{array}{l}\text { Imunoglobulina Anti- } \\
\text { Hepatite B } 600 \text { UI }\end{array}$ & Ampola & GRIFOLS & & & & & & & & & & & & & & & & & 5.980 & $1.881 .175,84$ & & & & & 5.980 & $1.881 .175,84$ \\
\hline Entecauir $0,5 \mathrm{mg}$ & comp. & Lawernee & & & & & & & & & & & & & & & & & 1.0662290 & 10.687.4224,67 & & & & & 1.0662290 & 10.687.424,67 \\
\hline Eneacari $1,0 \mathrm{mg}$ & comp. & Lawence & & & & & & & & & & & & & & & & & 349.50 & $5.425 .099,88$ & & & & & 399.50 & 54425.099,88 \\
\hline $\begin{array}{l}\text { Imungolobulina } \\
\text { Humana } 5,09\end{array}$ & Fa. & LFB & & & & & & & & & 20.000 & $12.525 .500,00$ & 10.000 & $6.266 .688,00$ & & & & & & & & & & & 30.000 & 18.792.188,00 \\
\hline 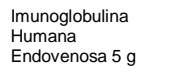 & $F / A$ & LFB & & & & & & & & & 20.000 & $12.525 .500,00$ & & & & & & & & & & & & & 20.000 & $12.525 .500,00$ \\
\hline 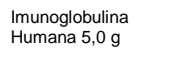 & $\mathrm{FAA}$ & MEZLER & & & & & & & & & 10.000 & $8.518 .750,00$ & & & 72.000 & 58.896.000,00 & & & & & & & & & 82.000 & $67.414 .750,00$ \\
\hline 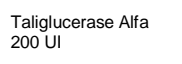 & trasso & Pizizer & & & & & & & & & & & & & & & & & 54,400 & 57.813.600,00 & & & & & 54.400 & $57.813 .600,00$ \\
\hline $\begin{array}{l}\text { AAtapepinitererona } \\
180 \mathrm{mg}\end{array}$ & seringa & Roche & & & & & & & & & 194.056 & 101.803.718, 16 & & & 224,734 & $112.077 .867,20$ & 224.734 & $112.077 .867,20$ & 270.000 & $106.702 .611,00$ & & & & & 91,524 & 432.662.063.56 \\
\hline 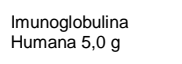 & $\mathrm{FAA}$ & OCtAAнARMA & & & & & & & & & 165.000 & $141.828 .525,00$ & 75.000 & $60.401 .025,00$ & 36.000 & $39.64 .800,00$ & & & 150.060 & $56.867 .112,75$ & & & 184.347 & $79.34,874,40$ & 60.407 & 378.096.337, 15 \\
\hline & Total & & 12.540 & 27.838.800 & ${ }^{66.435}$ & 147.485.700 & \begin{tabular}{|l|l|l|}
16.305 .874 \\
\end{tabular} & 195.544.886 & 70.000 & 121.730.000 & 596.337 & 535.745.468 & 215.000 & 201.667 .713 & 622.336 & 631.987.146 & 1.111.586 & 361.944.041 & 19.253.3939 & 12.054.439.888 & 。 & 0 & 21.310.634 & 218.323 .880 & 59.565.881 & 14.496.747.522 \\
\hline
\end{tabular}


Apêndice 19 - Elenco de medicamentos do Kit do Sistema Prisional e os que são produzidos pela FIOCRUZ.

\begin{tabular}{|c|c|}
\hline 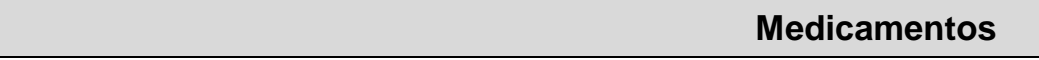 & Produtor \\
\hline Ácido Fólico $5 \mathrm{mg}$ & FIOCRUZ \\
\hline \multicolumn{2}{|l|}{ Albendazol 400 mg Mastigável } \\
\hline Amoxicilina $500 \mathrm{mg}$ & FIOCRUZ \\
\hline \multicolumn{2}{|l|}{ Atenolol $25 \mathrm{mg}$} \\
\hline \multicolumn{2}{|l|}{ Beclometasona (Dipropionato) $250 \mathrm{mcg} /$ Dose spray oral } \\
\hline \multicolumn{2}{|l|}{ Benzilpenicilina benzatina 1.200 .000 UI pó para suspensão injetável } \\
\hline \multicolumn{2}{|l|}{ Benzilpenicilina Procaína 3000.000 UI + Potássica 100.000 UI suspensão injetável } \\
\hline Captopril $25 \mathrm{mg}$ & FIOCRUZ \\
\hline \multicolumn{2}{|l|}{ Clorexidina (Gliconato) $0,12 \%$ solução bucal } \\
\hline \multicolumn{2}{|l|}{ Cloridrato de Clindamicina $300 \mathrm{mg}$} \\
\hline Cloridrato de propranolol $40 \mathrm{mg}$ & FIOCRUZ \\
\hline \multicolumn{2}{|l|}{ Dexametasona $0,1 \%$ (colírio) } \\
\hline Dexametasona $0,1 \%$ Creme & FIOCRUZ \\
\hline \multicolumn{2}{|l|}{ Dexclorfeniramina (Maleato) $2 \mathrm{mg}$} \\
\hline \multicolumn{2}{|l|}{ Enalapril (Maleato) $10 \mathrm{mg}$} \\
\hline \multicolumn{2}{|l|}{ Etiniestradiol $0,003 \mathrm{mg}+$ Levonorgestrel $0,15 \mathrm{mg}$} \\
\hline \multicolumn{2}{|l|}{ Fluconazol $150 \mathrm{mg}$} \\
\hline \multicolumn{2}{|l|}{ Furosemina $40 \mathrm{mg}$} \\
\hline \multicolumn{2}{|l|}{ Gentamicina (Sulfato) $5 \mathrm{mg}$ colírio } \\
\hline Glibenclamida $5 \mathrm{mg}$ & FIOCRUZ \\
\hline Hidroclorotiazida $25 \mathrm{mg}$ & FIOCRUZ \\
\hline \multicolumn{2}{|l|}{ Ibuprofeno $300 \mathrm{mg}$} \\
\hline \multicolumn{2}{|l|}{ Ibuprofeno $600 \mathrm{mg}$} \\
\hline \multicolumn{2}{|l|}{ Ivermectina $6 \mathrm{mg}$} \\
\hline \multicolumn{2}{|l|}{ Levonorgestrel $0,75 \mathrm{mg}$} \\
\hline \multicolumn{2}{|l|}{ Medroxiprogesterona (Acetato) $15 \mathrm{mg}$} \\
\hline \multicolumn{2}{|l|}{ Metformina $850 \mathrm{mg}$} \\
\hline Metildopa $250 \mathrm{mg}$ & FIOCRUZ \\
\hline Metoclopramida $10 \mathrm{mg}$ & \\
\hline
\end{tabular}




\begin{tabular}{|c|c|}
\hline \multicolumn{2}{|l|}{ Metronidazol $250 \mathrm{mg}$} \\
\hline \multicolumn{2}{|c|}{ Metronidazol 5\% Geléia Vaginal } \\
\hline \multicolumn{2}{|c|}{ Miconazol (Nitrito) 2\% Creme } \\
\hline \multicolumn{2}{|c|}{ Miconazol (Nitrito) 2\% Creme } \\
\hline \multicolumn{2}{|c|}{ Noretisterona (Enantato) $0,35 \mathrm{mg}$} \\
\hline \multicolumn{2}{|c|}{ Noretisterona (Enantato) $50 \mathrm{mg}+$ Estradiol (Valerato) $5 \mathrm{mg}$} \\
\hline \multicolumn{2}{|l|}{ Omeprazol $10 \mathrm{mg}$} \\
\hline \multicolumn{2}{|l|}{ Omeprazol 20 mg } \\
\hline \multicolumn{2}{|l|}{ Paracetamol $500 \mathrm{mg}$} \\
\hline \multicolumn{2}{|l|}{ Permetrina $5 \%$ loção } \\
\hline \multicolumn{2}{|l|}{ Prednisona 20mg } \\
\hline \multicolumn{2}{|l|}{ Prednisona 5mg } \\
\hline \multicolumn{2}{|c|}{ Sais para reidratação oral $27,9 \mathrm{~g}$} \\
\hline \multicolumn{2}{|c|}{ Salbutamol $100 \mu \mathrm{g}$ aerossol } \\
\hline \multicolumn{2}{|c|}{ Sulfametoxazol $400 \mathrm{mg}$ + Trimetoprima $80 \mathrm{mg}$} \\
\hline Sulfato Ferroso 40mg & FIOCRUZ \\
\hline
\end{tabular}

Fonte: Produção Própria. 
Apêndice 20 - Elenco de medicamentos e correlatos do Kit do Programa de Calamidade Pública e os que são produzidos pela FIOCRUZ.

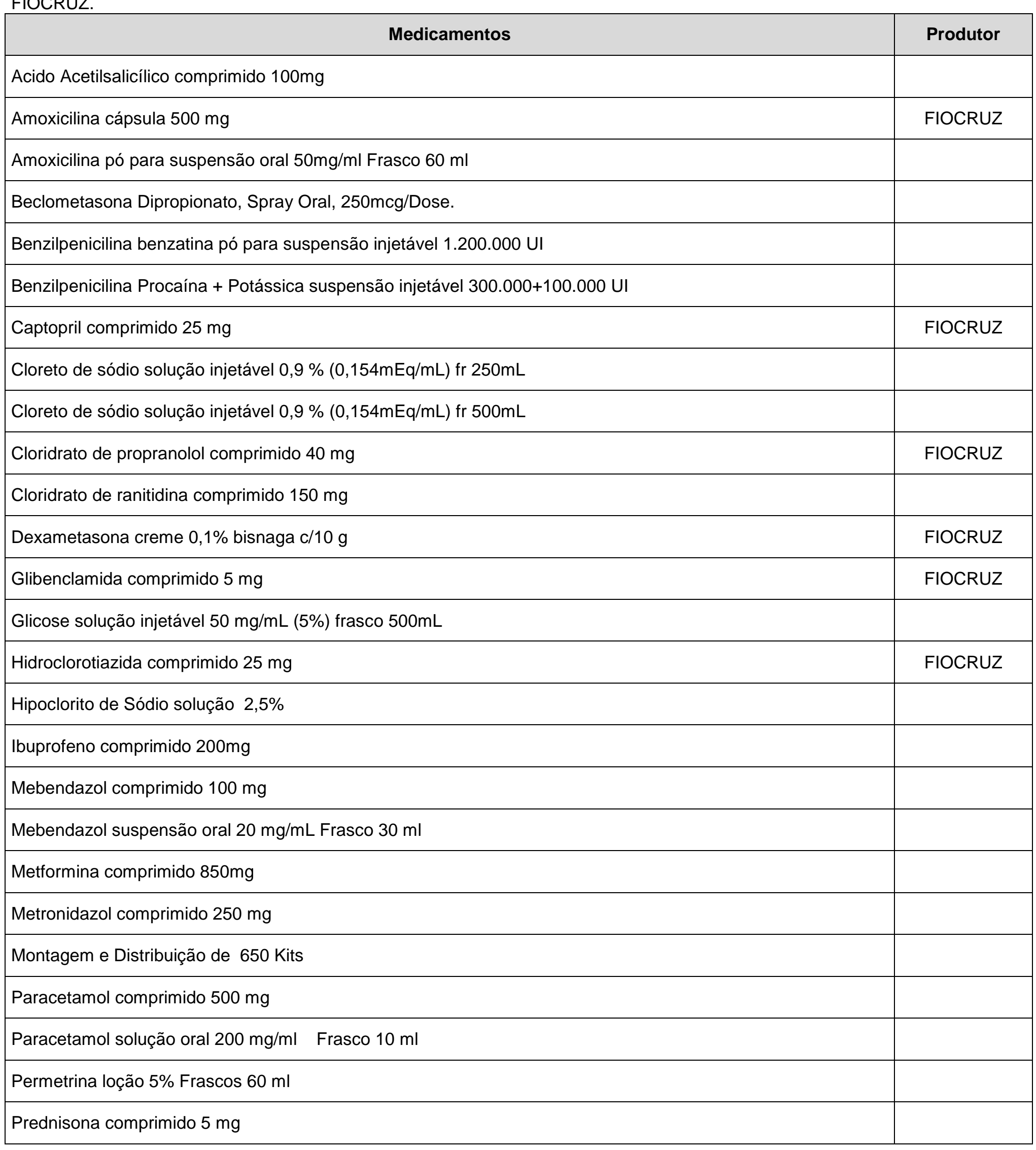




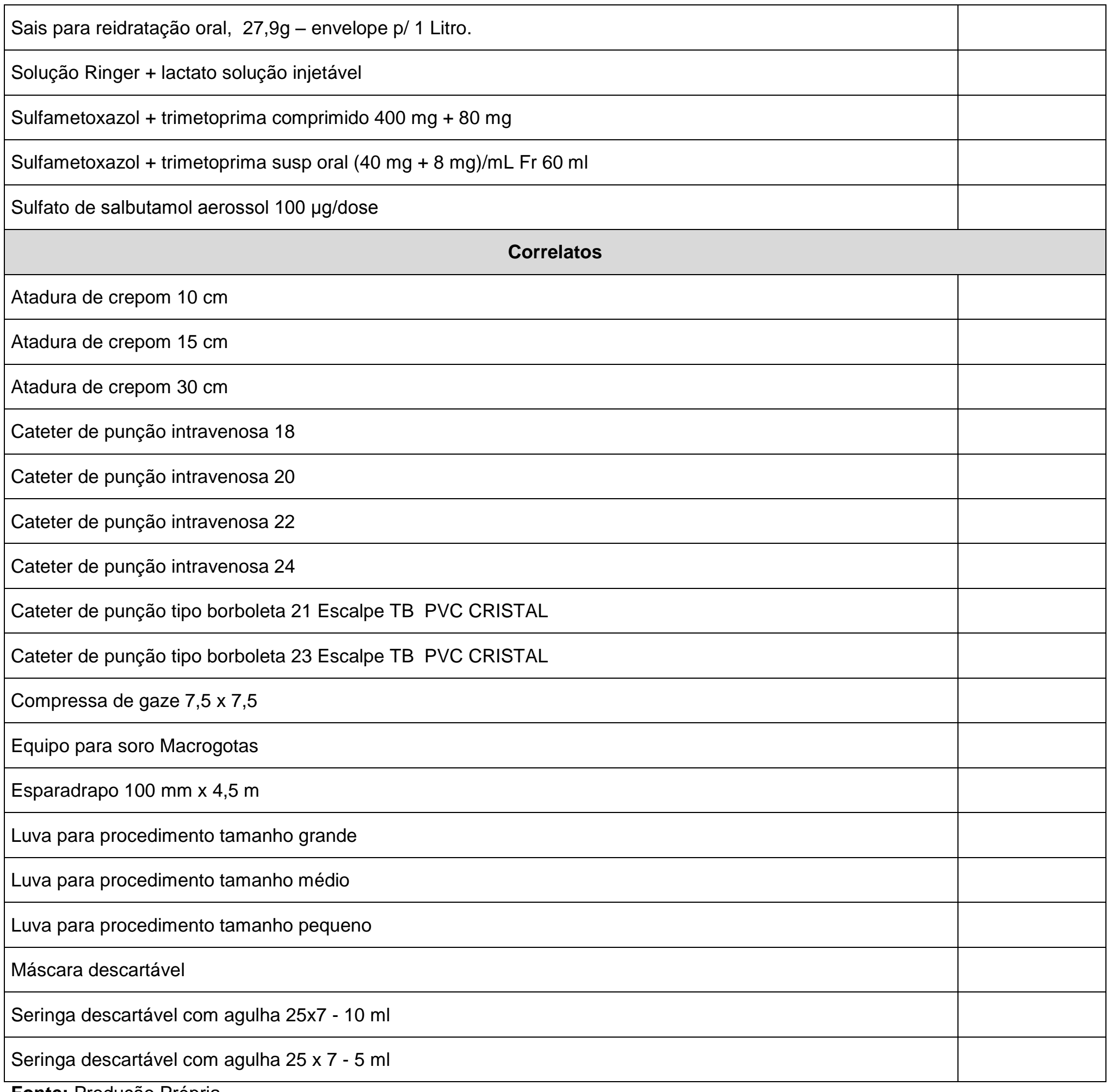

Fonte: Produção Própria 
Anexo 
